\title{
Desenvolvimento e aplicação de técnicas miniaturizadas de preparo de amostra na determinação de fármacos no ambiente
}

\author{
Paulo Clairmont Feitosa de Lima Gomes \\ Prof.Dr. Fernando M. Lanças
}

Tese apresentada ao Instituto de Química de São Carlos da Universidade de São Paulo, para fins de defesa do Título de Doutorado em Ciências

Área de concentração: Química Analítica 


\title{
Desenvolvimento e aplicação de técnicas miniaturizadas de preparo de amostra na determinação de fármacos no ambiente
}

\author{
Tese apresentada ao Instituto de Química de \\ São Carlos da Universidade de São Paulo, \\ para fins de defesa do Título de Doutorado em \\ Ciências \\ Área de concentração: Química Analítica \\ Orientador: \\ Prof.Dr. Fernando M. Lanças
}

Exemplar revisado

O exemplar original encontra-se em acervo reservado na Biblioteca do IQSC-USP 


\section{DEDICATÓRIA}

Dedico essa tese a minha família pelo suporte dado durante esses 5 anos. Aos meus pais Luiz Clairmont e Heloísa pelo esforço e inspiração ao longo de todos esses anos. À minha amada esposa, Gisela, e à Laura por serem minha motivação e companhia durante todos os instantes. Às minhas irmãs, Clarissa e Carmen, que foram como mães durante a minha infância e sempre incentivaram o meu estudo. Aos senhores Paulo Corsini e Célia Corsini por estarem sempre presentes na minha vida. Aos meus cunhados, PC, Thomaz, Érika, Rogério, Aninha e Pablito por proporcionarem momentos de felicidade e união.

A Deus por ter me proporcionado inúmeras bençãos, mesmo não sendo merecedor. 


\section{AGRADECIMENTOS}

Ao Prof. Dr. Fernando M. Lanças pela orientação, por ter me recebido em seu grupo e ter depositado confiança no meu trabalho e no projeto. Por ter aceitado grande parte das minhas sugestões, e ainda por ter aberto portas para colaborações com diversos professores. Por ter apoiado as minhas iniciativas durante a realização dessa tese, e ter contribuído no meu crescimento como pesquisador e pessoa.

Ao Prof. Dr. Nicholas H. Snow, pela orientação, pela recepção calorosa, pelos valiosos ensinamentos e oportunidades. Por ter proporcionado a participação em dois eventos internacionais NJGC e EAS.

À Profa. Dra. Maria Elisa Pereira Bastos de Siqueira por ter sido minha primeira incentivadora na área de pesquisa e por ter apresentado a cromatografia. Pelos momentos deliciosos que passei em seu laboratório durante quase 3 anos, além dos ensinamentos que irão perdurar por toda minha vida.

Aos demais pertencentes do corpo docente da Universidade Federal de Alfenas (UnifalMG) pelo valoroso ensino durante os 4 anos e meio de graduação.

Aos amigos Brian Barnes, Alvin Persad, Susanne Erz, Shilpi, Ramkumar, Atsu Apedo, Peter Panagiotis, Cierra Green e Kenneth Banks pela companhia durante minha estadia nos Estados Unidos.

Aos amigos Ed e Dorothea Hoffner, Krista, a família Shuster, Martha, e demais amigos da First Presbyterian and Trinity Church pelo auxílio e amizade durante os 7 meses nos Estados Unidos. 
Ao Prof. Dr. Marcos Lanza e à Dra. Juliana Cristina Barreiro pela valorosa discussão durante a qualificação.

À Profa. Dra. Gisela de Aragão Umbuzeiro pela colaboração e por cedido amostras ambientais para análise.

A Profa. Dra. Maria Eugênia por ter cedido o padrão de fluoxetina e o polímero polipirrol.

Ao Prof. Dr. Anil pela amizade, por ter dividido muitos ensinamentos durante seu pós-doc no grupo, além de ter cedido padrões das estatinas utilizados nesse projeto.

À Fapesp pelo financiamento concedido durante todos esses anos como aluno de doutorado direto, pela renovação concedida permitindo ter mais tempo para dedicar tempo para finalizar os últimos experimentos, publicar os últimos artigos e trabalhar ao mesmo tempo na tese.

À Capes e CNPq pelos finaciamentos concedidos ao laboratório de Cromatografia do IQSC (Croma-IQSC) fomentando a compra de materiais para os equipamentos.

Ao Alexandre e Sandra Tanday por me receberem em sua casa de portas abertas durante 15 dias, no meu estágio no CROMA em 2005, e por mais 20 dias em janeiro de 2007 quando me mudei para São Carlos e estava procurando um local para morar.

Ao Prof.Dr. Felipe Semaan pela amizade e incentivo.

Aos funcionários da pós-graduação, Silvia, Andréia e Gustavo pelo auxílio dado em todos os momentos.

Aos funcionários da biblioteca pelo auxílio nas buscas por periódicos, livros e teses. Em especial a Bernadete pela amizade e constante auxílio, a Eliana pelas revisões da referências.

Ao funcionário Paulo Cordeiro, pela amizade e incentivo, além do privilégio em participar de seu livro.

Ao Alexandre Cruz, pela amizade, pelo seu esforço em nos ajudar a resolver problemas mesmo que passando do horário do expediente, e claro pelo seus valorosos ensinamentos no manuseio e conservação dos equipamentos.

Aos amigos que estiveram no CROMA durante o meu estágio em 2005, Claudete, José Carlos, Ariane, Valéria, Sheila, Esmeraldo, Maribel e Rosilene.

Às mestres Juliana e Natália pela dedicação e colaboração estabelecida durante o desenvolvimento de seus projetos de mestrado.

À aluna de iniciação Camila Silva pela sua dedicação e colaboração nos trabalhos desen- 
volvidos.

Aos amigos que estiveram no CROMA durante os anos de 2007 a 2012, Lincoln, Alessandra, Gabriela, Wendell, Flávia, Leidimara, Maraíssa, Meire, Carlos, Scarlet, Maura, Felipe, Lucas, Juliano, Diana, Paula, Rogério, Robson, Alcimar, Luís, Patrícia, Carla, Bruno, Camila, Elke, Raquel, Thiago, Renato pelos momentos de diversão e descontração no horário do café, em churrascos, aniversários, pizzarias, bares. Além das contribuições científicas para esse trabalho.

Aos amigos do IIC, Adriana, Luciana, Gustavo, Elton, Guerreiro e Diego pelos momentos de descontração antes dos cursos.

Aos técnicos Guilherme e Elaine, pelo apoio em todos os momentos e por poder contar com vocês em todos os instantes.

A todos os funcionários, técnicos e demais colaboradores do IQSC pelo apoio fornecido.

À Odete pelo seu alto astral e felicidade que espalha e contagia todo o laboratório, além da sua dedicação para com os alunos.

Aos amigos Renata, Éverton, Maico, Hélder e Júlia pela nossa longa amizade desde a graduação que vem se mantendo apesar de estarmos separados geograficamente.

Ao grande amigo, Prof.Dr. Álvaro, pelos momentos felizes e difíceis divididos, pelas longas horas de trabalho juntos, pelas discussões e correções feitas, principalmente nos artigos. Em conjunto com sua esposa Inês, e seu filho Lucas, que participaram de vários momentos vividos nos últimos 5 anos.

Aos amigos Christian e Rafaela, pelo auxílio em todo tempo, por terem sido suporte no momento de aflição, sempre tendo palavras doces para ajudar a levantar a cabeça, e assim, prosseguir para vencer os desafios.

Aos amigos Daniel e Cecília e família, pela amizade e, principalmente, por terem sido apoio presente durante toda essa jornada.

Aos amigos Marcos, Cristiane e Vinícius Mazzetti pelo amor, carinho, dedicação e suporte presente durante esses últimos anos.

Aos membros e amigos da Igreja Presbiteriana Central de São Carlos por todos os momentos divididos, pelas orações e suporte espiritual. Em especial os pastores Roberto Fonseca por ter me recebido e feito meu casamento; e o pastor André Boechat pelo ensinamentos e aconselhamentos durante os últimos 2 anos. 
Aos tios Jecel e Leda, pelo carinho, amizade, orações, risadas divididas no horário do almoço que tornaram o restante do dia mais leve. Ao Jecel Jr. (Cezinho), por me incentivar e ajudar de perto a usar LaTeX para produzir textos de relatórios, qualificação, projetos e também nessa tese, além das conversas sobre a parte computacional.

Aos meus avós Maria Elisa, Hélcio (in memorian), Clairmont (in memorian), Inah (in memorian) pelo carinho e amor dados durante todos os momentos em que estivemos juntos.

A todos que participaram indiretamente, os que possivelmente possa ter omitido, por favor me perdoe. Sem todos vocês essa tese não poderia ser realizada, resta dizer muito obrigado! 


\section{LISTA DE FIGURAS}

1.1 Número de publicações na última década referente a presença de fármacos em água, retirado de $(1) \ldots \ldots \ldots \ldots$. . . . . . . . . . . . . . . . . .

1.2 Estrutura molecular dos hormônios. . . . . . . . . . . . . p. 36

1.3 Estrutura molecular dos hormônios. . . . . . . . . . . . p. 37

1.4 Estrutura molecular dos profenos. . . . . . . . . . . . p. 38

1.5 Estrutura molecular da fluoxetina. $\ldots \ldots \ldots \ldots \ldots$. . . . . . . . . . . .

1.6 Estrutura molecular da sinvastatina. $\ldots \ldots \ldots \ldots \ldots$. . . . . . . . . . . . .

1.7 Estrutura molecular da cafeína. . . . . . . . . . . . . . p. 40

1.8 Estrutura molecular do metilparabeno. . . . . . . . . . . . p. 40

1.9 Rota de entrada do resíduo de medicamentos nos compartimentos ambientais. p. 41

1.10 Componentes da SPME, retirado de $(2) \ldots \ldots \ldots \ldots$. . . . . . . . . . . . .

1.11 Ilustração da composição de uma barra de SBSE. . . . . . . . . . . . . . p. p. p

1.12 Recuperação teórica de analitos por SBSE e SPME de uma amostra de 10 $\mathrm{mL}$ de água, em função de $K_{o / w}$. Volume de PDMS na fibra de SPME: 0,5 $\mu \mathrm{L}$. Volume de PDMS na barra magnética: $100 \mu \mathrm{L}$, adaptado de (3) . . . . . p.48 
1.13 Dispositivo de VWSE testados por Kawaguchi et.al. A - PDMS depositado apenas no seu fundo, B - PDMS depositado no fundo com formato cônico e C - PDMS depositado nas paredes internas do frasco. 1 - frasco, 2 - fase polimérica extratora (PDMS) e 3 - tampa do frasco, adaptado de (4) . . . . . p. p.49

1.14 Disposição dos experimentos de um planejamento fatorial CCD. . . . . . . . p. 52

1.15 Disposição dos experimentos de uma matriz de Doehlert, retirado de (5). . . . p.53

1.16 Modelo linear apresentando homoscedasticidade, retirado de (6) . . . . . . . p.59

1.17 Modelo linear com comportamento heteroscedástico, retirado de (6). . . . . . p. 59

1.18 Resíduo distribuído aleatoriamente com variância constante, retirado de (7). p.59

1.19 Resíduo distribuído aleatoriamente com variância crescendo em conjunto com o aumento da concentração, retirado de (7). . . . . . . . . . . . p. 60

2.1 Cromatograma do íon extraído (EIC) de uma extração por SPME seguida de derivatização in situ de água de torneira fortificada com $10,0 \mu \mathrm{g} \mathrm{L}^{-1}$. 1- IBU, 2- FEN, 3- FLUR, 4- NAP, 5- KET, 6- FLX, 7- E1, 8- E2 e 9- SIMV. . . . . . p. 69

2.2 Mecanismo da reação da derivatização in situ utilizando ECF como derivatizante para os anti-inflamatórios. . . . . . . . . . . . . p.70

2.3 Espectro de massas obtido para (A) fenoprofeno e (B) flurbiprofeno após serem derivatizados. . . . . . . . . . . . . . . . . . p.71

2.4 Espectro de massas obtido para (C) naproxeno e (D) cetoprofeno após serem derivatizados. . . . . . . . . . . . . . . . p. 71

2.5 Espectro de massas obtido para ibuprofeno após ser derivatizado. . . . . . . . p.72

2.6 Mecanismo da reação da derivatização in situ utilizando ECF como derivatizante para os hormônios. . . . . . . . . . . . . . . . . . p.72

2.7 Mecanismo da reação da derivatização in situ utilizando ECF como derivatizante para a fluoxetina. . . . . . . . . . . . . . . . . p.72

2.8 Espectro de massas obtido para (F) $17 \beta$-estradiol e $(\mathrm{G})$ estrona após serem derivatizados. . . . . . . . . . . . . . . . . p. 73

2.9 Espectro de massas obtido para (H) fluoxetina após serem derivatizados. . . . p.73

2.10 Diagrama de Pareto do IBU obtido no planejamento fatorial fracionário aplicado para avaliar a derivatização in situ. 
2.11 Diagrama de Pareto da FLX obtido no planejamento fatorial fracionário aplicado para avaliar a derivatização in situ . . . . . . . . . . . . . . . p.75

2.12 Diagrama de Pareto para o FLUR avaliando o comportamento da extração por SPME. . . . . . . . . . . . . . . . . . . . p. 76

2.13 Diagrama de Pareto para a SIMV avaliando o comportamento da extração por

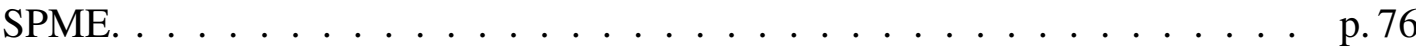

2.14 Diagrama de Pareto (A) NAP e (B) FLX avaliando o comportamento da extração por SPME. . . . . . . . . . . . . . . . . . . . . p.77

2.15 Diagrama de Pareto do E2 avaliando o comportamento da extração por SPME. p. 78

2.16 Superfície de resposta para $\mathrm{pH}$ e volume de derivatizante. . . . . . . . . . . p.79

2.17 Superfície de resposta para temperatura, tempo e volume para extração por SPME. . . . . . . . . . . . . . . . . . . p. 79

2.18 Filtro contendo partículas presentes na amostras (a) e frasco com amostra da entrada da ETE $(b) \ldots \ldots \ldots \ldots$. . . . . . . . . . . . . . . . . . .

2.19 Foto da fibra de SPME com fase de PDMS/DVB nova (a) e após ter sido usado por 25 vezes em amostras ambientais $(b) \ldots \ldots$. . . . . . . . . p.82

2.20 Cromatograma no modo SIM da entrada de ETE contendo IBU (1), FLUR (2), NAP (3), KET (4) e FLX (5), (1a) íon monitorado no modo SIM com relação massa/carga (m/z) 161 (IBU), e (4a) 209 (KET), respectivamente. . p. 83

3.1 Ilustração de um sistema de cromatografia gasosa multidimensional abrangente p. 87

3.2 Capacidade de pico em sistema ortogonal, retirado de (8) . . . . . . . . p. 88

3.3 Sobreposição de pico em sistema $1 \mathrm{D}$, retirado de $(9) \ldots \ldots \ldots$. . . . . . . . . p. 88

3.4 Diagrama de Pareto do METH obtido do planejamento fatorial. . . . . . . . . p.95

3.5 Superfície de resposta da matriz de Doehlert obtida para a CAF. . . . . . . p. p6

3.6 Cromatograma no modo SIM da extração por SPME de água de torneira fortificada com $100 \mu \mathrm{g} \mathrm{L}^{-1}$ com 1 - MP, 2 - CAF, 3 - EC, 4 - MTH, 5 - MSL, $6-\mathrm{MST}+\mathrm{MEE}+\mathrm{ADD}, 7-\mathrm{E} 1+5-\mathrm{ADD}, 8-\mathrm{E} 2,9-\mathrm{EE}+\mathrm{MA} . \quad \ldots . . \quad$ p. 97 
3.7 Diagrama de cores obtido do SPME-GCxGC-ToF/MS aplicado na análise de fármacos em água de torneira, sendo: 1 - ADD, 2 - MA, 3 - T-d3, 4 - MSL, 5 - MST, 6 - E1, 7 - E2, 8 - 5-ADD, 9 - EE, 10 - MEE, 11 - MTH, 12 EC, $13-\mathrm{CAF}$ and $14-\mathrm{MP} . \ldots \ldots \ldots$ p. 98

4.1 Número de publicações relacionados com a SBSE ao longo dos anos de 1999 a 2012, pesquisa retirada do Scopus, em busca avançada realizada no dia 17/04/2012 com a palavra SBSE estando presente no título, abstract, e

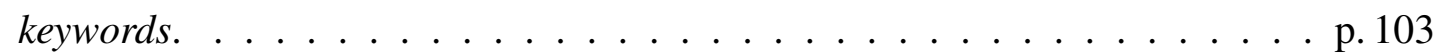

4.2 Primeiro molde usado para confecção das barras de SBSE. . . . . . . . . . . p. 109

4.3 Barras de SBSE (a) 5\% carvão ativo, (b) 10\% polipirrol, (c) 50\% OV-17, (d) 50\% OV-17-OH, (e) 5\% OV-17-vinil e (f) 100\% PDMS. . . . . . . . . . . p. 114

4.4 Molde de teflon apresentando amarelamento. . . . . . . . . . . p. 115

4.5 Molde de teflon com base de aço inox para melhorar o aquecimento na região em contato com o magneto. . . . . . . . . . . . . . . . p. 115

4.6 Novo molde projetado em um trabalho conjunto entre os grupos de pesquisa Croma e de Polímeros do IFSC. . . . . . . . . . . . . . . . . . p. 116

4.7 Fotografia apresentando a barra de PDMS feita no novo molde, enquanto na parte da direita mostra a mesma barra de PDMS obtida usando o molde antigo.p. 117

4.8 Barras de SBSE com novos revestimentos poliméricos: (a) PDMS/DVB, (b) PDMS 100\%, (c) OV-17 vinil 30\%, (d) OV-17 vinil 25\%, (e) carvão ativo 4\%ACB, (f) ACB 5\%, (g) ACB 9\%, (h) ACB 13\%, (i) ACB 18\% e (j) polipirrol

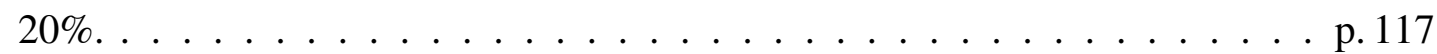

4.9 (a) Molde novo contendo magneto envolvido em vidro silanizado. (b) Barra de PDMS com magneto envolto por um capilar de vidro sintetizada no molde

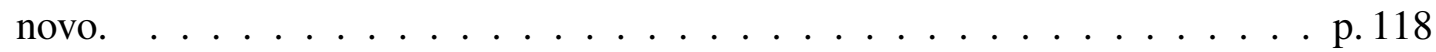

4.10 Comparação entre novas fases extratoras. . . . . . . . . . . . . p. 119

4.11 Cromatograma no modo SIM para as barras com fase de ACB 18\%, OV17-vinil 30\%, PDMS labmade e PDMS comercial, extração feita na concentração $0,5 \mathrm{mg} \mathrm{L}^{-1}$. 1 - ibuprofeno, 2 - fenoprofeno, 3 - flurbiprofeno , 4 - naproxeno, 5 - fluoxetina, 6 - cetoprofeno, 7 - estrona, 8 - estradiol e 9 simvastatina. 
4.12 Comparação SBSE versus SPME. . . . . . . . . . . . . . . . p. 121

4.13 Cromatograma no modo SIM comparando extração por SBSE usando barra de OV-17-vinil 30\% e SPME (fase PDMS/DVB), ambos com dessorção em solvente. Extração feita na concentração de $0,5 \mathrm{mg} \mathrm{L}^{-1}$. . . . . . . . . . . . p. 122

4.15 Mecanismo da reação da derivatização in situ para os compostos fenólicos. . p. 123

4.14 Cromatograma do íon total (TIC) da extração de fenol em urina por SBSE usando barra ACB 5\%. Extração feita na concentração de $10 \mathrm{mg} \mathrm{L}^{-1}$. . . . . p. 123

4.16 Espectro de massas obtido para o fenol após ser derivatizado. . . . . . . . . . p. 124

4.17 Espectro de massas obtido para o 4-cloro-3-metilfenol após ser derivatizado. . p. 124

4.18 Fases confeccionadas para os protótipos de VWSE, sendo 70:30, 85:15, 90:10, 95:5\% para PDMS/DVB, 100\% PDMS e ACB 18 e 23\% . . . . . . . . . p. 125

4.19 Cromatograma no modo SIM usando VWSE de 95:5 PDMS/DVB na concentração de $0,5 \mathrm{mg} \mathrm{L}^{-1}$. 1 - ibuprofeno, 2 - fenoprofeno, 3 - flurbiprofeno, 4 - naproxeno, 5 - fluoxetina. . . . . . . . . . . . . . . p. 126

4.20 Cromatograma no modo SIM usando VWSE de ACB $18 \%$ na concentração de $0,5 \mathrm{mg} L^{-1} .1$ - ibuprofeno. . . . . . . . . . . . . . . . . . p. 127

4.21 Comparações das áreas obtidas nas extrações de progesterona: (a) Extração realizada com $\mathrm{V}=0,5 \mathrm{~mL}$ e tempo de extração de 30 minutos. . . . . . . . . p. 128

4.22 Configuração para síntese de polímeros depositados no fundo e nas paredes internas do frasco. . . . . . . . . . . . . . . . . . . . . . p. 129

4.23 Fases de ACB na parede de frasco (a), ACB (b) e PDMS (c) no fundo do frasco.p. 129

4.24 Gráfico da comparação das áreas obtidas da análise de cafeína utilizando frascos com diferentes porcentagens de carvão ativado. . . . . . . . . . . . . p. 130 


\section{LISTA DE TABELAS}

1.1 Excreção diária em $\mu \mathrm{g}$ de hormônios esteróides humanos, retirado de (10). p. 34

1.2 Propriedades físico-químicas dos hormônios. . . . . . . . . . p. 36

1.3 Propriedades físico-químicas dos profenos. . . . . . . . . . . p. 38

1.4 Fases poliméricas disponíveis comercialmente para SPME, retirado de (11). . p. 45

1.5 Matriz para um planejamento fatorial completo em 2 níveis para 3 variáveis,

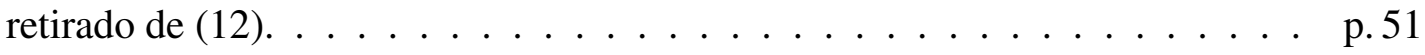

1.6 Planejamento fatorial fracionário $2^{3-1}$ adaptado de (12) $\ldots \ldots \ldots$. . . . . 52

1.7 Planejamento fatorial composto central $2^{2}$ adaptado de (12) . . . . . . . p.53

1.8 Experimentos usando matriz de Doehlert com 3 variáveis, retirado de (12). . . p. 54

1.9 Tabela ANOVA para testar a linearidade do método validado. . . . . . . . . p. 61

2.1 Planejamento fatorial fracionário para avaliar as principais variáveis da derivatização in situ e extração por SPME. . . . . . . . . . . . . . . . . . . . p.67

2.2 Matriz de Doehlert para otimizar a derivatização in situ e a extração por SPME. p. 68

2.3 Íons utilizados para monitoramento no modo $S I M \ldots \ldots$. . . . . . p. 68

2.4 Dados da validação . . . . . . . . . . . . . . . . . p. 80

3.1 Planejamento fatorial fracionário para avaliar as principais variáveis da extração por SPME. . . . . . . . . . . . . . . . . . p.91

3.2 Matriz de Doehlert aplicado para otimizar a extração por SPME. . . . . . . . p.91 
3.3 Dados da validação obtidos para analise por SPME-GCxGC-ToF/MS . . . . . p.99

3.3 Dados da validacao obtidos para analise por SPME-GCxGC-ToF/MS. (cont.) p. 100

4.1 Revisão das inovações para técnica de SBSE. . . . . . . . . . . . . . . . . p. 105

4.1 Revisão da inovações para técnica de SBSE. (cont.) . . . . . . . . . . . . . . p. 106

4.1 Revisão da inovações para técnica de SBSE. (cont.) . . . . . . . . . . . . . . p. 107

4.2 Confecção das fases poliméricas de PDMS/DVB. . . . . . . . . . . . . . . . p. 112

4.3 Dados da validação da análise de fenol em urina usando a SBSE. . . . . . . . . p. 124 


\section{LISTA DE ABREVIATURAS}

ACB - Carvão ativo

ADD - 4-androstenodiona

AIBN - 2,2-Azobis(2-metilpropionitrila)

ANOVA - Análise de variância

ANVISA - Agência Nacional de Vigilância Sanitária

CAF - Cafeína

CAR - Carboxeno

CCD - Planejamento fatorial composto central

COX - Enzima ciclooxigenase

DAD - Detector com arranjo de diodos

EC - Etiocolan-3- $\alpha$-ol-17-ona

ECF - Cloroformato de etila

ED - Detector eletroquímico

EDC - Desreguladores endócrinos

EE - 17- $\alpha$-etinilestradiol

EIC - Cromatograma do íon extraído

EPA - Environmental Protection Agency 
EURACHEM - Comitê Europeu para análise química

et:pyr - mistura etanol e piridina

ETE - Estação de tratamento de água e esgoto

E1 - Estrona

E2 - $17-\beta$-estradiol

FDA - Food and Drug Administration

FEN - Fenoprofeno

FID - Detector por ionização de chama

FLUR - Flurbiprofeno

FLX - Fluoxetina

GC - Cromatografia gasosa

GCxGC - Cromatografia bidimensional abrangente

GCxGC-ToF/MS - Cromatografia bidimensional abrangente com detecção por espectrometria de massa usando analisador tempo de voo

HLB - Fase de SPE contendo polímero com propriedades lipo e hidrofílicas

HMG-CoA redutase - 3-hidroxi-3-metilglutaril coenzima A redutase

IBU - Ibuprofeno

IBU-d3 - Ibuprofeno deuterado

ICH - International Conference on Harmonisation

INMETRO - Instituto Nacional de Metrologia, Normalização e Qualidade Industrial

IS - Padrão interno

ISO - Organização Internacional para Padronização

IUPAC - União Internacional de Química Pura e Aplicada

$\mathbf{K}_{D / \text { solo }}$ - Constante de sorção no solo

KET - Cetoprofeno

$\mathbf{K}_{o / w}$ - Coeficiente de partição octanol/água 
$K_{P D M S / w}$ - Coeficiente de partição do PDMS/água

LC - Cromatografia líquida

LD - Dessorção em líquido

LMCS - Modulador criogênico longitudinalmente modulado

LOD - Limite de detecção

LOQ - Limite de quantificação

LPME - Microextração em fase líquida

MA - Metandrostanolona

MEE - Mestranol

MEPS - Microextração em sorvente empacotado

MIP - Polímero molecularmente impresso

MP - Metilparabeno

MQ - Média quadrática

$\mathbf{M Q}_{r}$ - Média quadrática dos resíduos

$\mathbf{M Q}_{\text {reg }}$ - Média quadrática da regressão

MS - Espectrometria de massas

MSL - Mestanolona

MST - Mesterolona

MTH - Metandriol

NAP - Naproxeno

NSAID - Anti-inflamatórios não-esteroidais

OVAT - Método de otimização univariado

PA - Poliacrilato

PAH - Hidrocarbonetos poliaromáticos

PDMS - Polidimetilsiloxano

PDMS-ACB - Fase mista de polidimetilsiloxano-carvão ativo 
PDMS/CAR - Fase mista de PDMS e carboxeno

PDMS- $\beta$-CD - Fase mista de polidimetilsiloxano- $\beta$-ciclodextrina

PDMS-CD-DVB - Fase mista polidimetilsiloxano-ciclodextrina-divinilbenzeno

PDMS/DVB - Fase mista de PDMS e divinilbenzeno

PDMS-EG - Fase mista de polidimetilsiloxano e etilenoglicol

PEG - Carbowax

Propet:pyr -Proporção da solução etanol e piridina

$\boldsymbol{r}$ - Coeficiente de correlação

RAM - Material de acesso restrito

RSD - Desvio padrão relativo

Scan - Modo de varredura de análise

SBSE - extração por sorção em barra de agitação

SIM - Modo íon selecionado de análise

SPDE - Microextração em gota suspensa

SPE - Extração em fase sólida

SPME - Microextração em fase sólida

SQ - Soma quadrática

$\mathbf{S Q}_{e p}$ - Soma quadrática do erro puro

$\mathbf{S Q}_{f a j}$ - Soma quadrática da falta de ajuste

$\mathbf{S Q}_{r}$ - Soma quadrática dos resíduos

$\mathbf{S Q}_{\text {reg }}$ - Soma quadrática da regressão

t-d3 - testosterona deuterada

TD - Dessorção térmica

TIC - Cromatograma do íon total

u - Unidades de massa atômica

UNC - Fármacos na forma não-biotransformada 
Vderiv - Volume de agente derivatizante

Vet:pyr - Volume da solução etanol e piridina

VWSE - Extração por sorção nas paredes do frasco

5-ADD - 5-androsteno-4-ol-3 $\beta, 17 \beta$-diona-3-acetato

$\mu$-ECD - Detector de captura de elétrons miniaturizado 


\section{RESUMO}

A presença de fármacos no ambiente é um problema preocupante em virtude dos efeitos ecotoxicológicos conhecidos, e ainda os que continuam desconhecidos. A água é um dos compartimentos ambientais mais afetado por esses contaminantes, já que é utilizado em diversas atividades humanas. A contaminação da água afeta não somente os humanos, mas também todos os demais seres vivos que vivem ou utilizam dessa água. Por esse motivo, o desenvolvimento de métodos para análise de medicamentos em matrizes ambientais é essencial para o monitoramento desses contaminantes. Além disso, os métodos já desenvolvidos podem ainda ser aplicados para auxiliar no desenvolvimento de novas tecnologias de tratamento de água, bem como no estudo de produtos de degradação de fármacos durante as etapas de tratamento. Para essas finalidades, são utilizadas técnicas cromatográficas com detecção por espectrometria de massas para obter a separação dos compostos, permitindo a quantificação e a identificação inequívoca. Para realização dessas análises é necessário adotar métodos de preparo de amostra que possibilitem a concentração dos analitos presentes, e também, a eliminação dos interferentes presentes na matriz. Dessa maneira, nesse trabalho foram desenvolvidos 2 métodos de análise, um usando a cromatografia gasosa convencional acoplada a espectrometria de massas (GC-MS), e outro usando a cromatografia bidimensional abrangente com detecção por espectrometria de massas usando analisador do tipo tempo de voo (GCxGC-ToF/MS) para análise de resíduo de fármacos em matrizes aquosas, ambos utilizando como técnica de preparo de amostra a microextração em fase sólida (SPME). Na análise usando SPME-GC-MS foi utilizado a derivatização in situ para evitar picos assimétricos e possibilitar uma melhor separação cromatográfica. Esse método foi aplicado em amostras de rio, águas residuárias de entrada e saída de estação de tratamento (ETE) e esgoto industrial. Em todas as amostras foi possível detectar a presença dos fármacos, porém somente na entrada da ETE foi possível quantificar a

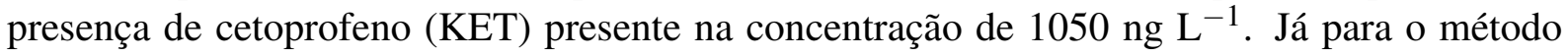
SPME-GCxGC-ToF/MS, devido o alto poder de separação do sistema bidimensional, foi possível separar 13 fármacos sem necessitar de derivatização. O método foi aplicado para amostras de rio, sendo que em nenhuma das amostras não foi detectado e quantificado os medicamentos em estudo. Em ambos os métodos foi aplicado planejamento experimental para otimizar o preparo de amostra e a reação de derivatização in situ quando utilizada. Após o desenvolvimento desses métodos, uma nova vertente foi estudada com o desenvolvimento de novas fases extratoras para extração por sorção em barras de agitação (SBSE) labmade foram desenvolvi- 
das. Cerca de 7 novas fases extratoras foram desenvolvidas, sendo mistas tendo como base uma mistura de polidimetilsiloxano (PDMS) com outros polímeros e/ou outro material adsorvente. Essas fases foram testadas e comparadas com a barra de PDMS comercial na extração de 9 fármacos presentes em água. A barra que apresentou melhor desempenho tinha como fase extratora uma mistura de PDMS com 30\% OV-17-vinil. Além disso, uma barra de SBSE contendo $5 \%$ carvão ativo foi aplicado com sucesso na análise de fenol em urina. Além dessas novas fases, foi explorado em conjunto o desenvolvimento de novas fases extratoras para extração por sorção nas paredes do frasco (VWSE) direcionados para extração de fármacos em água. As fases desenvolvidas eram compostas por uma mistura de carvão ativo com PDMS, e PDMS com divinilbenzeno (PDMS/DVB), em diferentes proporções. Por último, um aperfeiçoamento foi realizado na técnica de VWSE. Essas modificações foram testadas na extração de compostos com caracerísticas não-polares (progesterona) e polares (cafeína), e demonstrou eficiência na extração de ambos. 


\section{ABSTRACT}

The occurrence of pharmaceutical drugs in the environment is a worldwide problem caused by the genotoxicity and ecotoxicity activities of those compounds. Water is one of most used natural resource in human activities which explain the presence of emerging contaminants. Those compounds affect not only humans but also aquatic animals that spend the whole life cycle in this environment. In order to monitor drugs in the environment, it is essential the development of analytical methods to analyze pharmaceutical drugs in environmental matrices. Moreover, those methods developed are useful for the development of new water treatment techniques, and analysis of drug metabolites formed during the water treatment process. To accomplish all these purposes, chromatographic methods of analysis coupled to mass spectrometry detection are essential to separate the analytes, and further to identify and quantify them unequivocally. Before the analysis, the sample preparation step is fundamental to concentrate the analytes, eliminate and clean-up all the matrices interferents. Thus, in this thesis is described the development of 2 methods, one using conventional gas chromatography coupled to mass spectrometry (GC-MS), the latter one using comprehensive two dimensional gas chromatography coupled to time of flight mass spectrometry (GCxGC-ToF/MS) to analyze pharmaceutical drugs in water matrices. In both methods, solid phase microextraction (SPME) was used in the sample preparation procedure. In the SPME-GC-MS method in situ derivatization was applied to improve the chromatographic separation, providing neat and sharp peaks. This method were applied to analyze river, sewage and wastewater samples. In all samples were detected the presence of pharmaceutical drugs. However, one wastewater sample from the entrance of wastewater treatment plants (WWTP) presented ketoprofen in the concentration level of $1050 \mathrm{ng} \mathrm{\textrm {L } ^ { - 1 }}$. GCxGC-ToF/MS method it was possible to accomplish a complete separation of 13 analytes absent of peak tailing, co-elution and degradation without a derivatization reaction. River water samples were analyzed using this method, although, in none of the compounds were present in the samples. In both methods, an experimental design was used to optimize the SPME extraction and derivatization reaction. A second phase in this study explored the development of new polymeric phases for stir bar sorptive extraction (SBSE). About 7 new phases were developed, all phases were mixed of polidimethylsiloxane (PDMS) with other polymeric phases or with adsorptive material. All these new phases were tested and compared against the comercial version in the extraction of 9 pharmaceuticals compounds in water. The mixed polymeric phase of PDMS and OV-17-vinyl demonstrated a suitable selectivity to extract all pharmaceutical drugs in wa- 
ter. Also, a SBSE bar containing activated carbon 5\% was applied in the analysis of phenol in urine. Also, it was studied the development of new polymeric phases applied for the vial wall sorptive extraction (VWSE) used in the analysis of drugs in water. These new phases were based on a mixture of PDMS with activated carbon, and PDMS combined with divinylbenzene (PDMS/DVB) in different amounts of each compound. At least, a new configuration in the VWSE was purposed. This new configuration was tested for the extraction of non-polar (progesterone) and polar (caffeine) compounds in water, and presented adequate response for both compounds. 


\section{SUMÁRIO}

1 Introdução geral $\quad$ p. 30

1.1 Aspectos farmacológicos . . . . . . . . . . . . . p. 30

1.1.1 Fatores internos condicionais . . . . . . . . . . p. 32

1.1.2 Fatores Externos $\ldots \ldots \ldots \ldots \ldots$ p. 32

1.1 .3 Excreção . . . . . . . . . . . . . . . p. 33

1.2 Características dos fármacos e seu comportamento no ambiente . . . . . . . p. 34

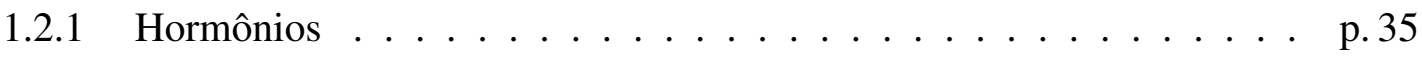

1.2.2 anti-inflamatórios não-esteroidais (NSAID) $\ldots \ldots \ldots$. . . . . . 37

1.2 .3 Antidepressivos . . . . . . . . . . . . . p. 38

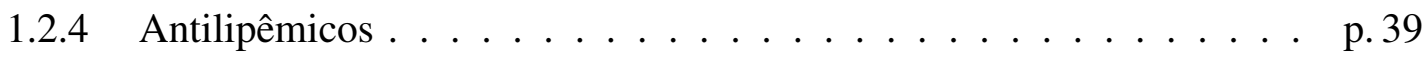

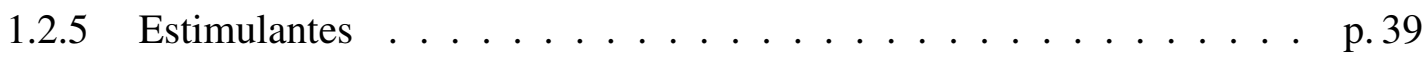

1.2.6 Conservantes ........................... p. 40

1.3 Riscos da presença de fármacos no ambiente . . . . . . . . . . p. 40

1.4 Mecanismos de entrada dos fármacos no ambiente . . . . . . . . . . . p. 41

1.5 Análise dos fármacos no ambiente $\ldots \ldots \ldots \ldots \ldots \ldots$ p. . . . . . . . . .

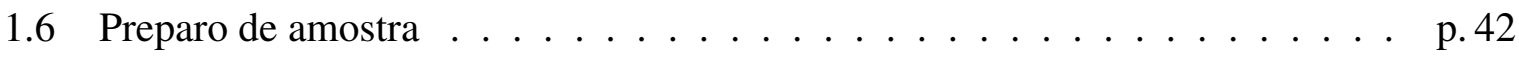


1.6.1 Extração em Fase Sólida $(\mathrm{SPE}) \quad \ldots \ldots$. . . . . . . . . . p.42

1.6.2 Microextração em fase sólida . . . . . . . . . . . . . p.43

1.6.3 Extração em barras de sorção . . . . . . . . . . . . . . p.47

1.6.4 Extração por sorção nas paredes do frasco . . . . . . . . . . . . . . . p.48

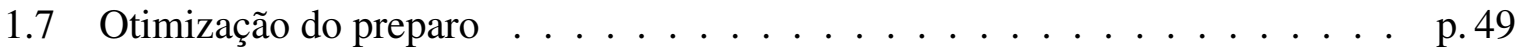

1.7.1 Triagem usando planejamento fatorial . . . . . . . . . . . p.50

1.7.2 Otimização por Matriz de Doehlert . . . . . . . . . . . . p.52

1.8 Validação do método de análise . . . . . . . . . . . . . . . p. 53

1.8.1 Seletividade e/ou especificidade . . . . . . . . . . p. 55

1.8.2 Precisão intra e inter-dia . . . . . . . . . . . . p. 55

1.8.3 Robustez ......................... p. 56

1.8 .4 Recuperação . . . . . . . . . . . . . . . . p. p. 56

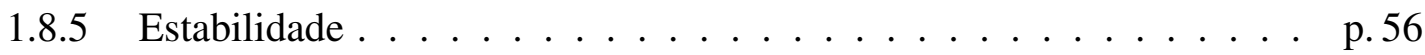

1.8 .6 Exatidão . . . . . . . . . . . . . . . p. 56

1.8.7 Linearidade ou faixa de trabalho . . . . . . . . . . . . . p.57

1.8.8 Avaliação estatística . . . . . . . . . . . . . . p.58

2 Capítulo 2 - Análise de resíduos de fármacos em águas residuárias usando microextração em fase sólida (SPME) e derivatização in situ p. 63

2.1 Introdução . . . . . . . . . . . . . . . p. 63

2.2 Experimental . . . . . . . . . . . . . . . . . p. 64

2.2.1 Reagentes........................... p. 64

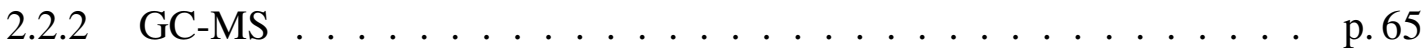

2.2.3 SPME e derivatização in situ . . . . . . . . . . . . . . . . p. 65

2.2.4 Planejamento fatorial . . . . . . . . . . . . . p. 66

2.2.5 Validação do método . . . . . . . . . . . . . p. 66

2.2.6 Amostras ambientais ..................... p. 67 
2.3 Resultados e Discussão . . . . . . . . . . . . . . . . . . . . . p. 69

2.3.1 Separação Cromatográfica . . . . . . . . . . . . . . . p. 69

2.3.2 Extração por SPME e derivatização in situ . . . . . . . . . . . . . . . p.69

2.3.3 Otimização do método . . . . . . . . . . . . . p. 74

2.4 Validação do método $\ldots \ldots \ldots \ldots \ldots \ldots$ p. . . . . . . . . . . . . . .

2.5 Amostras ambientais $\ldots \ldots \ldots \ldots \ldots \ldots \ldots$ p. 82

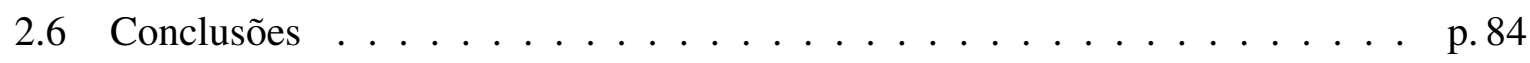

3 Análise de resíduos de fármacos em água de rio usando microextração em fase sólida e cromatografia bidimensional abrangente acoplada à espectrometria $\begin{array}{lr}\text { de massas (SPME-GCxGC-ToF/MS) p. } 85 & \text { p }\end{array}$

3.1 Introdução . . . . . . . . . . . . . . . . p. 85

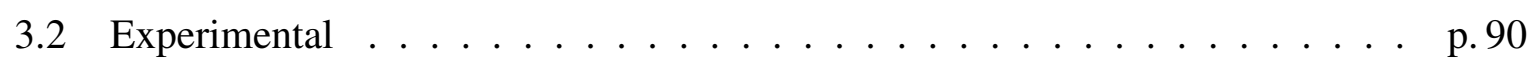

3.2 .1 Reagentes .......................... p. 90

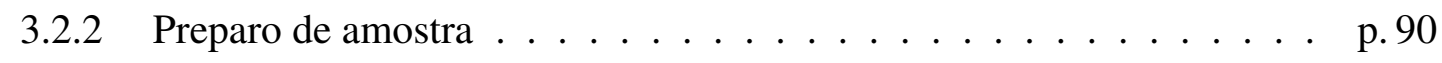

3.2 .3 Planejamento fatorial . . . . . . . . . . . . p. 91

3.2.4 Condições de análise . . . . . . . . . . . . . . . p. 92

3.2.5 Validação do método . . . . . . . . . . . . . . p. 92

3.3 Resultados e Discussão . . . . . . . . . . . . . . . . . . p.93

3.3.1 Planejamento fatorial . . . . . . . . . . . . p. 93

3.3.2 Análise por GC-MS . . . . . . . . . . . p. 96

3.3.3 Análise por GCxGC-ToF/MS . . . . . . . . . . p. 97

3.4 Figuras de Mérito . . . . . . . . . . . . . . . . . p. 99

3.5 Conclusão . . . . . . . . . . . . . . . . . . p. 101

4 Desenvolvimento de novos recobrimentos poliméricos para extração por sorção em barras de agitação (SBSE) e extração por sorção na parede do frasco $\quad$ p. 102 4.1 Introdução . . . . . . . . . . . . . . . . . p. 102 


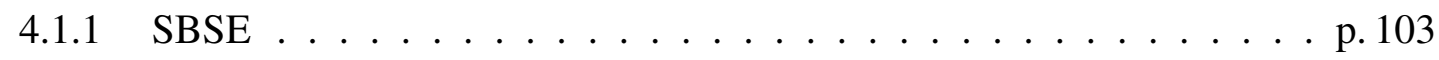

4.1.2 Extração por sorção na parede do frasco . . . . . . . . . . . . . p. 107

4.2 Experimental $-\mathrm{SBSE} \ldots \ldots \ldots \ldots \ldots$. . . . . . . . . . 108

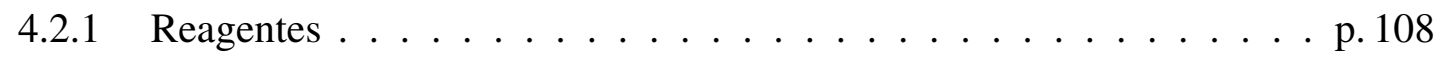

4.2.2 Extração de fármacos em água - testes preliminares . . . . . . . . . . p. 109

4.2.3 Novo molde projetado . . . . . . . . . . . . . . p. 110

4.2.4 Análise de fenol usando barra de SBSE labmade . . . . . . . . . . . p. 110

4.3 Preparo dos dispositivos de extração na parede do frasco (VWSE) . . . . . p. 111

4.3.1 Procedimento de extração para VWSE . . . . . . . . . . . . . p. 113

4.4 Resultados e Discussão . . . . . . . . . . . . . . . . . . . . . p. 114

4.4.1 Moldes e novos recobrimentos poliméricos desenvolvidos . . . . . p. 114

4.4.2 Aplicação das barras de SBSE na análise de fármacos . . . . . . . . . p. 117

4.4.3 Aplicação da SBSE na análise de fenol em urina . . . . . . . . . . . p. 122

4.4.4 Aplicação dos VWSE . . . . . . . . . . . . . . . p. 125

4.5 Conclusões . . . . . . . . . . . . . . . . p. 130

4.6 Perspectivas futuras $\ldots \ldots \ldots \ldots \ldots \ldots$. . . . . . . . . 130

$\begin{array}{ll}\text { Referências Bibliográficas } & \text { p. } 131\end{array}$ 


\section{PREFÁCIO}

Essa tese foi baseada em projeto que surgiu a partir de uma conversa com a professora da Texas A\&M University, Carmen Gomes. A presença de medicamentos no ambiente estava sendo muito estudado nessa universidade. Então percebi que esse era um problema que afeta não somente uma região específica mas também grande parte dos países desenvolvidos e em desenvolvimento. E no Brasil, em especial, em virtude do rápido desenvolvimento do país, seria interessante avaliar a contaminação do ambiente aquático por resíduo de fármacos.

Com isso, iniciou-se o projeto que originalmente seria análises de antibióticos em matrizes aquosas, contudo devido a demora na entrega dos padrões analíticos adquiridos, foi realizada uma mudança no projeto para análise de fármacos de diferentes classes terapêuticas em água, usando os padrões analíticos disponíveis em nosso laboratório. A análise foi realizada em sistemas de cromatografia gasosa com detecção por espectrometria de massas (GC-MS), já que essa técnica apresenta uma alta resolução e capacidade de separação, e produz mínimo resíduo químico. Na proposta inicial, o preparo de amostra deveria ser realizado por extração por sorção em barras de agitação (SBSE), porém, a etapa de preparo das barras estava apresentando problema, levando tempo extremamente longo para, o que levou adotar o preparo de amostra utilizando a microextração em fase sólida (SPME).

A partir desse ponto, surgiu o Capítulo 2 e 4. O Capítulo 2 descreve a aplicação da SPMEGC-MS na análise de fármacos em matrizes aquosas usando em conjunto a derivatização in situ. O Capítulo 4 mostra o processo de melhoramento do preparo das barras de SBSE labmade, desenvolvimento de novas fases poliméricas, e ainda avanços feitos no mesmo sentido para uma nova técnica de extração, a extração por sorção nas paredes do frasco (VWSE).

O Capítulo 3 é resultado de um estágio sanduíche realizado na Seton Hall University, 
localizada em South Orange, New Jersey. Foi um desafio proposto pelo professor Nicholas H. Snow que queria estudar a análise por GC-MS e cromatografia bidimensional abrangente (GCxGC) de fármacos sem o uso de derivatização, fazendo sua aplicação em amostras de água de rio da cidade, já que o estado de New Jersey concentra a grande maioria das indústrias farmacêuticas do país. 


\section{CAPÍTULO 1}

\section{INTRODUÇÃO GERAL}

A presença de contaminantes no ambiente é uma preocupação mundial. Com o crescimento da população, a necessidade de água, alimentos e combustíveis aumentam. O desenvolvimento tecnológico e a criação de pólos industriais estão ocorrendo de forma acelerada. Juntamente a estes processos, a contaminação dos recursos hídricos vem sendo observada. (13)

A água é um recurso natural indispensável para vida de todos os seres vivos. Sua utilização é ampla, seja como solvente,alimento, meio de desenvolvimento parcial ou total de seres vivos. Dessa maneira, a contaminação dos recursos hídricos prejudica não somente as atividades humanas, mas também a fauna e a flora aquática, sendo muito importante a investigação da presença de contaminantes orgânicos e inorgânicos nesse meio.

Dentre os contaminantes orgânicos, nos últimos anos se destaca a presença de resíduos medicamentos em água. Houve um aumento no número de publicações relacionadas a ocorrência de fármacos em águas residuárias, de superfície e subterrâneas, como pode ser observado na Figura 1.1. O número de artigos alcançou 3000 no ano de 2010, demonstrando a importância dessa temática.

Para melhor entender a preocupação com a presença dos fármacos, uma breve revisão de farmacologia e toxicologia será apresentada.

\subsection{Aspectos farmacológicos}

Resumidamente, a farmacocinética estuda o movimento dos fármacos no organismo, e a farmacodinâmica trata do local de ação, mecanismos de ação e seus efeitos. Ambos estão ligados 
Figura 1.1: Número de publicações na última década referente a presença de fármacos em água, retirado de (1).

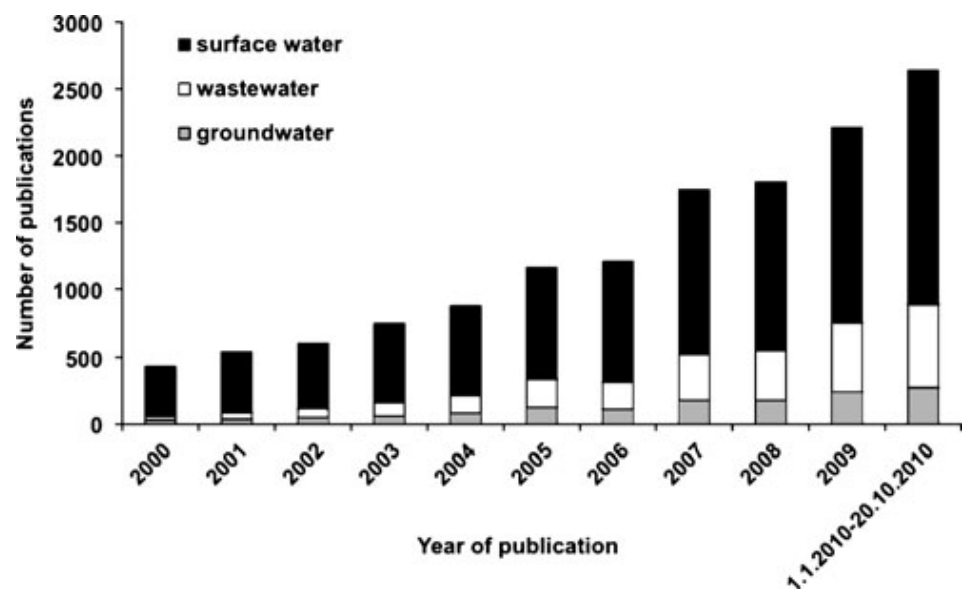

diretamente às vias de administração. Dentro da farmacocinética, a excreção e a biotransformação dos fármacos são dois processos que se destacam por estarem ligados diretamente com a presença dos medicamentos no ambiente.

Após a administração e absorção do medicamento, inicia-se o processo de metabolismo ou biotransformação, caracterizado por ocorrer em duas fases, chamadas de fase I e II. As reações de fase I correspondem a oxidação, redução e hidrólise da substância química. Já a fase II são reações de conjugação ou síntese, as moléculas são complexadas com outras produzidas pelo próprio organismo. A glicuronidação, sulfatação, acilação, metilação e conjugações com a glutationa e aminoácidos são as principais reações de fase II. (14)

As reações de fase I são catalisadas por enzimas microssômicas que compõem o citocromo P-450 (CYP), uma hemoproteína que atua em conjunto com o NADPH citocromo p-450 redutase e o citrocromo b5 redutase, responsáveis pelo metabolismo de fase I. Existem várias isoformas responsáveis pelo metabolismo e cada fármaco é metabolizado em uma ou mais dessas isoformas. As isoformas são CYP1A2, CYP2E1, CYP3A4, CYP2C9, CYP2C19 e CYP2D6. (15)

As enzimas citosólicas são responsáveis pelas biotransformações de fase II. A glicuroniltransferase, sulfonotransferase, metiltransferase, $\mathrm{N}$-acetiltransferase (co-fator acetilcoenzima A), e glutationa S-transferase (co-fator glutationa) são as principais enzimas envolvidas. Existem inúmeros fatores que interferem diretamente na biotransformação dos fármacos, chamados de fatores internos relacionados ao sistema biológico, que compreendem a constituição do organismo (espécie, idade, peso, sexo, genética). Além disso, há os fatores condicionais relacionados ao estado patológico e nutricional. Fatores externos são dependentes da substância e sua via de introdução.(16) 


\subsubsection{Fatores internos condicionais}

Espécie e raça: Esses fatores causam variações qualitativas e quantitativas na biotransformação, em algumas raças a presença ou ausência de enzimas pode variar. Essa variação de espécie é comumente observada em animais.

Fatores genéticos: Cada indivíduo possui uma capacidade metabolizadora diferente, podendo ocorrer variações bruscas na presença de determinadas isoformas do CYP-450. Um exemplo, indivíduos asiáticos ou de origem asiática apresentam variações em algumas isoformas como CYP2D6. Essa isoforma é responsável pela biotransformação de vários fármacos como os antidepressivos tricíclicos. Os asiáticos apresentam uma menor atividade dessa isoforma quando se compara com indivíduos europeus. (17)

Gênero: Existe variação da intensidade de biotransformação entre o sexo masculino e feminino. Na espécie humana, essa diferença não é extremamente acentuada. Entretanto, o uso de anticoncepcionais pelas mulheres pode exercer influência na capacidade de metabolismo.

Idade: É um fator de extrema importância, pois recém-nascidos e fetos são praticamente desprovidos bioquimicamente para metabolizar medicamentos, sendo susceptíveis à sua ação tóxica. Em idosos o efeito farmacológico e o metabolismo serão diferenciados, uma vez que mudanças bioquímicas estão ocorrendo alterando a constituição corpórea. Alia-se esse fato ao aparecimento de algumas patologias crônicas, causando uma mudança na velocidade das reações metabólicas.

Nutrição: O jejum e a subnutrição diminuem a presença de proteínas, outros elementos nutricionais ligados a síntese das enzimas do sistema de biotransformação, e diminui a capacidade metabólica. Alimentação rica em determinados alimentos pode inativar isoformas do CYP450. Como exemplo, o suco de toranja (grapefruit), inativa a isoforma CYP3A4 e diminui a biotransformação realizada por essa enzima.

Patologias: Algumas patologias afetam diretamente a biotransformação, principalmente doenças hepáticas como cirrose, icterícia obstrutiva, carcinomas e hepatite. Além de comprometimentos cardiovasculares, resultam na diminuição do fluxo sanguíneo hepático e modificam também a biotransformação.

\subsubsection{Fatores Externos}

Alguns compostos químicos interferem na biotransformação por atuarem sobre os sistemas enzimáticos inibindo-os ou ativando-os, sendo chamados de indutores ou inibidores enzimáticos. Diversas substâncias químicas como álcool, hormônios, praguicidas, barbitúricos, hidrocarbonetos poliaromáticos $(\mathrm{PAH})$, antidepressivos, antibióticos e antifúngicos podem atuar inibindo ou ativando, sendo uma característica particular de cada substância. 


\subsubsection{Excreção}

É o processo de retirada de uma substância do organismo. As principais vias de excreção de fármacos são a urinária e a fecal. A urina excreta substâncias hidrossolúveis enquanto as fezes levam substâncias não absorvidas no trato digestivo e produtos excretados pela bile, obtidos após sofrer fase II de biotransformação.

Os capilares glomerulares dos rins possuem poros grandes permitindo a passagem de elementos contidos no sangue, exceto macromoléculas e elementos figurados do sistema circulatório. Os fármacos não-ligados às proteínas plasmáticas são excretados na urina. A excreção urinária de substâncias ácidas e básicas sofre influência do pH da urina. Nas fezes encontram-se fármacos não absorvidos no trato digestivo, com baixa polaridade e elementos vindos do fígado e vesícula biliar.

Dessa maneira, da grande variedade de fármacos disponíveis se destacam alguns grupos como os antibióticos, antiflogísticos, anti-epiléticos, $\beta$-bloqueadores, reguladores lipêmicos, vasodilatores, antidepressivos, antipiréticos, hormônios esteróides, anti-inflamatórios não-esteroidais (NSAID), anti-inflamatórios esteroidais, entre outros. A presença desses medicamentos no ambiente está intrinsicamente ligada à excreção desses compostos na urina e nas fezes de humanos. Além disso, muito desses medicamentos são usados para fins veterinários, o que a excreção dos fármacos pelos animais em um fator muito importante. Apesar das exigências feitas por órgãos como Food and Drugs Administration (FDA) (18) sobre a necessidade de ensaios para avaliar a presença e a persistência desses medicamentos no ambiente, para ter sua aprovação para comercialização; muitos medicamentos hoje comercializados não sofreram essa avaliação, e possuem doses elevadas semelhantes a compostos agroquímicos. (19)

Os fármacos podem ser excretados como metabólitos, conforme já descrito, ou ainda na sua forma não-biotransformada (UNC). A porcentagem de fármaco excretado na forma UNC é classificada como baixa ( $\leq 5 \%$ ), moderada (6 a 39\%), alta (40 a 69\%) e elevada (acima de $70 \%$ ). Alguns NSAID (como ibuprofeno, fenoprofeno, flurbiprofeno, cetoprofeno), a cafeína e a fluoxetina possuem excreção na forma UNC por volta de 5\%, já outros como o flurbiprofeno e a sinvastatina apresentam excreção moderada na forma UNC. Com taxas consideradas altas estão testosterona, furosemida, digoxina e trimetoprima; com elevadas taxas alguns antibióticos se destacam a tetraciclina e a ciprofloxacina.

Alguns hormônios são naturais do organismo humano, exercem funções primordiais para manter os órgãos do sistema reprodutivo, pele e cérebro, sendo também essenciais na regeneração pele, tecidos, ossos e músculos. Pelo fato de serem naturais, são excretados diariamente conforme mostra a Tabela 1.1 .

Dessa maneira, aumenta a relevância da excreção para entrada de fármacos no ambiente, principalmente pelo fato da grande maioria das mulheres em idade fértil utilizarem anticoncep- 
Tabela 1.1: Excreção diária em $\mu \mathrm{g}$ de hormônios esteróides humanos, retirado de (10).

\begin{tabular}{|l|c|c|c|c|}
\hline \multicolumn{1}{|c|}{ Gênero } & Estrona & Estradiol & Estriol & Etinilestradiol \\
\hline \multicolumn{1}{|c|}{ Masculino } & 1,6 & 3,9 & 1,5 & - \\
\hline Feminino (périodo menstrual) & 3,5 & 8,0 & 4,8 & - \\
\hline Feminino (menopausa) & 2,3 & 4,0 & 1 & - \\
\hline Feminino (gravidez) & 259 & 600 & 6000 & - \\
\hline Feminino (usando anticoncepcional) & - & - & - & 35 \\
\hline
\end{tabular}

cionais que fornecem $35 \mu \mathrm{g}$ diárias de etinilestradiol.

Além da contribuição humana, deve ser considerada a contribuição vinda dos animais comumente usados nas criações, que por possuírem semelhanças com o sistema endócrino humano, também excretam uma parcela de hormônios esteroidais.

\subsection{Características dos fármacos e seu comportamento no ambi- ente}

O comportamento dos fármacos no ambiente é importante para determinar sua persistência no mesmo. Está relacionado com suas propriedades físico-químicas como coeficiente de partição octanol/água $\left(\mathrm{K}_{o / w}\right)$ ou Log $\mathrm{P}$, constante de dissociação, solubilidade, pressão de vapor, e outros fatores. Estas propriedades podem auxiliar na localização dos fármacos no ambiente, e se estarão ligadas ou não a matéria orgânica presentes no sedimento, solo, esgoto e água. A não detecção dos fármacos não exclui sua presença, pois podem estar ligados à matéria-orgânica ou em outra matriz ambiental. (20) Cabe ressaltar que as propriedades dos fármacos refletem muito bem o comportamento deles nos tecidos, porém nem sempre o mesmo comportamento se repete no ambiente, já que as propriedades são obtidas em situações controladas. Estudos feitos pelo Jjemba (19) corroboram com esse fato por demonstrarem medicamentos com baixa solubilidade, inferior a $0,1 \mathrm{mg} / \mathrm{mL}$, podem estar presentes em compartimentos diferentes desde águas subterrâneas até águas superficiais, sendo essencial estudos para conhecer e correlacionar as propriedades dos fármacos com sua presença nos compartimentos ambientais.

No solo, por exemplo, o fármaco pode se ligar a matéria orgânica presente, dependendo de sua polaridade. É fundamental estudar o processo de sorção e dessorção dos fármacos no solo para determinar o seu transporte, transformação e atividade biológica. E dessa maneira, predizer a tendência de contaminar outros compartimentos ambientais como águas subterrâneas e lençóis freáticos. As características do solo são essenciais para determinar esse comportamento. A composição com relação à quantidade de argila, areia, sílica, $\mathrm{pH}$, granulometria e textura, e a quantidade de carbono orgânico são fatores que influenciam diretamente o comportamento de sorção e dessorção do fármaco no solo. Sukul et al. (21), estudou o comportamento de um derivado de sulfonamidas no solo, percebendo a interação da amina aromática presentes nesses 
compostos, que fazem uma ligação covalente cruzada com a matéria orgânica presente no solo. E ainda, o grupo amino presente no grupo sulfonamida apresenta interação com grupamentos cetônicos, enólicos, alcoóis, fenólicos e carboxilas presente na matéria orgânica.

Comportamento semelhante se observa no sedimento. A persistência de fármacos no sedimento dependerá de sua capacidade de adsorção e sorção, da taxa de sedimentação e da lixiviação da água. Assim como no solo, a constante de sorção $\left(\mathrm{k}_{D / \text { solo }}\right)$ é definida pela razão da concentração do composto sorvido pela concentração na água em condições de equilíbrio, é fator essencial para prever o comportamento de determinado composto. Contudo, esse coeficiente possui um cálculo complexo, e é particular para cada compartimento. Além de se ligar a matéria orgânica, os fármacos podem adsorver em constituintes minerais, por troca iônica, formação de complexos com íons $\mathrm{Ca}^{+2}, \mathrm{Mg}^{+2}, \mathrm{Fe}^{+3}, \mathrm{Al}^{+3}$, ou ainda fazer ligações de hidrogênio com constituintes no sedimento. (20)

No esgoto os fármacos podem ser degradados por microorganismos presentes, gerando compostos ainda mais tóxicos. Muitas vezes, os medicamentos eliminados na forma metabolizada de glicuronídeo podem se desligar e retornar a forma inicial presentes na forma farmacêutica. Esse fato ocorre com o sulfametoxazol, sendo encontrado na forma N-4-acetilsulfametoxazol, convertido novamente a sulfametoxazol. (22)

Além disso, os fármacos podem reagir com outros componentes do esgoto e gerar compostos de toxicidade desconhecida. Dependendo das propriedades do fármaco pode ligar-se à matéria orgânica dissolvida no esgoto (sorção ou adsorção), ou ligar-se pelo mesmo mecanismo no lodo. (23)

Se o composto for estável, não se ligar ao solo, sedimento, lodo ou mesmo componentes do esgoto, tem a tendência a lixiviar para águas subterrâneas, e ainda atingir águas superficiais de rios e lagos, comprometendo essas fontes de água potável para consumo e uso diário.

Assim, o conhecimento das propriedades físico-químicas dos medicamentos é um passo inicial para auxiliar nos estudos analíticos para avaliar sua presença em matrizes ambientais, como será apresentado.

\subsubsection{Hormônios}

Os hormônios são ácidos muito fracos, derivados do colesterol, tendo em comum o anel ciclopentano-perhidrofenatreno, conforme mostra as Figuras 1.2 e 1.3. Algumas de suas propriedades estão listadas na Tabela 1.2.

A seguir, serão mostrados as principais características dos compostos estudados durante a elaboração dessa tese. 
Tabela 1.2: Propriedades físico-químicas dos hormônios.

\begin{tabular}{ccc}
\hline Hormônios & Log P Massa molecular $\left(\mathrm{g} \mathrm{mol}^{-1}\right)$ \\
\hline Estradiol & 4,0 & 272,4 \\
Estrona & 3,1 & 270,4 \\
Etinilestradiol & 3,7 & 296,4 \\
Mestranol & 4,7 & 310,4 \\
Mesterolona & 3,5 & 304,5 \\
Metandriol & 4,4 & 304,5 \\
Mestanolona & 4,3 & 304,5 \\
Metandrosterolona & 4,0 & 300,4 \\
4-androstenodiona & 2,71 & 286,4 \\
Etiocolanona & 2,75 & 286,4 \\
5-androsteno-4-ol-3 $\beta, 17 \beta$-diona-3-acetato & 2,5 & 344,5 \\
\hline
\end{tabular}

Figura 1.2: Estrutura molecular dos hormônios.<smiles>C[C@]12CCC3C(CCC4=CC(=O)CC[C@]43C)C1CCC2=O</smiles>

4-androstenodiona<smiles>C[C@]12CCC3C(CCC4C[C@H](O)CC[C@@]43C)C1CCC2=O</smiles>

Etiocolanona<smiles>CC(=O)OC1CC[C@@]2(C)C(=CC(=O)C3C4CCC(=O)[C@@]4(C)CCC32)C1</smiles>

5-androsteno-4-ol-3beta,17beta-diona-3-acetato 
Figura 1.3: Estrutura molecular dos hormônios.<smiles>C[C@]12CCC3c4ccc(O)cc4CCC3C1CCC2O</smiles>

Estradiol<smiles>C#C[C@]1(O)CCC2C3CCc4cc(O)ccc4C3CC[C@@]21C</smiles>

Etinilestradiol<smiles>C[C@H]1CC(=O)CC2CCC3C4CC[C@H](O)[C@@]4(C)CCC3[C@]21C</smiles>

Mesterolona<smiles>C[C@]12CCC3C(CCC4CC(=O)CC[C@]43C)C1CC[C@@]2(C)O</smiles>

Mestanolona<smiles></smiles>

Estrona<smiles>C#CC1(O)CCC2C3CCc4cc(OC)ccc4C3CC[C@]21C</smiles>

Mestranol

$\mathrm{HO}$<smiles>C[C@]12CCCCC1=CCC1C2CC[C@]2(C)C1CC[C@@]2(C)O</smiles>

Metandriol<smiles>C[C@]12C=CC(=O)C=C1CCC1C2CC[C@@]2(C)C1CC[C@@]2(C)O</smiles>

Metandrostenolona

\subsection{2 anti-inflamatórios não-esteroidais (NSAID)}

Nesse estudo foram selecionados os derivados do ácido propiônico, conhecido como profenos. Essa classe de NSAID é muito utilizado e sua comercialização não exige prescrição médica na maioria dos países. Podem ser usados no tratamento da artrite reumatóide ou oste- 
oartrite, problemas musculares, dores causados por cirurgias dentárias, entre outras aplicações. O mecanismo de ação de NSAID é inibir a biosíntese de prostaglandinas, podendo inibir reversilvemente ou irreversilvemente a enzima ciclooxigenase (COX), esse fato está ligado ao tipo de fármaco administrado. A COX é dividida em COX1, COX2 e COX3, podendo ter uma ação específica ou inespecífica. Os profenos são COX não-seletivos, suas estruturas estão presentes na Figura 1.4, algumas de suas propriedades físico-químicas destacadas na Tabela 1.3.

Tabela 1.3: Propriedades físico-químicas dos profenos.

\begin{tabular}{|c|c|c|c|}
\hline anti-inflamatórios & Massa molar $\left(\mathrm{g} \mathrm{mol}^{-1}\right)$ & $\log \mathrm{P}$ & $\mathrm{pka}$ \\
\hline Ibuprofeno & 206,3 & 4,0 & 4,4 \\
\hline Fenoprofeno & 242,3 & 0,8 & 4,5 \\
\hline Flurbiprofeno & 244,3 & 4,2 & 4,22 \\
\hline Naproxeno & 230,3 & 3,2 & 4,2 \\
\hline Cetoprofeno & 254,3 & 0,0 & 4,5 \\
\hline
\end{tabular}

Figura 1.4: Estrutura molecular dos profenos.<smiles>CC(C)Cc1ccc(C(C)C(=O)O)cc1</smiles><smiles>CC(C(=O)O)c1ccc(-c2ccccc2)c(F)c1</smiles>

Flurbiprofeno<smiles>CC(C(=O)O)c1cccc(C(=O)c2ccccc2)c1</smiles>

Cetoprofeno<smiles>CC(C(=O)O)c1cccc(Oc2ccccc2)c1</smiles>

Fenoprofeno<smiles>COc1ccc2cc(C(C)C(=O)O)ccc2c1</smiles>

Naproxeno

\subsubsection{Antidepressivos}

O uso de antidepressivos e tranquilizantes apresentou um aumento considerável. Desse grupo foi estudado a fluoxetina, um dos medicamentos mais vendidos nos últimos anos, usado 
para combate da depressão, síndrome do pânico, distúrbios alimentares, transtornos obssessivoscompulsivos. É um inibidor pré-sináptico da reacaptação de serotonina, combatendo os sintomas depressivos e compulsivos dos pacientes. A fluoxetina tem massa molecular de 309,3 $\mathrm{g}$ $\mathrm{mol}^{-1}$, Log P de 4,6 e pka de 8,7; sua estrutura encontra-se na Figura 1.5.

Figura 1.5: Estrutura molecular da fluoxetina.<smiles>CNCCC(Oc1ccc(C(F)(F)F)cc1)c1ccccc1</smiles>

Fluoxetina

\subsubsection{Antilipêmicos}

A sinvastatina é um agente antilipêmico que atua inibindo competitivamente a 3-hidroxi3-metilglutaril coenzima A redutase (HMG-CoA redutase), enzima responsável pela síntese de colesterol. A inibição da HMG-CoA diminui a síntese de colesterol pelo fígado e a concentração de colesterol intracelular. A sinvastatina reduz não somente a concentração de colesterol total mas também as frações do colesterol (LDL, VLDL) e triglicérides, aumentando a concentração de HDL. A sinvastatina tem Log P de 4,68; massa molar de 418,6 g mol$^{-1}$ e pka 13,49. Sua estrutura está representa na Figura 1.6.

Figura 1.6: Estrutura molecular da sinvastatina.<smiles>CCC(C)(C)C(=O)OC1C[C@@H](C)C=C2C=C[C@H](C)[C@H](CCC3C[C@@H](O)CC(=O)O3)C21</smiles>

Simvastatina

\subsubsection{Estimulantes}

A cafeína é um dos principais estimulantes encontrados em diversos alimentos e bebidas. Tendo em vista seu grande consumo e a sua persistência no ambiente, vem sendo adotado como principal marcador da contaminação antropogênica. Como característica a cafeína é uma 
metilxantina, com massa molar de 194,2 $\mathrm{g} \mathrm{mol}^{-1}$, Log P de -0,1 e pka 14. Sua estrutura está representada na Figura 1.7.

\subsubsection{Conservantes}

São substâncias com propriedades bactericidas e antimicrobianas usadas na conservação de bebidas, alimentos enlatados, produtos de cuidado pessoal como desodorantes, pasta de dentes, filtros solares, géis de banho e cremes de cuidado da pele. Um dos conservantes mais utilizado é o metilparabeno, um éster do ácido $p$-hidroxibenzóico. Como propriedades o metilparabeno possui pka de 8,5, Log P de 1,91 e massa molecular de 152,2 $\mathrm{g} \mathrm{mol}^{-1}$, conforme mostrado na Figura 1.8.

Figura 1.7: Estrutura molecular da cafeína.<smiles>Cn1c(=O)c2c(ncn2C)n(C)c1=O</smiles>

Figura 1.8: Estrutura molecular do metilparabeno.<smiles>COC(=O)c1ccc(O)cc1</smiles>

Metilparabeno

\subsection{Riscos da presença de fármacos no ambiente}

Com relação aos riscos e presença dos medicamentos no ambiente, grande destaque é dado aos hormônios. A presença deles mesmo em níveis baixos na água causa efeitos deletérios, ainda não totalmente conhecidos. Há relatos sobre a ocorrência de feminização de peixes expostos a baixas concentrações de hormônios (24), além de mudança na proporção de machos e fêmeas de 1:1 para 1:2 de Gammarus pulex, uma éspecie de crustáceos. $(25,26)$

Além dos hormônios outros compostos possuem a capacidade de provocar alterações hormonais, sendo chamados de desreguladores endócrinos (EDC). Estes são substâncias não produzidas no corpo que agem imitando ou antagonizando os hormônios naturais. Dessa forma, 
interferem na síntese, secreção, transporte, ligação, ação ou eliminação dos hormônios naturais do corpo responsáveis pela manutenção da homeostase, reprodução, desenvolvimento e comportamento.(27) Os derivados do ácido $p$-hidroxibenzóico apresentam atividade EDC, com possível potencial para causar câncer de mama. (28)

Um dos principais anti-inflamatórios NSAID vendido livremente, o ibuprofeno, apresenta toxicidade para os embriões do peixe da espécie D. rerio, mais conhecido como zebrafish.

\subsection{Mecanismos de entrada dos fármacos no ambiente}

Os mecanismos de entrada dos fármacos no ambiente são diversificados, conforme mostra a Figura 1.9. Como referido anteriormente, os medicamentos podem vir da excreção, ao serem administrados e aplicados na criação de animais, como também podem ser proveniente da agricultura, do consumo humano doméstico e hospitalar, e da criação de peixes que dispõem os compostos diretamente na água, contaminando não somente a água como também solo que por lixiviação pode atingir regiões profundas. Além disso, resíduos são gerados durante as etapas de preparo dos medicamentos pela indústria farmacêutica e farmácias de manipulação, o que pode implicar na contaminação direta da água, caso não exista nenhum tipo de tratamento adequado para sua eliminação.

Figura 1.9: Rota de entrada do resíduo de medicamentos nos compartimentos ambientais.

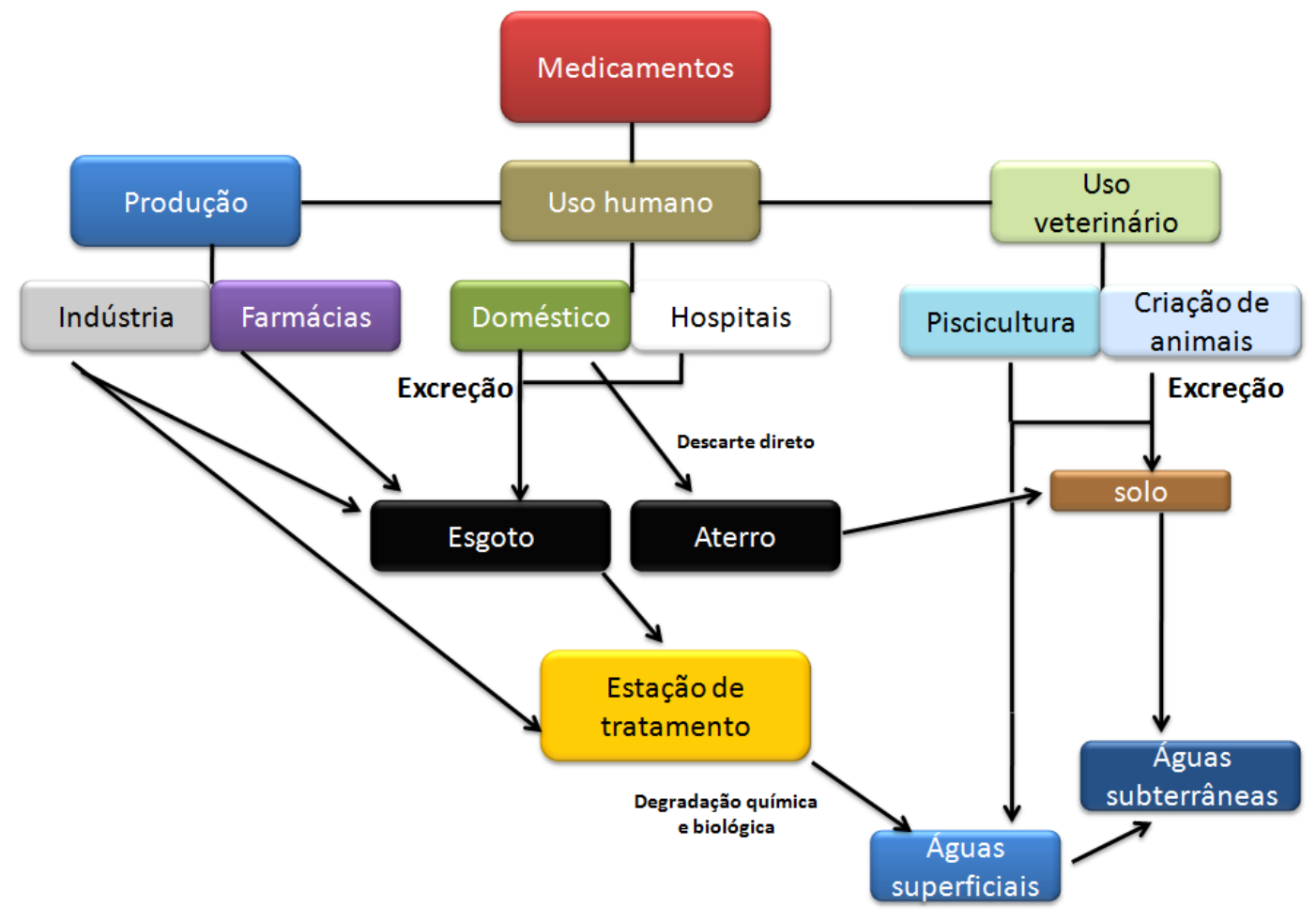




\subsection{Análise dos fármacos no ambiente}

O monitoramento de fármacos em esgoto, efluentes de ETE, ou mesmo da água de rio é desafiador já que essas matrizes são complexas, contendo uma grande quantidade de matéria orgânica, o que pode interferir no processo de análise. Dessa maneira o uso de detecção por espectrometria de massas (MS) é fundamental para a identificação de compostos alvo, diminuindo a ocorrência de falso positivo.

Diversos métodos são encontrados para análise de fármacos em amostras ambientais usando cromatografia líquida (LC) ou cromatografia gasosa (GC) acoplada ao espectrômetro de massas (MS). (29-38) Cada técnica cromatográfica possui suas pecualiaridades, apresentando vantagens e desvantagens. LC-MS e LC-MS/MS são técnicas apropriadas para análise de compostos instáveis termicamente, possuem adequada detectabilidade, porém o equipamento possui um alto custo para aquisição e manutenção, além de ser susceptível a efeito de matriz em amostras ambientais. O GC-MS/MS, principalmente, o GC-MS são equipamentos de menor custo, comum na maioria dos laboratórios de química analítica.

A cromatografia bidimensional abrangente $(\mathrm{GCxGC})$ vem sendo utilizada com sucesso em análises ambientais, por apresentar um ganho primordial de seletividade, permitindo separar os analitos dos componentes da matriz. (39)

Por esse motivo, todas as análises descritas nesse estudo foram feitas usando o sistema de $\mathrm{GC}$, apesar de que em alguns casos, para analisar compostos contendo grupamentos - $\mathrm{OH},-\mathrm{NH}_{2}$ e -COOH foi necessário usar reações de derivatização.

Uma etapa prévia à análise cromatográfica é o preparo de amostra. Essa etapa é de extrema importância para evitar danos ao sistema cromatográfico, e ainda eliminar interferentes que contribuiriam para o acontecimento de um falso positivo.

\subsection{Preparo de amostra}

\subsubsection{Extração em Fase Sólida (SPE)}

O tratamento da amostra ou seu preparo é necessário para eliminar os macrocomponentes da amostra, evitar danos tais como entupimento de tubulação, contaminação do sistema de detecção dos equipamentos de análise, e principalmente, danos à coluna cromatográfica. Outra função do preparo de amostra, além de eliminar os interferentes, é concentrar os analitos de interesse para análise.

A extração em fase sólida (SPE) é um dos métodos de preparo de amostra mais usados para extração e pré-concentração de fármacos em amostras ambientais. Um dos modos mais 
utilizada da SPE é semelhante ao corpo de uma seringa, denominada de cartucho, contendo na sua base uma fase sorvente composta por uma fase extratora com afinidade pelos analitos presentes na amostra. A amostra é percolada usando uma bomba à vácuo, e ao passar pelo sorvente, os compostos com afinidade química pela fase do SPE ficam retidos. Em seguida, os compostos aprisionados são eluídos utilizando solventes compatíveis com os analitos de interesse.

A SPE é uma técnica clássica de preparo com inúmeros tipos diferentes de fases estacionárias, aumentando a versatilidade das suas aplicações. A fase extratora de C8, C18 usadas sobre um suporte de sílica, foram muito difundidas e utilizadas para vários tipo de análises, com ênfase para compostos não-polares e de média polaridade. Atualmente, novas fases surgiram para aumentar a seletividade da SPE, dentre essas, fases de origem polimérica. Um recobrimento polimérico misto, chamado de HLB (hydrophilic lipophilic balanced), vem sendo relatado como um dos mais eficientes para análise de fármacos em amostras ambientais, principalmente para fármacos polares. $(40,41)$

Apesar da versatilidade do SPE, quando usado no modo off-line, apresenta muitas etapas (condicionamento, amostragem, limpeza e eluição). Quanto maior o número de etapas, maior a possibilidade de gerar erros durante a análise, e com isso, prejudicar o seu desempenho.

O preparo de amostra é a maior fonte de erros em uma análise, sendo essencial a automatização e a diminuição de etapas.

\subsubsection{Microextração em fase sólida}

A microextração em fase sólida foi descrita pela primeira vez em um trabalho realizado em 1990 por Catherine L. Arthur e Janusz Pawliszyn. (42) No desenvolvimento dessa técnica buscou-se a miniaturização da fase extratora(de origem polimérica), depositada sobre uma fibra de sílica fundida. Um sistema denominado de holder, foi criado para proteger melhor os componentes da fase extratora, conforme mostra a Figura 1.10.

A SPME baseia-se na sorção dos analitos presentes na amostra para a fase extratora, e a presença dos compostos nas duas fases irá depender da afinidade química. Além disso, a extração é equilíbrio-dependente, quando a fase extratora é introduzida na amostra, os analitos com afinidade pela fase se direcionam à fase até atingir o equilíbrio de concentração. Dessa maneira, a SPME é uma técnica não exaustiva de extração, após atingido o equilíbrio de extração, mesma que haja mais compostos presentes, estes permanecerão na amostra. 


\section{Fases extratoras}

Existem basicamente dois tipos de mecanismos, extração por absorção quando o analito entra inteiramente na fase polimérica, ou por adsorção, quando a fase extratora possui poros e os analitos penetram nesses poros presentes na superfície da fase polimérica. Em fases mistas, contendo os polímeros de polidimetilsiloxano (PDMS) associado com um sólido adsorvente como o carboxeno (CAR), é possível ocorrer ambos processos. Outras fases mistas como PDMS e divinilbenzeno (PDMS/DVB), DVB/CAR/PDMS apresentam a mesma possibilidade. Em fases homogêneas como PDMS, poliacrilato (PA) e carbowax (PEG) ocorre a extração apenas por absorção.

A SPME, por ter sido desenvolvida em 1990, já se encontra consolidada, diversos tipos de fases polimérica estão disponíveis conforme mostra a Tabela 1.4

A constante de distribuição $K_{f s}$, fornece a concentração dos analitos no equilíbrio presentes na fase extratora, $C_{e}^{\infty}$, e $C_{s}^{\infty}$ corresponde a concentração na amostra após atingir o equilíbrio, conforme mostra a Equação 1.1.

$$
K_{f s}=\frac{C_{e}^{\infty}}{C_{s}^{\infty}}
$$

Considerando a extração no modo direto, com imersão direta da fibra em amostra líquida tem-se a Equação 1.2, onde $\mathrm{C}_{o}$ é a concentração inicial de analito na amostra, $\mathrm{V}_{s}$ é o volume de amostra. $\mathrm{O} \mathrm{C}_{e}^{\infty}$ é a concentração de analito presente na fase extratora e $\mathrm{V}_{e}$ refere ao volume de fase. Já $\mathrm{C}_{S}^{\infty}$ é a concentração de analito no equilíbrio presente na amostra e $\mathrm{V}_{s}$ refere ao volume da amostra.

$$
C_{o} \cdot V_{s}=C_{e}^{\infty} \cdot V_{e}+C_{s}^{\infty} \cdot V_{s}
$$

Figura 1.10: Componentes da SPME, retirado de (2).

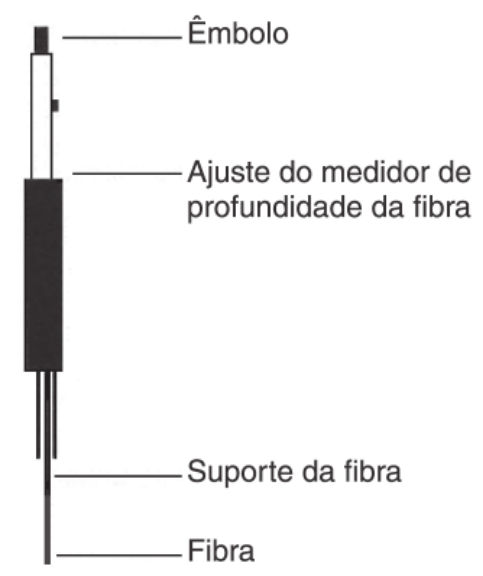


Tabela 1.4: Fases poliméricas disponíveis comercialmente para SPME, retirado de (11).

\begin{tabular}{|c|c|c|}
\hline Fase polimérica & Espessura de filme $(\mu \mathrm{m})$ & Aplicação \\
\hline PDMS & 7 & $\begin{array}{l}\text { Compostos não-polares com } \\
\text { massa molecular de } \\
125 \text { a } 600 \mathrm{~g} \mathrm{~mol}^{-1}\end{array}$ \\
\hline PDMS & 30 & $\begin{array}{l}\text { Compostos não-polares } \\
\text { semi-voláteis de massa molecular } \\
\text { de } 80 \text { a } 500 \mathrm{~g} \mathrm{~mol}^{-1}\end{array}$ \\
\hline PDMS & 100 & $\begin{array}{c}\text { Compostos voláteis com massa molecular } \\
\text { variando de } 60 \text { a } 275 \mathrm{~g} \mathrm{~mol}^{-1}\end{array}$ \\
\hline PDMS/CAR & 75 e 85 & $\begin{array}{l}\text { Gases e compostos de } \\
\text { baixo peso molecular } \\
\left(60 \text { a } 275 \mathrm{~g} \mathrm{~mol}^{-1}\right)\end{array}$ \\
\hline PDMS/DVB & 65 & $\begin{array}{l}\text { Compostos voláteis, } \\
\text { aminas e compostos } \\
\text { nitro-aromáticos }\end{array}$ \\
\hline PDMS/DVB & 60 & Aminas e compostos polares \\
\hline $\mathrm{PA}$ & 85 & Compostos polares semi-voláteis \\
\hline PEG & 60 & Compostos polares e alcoóis \\
\hline $\begin{array}{l}\text { DVB/CAR/PDMS } \\
\text { stableflex }\end{array}$ & $50 / 30$ & $\begin{array}{c}\text { Aromas, compostos voláteis } \\
\text { e semi-voláteis de C3 a C20 } \\
\quad\left(40 \text { a } 275 \mathrm{~g} \mathrm{~mol}^{-1}\right)\end{array}$ \\
\hline $\begin{array}{l}\text { DVB/CAR/PDMS } \\
\text { em } 2 \mathrm{~cm} \text { de fibra } \\
\text { stableflex }\end{array}$ & $50 / 30$ & $\begin{array}{c}\text { Análise de traço } \\
\text { de compostos com massa molecular } \\
\text { de } 40 \text { a } 275 \mathrm{~g} \mathrm{~mol}^{-1}\end{array}$ \\
\hline
\end{tabular}

Ao combinar as equações 1.1 e 1.2, levando em consideração $C=\frac{m}{v}$, obtém a Equação 1.3.

$$
C_{e}^{\infty}=\frac{K_{f s} V_{s}}{V_{s}+K_{f s} \cdot V_{e}^{\infty}} \cdot C_{o}
$$

Ao substituir $C_{e}^{\infty}=\frac{m_{e}^{\infty}}{V_{e}^{\infty}}$, isolando em a $m_{e}^{\infty}$ obtemos a Equação 1.4:

$$
m_{e}^{\infty}=\frac{K_{f s} V_{s} V_{e}}{V_{s}+K_{f s} \cdot V_{e}^{\infty}} \cdot C_{o}
$$

A partir da Equação 1.4 é possível notar, que atingido o equilíbrio, a massa extraída em $\mathrm{m}_{e}^{\infty}$ pela fase extratora é linearmente proporcional à concentração de analito presente inicialmente na amostra.

Alguns parâmetros influenciam diretamente na partição dos analitos para a fase extratora. Os parâmetros podem estar relacionados com a termodinâmica ou com a cinética da extração, os parâmetros mais importantes serão descritos. 


\section{Temperatura}

A Equação 1.5 mostra a influência da temperatura na extração por SPME quando há uma mudança de $\mathrm{T}$ para $\mathrm{T}_{o}$.

$$
K_{f s}=K_{o} \cdot \exp .-\frac{\Delta H}{R} \cdot\left(\frac{1}{T}-\frac{1}{T_{o}}\right)
$$

$\mathrm{K}_{o}$ é a constante de distribuição dos analitos quando a fibra e amostra estão na temperatura ( $\mathrm{T}_{o}$ em Kelvin). $\mathrm{O} \Delta \mathrm{H}$ é a entalpia do analito quando sai da amostra para a fase extratora e $\mathrm{R}$ é a constante de gases. Observando a equação, o aumento na temperatura causa uma diminuição no $\mathrm{K}_{f s}$ (partição dos analitos da amostra para fibra), considerando um sistema com duas fases homogêneas.

\section{pH}

$\mathrm{O}$ ajuste do $\mathrm{pH}$ em uma solução aquosa modifica o $K_{f s}$ para compostos ácidos ou básicos. Assumindo que somente teremos a extração dos analitos na sua forma não-ionizada, a Equação 1.6 demonstra o comportamento da extração por SPME.

$$
K_{f s}=K_{o} \frac{\left[H^{+}\right]}{K_{a}+\left[H^{+}\right]}
$$

$\mathrm{K}_{o}$ é a constante de distribuição entre a fibra e a amostra na forma não-dissociada, o aumento das espécies de $\left[\mathrm{H}^{+}\right]$, causa um descréscimo na valor de $\mathrm{K}_{f s}$. É sugerido por Pawliszyn (43) utilizar $\mathrm{pH}$ duas unidades inferior ao pka do analito de interesse para maximizar a resposta da SPME. Deve-se salientar não realizar extração em pH abaixo de 2 e acima de 11, para evitar danos a fase extratora.

\section{Efeito Salting out}

A adição de sal é uma técnica comumente aplicada para aumentar a extração de compostos orgânicos em matrizes aquosas. O sal pode também causar uma diminuição na extração, dependendo da concentração de sal e do composto.O efeito do sal não foi estudado exclusivamente para SPME, apenas testado experimentalmente, não há equações dedicadas para esse fim. Normalmente, são utilizadas de 1 a 30\% (massa por volume de amostra) de sal. A adição de sal também permite manter a força iônica constante em amostra reais que apresentam variação.

\section{Tempo de extração}

É necessário que se faça um estudo sobre o tempo necessário para que os analitos atinjam o equilíbrio. Fora do equilíbrio, haverá baixo desempenho comprometendo diretamente a 
detectabilidade do método.

\subsubsection{Extração em barras de sorção}

A extração por sorção em barra de agitação (SBSE), assim como a descoberta da injeção no modo splitless, foi desenvolvida por acaso. Erik Baltussen estava fazendo extração de compostos voláteis (benzeno, tolueno) em água por SPME, usando o modo headspace, e observou a não-extração dos analitos. Apesar de estar com todo o sistema em ordem, fibra de SPME nova, o equipamento de GC funcionando normalmente. Injetou a água para ver se por algum motivo não volatilizou. Por último, resolveu testar a barra magnética de agitação, apenas passou solvente na barra e fez a injeção. Para surpresa dele, os analitos apareceram no solvente usado para dessorver.

A partir dessa descoberta, uma barra magnética foi recoberta com vidro, em volta do vidro foi depositado o material polimérico para ser a fase extratora, como mostra a Figura 1.11

A SBSE possui aspectos teóricos semelhantes à SPME, sendo necessário fazer uma aproximação do coeficiente de partição do PDMS/água $\left(K_{P D M S / w}\right)$ proporcional a partição octanol/água $\left(K_{o / w}\right)$, para uma análise em água.

$$
K_{o / w} \approx K_{P D M S / w}=\frac{C_{\text {sbse }}}{C_{w}}=\frac{m_{\text {sbse }}}{m_{w}} x \frac{v_{w}}{v_{s b s e}}
$$

Onde $\mathrm{C}_{s b s e}$ e $\mathrm{C}_{w}$ é a concentração do analito na fase extratora e na água (amostra), já $\mathrm{m}_{s b s e}$ e $\mathrm{m}_{w}$ correspondem as massas respectivas do analito na barra de SBSE e na amostra. A razão $\frac{v_{w}}{v_{s b s e}}$ é a razão de fases, podendo modificar a Equação 1.7 para Equação 1.8.

$$
K_{o / w}=\frac{m_{s b s e}}{m_{w}} \beta
$$

Substituindo $\mathrm{m}_{w}$ por $\mathrm{m}_{o}-\mathrm{m}_{\text {sbse }}$, obtém-se a seguinte equação:

$$
K_{o / w}=\frac{m_{\text {sbse }}}{m_{o}-m_{\text {sbse }}} . \beta
$$

Figura 1.11: Ilustração da composição de uma barra de SBSE.

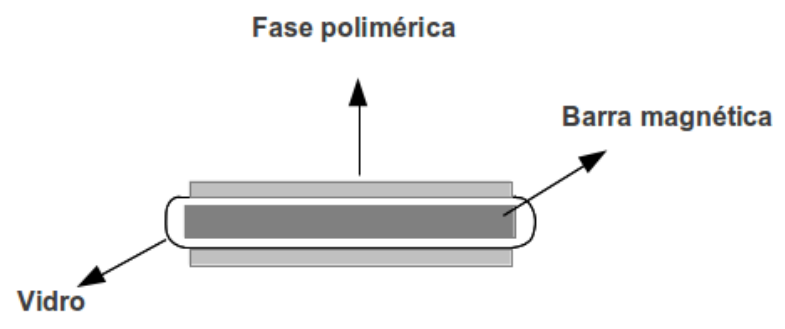


Para obter a recuperação teórica pode ser utilizada a seguinte equação:

$$
\frac{m_{s b s e}}{m_{o}}=\frac{\left(\frac{K_{o / w}}{\beta}\right)}{1+\left(\frac{K_{o / w}}{\beta}\right)}
$$

Dessa maneira, a recuperação da SBSE está condicionada a constante de partição, e a razão de fases entre fase extratora e a amostra (PDMS e água). Quando a razão $\frac{K_{o / w}}{\beta}$ é igual a 1 , a recuperação será de $50 \%$. Sempre que possível, é interessante comparar a recuperação teórica com a recuperação obtida na prática.

A SBSE apresenta como vantagens sobre a SPME um volume polimérico maior, enquanto uma fibra de SPME de $100 \mu \mathrm{m}$ possui um volume de $0,5 \mu \mathrm{L}$ de fase polimérica, a SBSE apresenta volumes de 35 a $219 \mu \mathrm{L}$ de fase polimérica extratora. Com isso, amostra de $10 \mathrm{~mL}$ de água, com relação de fase de $2 \times 10^{4}$, a recuperação seria de próxima a $100 \%$ apenas para composto com $\log \mathrm{P} \geq 5$, usando a SPME. Enquanto para a SBSE, o aumento do volume polimérico irá permitir extrair compostos nessa mesma condição com Log $\mathrm{P}$ próximo a 3, conforme pode ser visto na Figura 1.12.

Figura 1.12: Recuperação teórica de analitos por SBSE e SPME de uma amostra de $10 \mathrm{~mL}$ de água, em função de $K_{o / w}$. Volume de PDMS na fibra de SPME: 0,5 $\mu \mathrm{L}$. Volume de PDMS na barra magnética: $100 \mu \mathrm{L}$, adaptado de (3).

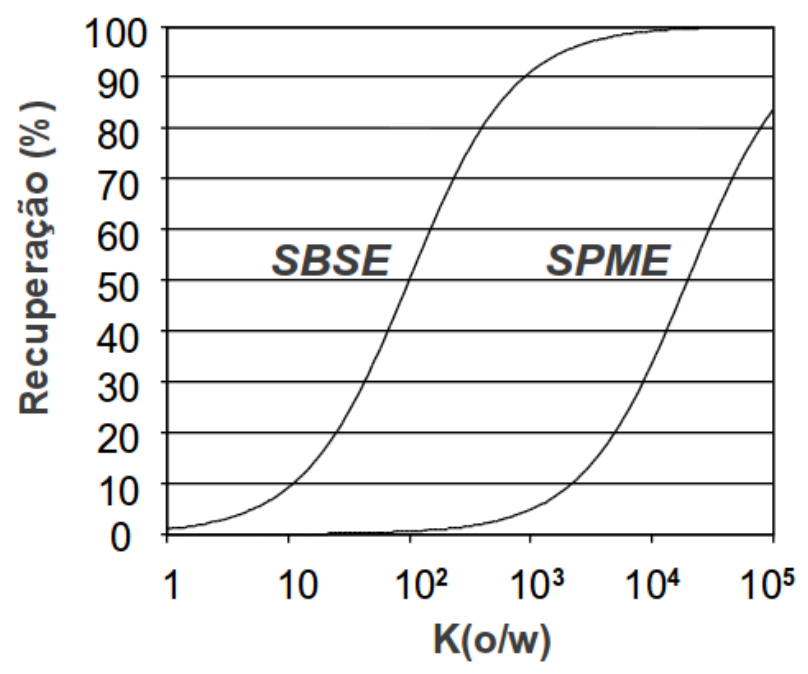

\subsubsection{Extração por sorção nas paredes do frasco}

Toda parte teórica da extração por sorção nas paredes do frasco (VWSE) é semelhante ao apresentado para SBSE e SPME. Esse modo de extração recebeu esse nomenclatura em 2009, em um trabalho realizado por Kawaguchi e colaboradores (4) que aplicaram essa tecnologia avaliando 3 maneiras de depositar os polímeros conforme mostra a Figura 1.13.

O VWSE ampliou a área superficial, contribuindo para aumentar a recuperação da extração, 
Figura 1.13: Dispositivo de VWSE testados por Kawaguchi et.al. A - PDMS depositado apenas no seu fundo, B - PDMS depositado no fundo com formato cônico e C - PDMS depositado nas paredes internas do frasco. 1 - frasco, 2 - fase polimérica extratora (PDMS) e 3 - tampa do frasco, adaptado de (4)
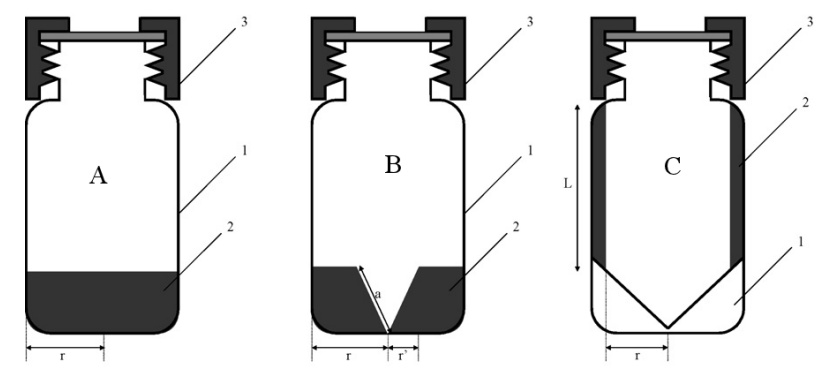

já que diminui a razão de fase $\beta$, ao aumentar a massa de fase polimérica. O frasco A apresenta uma área de contato de $0,785 \mathrm{~cm}^{2}$, o B possui $0,899 \mathrm{~cm}^{2}$ e o $\mathrm{C} 5,20 \mathrm{~cm}^{2}$. Este último, foi aplicado por fornecer um alto desempenho, com recuperação de $94 \%$, e atingir o equilíbrio em apenas 30 minutos. Os demais frascos forneceram recuperação inferior, e ainda, foram testados por 75 minutos, e mesmo com esse tempo não atingiram o equilíbrio.

Além disso, uma hipótese para o surgimento da VWSE é a dificuldade de sintetizar novas fases para a SBSE, por necessitar usar molde e outros artefatos. A VWSE apenas necessita adicionar o monômero e seus iniciadores no frasco, levá-lo para o aquecimento por alguns instantes. Esse procedimento é muito simples, sendo rápido e de baixo custo. Além disso, melhora a detectabilidade em relação a SBSE, pode ser facilmente automatizada, e utiliza pequenos volumes de amostra, fator essencial em análises de fluído biológico, como plasma.

\subsection{Otimização do preparo}

A otimização dos métodos de preparo de amostra é fundamental para maximizar a resposta analítica e atingir baixos limites de detecção e quantificação, principalmente em análise de traço em matrizes ambientais.

Como as técnicas miniaturizadas apresentam diversos fatores relacionados à extração, é necessário estudar esses fatores para estabelecer as melhores condições de preparo de amostra. Basicamente existem duas formas de otimizar, sendo a primeira aplicando método univariado (OVAT), avaliando cada variável separadamente, fixa-se uma condição inicial para todas as variáveis, em seguida, aumenta somente uma delas e compara essa última condição com a inicial, até obter a melhor resposta analítica. As desvantagens desse método é o tempo e reagentes gastos, além de ignorar a presença de interação entre as variáveis avaliadas, o que pode comprometer no desempenho final do método. (44)

A outra forma de otimizar é usando ferramentas quimiométricas. A quimiometria apre- 
senta atividades desde a década de 70, porém seu uso se consolidou apenas nos últimos 15 anos graças à popularização dos computadores e o desenvolvimento de softwares para auxiliar os pesquisadores nos cálculos estatísticos. A quimiometria também é aplicada no planejamento e otimização de experimentos, reconhecimento de padrões (análise exploratória e classificação) e calibração multivariada (45), por utilizar modelos matemáticos, aliado a ferramentas de estatística e lógica para planejar ou otimizar experimentos. Dessa maneira é possível obter o máximo de informações relevantes sobre o sistema e obter informações sobre o sistema químico envolvido.

A aplicação da quimiometria no preparo de amostra também conhecida como planejamento fatorial ou experimental, consiste na variação de todos os fatores de acordo com uma combinação estabelecida aleatoriamente. Esse fato, permite estudar as interações entre as variáveis, e ainda, em muitos casos utiliza de poucos experimentos, resultando em um menor gasto de reagentes. (46)

Em planejamento fatorial é fundamental selecionar os principais fatores que influenciam no preparo de amostra. Após selecionados, é necessário fazer uma triagem para verificar a influência das variáveis sobre o sinal analítico. Este sinal pode ser adotado como área do pico, altura, relação sinal:ruído e outros de acordo com a técnica de análise. Os resultados são analisados usando a análise de variância, para verificar se houve interações entre as variáveis, além de checar se a variável influencia de forma significativa na análise.

Em seguida, um novo planejamento é realizado contendo as variáveis significativas. Normalmente, é utilizado metodologias de superfície de resposta como planejamento compostos centrais, matriz de Doehlert e Box-Behnken, para encontrar o ponto ótimo.

\subsubsection{Triagem usando planejamento fatorial}

O planejamento fatorial completo investiga a influência de todas as variáveis experimentais de interesse e os efeitos na resposta. A combinação de $k$ fatores é pesquisada em 2 níveis diferentes obtendo $2^{k}$ experimentos. Para fatores quantitativos ( $\mathrm{pH}$, tempo e etc) os níveis são $(-)$ para valores mais baixo daquela variável e (+) para valores altos. Apenas para exemplificar um planejamento em 2 níveis e com 3 variáveis, $2^{3}$, fornece a seguinte Tabela 1.5 .

Os sinais para os efeitos das interações de segunda ordem ( $\mathrm{v}_{12}$, por exemplo), ou de ordem superior $\left(\mathrm{v}_{123}\right)$ são obtidos pelo produto dos sinais originais das variáveis. O planejamento fatorial completo fornece informações completas, porém na presença de muitas variávies, dificulta o uso desse tipo de planejamento, devido ao excessivo número de experimentos.

Para superar essa dificuldade o planejamento fatorial fracionário é aplicado, valendo-se de um número menor de experimentos. Informações podem ser perdidas quando comparadas ao 
um planejamento fatorial completo, mas mesmo assim ainda é uma alternativa para evitar excessivo número de experimentos. O número de experimentos é dado por $2^{k-b}$, onde $k$ são as variáveis, e $b$ o tamanho da fração $\left(\frac{1}{2}, \frac{1}{4}, \frac{1}{8} \cdots \frac{1}{16}\right)$. O tamanho da fração influencia nos efeitos estimados e no número de experimentos. A construção de um planejamento fatorial está mostrada na Tabela 1.6, como exemplo um planejamento $2^{3-1}$. Este será semelhante a um fatorial completo $2^{2}$, dois fatores serão variados aleatoriamente e o terceiro irá variar de acordo com a interação dos dois primeiro fatores.

O planejamento fatorial composto central (CCD) também é usado na triagem das variáveis bem como na otimização. Permite avaliar e estimar a falta de ajuste do método (lack off it). Aplicado no formato completo ou fracionário, a conformação estrela é comum de ser observada, apresentando pontos $\alpha\left(\sqrt[4]{2^{4}}\right)$ distantes do ponto central. Normalmente experimentos de CCD consiste $2^{k}$, onde $k$ é o número de fatores, com $2 k$ fatores axiais e um ponto central $\mathrm{C}_{0}$, com número total dado por $\mathrm{N}=2 k+2 k+\mathrm{C}_{o}$, observar a Tabela 1.7. A Figura mostra $1.14 \mathrm{a}$ disposição espacial dos experimentos de um planejamento fatorial CCD.

O ponto central é uma alternativa que deve ser sempre explorada mesmo em planejamento em que não há necessidade de avaliá-lo, pois avalia os erros do planejamento tornando mais confiável os dados obtidos.

Tabela 1.5: Matriz para um planejamento fatorial completo em 2 níveis para 3 variáveis, retirado de (12).

\begin{tabular}{|c|c|c|c|c|c|c|c|}
\hline Experimento & \multicolumn{3}{|c|}{ Variáveis } & \multicolumn{5}{|c|}{ Interaçoes } \\
\hline & $v_{1}$ & $v_{2}$ & $v_{3}$ & $v_{12}$ & $v_{13}$ & $v_{23}$ & $v_{123}$ \\
\hline 1 & - & - & - & + & + & + & - \\
\hline 2 & + & - & - & - & - & + & + \\
\hline 3 & - & + & - & - & + & - & + \\
\hline 4 & - & - & + & + & - & - & - \\
\hline 5 & + & - & + & + & - & - & + \\
\hline 6 & + & - & + & - & + & - & - \\
\hline 7 & - & + & + & - & - & + & - \\
\hline 8 & + & + & + & + & + & + & + \\
\hline
\end{tabular}


Figura 1.14: Disposição dos experimentos de um planejamento fatorial CCD.

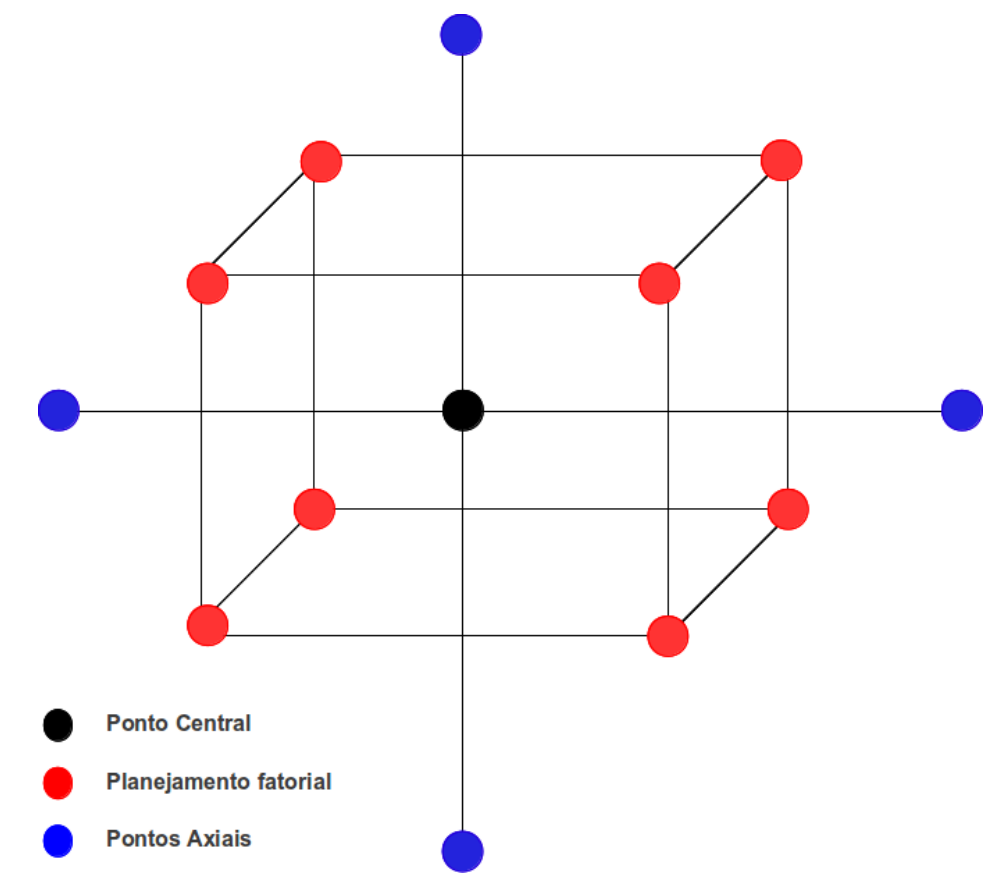

\subsubsection{Otimização por Matriz de Doehlert}

A otimização por matriz de Doehlert é uma alternativa bastante atrativa para planejamentos de segunda ordem, pois necessita de um menor número de experimentos em relação à CCD para se chegar a região ótima.

Os pontos da matriz de Doehlert correspondem a um hexágono com pontos experimentais descritos pela equação $k^{2}+k+p c, k$ corresponde ao número de fatores e $p c$ equivale aos experimentos no ponto central. Dois hexágonos podem são construídos, o segundo utiliza pontos do primeiro o que fornece domínios próximos aos avaliados no formato circular para 2 variáveis, esférico para 3 e hiperesférico para mais de 3 variáveis com uniformidade no espaço estudado. A Figura 1.15 mostra um hexágono simples formado pela matriz de Doehlert, mostrando a distrubuição dos pontos experimentais para 2 variáveis. $(47,48)$ Cada variável será avaliada pelo menos em três níveis diferentes, o que mostra a vasta amplitude experimental dessa matriz, aumentando ainda mais a confiança nos dados obtido, visto na Tabela 1.8.

Tabela 1.6: Planejamento fatorial fracionário $2^{3-1}$ adaptado de (12).

\begin{tabular}{cccc}
\hline \hline Experimento & \multicolumn{3}{c}{ Variáveis } \\
\hline & $v_{1}$ & $v_{2}$ & $v_{3}=v_{1} \cdot v_{2}$ \\
\hline 1 & - & - & + \\
3 & + & - & - \\
4 & - & + & - \\
& + & + & + \\
\hline
\end{tabular}


Tabela 1.7: Planejamento fatorial composto central $2^{2}$ adaptado de (12).

\begin{tabular}{cccc}
\hline Experimentos Variáveis & Ponto \\
\hline & $v_{1}$ & $v_{2}$ & \\
1 & -1 & -1 & \\
2 & 1 & -1 & Planejamento fatorial \\
3 & -1 & 1 & \\
4 & 1 & 1 & \\
5 & 0 & 0 & Ponto Central \\
6 & $-\alpha$ & 0 & \\
7 & $\alpha$ & 0 & Pontos axiais \\
8 & 0 & $-\alpha$ & \\
9 & 0 & $\alpha$ & \\
\hline
\end{tabular}

Figura 1.15: Disposição dos experimentos de uma matriz de Doehlert, retirado de (5).

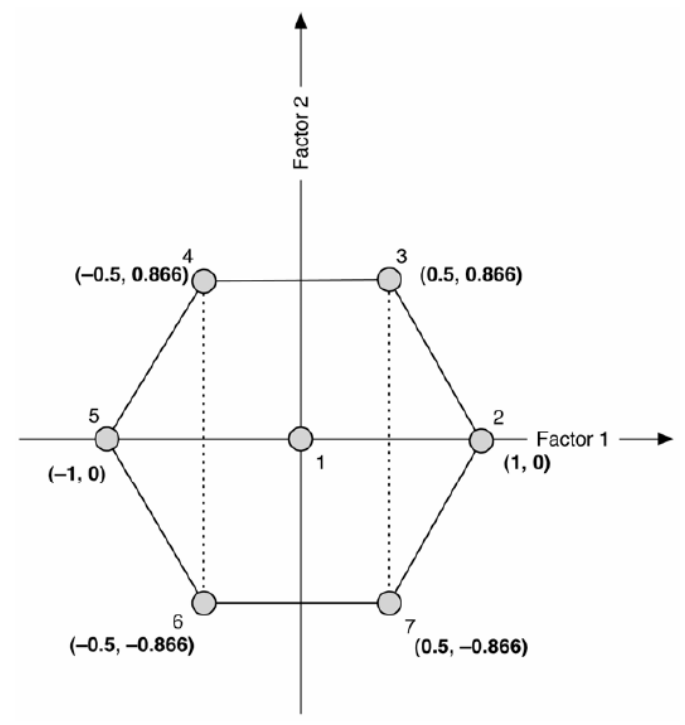

\subsection{Validação do método de análise}

É necessário garantir a qualidade dos dados obtidos durante uma análise química. Dados analíticos errôneos podem trazer consequências imensuráveis, e ainda prejuízos financeiros irreparáveis. Para garantir a confiabilidade do método é necessário que o mesmo sofra uma validação. (49)

A validação é o processo pelo qual todo método analítico deve passar para provar que está apto para analisar uma determinada substância ou conjunto de substâncias. Além disso, as características do método devem ser compatíveis com o parâmetros requeridos para efetuar a análise. O processo de validação é longo e contínuo exigindo do analista planejamento e conhecimento para obter todos os resultados, e avaliar sua validade perante as exigências das análises. O processo de validação deve ser bem definido e fundamentado para atender às exigências das agências regulamentadoras. 
Tabela 1.8: Experimentos usando matriz de Doehlert com 3 variáveis, retirado de (12).

\begin{tabular}{cccc}
\hline \hline Experimentos & \multicolumn{3}{c}{ Variáveis } \\
\hline- & $\mathrm{v}_{1}$ & $\mathrm{v}_{2}$ & $\mathrm{v}_{3}$ \\
\hline 1 & 0 & 0 & 0 \\
2 & 1 & 0 & 0 \\
3 & 0,5 & 0,866 & 0 \\
4 & 0,5 & 0,289 & 0,817 \\
5 & -1 & 0 & 0 \\
6 & $-0,5$ & $-0,866$ & 0 \\
7 & $-0,5$ & $-0,289$ & $-0,817$ \\
8 & 0,5 & $-0,289$ & $-0,817$ \\
9 & $-0,5$ & 0,866 & 0 \\
10 & 0 & 0,289 & 0,817 \\
11 & $-0,5$ & 0,289 & 0,817 \\
12 & 0 & $-0,577$ & 0,817 \\
\hline
\end{tabular}

Essas agências estabelecem parâmetros que devem ser preenchidos para tornar um método válido. Nacionalmente, se destacam, a Agência Nacional de Vigilância Sanitária (ANVISA) e o Instituto Nacional de Metrologia, Normalização e Qualidade Industrial (INMETRO), que fornecem guias de validação, sendo a Resolução ANVISA RE no 899 (50) e o documento DOQCGCRE-008. (51) Internacionalmente, existem órgãos como Food and Drug Administration (FDA), União Internacional de Química Pura e Aplicada (IUPAC), Organização Internacional para Padronização (ISO), Comitê Europeu para análise química (EURACHEM), International Conference on Harmonisation (ICH) e Environmental Protection Agency (EPA). É necessário salientar que os guias são recomendações muitas vezes vagas, tornando flexível a forma como será realizado o procedimento de validação, deixando o analista ajustar de acordo com os materiais disponíveis em laboratório.

Pelo fato das comissões que elaboram os guias serem formadas por diferentes profissionais, as definições possuem diferenças, e até mesmo, aparecendo divergências nessas definições. As diferenças aumentam ainda mais pelo fato do protocolo de validação estar condicionado ao tipo de matriz e a sua origem (ambiental, biológica ou farmacêutica). O mesmo acontece para técnicas de análise, por exemplo, as técnicas espectroscópicas possuem procedimentos diferenciados em relação às técnicas cromatográficas.

Os parâmetros avaliados na maioria dos guias feitos pelas organizações supracitadas são: seletividade e/ou especificidade, faixa de trabalho ou linearidade, limite de detecção (LOD), limite de quantificação (LOQ), exatidão, precisão intra e inter-dia, robustez , recuperação, estabilidade e exatidão. Abaixo cada um desses conceitos será introduzido seguindo os principais guias de validação da área de cromatografia, tais como IUPAC, ICH, ANVISA e FDA. 


\subsubsection{Seletividade e/ou especificidade}

A seletividade e/ou especificidade possuem definições muito semelhantes. A seletividade avalia o grau de interferência que metabólitos, produtos de degradação, impurezas, excipientes, componentes da matriz podem interferir na análise e gerar resultados imprecisos. A seletividade afere a capacidade que um método de análise possui para diferenciar todos os interferentes do seu composto de interesse. Em termos cromatográficos é a garantia de que o pico do analito seja a resposta exclusiva do analito de interesse dentro de um número variado de compostos analisados simultaneamente. Essa capacidade pode ser avaliada pela pureza do pico obtido em uma amostra em relação ao padrão usado na calibração, quando utilizado detectores com arranjo de diodos (DAD); ou pela proximidade com a biblioteca em uma análise por MS.

A especificidade é a resposta que um método possui para apenas um analito, mesmo na presença de vários interferentes, o pico obtido em um determinado tempo de retenção vem somente do analito de interesse, e de nenhum outro componente.

Pelo fato de possuírem definições semelhantes alguns guias sugerem seletividade e especificidade no mesmo contexto, esse é o caso da ANVISA (50), FDA. (52) Já a IUPAC (53) considera apenas a seletividade, e o ICH (54) apenas a especificidade. Contudo, o ICH adiciona uma ressalva que possibilidade de falha no parâmetro da especificidade, e recomenda o uso de 2 ou mais métodos de análise.

\subsubsection{Precisão intra e inter-dia}

Precisão é a proximidade dos resultados em uma série de medidas em determinada condições de análise. Demonstra dispersão dos resultados independente se foi analisada em uma mesma amostra, amostras semelhantes ou ainda se a análise é de padrões. Essa análise é feita em relação ao desvio padrão ou desvio padrão relativo das medidas no mínimo de 3 replicatas em 3 diferentes níveis de concentração.

A precisão intra-dia ou intra-corrida (repetibilidade) mede a concordância dos resultados em um curto período de tempo utilizando as mesmas condições estabelecidas como mesmo analista, no mesmo dia e com o mesmo equipamento. O valor máximo aceitável está entre 10 a $20 \%$ de oscilação entre as medidas feitas, dependendo da sua aplicação, e do guia usado durante a validação.

A precisão inter-dia é semelhante a anterior conduzida no mesmo laboratório, em dias diferentes não consecutivos e se possível o teste deve ser realizado por analistas diferentes. A reprodutibilidade é designada como precisão intra-laboratorial, os resultados são obtidos usando as mesmas amostras em laboratórios e temperatura de sala diferentes, com outros analistas e equipamentos. (55) 


\subsubsection{Robustez}

É a capacidade do método não ter sua resposta alterada por pequenas variações dos parâmetros analíticos. Pode ser avaliada pela mudança na marca dos reagentes, troca de analista, pequena variação no $\mathrm{pH}$ ou força iônica de determinada solução, alterar a temperatura, coluna cromatográfica e outros. Há também testes preconizados como o teste de Youden para avaliar a robustez de um método. (56)

\subsubsection{Recuperação}

Mede a eficiência do método de preparo de amostra utilizado ao comparar o padrão injetado com uma certa quantidade de massa contra essa mesma massa adicionada na amostra. Compara os dados obtidos em termos de porcentagem para avaliar a eficiência do método de preparo de amostra, para extrair o analito ou analitos e eliminar os interferentes. É recomendado fazer esse teste em pelo menos 3 níveis de concentração. É considerada ideal uma recuperação variando entre 70 a $120 \%$, porém é possível ter exceções a essa regra.

\subsubsection{Estabilidade}

É necessário avaliar a estabilidade dos analitos para que eles não sofram degradação durante a etapa de preparo de amostra, armazenamento da amostra e sua estocagem. É interessante avaliar a estabilidade em diversas situações como quando os analitos forem dissolvidos nas soluções padrão, estabilidade após ciclos de congelamento e descongelamento, estabilidade de curta e longa duração, e estabilidade após terem sofrido processo de preparo de amostra. (55)

\subsubsection{Exatidão}

É a medida ou estimativa de concordância entre um amostra referência e medida dada pelo método. Essa amostra sofrerá análise usando o método proposto para quantificar o analito dessa amostra. A diferença entre a quantidade presente no certificado da amostra referência e a obtida pelo método é chamado de bias. Quanto menor é essa diferença, melhor será o bias, e mais exato será o método. Para ter essa medida avaliada é necessário adquirir padrão de referência, o que normalmente eleva o preço das análises. (53)

Para fins de publicação científica de métodos não-oficiais, quando não existe amostra referência, é aceito a amostra preparada pelo analista como amostra referência. Mesmo quando está disponível comercialmente a amostra referência, em virtude do seu alto custo, ainda pode ser aceito como amostra referência aquela preparada pelo analista. 


\subsubsection{Linearidade ou faixa de trabalho}

É a capacidade de um método analítico demonstrar que o sinal obtido é diretamente proporcional a massa de analito adicionado. Recomenda-se que a linearidade deva ser avaliada usando mínimo de 5 a 6 concentrações diferentes. $(50,53,55)$ A linearidade é avaliada visualmente ao se construir um gráfico de resposta pela concentração do analito. Em seguida pode ser avaliada matematicamente usando o método do mínimos quadrados para obter uma função $y=a x+b$. Onde $y$ é a resposta, $a$ é o coeficiente angular ou inclinação da reta e $b$ é o coeficiente linear ou intercepto. Além disso, obtêm-se uma correlação entre os dados obtidos e o modelo obtido a partir desses dados, chamado de coeficiente de correlação. Esse coeficiente deve ser maior ou igual 0,90 ou a 0,98 , variando de acordo com o guia utilizado.

A faixa de trabalho é referente a concentração ou massa que o método é capaz de quantificar. Normalmente essa faixa de concentração ou massa foram empregados no estudo da linearidade. Ao obter o modelo matemático é necessário estudá-lo e verificar se a relação é realmente linear, caso não seja realizar uma transformação matemática em um modelo apropriado. Esse tópico será apresentado com maiores detalhes.

Para avaliar a linearidade existem diversas maneiras. A priori é necessário que o método já tenha a maioria dos seus parâmetros de validação estudados, a fim de evitar problemas no momento de se estudar a linearidade. Uma das formas de avaliar a mesma é usando a padronização externa. Esse método é utilizado em amostras que não necessitam de um extenso preparo. Os padrões de calibração dos analitos, preparados em soluções com concentrações conhecidas serão introduzidas na matriz de análise isenta do composto a ser analisado, essa pode sofrer etapas de preparo, para ser inserida no sistema cromatográfico. A seguir, a amostra real a ser analisada é submetida aos mesmos processos e compara-se área obtida com área obtida nos padrões de calibração, usando o gráfico e a equação da linearidade.

Outra maneira de avaliar a linearidade é usando padronização interna. Nesse caso, utiliza um padrão interno (IS) o qual é um composto que possui características físico-químicas e estruturais semelhantes aos analitos ou ao analito. Esse IS é mantido em concentração constantes, enquanto a concentração dos analitos varia de forma crescente. Tanto o IS como os analitos são introduzidos na matriz isenta desses compostos, sofre todo o processo de preparo de amostra, e em seguida, é analisado por um método analítico. Uma relação é construída, a área obtida pelos analitos é dividida pela área do IS. Assim, a curva de calibração da resposta relativa pela concentração dos analitos ou analito é construída. Após estabelecida a linearidade, um amostra é analisada, o IS é acrescentado na mesma concentração usada na calibração, e por último a área obtida do analito na amostra é dividido pela área do IS. Essa relação é comparada com o modelo matemático obtido durante a calibração do método.

A padronização interna, é uma alternativa para diminuir a occorência des erros provenientes 
da etapa de preparo de amostra, e até, mesmo pequenas oscilações causadas pelo sinal elétrico. Ao dividir o sinal do analito pela resposta do IS, anula o ruído de fundo presente na amostra. Como desvantagem é a dificuldade de encontrar um IS que possua as mesmas características dos analitos, muitas vezes é usado o próprio analito na sua forma deuterada ou com carbono 13; contudo, esse tipo de IS possui um alto custo.

Outra maneira de avaliar a linearidade é a padronização por adição de padrão. Esta é usada quando não possui matrizes isentas dos analitos, ou em amostras muito complexas que apresentam com fortes interações entre o analito e a matriz. Os analitos são introduzidos diretamente na amostra real com concentrações crescentes conhecidas, obtém-se a equação da linearidade da mesma forma mostrada nos parágrafos anteriores. Para descobrir a concentração da amostra basta extrapolar até tocar a reta no eixo das abscissas (eixo $\mathrm{X}$ ), no qual o $Y=0$, e o valor referente a concentração da amostra é obtida pela divisão dos termos $b$ e $a$ como mostra a seguir, $x=\frac{b}{a}$.

\subsubsection{Avaliação estatística}

Em muitos métodos os parâmetros de precisão estão dentro da faixa recomendada pelos guias de validação, a linearidade apresenta valores compatíveis com preconizados, e ainda assim, o método pode apresentar falta de ajuste tornando inválido o modelo matemático estabelecido. (7) $\mathrm{O}$ coeficiente de correlação ( $r$ ) pode ser alto, valor próximo a 1,00, e mesmo assim, a função estabelecida pode não ser linear. (6) $\mathrm{O} r$ erroneamente é interpretado como função que mede o desvio da linearidade, sendo usado para avaliar se uma função é linear ou não. Não há como medir a presença de linearidade, e sim avaliar se o modelo matemático estimado possui falta de ajuste ou não. Caso possua falta de ajuste esse modelo não pode ser aplicado para predizer o comportamento do método avaliado, caso contrário, o modelo matemático estabelecido prediz perfeitamente o comportamento daquele método analítico.

A ocorrência de homoscedasticidade e heteroscedasticidade devem ser avaliados também. O primeiro mostra a ocorrência de variância constante dos erros aleatórios. Já o segundo, demonstra a variância dos erros em conjunto com o aumento da concentração usada para estimar a curva de calibração, as Figuras 1.16 e 1.17 ilustram os fenômenos apresentados. O modelo que apresentar heteroscedasticidade, deverá sofrer ajustes matemáticos, chamado de weight least squares para poder encontrar um novo modelo que explique o comportamento do sistema, e assim, aumentar a validade do modelo. (57) Uma outra forma de avaliar a ocorrência de homoscedasticidade e heteroscedasticidade é usando o gráfico de resíduos obtido ao tratar os dados provenientes da linearidade, conforme será mostrado nas Figuras 1.18 e 1.19.

Na Figura 1.18, a distribuição está aleatória e independente da concentração, demonstrando a homoscedasticidade do método. Já na Figura 1.19, é perceptível o aumento da variância nas 
Figura 1.16: Modelo linear apresentando homoscedasticidade, retirado de (6).

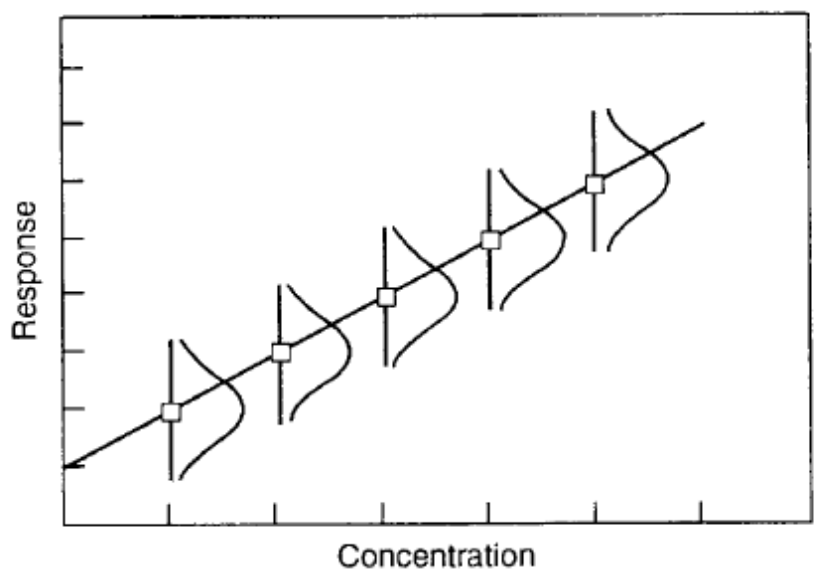

Figura 1.17: Modelo linear com comportamento heteroscedástico, retirado de (6).

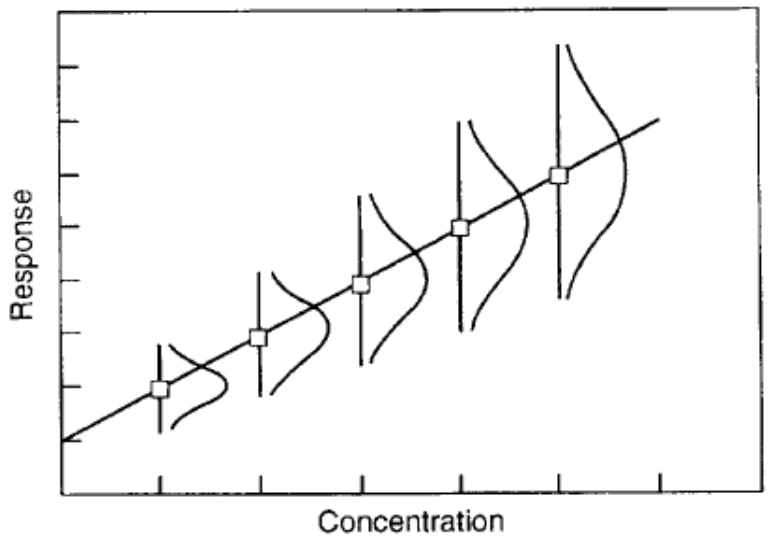

Figura 1.18: Resíduo distribuído aleatoriamente com variância constante, retirado de (7).

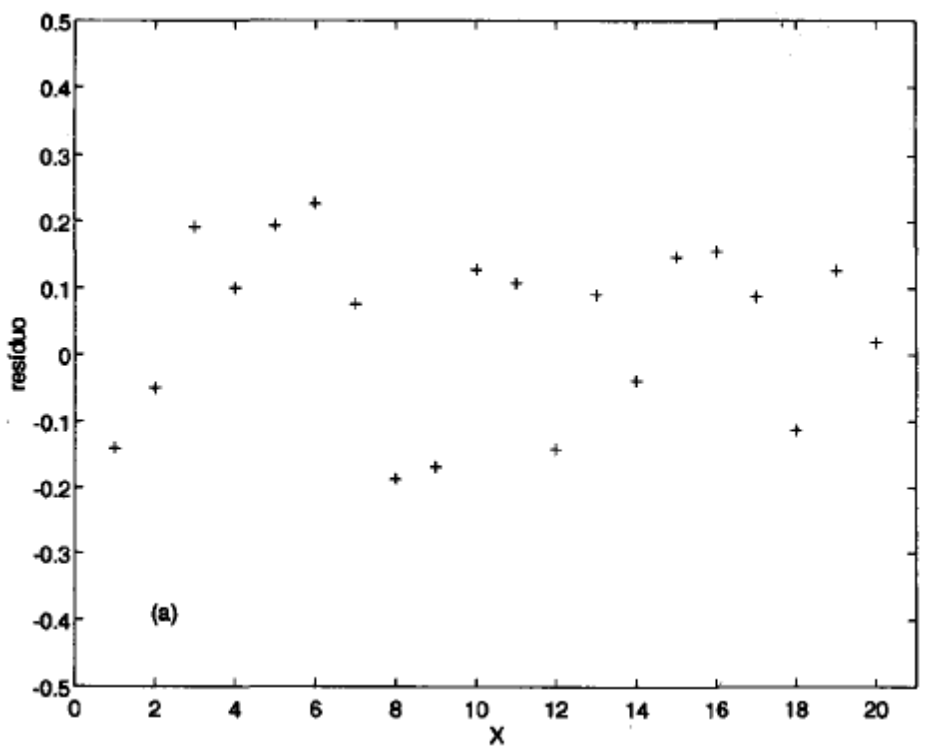


Figura 1.19: Resíduo distribuído aleatoriamente com variância crescendo em conjunto com o aumento da concentração, retirado de (7).

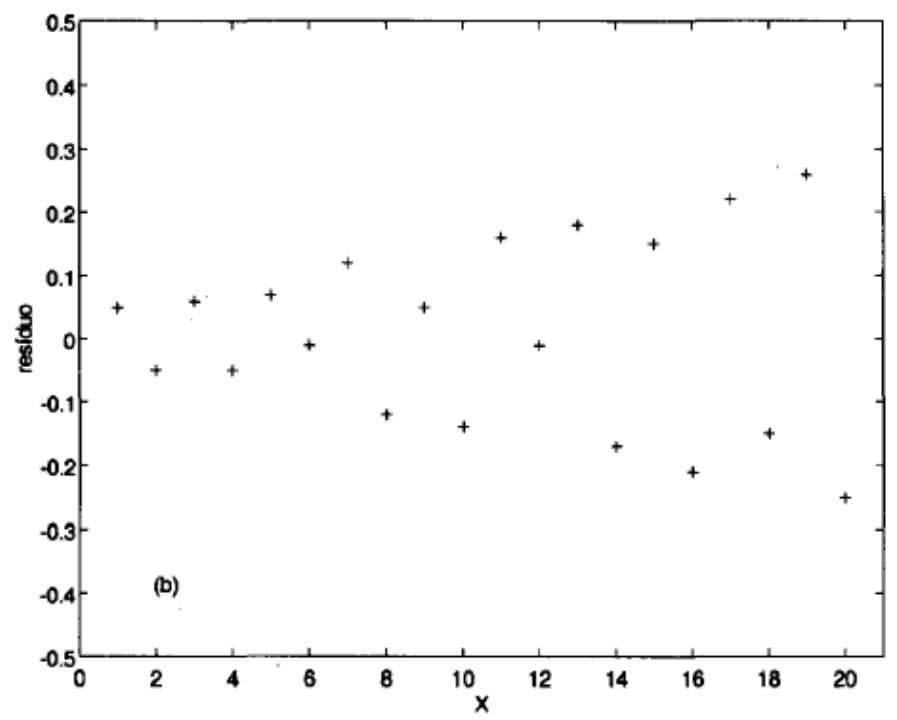

concentrações maiores, demonstrando a heteroscedasticidade.

Após avaliar a homoscedasticidade e heteroscedasticidade, é necessário avaliar o modelo obtido. Essa análise usa a ferramenta estatística chamada de Análise de Variância (ANOVA). A ANOVA se caracteriza pela decomposição da soma quadrática (SQ) dos desvios de todas as observações em relação à média. Divide em 2 parcelas, $S Q$ da regressão $\left(S Q_{\text {reg }}\right)$ e $S Q$ dos resíduos $\left(S Q_{r}\right)$, sendo $S Q_{\text {total }}=S Q_{r e g}+S Q_{r}$. Para verificar a linearidade do modelo basta dividir o $S Q_{r e g}$ pelo $S Q_{r}$, contudo para melhorar a precisão dos dados deve ser considerado o grau de liberdade. Dessa maneira, as médias quadráticas $(M Q)$ da regressão $\left(M Q_{\text {reg }}\right)$ e do resíduo $\left(M Q_{r}\right)$ são designadas com a melhor forma para avaliar a linearidade, quanto maior a razão entre $M Q_{r e g}$ e $M Q_{r}$, melhor será o modelo. A Equação 1.11 do $M Q_{r e g}$ é apresentada, onde $p$ é o número de parâmetros do modelo. $\mathrm{O} M Q_{r}$ é dado pela Equação 1.12, onde $n$ é o número total de medida.

$$
\begin{gathered}
M Q_{r e g}=\frac{S Q_{r e g}}{p-1} \\
M Q_{r}=\frac{S Q_{r}}{n-p}
\end{gathered}
$$

Como ao determinar a linearidade, normalmente, é feito por meio de ensaios tendo no mínimo em 5 níveis diferentes de concentração com réplicas, haverá variação em torno da média que não serão explicados pelo modelo. Então, parte da variação total que não pode ser explicada é chamada de erro puro proveniente da $S Q_{r}$ dado pela fórmula $S Q_{r}=S Q_{f a j}+S Q_{e p}$ , sendo o $S Q_{f a j}$ e o $S Q_{e p}$ soma quadrática da falta de ajuste do modelo e soma quadrática do 
erro puro, respectivamente. Dividindo cada termo pelo seu grau de liberdade obtêm-se a média quadrática (MQ), $M Q_{f a j}$ e $M Q_{e p}$. O $M Q_{f a j}$ é dado pela seguinte fórmula, sendo $m$ número de níveis distintos da variável $x$.

$$
M Q_{f a j}=\frac{S Q_{f a j}}{m-p}
$$

$\mathrm{O} M Q_{e p}$ é obtido pela a Equação 1.14 .

$$
M Q_{e p}=\frac{S Q_{e p}}{n-m}
$$

Para facilitar basta montar a tabela de ANOVA, conforme mostra a Tabela 1.9.

É necessário verificar a falta de ajuste no modelo, para esse teste, basta ver a razão obtida entre $M Q_{f a j} / M Q_{e p}$. Se a razão for menor do que o $\mathrm{F}$ tabelado indica que não ocorre falta de ajuste no modelo, significando que a equação linear obtida está correta, podendo ser aplicada para quanticação. Caso contrário, a falta de ajuste é significativa, e assim o modelo precisa ser melhorado.

Outro teste necessário é o teste de significância da regressão, comparando o $M Q_{r e g} / M Q_{r}$ com o valor tabelado de $\mathrm{F}$ para os graus de liberdade do numerador/denominador, um valor de $M Q_{r e g} / M Q_{r}$ superior ao valor de F tabelado, indica relação linear entre as variáveis. Quanto maior esse valor mais significante será a relação. É necessário ressaltar que o valor de $M Q_{\text {reg }}$ deve ser no mínimo 5 vezes maior que o $M Q_{r}$, para que a regressão tenha utilidade prática. (58) Após, verificar todos esses testes e certificar a conformidade dos dados é possível aplicar o método em amostras para avaliar sua funcionalidade prática.

Tabela 1.9: Tabela ANOVA para testar a linearidade do método validado.

\begin{tabular}{cccc}
\hline Fonte & SQ & Graus de liberdade & MQ \\
\hline Modelo & $S Q_{r e g}$ & $\mathrm{p}-1$ & $M Q_{r e g}=\frac{S Q_{\text {reg }}}{p-1}$ \\
Residual & $S Q_{r}$ & $\mathrm{n}-\mathrm{p}$ & $M Q_{r}=\frac{S Q_{r}}{n-p}$ \\
Falta de ajuste & $S Q_{f a j}$ & $\mathrm{~m}-\mathrm{p}$ & $M Q_{f a j}=\frac{S Q_{f a j}}{m-p}$ \\
Erro puro & $S Q_{e p}$ & $\mathrm{n}-\mathrm{m}$ & $M Q_{f e p}=\frac{S Q_{f e p}}{n-m}$ \\
\hline Total & $S Q_{t}$ & $\mathrm{n}-1$ & \\
\hline
\end{tabular}




\section{OBJETIVOS}

Essa tese tem como objetivo principal buscar melhorias para as técnicas mais recentes de preparo de amostra (novas fases poliméricas, novas configurações e novos dispositivo para fabricação de fases extratoras), e aplicar técnicas já consolidas na determinação de fármacos presente no ambiente, principalmente em amostras aquosas. 


\section{CAPÍTULO 2}

\section{CAPÍTULO 2 - ANÁLISE DE RESÍDUOS DE FÁRMACOS EM ÁGUAS RESIDUÁRIAS USANDO} MICROEXTRAÇÃO EM FASE SÓLIDA (SPME) E DERIVATIZAÇÃO IN SITU

\subsection{Introdução}

Atualmente, fármacos, hormônios e desreguladores endócrinos (EDC) são importantes contaminantes ambientais. A presença de medicamentos no ambiente é devido à sua aplicação diária em medicina humana e veterinária. Por volta de 3000 substâncias são utilizados como medicamentos, divididos em diversas classes como antipiréticos, analgésicos, hormônios anticoncepcionais, reguladores lipêmicos, antidepressivos, anti-inflamatórios, entre outras. (59) Os medicamentos se encontram no ambiente aquático em virtude da ineficiência do tratamento das águas residuárias nas estações de tratamento de água e esgoto (ETE). A presença no ambiente aquático ocorre em baixas concentrações (de $\mathrm{ng} \mathrm{L}^{-1}$ a $\mu \mathrm{g} \mathrm{L}^{-1}$ ), apesar disso o potencial tóxico ainda não está totalmente elucidado. Já se sabe que mesmo em concentrações a nível de traço, hormônios e EDC induzem alterações nas gônadas de peixes causando a feminização desses. (24) Outro relato relevante é o desaparecimento de abutres e urubus que se alimentaram de carcassas de animais contendo o anti-inflamatório. (60) 
Em virtude desses efeitos tóxicos, é necessário monitorar a presença dos fármacos no ambiente. Por outro lado, análises ambientais, como monitoramento de águas residuárias, são complexas já que é uma matriz contendo uma grande quantidade de matéria orgânica, minerais e sólidos suspensos, que são interferentes na análise química. Assim, é necessário utilizar espectrometria de massas (MS) para quantificar e identificar de forma inequívoca os analitos. Muitos métodos foram desenvolvidos utilizando o acoplamento cromatografia líquida (LC) e a gás (GC) com MS. Esse acoplamento com LC e GC apresenta vantagens e desvantagens. LCMS e LC-MS/MS são técnicas caras devido a sua manutenção, também é susceptível a sofrer efeito de matriz, porém é capaz de analisar compostos instáveis termicamente não passíveis de serem analisado por GC. (61) GC-MS/MS e, principalmente GC-MS, são técnicas mais baratas e comuns na maioria dos laboratórios de química analítica, contudo, é necessário derivatizar compostos termo-instáveis e/ou possuindo grupos $-\mathrm{OH},-\mathrm{NH}_{2}$, e $-\mathrm{COOH}$ que geram caudas cromatográficas.

A etapa de preparo é requisito obrigatório em análise por GC ou LC de amostras complexas. A SPME é uma técnica consolidada de preparo de amostras, possuindo comercialmente diversos recobrimentos poliméricos usados como fase extratora, o que proporciona a capacidade de extrair compostos com diferentes características. Além disso, SPME apresenta compatibilidade para realizar etapas de extração e derivatização simultaneamente. Como desvantagens a extração por SPME se baseia no equilíbrio de partição do analito, e dessa forma, diversas variáveis devem ser otimizadas para evitar baixos níveis de recuperação. Assim, o planejamento fatorial é ferramenta essencial na etapa de otimização, para diminuir o número de experimentos e gasto de reagente, além de estudar as interações possíveis entre as variáveis.

Dessa maneira, esse estudo demonstra a otimização da SPME e derivatização in situ para extração de nove fármacos de diferentes classes (anti-inflamatórios, antidepressivo, hormônios e regulador lipêmico) presente em águas residuárias. Um planejamento fatorial fracionário foi aplicado para avaliar o comportamento das variáveis da SPME e derivatização in situ, separadamente. Após, para otimizar ambas etapas foi usado a matriz de Doehlert, em seguida, o método foi validado e aplicado em amostras de esgoto industrial, água de rio e águas residuárias de ETE.

\subsection{Experimental}

\subsubsection{Reagentes}

Água ultra pura foi fornecida pelo sistema Elga Purelab Ultra (High Wycombe, Inglaterra). A piridina (pyr) foi adquirida da Merck (Darmstadt, Alemanha); o carbonato de sódio comprado da Synth (Diadema, Brasil); o acetato de etila, cloreto de sódio e hidrogeno carbonato de sódio 
foram obtido da J.T. Baker (Phhillipsbourg, EUA), e etanol (et) proveniente da Tedia (Fairfield, EUA).

Os padrões analíticos de ibuprofeno (IBU), fenoprofeno (FEN), naproxeno (NAP), cetoprofeno (KET), flurbiprofeno (FLUR), fluoxetina (FLX), e estrona (E1) foram adquiridos da Sigma-Aldrich (Steinheim, Alemanha). O $17-\beta$ estradiol (E2), foi obtido da Alfa Aesar (Karlsruche, Alemanha) e a sinvastatina foi fornecida pela Krebs Biochemicals (Andhara, Pradesh, India). O padrão deuterado de ibuprofeno-d-3 foi usado como padrão interno (IS) ou surrogate standard. O cloroformato de etila (ECF) foi usado como agente derivatizante, o qual foi obtido da Aldrich (Steinheim, Alemannha).

A solução estoque de cada analito foi preparado a cada 3 meses em etanol na concentração de $1,0 \mathrm{mg} \mathrm{mL}^{-1}$. Soluções intermediárias na concentração de $550 \mu \mathrm{g} \mathrm{L}^{-1}$ foram obtidas da diluição da solução estoque. Ambas soluções foram acondicionadas em frasco âmbar a $4{ }^{\circ} \mathrm{C}$. O padrão interno deuterado teve sua solução estoque preparada em etanol na concentração de 0,1 $\mathrm{mg} \mathrm{mL} \mathrm{m}^{-1}$, sendo armazenado em vial âmbar a $-20{ }^{\circ} \mathrm{C}$. A sua solução intermediária em etanol veio da diluição da estoque até obter a concentração de $11 \mu \mathrm{g} \mathrm{L}^{-1}$.

\subsubsection{GC-MS}

Foi usado o GC-MS QP-5000 da Shimadzu (Kyoto, Japão) juntamente com uma coluna de sílica fundida RTX-5MS da Restek (Bellefonte, EUA) com dimensões de $15 \mathrm{~m}$ x 0,25 mm x 0,25 $\mu \mathrm{m}$. Hélio foi utilizado como gás de arraste com velocidade linear de $46 \mathrm{~cm} / \mathrm{s}$, gerando uma pressão de 2,2 KPa no início da coluna. As injeções foram feitas no modo splitless mantendo a válvula de split fechada por 3 minutos. A programação de temperatura do forno iniciou a temperatura de $80{ }^{\circ} \mathrm{C}$, permanecendo por 2 minutos, aumentando até $280{ }^{\circ} \mathrm{C}$ com uma taxa de

aquecimento de $30^{\circ} \mathrm{C} \mathrm{min}-1$ e ficando nessa temperatura por 8 minutos, completando um total de 18,7 minutos de corrida cromatográfica. A temperatura do injetor, linha de transferência e fonte de íons foram de $250{ }^{\circ} \mathrm{C}$ e $300{ }^{\circ} \mathrm{C}$.

\subsubsection{SPME e derivatização in situ}

As fibras e holders foram adquiridos da Supelco (Bellefonte, EUA), sendo condicionadas conforme recomenda o manual do usuário a $250{ }^{\circ} \mathrm{C}$ durante 30 minutos. As extrações foram realizadas no modo direto sob agitação magnética, tendo a fibra de PDMS/DVB como fase extratora. Outras fases também foram testadas como a PDMS, PDMS/carboxeno (PDMS/CAR) e poliacrilato (PA). A derivatização in situ foi realizada em conjunto com a extração por SPME, tendo o ECF como agente derivatizante e a mistura etanol e piridina como catalisador. Após cada extração, a dessorção térmica era feita no injetor durante 15 minutos, no entanto, a fibra 
era mantida por mais 10 minutos após o início da corrida. No fim do dia, a fibra era limpa com $5 \mathrm{~mL}$ de etanol para evitar danos causados por possíveis resíduos de ECF.

Todo o preparo de amostra foi otimizado usando ferramentas de planejamento experimental, tendo suas condições descritas a seguir. Para a extração por SPME foi usada a temperatura de extração de $70^{\circ} \mathrm{C}$, tempo de extração de 60 minutos, $11 \mathrm{~mL}$ de amostra, sem adição de sal para alterar a força iônica. Em relação a derivatização in situ, o $\mathrm{pH}=10$ fornecido pelo tampão carbonato $0,50 \mathrm{~mol} \mathrm{~L}^{-1}, 0,30 \mathrm{~mL}$ de etanol:piridina na proporção de $3: 2$ e $0,16 \mathrm{~mL}$ do agente derivatizante cloroformato de etila $(\mathrm{ECF})$.

\subsubsection{Planejamento fatorial}

Tanto a SPME como também derivatização in situ tiveram suas variáveis avaliadas pelo planejamento fatorial. Oito variáveis foram identificadas como parâmetros que poderiam afetar a resposta analítica. Então, dois planejamentos fatorias fracionários foram aplicados separadamente, um estudando os fatores da derivatização in situ que são o pH, volume de derivatizante, volume da solução de etanol:piridina (et:pyr) e proporção dessa solução. Para a SPME foi investigado a temperatura de extração, tempo de extração, volume de amostra e força iônica, como está representado na Tabela 2.1. O ponto central foi estudado em triplicata para medir o erro puro de cada planejamento. O total de 11 experimentos para SPME e derivatização in situ foram realizados de maneira aleatória.

Após os experimentos, os dados do planejamento fatorial foram processados no software Statistica 6.0, usando análise de variância (ANOVA) para selecionar os melhores modelos. As variáveis significativas da derivatização foram $\mathrm{pH}$ e volume de derivatizante; já a temperatura da extração, tempo de extração e volume de amostra foram significativas para a SPME, sendo posteriormente otimizadas usando o método de superfície de resposta a Matriz de Doehlert, demonstrada na Tabela 2.2.

\subsubsection{Validação do método}

O método foi validado tendo como base critérios aceitos internacionalmente. (50, 5254) Foram monitorados de três a cinco íons dependendo do analito, sendo um íon usado para quantificação e os adicionais para auxiliar na confirmação do composto em análise, conforme mostra a Tabela 2.3. A linearidade foi avaliada pela fortificação dos analitos em cinco níveis crescentes de concentração em amostras de água de torneira isentas dos analitos, sendo que cada nível feito em duplicata ou triplicata.

A curva de calibração é obtida plotando a razão da área (divisão da área do analito pela área do IS) versus a concentração adicionada na amostra. O ibuprofeno-d3 foi escolhido como 
Tabela 2.1: Planejamento fatorial fracionário para avaliar as principais variáveis da derivatização in situ e extração por SPME.

\begin{tabular}{ccccc|cccc}
\hline \multicolumn{4}{c|}{ Derivatização in situ } & \multicolumn{4}{c}{ Extração por SPME } \\
\hline Experimentos & $\begin{array}{c}\text { Volume } \\
\text { de } \\
\text { ECF } \\
(\mu \mathrm{L})\end{array}$ & $\begin{array}{c}\text { Volume } \\
\text { de } \\
(\mathrm{mL})\end{array}$ & $\begin{array}{c}\text { Proporção } \\
\text { de } \\
\text { et:pyr }\end{array}$ & $\begin{array}{c}\text { Temperatura } \\
\left({ }^{\circ} \mathrm{C}\right)\end{array}$ & $\begin{array}{c}\text { Tempo } \\
\text { de } \\
\text { Extração } \\
(\mathrm{min})\end{array}$ & $\begin{array}{c}\text { Volume } \\
\text { de } \\
\text { amostra } \\
(\mathrm{mL})\end{array}$ & $\begin{array}{c}\text { Força iônica } \\
(\% \text { NaCl m/v })\end{array}$ \\
\hline 1 & 4,50 & 30 & 300 & $1: 2$ & 30 & 60,0 & 5,0 & 30 \\
2 & 4,50 & 80 & 300 & $3: 2$ & 30 & 60,0 & 10 & 5 \\
3 & 4,50 & 30 & 800 & $3: 2$ & 30 & 15,0 & 10 & 30 \\
4 & 4,50 & 80 & 800 & $1: 2$ & 30 & 15,0 & 5,0 & 5 \\
5 & 10,0 & 30 & 300 & $3: 2$ & 70 & 60,0 & 10 & 30 \\
6 & 10,0 & 30 & 800 & $1: 2$ & 70 & 60,0 & 5,0 & 5 \\
7 & 10,0 & 80 & 300 & $1: 2$ & 70 & 15,0 & 5,0 & 30 \\
8 & 10,0 & 80 & 800 & $3: 2$ & 70 & 15,0 & 10 & 5 \\
9 & 7,25 & 55 & 550 & $2: 1$ & 55 & 37,5 & 7,5 & 15 \\
10 & 7,25 & 55 & 550 & $2: 1$ & 55 & 37,5 & 7,5 & 15 \\
11 & 7,25 & 55 & 550 & $2: 1$ & 55 & 37,5 & 7,5 & 15 \\
\hline
\end{tabular}

IS por apresentar estrutura química similar aos analitos em análise, além de sofrer a mesma reação de derivatização. A curva de calibração de cada analito foi avaliada usando ANOVA para avaliar a significância da falta de ajuste de cada analito, e assim assegurando que o modelo obtido possuía linearidade adequada.

A precisão intra e inter-dia foram verificadas em três níveis de concentração avaliados em triplicata, sendo baixo, médio e alto. O efeito de matriz foi avaliado comparando as curvas de calibração feitas em água de torneira versus a calibração feita em esgoto industrial, águas residuárias e água de rio.

O limite de detecção (LOD) foi estimado usando a seguinte fórmula:

$$
L O D=3,3 \frac{s}{S}
$$

onde $s$ refere ao desvio padrão de uma amostra com relação sinal:ruído 3:1 e $S$ é a inclinação da curva de calibração. O limite de quantificação (LOQ) foi adotado como a menor concentração que permitisse quantificar com precisão, exatidão (RSD $\leq 20 \%$ ) e com relação sinal:ruído 3 vezes maior em relação ao LOD.

\subsubsection{Amostras ambientais}

Após o método ter sido validado, e todos os seus parâmetros passados na avaliação estatística, o mesmo foi aplicado em amostras ambientais de águas residuárias provenientes de ETE. Além do esgoto industrial que era despejado diretamente em um rio, também foi avaliado a água 
Tabela 2.2: Matriz de Doehlert para otimizar a derivatização in situ e a extração por SPME.

\begin{tabular}{ccc|ccc}
\hline Experimentos & Derivatização in situ & \multicolumn{3}{c}{ Extração por SPME } \\
\hline & pH & Volume de ECF $(\mu \mathrm{L})$ & Temperatura $\left({ }^{\circ} \mathrm{C}\right)$ & $\begin{array}{c}\text { Tempo de } \\
\text { extração }(\mathrm{min})\end{array}$ & $\begin{array}{c}\text { Volume de } \\
\text { amostra }(\mathrm{mL})\end{array}$ \\
\hline $\mathbf{1}$ & 7,25 & 115 & 60 & 35,0 & 14 \\
$\mathbf{2}$ & 7,25 & 115 & 60 & 35,0 & 14 \\
$\mathbf{3}$ & 7,25 & 115 & 60 & 35,0 & 14 \\
$\mathbf{4}$ & 10,0 & 115 & 60 & 35,0 & 20 \\
$\mathbf{5}$ & 8,63 & 160 & 60 & 60,0 & 17 \\
$\mathbf{6}$ & 4,50 & 115 & 90 & 43,3 & 17 \\
$\mathbf{7}$ & 5,88 & 70 & 60 & 35,0 & 8,0 \\
$\mathbf{8}$ & 8,63 & 70 & 60 & 10,0 & 11 \\
$\mathbf{9}$ & 5,88 & 160 & 30 & 26,7 & 11 \\
$\mathbf{1 0}$ & - & - & 60 & 10,0 & 17 \\
$\mathbf{1 1}$ & - & - & 30 & 26,7 & 17 \\
$\mathbf{1 2}$ & - & - & 60 & 60,0 & 11 \\
$\mathbf{1 3}$ & - & - & 30 & 51,7 & 14 \\
$\mathbf{1 4}$ & - & - & 90 & 43,3 & 11 \\
$\mathbf{1 5}$ & - & - & 90 & 18,3 & 14 \\
\hline
\end{tabular}

Tabela 2.3: Íons utilizados para monitoramento no modo SIM

\begin{tabular}{ccc}
\hline \hline Fármaco & $\begin{array}{c}\text { Íons monitorados } \\
(\mathbf{m} / \mathbf{z})\end{array}$ & $\begin{array}{c}\text { Íon selecionado } \\
\text { para quantificação }(\mathbf{m} / \mathbf{z})\end{array}$ \\
\hline IBU & $234,191,161$ & $\mathbf{1 6 1}$ \\
FEN & $270,197,178$ & $\mathbf{1 9 7}$ \\
FLUR & $272,198,181$ & $\mathbf{2 7 2}$ \\
NAP & $258,185,170,141$ & $\mathbf{2 5 8}$ \\
KET & $282,209,194,165$ & $\mathbf{2 0 9}$ \\
FLX & $335,232,220,116$ & $\mathbf{1 1 6}$ \\
E1 & $342,298,270,172$ & $\mathbf{2 7 0}$ \\
E2 & $344,300,272,146$ & $\mathbf{2 7 2}$ \\
SIM & $284,199,172,159,157$ & $\mathbf{1 5 7}$ \\
\hline
\end{tabular}

do rio durante o curso antes e após receber o esgoto industrial. As amostras foram coletadas em frascos âmbar de 1,0 L, transportados para o laboratório refrigerados aproximadamente a 8 ${ }^{\circ} \mathrm{C}$. No laboratório, a amostra foi filtrada usando um filtro de papel com porosidade de $8 \mu \mathrm{m}$ a pressão reduzida. As amostras foram armazenadas a $4{ }^{\circ} \mathrm{C}$, sendo analisados no dia seguinte a coleta. 


\subsection{Resultados e Discussão}

\subsubsection{Separação Cromatográfica}

A Figura 2.1 mostra um cromatograma no modo SIM obtido da extração por SPME de água de torneira fortificada. Como pode ser percebido todos os picos estão simétricos e sem caudas cromatográficas. Nenhum dos analitos co-eluiram ou mesmo apresentou sinais de instabilidade térmica, os picos sem identificação correspondem a subprodutos da reação de derivatização in situ.

\subsubsection{Extração por SPME e derivatização in situ}

A fibra de PDMS e PDMS/CAR foram eficientes na extração da E2, FLUR, IBU e SIMV, no entanto, demonstraram baixa capacidade extrativa para E1, FLX, FEN, KET e NAP. Esse fato, é explicado pela características do polímero de PDMS ser compatível para extrair com maior eficiência compostos com Log P maior que 4,0. A fase de PDMS/CAR apresenta como características a capacidade de extrair compostos não-polares do PDMS, aliado com a capacidade adsorptiva do carboxeno, sendo apropriada para extrair compostos polares, voláteis e semi-voláteis, não tendo seletividade para todos os analitos de interesse. A fibra de PA mostrou um comportamento totalmente contrário ao de PDMS, não extraindo todos os analitos, além de ter sido danificado rapidamente. Já o recobrimento de PDMS/DVB, demonstrou ser uma fase quimicamente balanceada, o PDMS tem afinidade por compostos não-polares enquanto o DVB apresenta compatibilidade para extrair analitos polares.

Figura 2.1: Cromatograma do íon extraído (EIC) de uma extração por SPME seguida de derivatização in situ de água de torneira fortificada com 10,0 $\mu \mathrm{g} \mathrm{L}^{-1}$. 1- IBU, 2- FEN, 3- FLUR, 4- NAP, 5- KET, 6- FLX, 7- E1, 8- E2 e 9- SIMV.

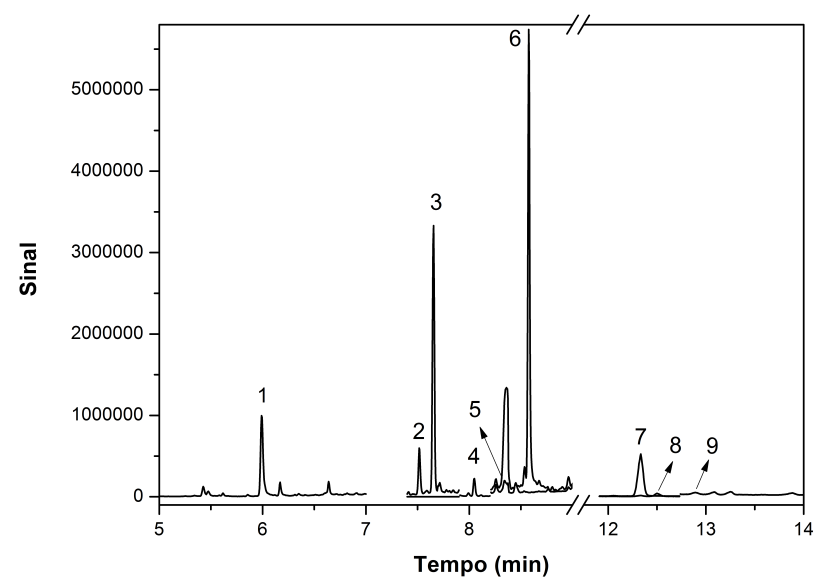


Dessa maneira a fase de PDMS/DVB foi capaz de superar os problemas ocorridos com as demais fases testadas, com seletividade para todos os fármacos de interesse.

A derivatização in situ tem sido usada não somente para melhorar a eficácia na extração, mas também para melhorar o desempenho da análise por GC. (62) Em técnicas miniaturizadas de preparo de amostra é essencial utilizar reações que necessitam de baixas quantidades de agente derivatizante e catalisador, principalmente para evitar danos na fase extratora. Por atender essas exigências, o ECF foi escolhido como agente derivatizante, por apresentar uma reatividade molecular intrínseca, reagindo rapidamente com diversos tipos de compostos presentes no meio aquoso.

Primeiramente, a derivatização in situ foi baseada nos métodos de Fernandes et.al. (63) e Stopforth et.al. (64). Em seguida, os mecanismo de reação foram estudados para cada composto. Para os compostos ácidos, como o IBU, FEN, FLUR, NAP e KET, a derivatização ocorre no grupamento do ácido carboxílico terminal de cada composto. A piridina atrai o hidrogênio do grupo ácido, tendo uma carga negativa no grupo carboxil por indução, o que permite o oxigênio do carboxil atacar o ECF, formando um carbonato. No entanto, esse carbonato é instável, sendo passível de sofrer ataque pelo grupo etil do etanol adicionado em conjunto com a piridina, conforme é mostrado na Figura 2.2. Assim, é formado um éster etílico, resultando em composto com íon molecular caracterizado pela perda de um hidrogênio e ganho de 29 unidades de massa atômica (u), conforme pode ser visualizados nos espectro de massas das Figuras 2.3, 2.4 e 2.5.

Figura 2.2: Mecanismo da reação da derivatização in situ utilizando ECF como derivatizante para os anti-inflamatórios.<smiles>[R]C(=O)O</smiles><smiles>CCOC(=O)Cl</smiles><smiles>CCCC1CCN(CC)CC1</smiles><smiles>[R]C(=O)OCC</smiles> 
Figura 2.3: Espectro de massas obtido para (A) fenoprofeno e (B) flurbiprofeno após serem derivatizados.
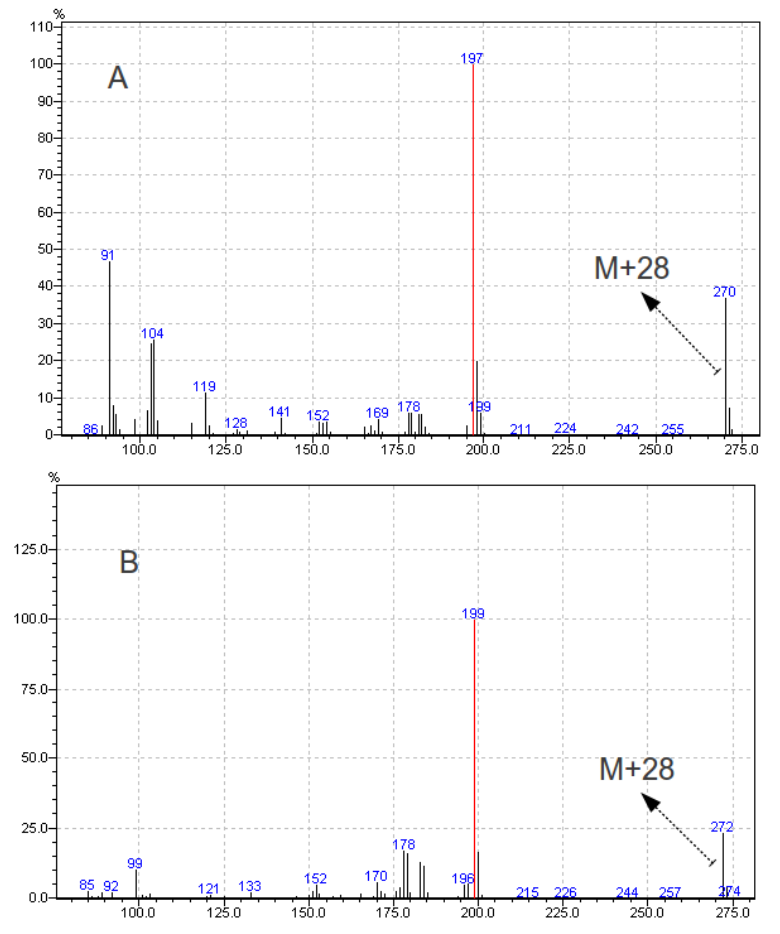

Figura 2.4: Espectro de massas obtido para (C) naproxeno e (D) cetoprofeno após serem derivatizados.
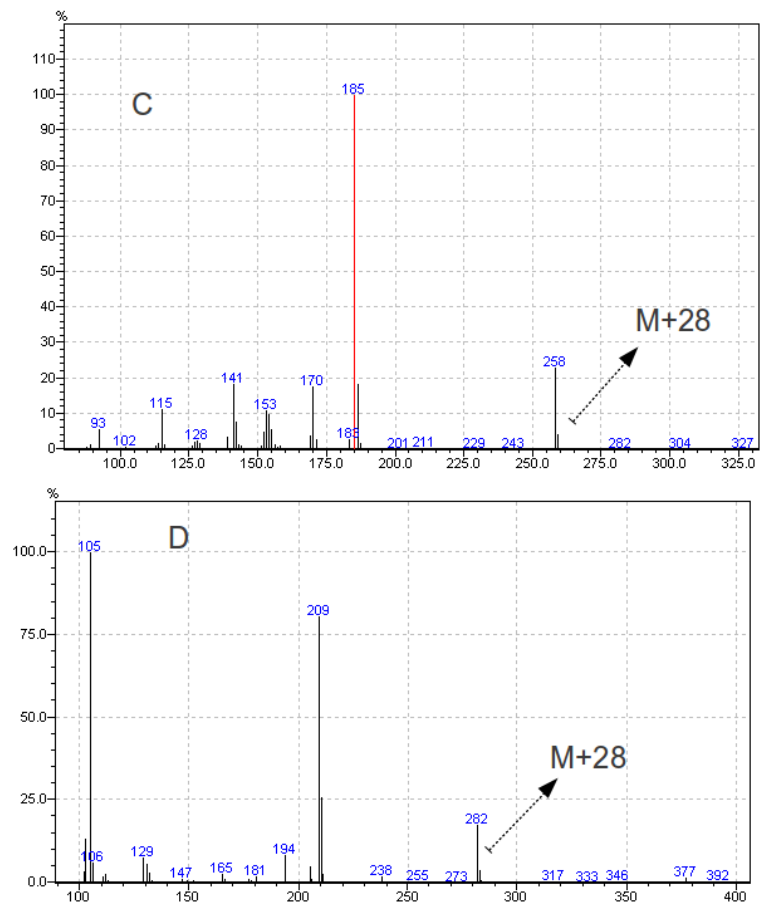
Figura 2.5: Espectro de massas obtido para ibuprofeno após ser derivatizado.

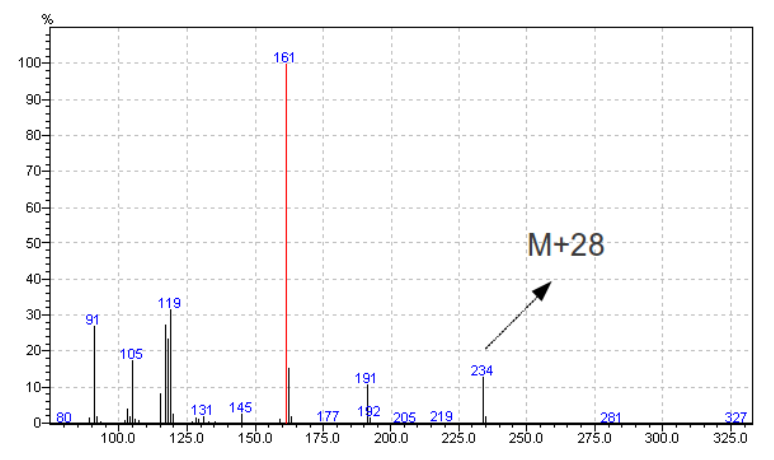

De maneira similar, o hidrogênio dos fenóis e aminas (E1, E2 e FLX) liberado em solução é capturado pela piridina. A carga negativa no oxigênio e os elétrons livres no grupo amino permitiram o ataque ao carbono do ECF, formando um carbonato para os hormônios (E1 e E2) e um carbamato para a FLX, conforme pode ser visto nas Figuras 2.6 e 2.7. Ambos são estáveis resultando em E1, E2 e FLX com íons moleculares com 72 u a mais do que o fármaco correspondente na forma não derivatizada, conforme pode ser visto nas Figuras 2.8 e 2.9 .

Figura 2.6: Mecanismo da reação da derivatização in situ utilizando ECF como derivatizante para os hormônios.
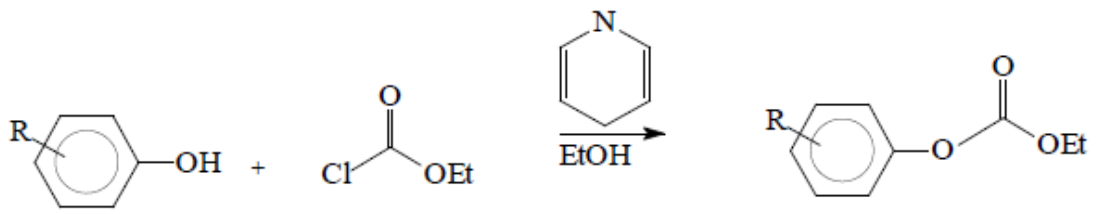

Figura 2.7: Mecanismo da reação da derivatização in situ utilizando ECF como derivatizante para a fluoxetina.<smiles>[R2]N[CH-]C(Cl)OCC</smiles><smiles>Oc1ccccc1</smiles><smiles>[R]N([R])C(=O)OCC</smiles> 
Figura 2.8: Espectro de massas obtido para (F) $17 \beta$-estradiol e $(\mathrm{G})$ estrona após serem derivatizados.
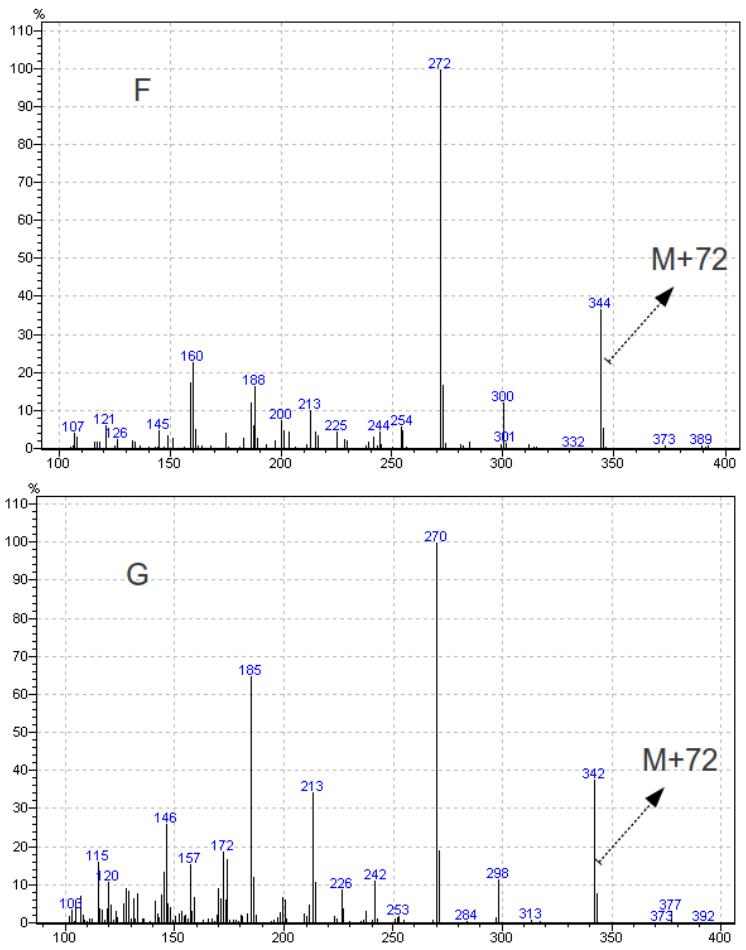

Figura 2.9: Espectro de massas obtido para $(\mathrm{H})$ fluoxetina após serem derivatizados.

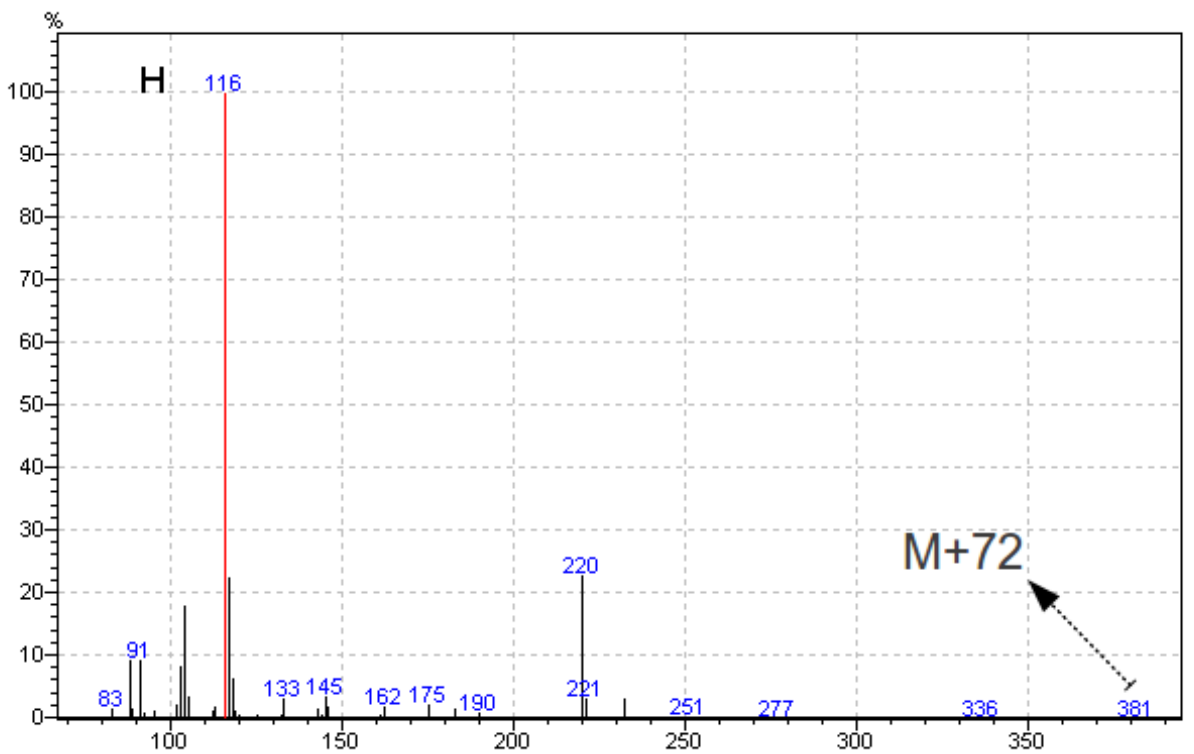

A SIMV não necessita derivatização, já que não apresenta degradação térmica e gera resposta cromatográfica adequada sem a presença de caudas. 


\subsubsection{Otimização do método}

O planejamento fatorial foi escolhido para otimizar o método já que a derivatização in situ associada com a extração por SPME possui diversas variáveis as quais podem interagir entre elas influenciando na resposta analítica. Planejamento fatorial fracionário foi feito para avaliar como cada variável influencia a derivatização in situ e a extração por SPME.

\section{Planejamento Fatorial Fracionário da derivatização in situ}

As principais variáveis que poderiam afetar a derivatização foram o $\mathrm{pH}$, o volume de agente derivatizante (Vderiv), o volume da solução de et:pyr (Vet:pyr) e a proporção de et:pyr (Prop et:pyr). $\mathrm{O}$ pH da solução influencia na ionização dos analitos em solução, embora não seja um requisito estar ionizado para sofrer a reação de derivatização. O Vderiv causa impacto diretamente na eficiência da reação, o Vet:pyr e a Prop et:pyr ajusta a disponibilidade do hidrogênio ionizado em solução, o que determina a eficácia da reação.

Os resultados desse planejamento estão representados no diagrama de Pareto do IBU e da FLX na Figuras 2.10 e 2.11 que apresentam um comportamento representativo para os demais analitos. $\mathrm{O}$ volume de ECF, além de sua interação com $\mathrm{pH}$ foram as únicas variáveis que influenciaram positivamente e de forma significativa, sendo melhor otimizado em um estudo futuro.

Figura 2.10: Diagrama de Pareto do IBU obtido no planejamento fatorial fracionário aplicado para avaliar a derivatização in situ.

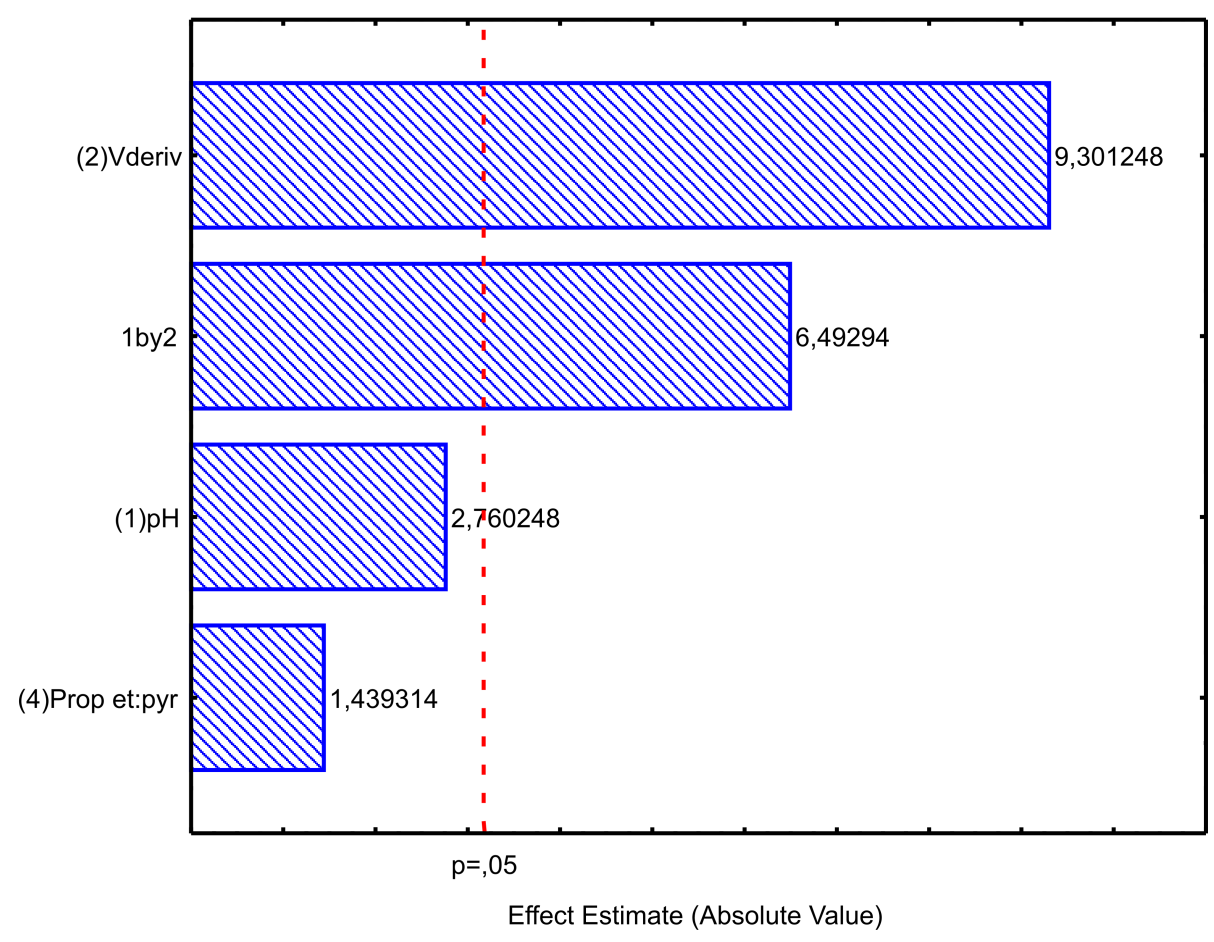


Figura 2.11: Diagrama de Pareto da FLX obtido no planejamento fatorial fracionário aplicado para avaliar a derivatização in situ.

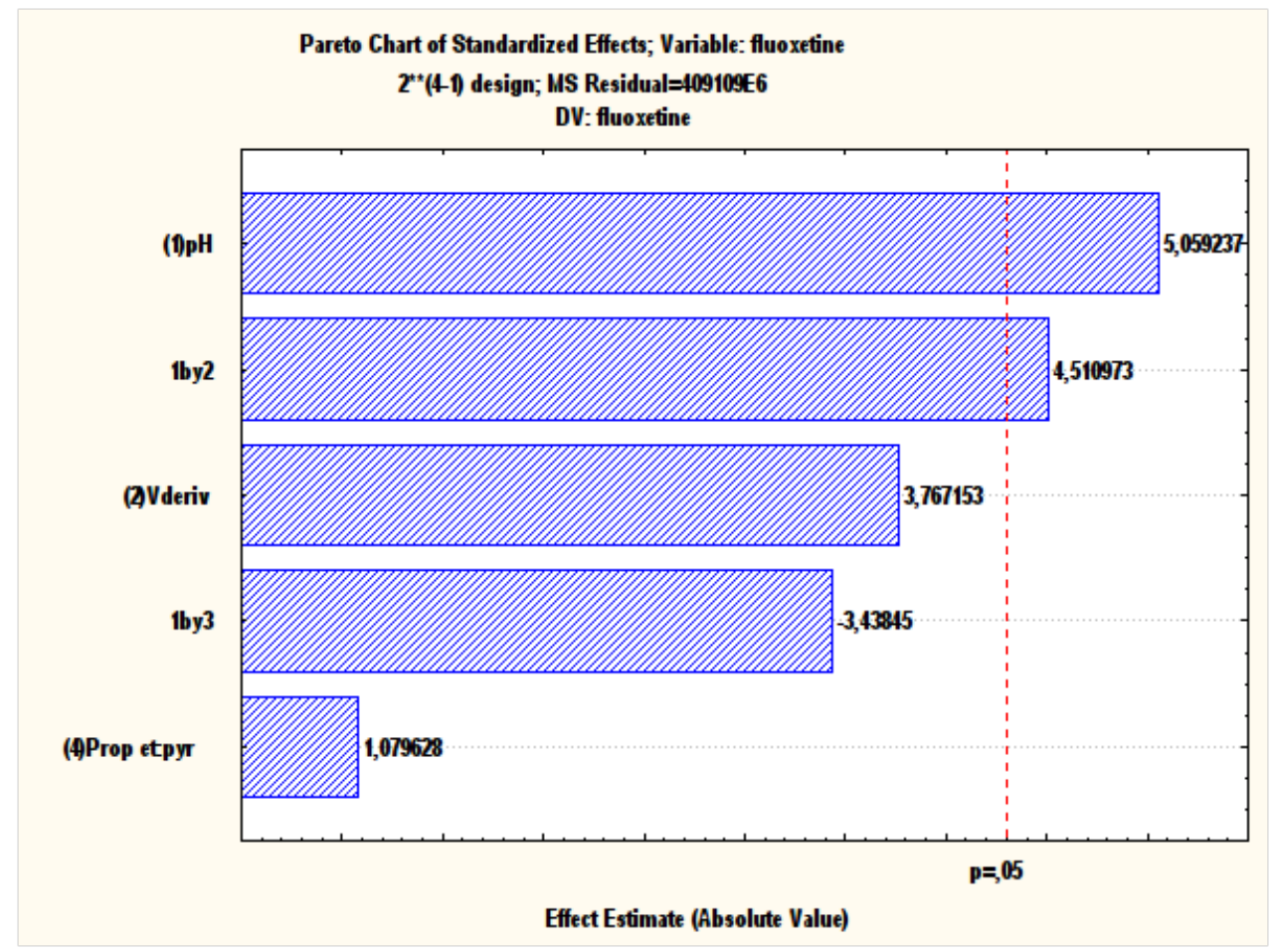

De maneira similar foi observado em outros estudo realizados por Zhou et. al. (65) e Canosa et. al. (36). Esse comportamento era esperado, já que o agente derivatizante controla a progressão da reação. $\mathrm{O}$ pH controla a ionização dos analitos, o que aumenta a disponibilidade de íons $\mathrm{H}_{3} \mathrm{O}^{+}$em solução, o que aumenta também o efeito indutivo, favorecendo o ataque às moléculas de ECF. O pH também é fundamental na extração por SPME, já que os analitos são extraídos por absorção e adsorção, estando na forma não-ionizada ambos mecanismos podem ocorrer enquanto que se os analitos estiverem na sua forma ionizada apenas a adsorção ocorrerá. Esse efeito foi notado para SIMV que em solução básica encontra-se ionizada e teve seu desempenho inferior quando comparado com a extração em meio ácido. Apesar disso, esse parâmetro não impediu a análise de SIMV, apenas demonstrou a necessidade de otimizar nas condições que favorecessem tanto a derivatização in situ como também a extração por SPME.

As variáveis envolvendo a SPME referem fatores relacionados com a cinética e dinâmica da extração. A Figura 2.12 mostra o diagrama de Pareto do FLUR que representa os efeitos de cada variável para os analitos estudados.

A temperatura, o volume de amostra e o tempo de extração apresentaram valor positivo e significativo, para maioria dos analitos, o que fez com que tenham sido melhor estudados para alcançar a melhor condição de extração, somente a SIMV apresentou novamente um modelo oposto relacionado com o comportamento da temperatura, conforme pode ser visto na Figura 2.13. Para essa última variável, apresentou um efeito negativo no modelo, sendo to- 
talmente oposto aos demais analitos. É necessário ainda ressaltar que para alguns compostos nenhuma dessas variáveis foram significativas, o que facilitou em encontrar a melhor condição para a SPME, conforme ilustra a Figura 2.14.

Figura 2.12: Diagrama de Pareto para o FLUR avaliando o comportamento da extração por SPME.

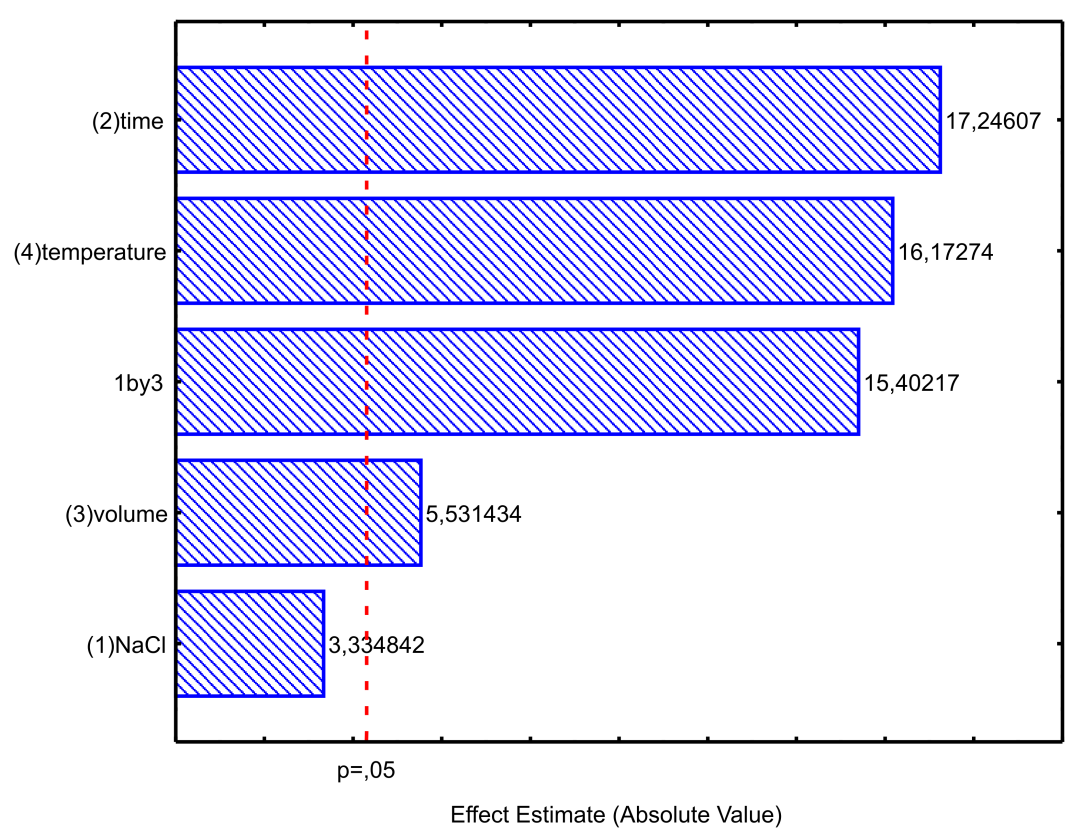

Figura 2.13: Diagrama de Pareto para a SIMV avaliando o comportamento da extração por SPME.

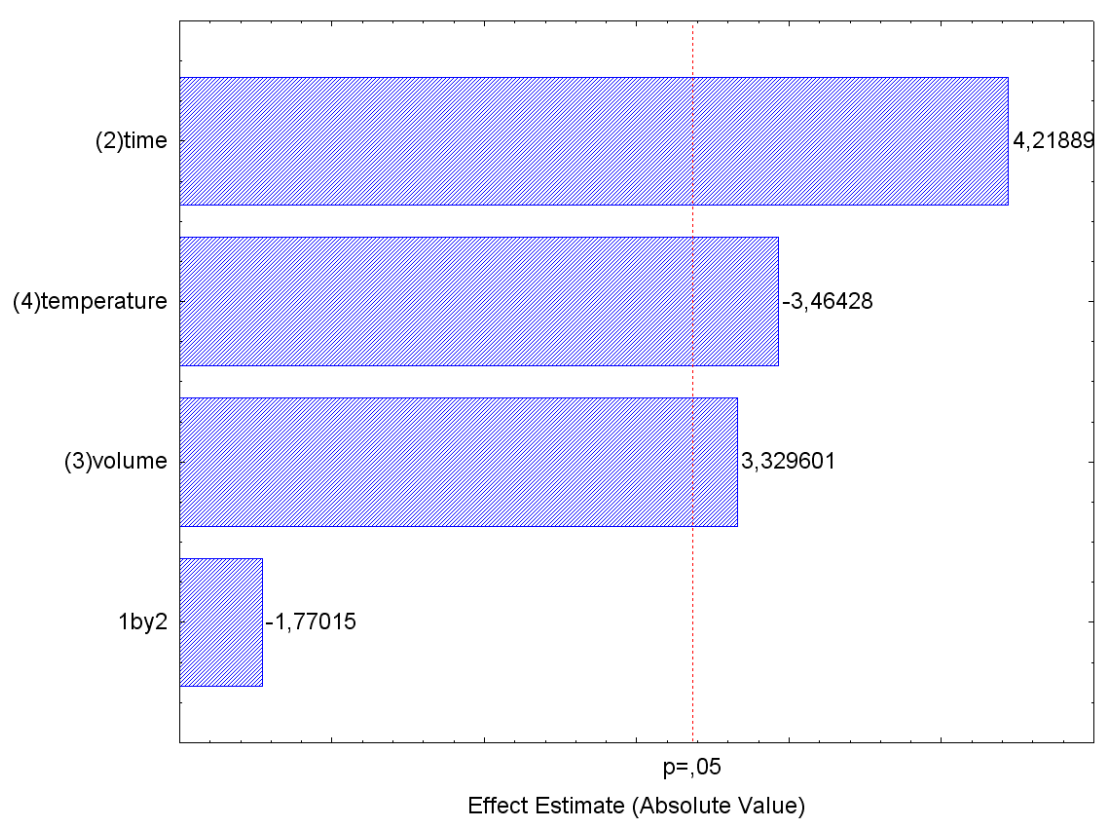


Figura 2.14: Diagrama de Pareto (A) NAP e (B) FLX avaliando o comportamento da extração por SPME.

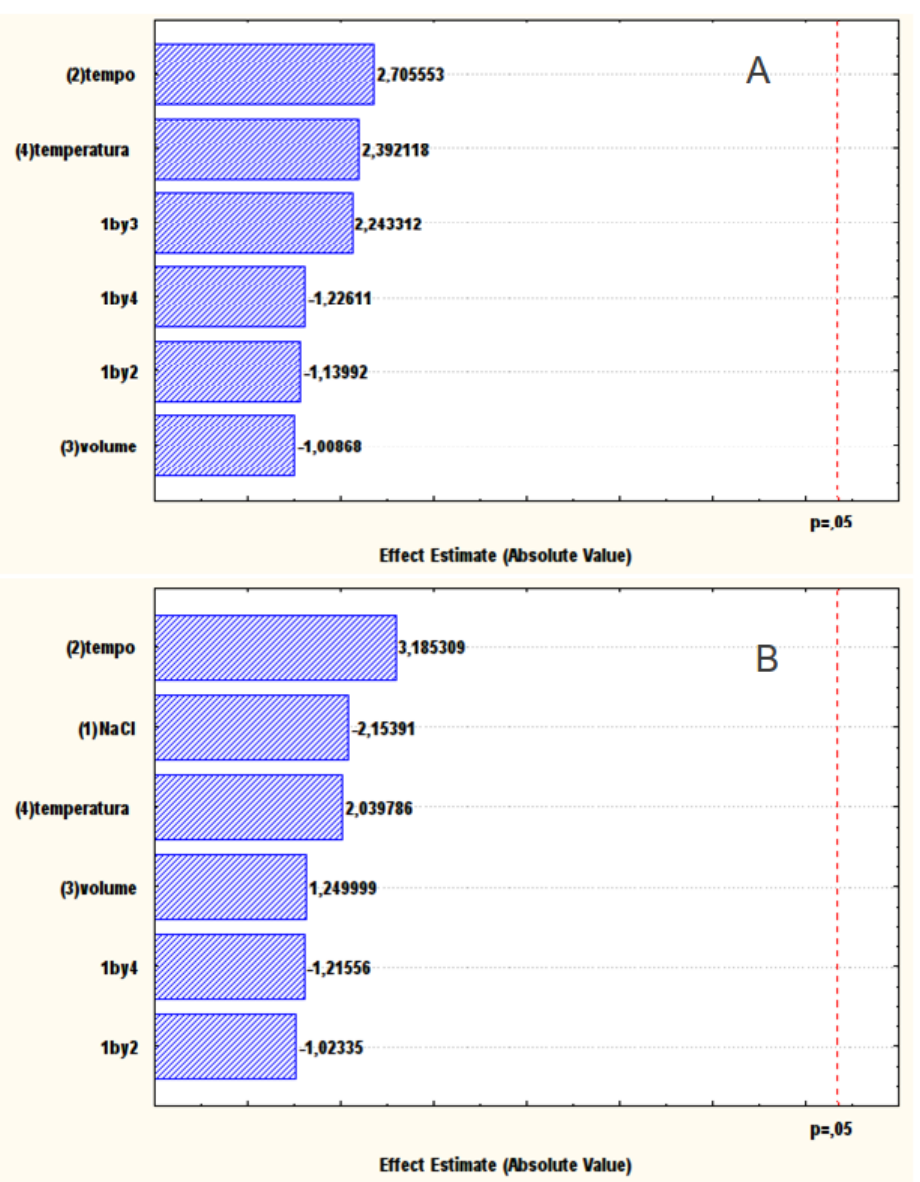

Essas diferenças de comportamento eram esperados. A temperatura, por exemplo, tem um comportamento duplo, com o aumento da temperatura ocorre um aumento na difusão dos analitos, o que melhora a eficiência de extração. Por outro lado, ocorre uma diminuição no coeficiente de partição, o que diminui a extração dos compostos. O volume de amostra é parâmetro fundamental, já que nela haverá distribuição dos analitos entre a fase extratora e amostra, e quanto maior o volume, maior será a massa extraída. O tempo está relacionado com cinética de extração, significando que é necessário um tempo mínimo deve ser proporcionado para atingir o equilíbrio dinâmico, e assim, extrair os compostos. Por último, a força iônica, foi avaliada pela adição de $\mathrm{NaCl}$ que apresentou efeito negativo significativo na extração de E2 (ver Figura 2.15), enquanto para os demais analitos nenhum tipo de efeito significativo ocorreu, determinando a não inclusão de sal na amostra.

\section{Matriz de Doehlert}

A matriz de Doehlert foi utilizada para avaliar os parâmetros que demonstraram importância significativa tanto na derivatização in situ como também na extração por SPME. A matriz de 
Doehlert foi escolhida por possuir uma distribuição uniforme dos pontos experimentais que permitiram avaliar as variáveis de forma precisa e com um número reduzido de experimentos. (48) Para a derivatização foram otimizados o $\mathrm{pH}$ e o Vderiv, enquanto para a SPME foram a temperatura, tempo de extração e volume de amostra.

A condição ótima para a derivatização in situ é em solução alcalina e com adição de grandes volumes de ECF, como pode ser observado na Figura 2.16

Figura 2.15: Diagrama de Pareto do E2 avaliando o comportamento da extração por SPME.

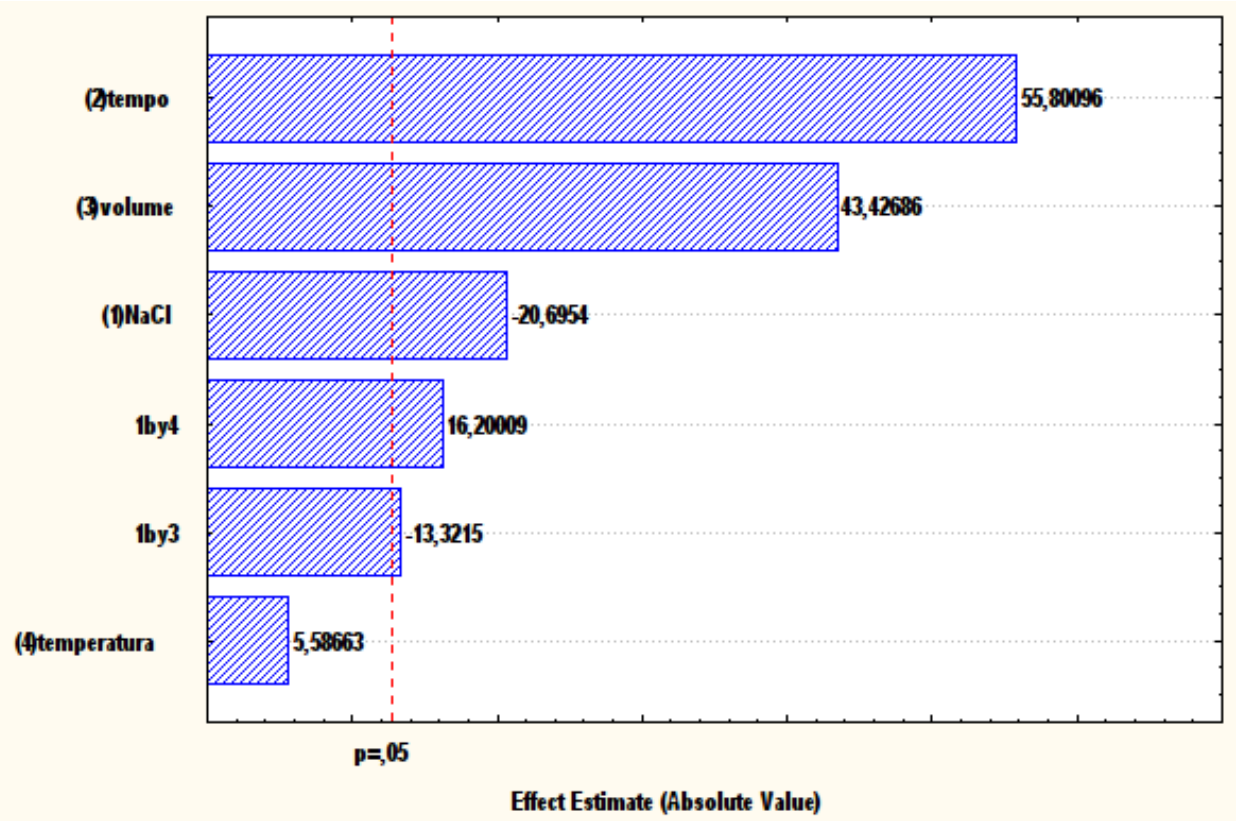

Essa figura mostra a tendência do aumento da resposta analítica com o aumento do pH e volume de ECF. Porém, ambos foram limitados para o valor máximo estudado a fim de evitar dano na fase extratora da fibra de SPME. O ECF é corrosivo, em grandes quantidades pode danificar a fibra, assim como soluções em $\mathrm{pH}$ muito alcalino. Dessa maneira, a condição otimizada foi $\mathrm{pH}=10$, adição de $0,16 \mathrm{~mL}$ de ECF, juntamente com $0,3 \mathrm{~mL}$ da solução de et:pyr (3:2) (estes dois últimos foram obtidos do estudo prévio com planejamento fatorial fracionário). O modelo apresentou correlação satisfatória de 0,97 , sem falta de ajuste dando segurança nos resultados obtidos.

Para a extração por SPME, a melhor condição obtida foi a temperatura de $75^{\circ} \mathrm{C}$, tempo de extração de 60 min e $11 \mathrm{~mL}$ de volume de amostra, como mostra a Figura 2.17.

No entanto, a temperatura foi restrita a $70{ }^{\circ} \mathrm{C}$ para evitar danos à fibra de SPME e a agulha do holder de SPME. De maneira semelhante ao anterior, modelo descrito apresentou correlação adequada sem falta de ajuste. Os pontos experimentais selecionados estão dentro da região ótima obtida pelo estudo de otimização. 
Figura 2.16: Superfície de resposta para pH e volume de derivatizante.

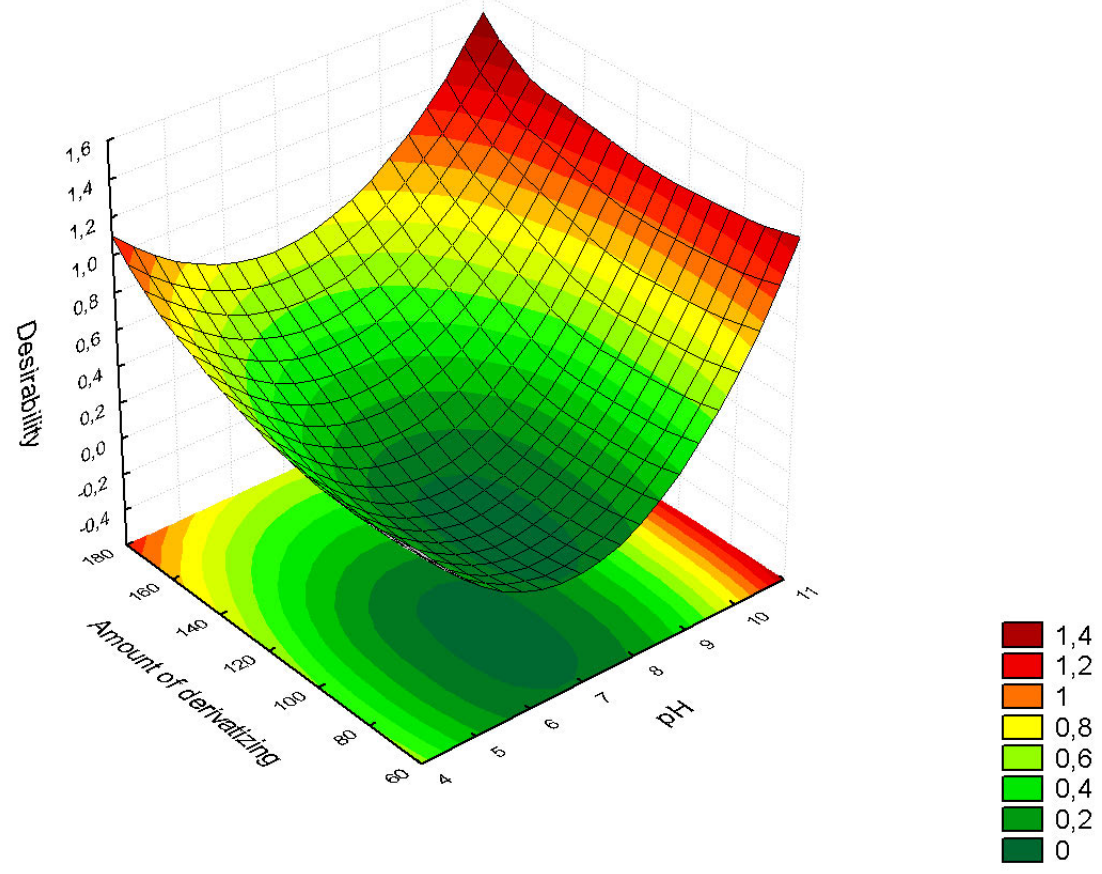

Figura 2.17: Superfície de resposta para temperatura, tempo e volume para extração por SPME.
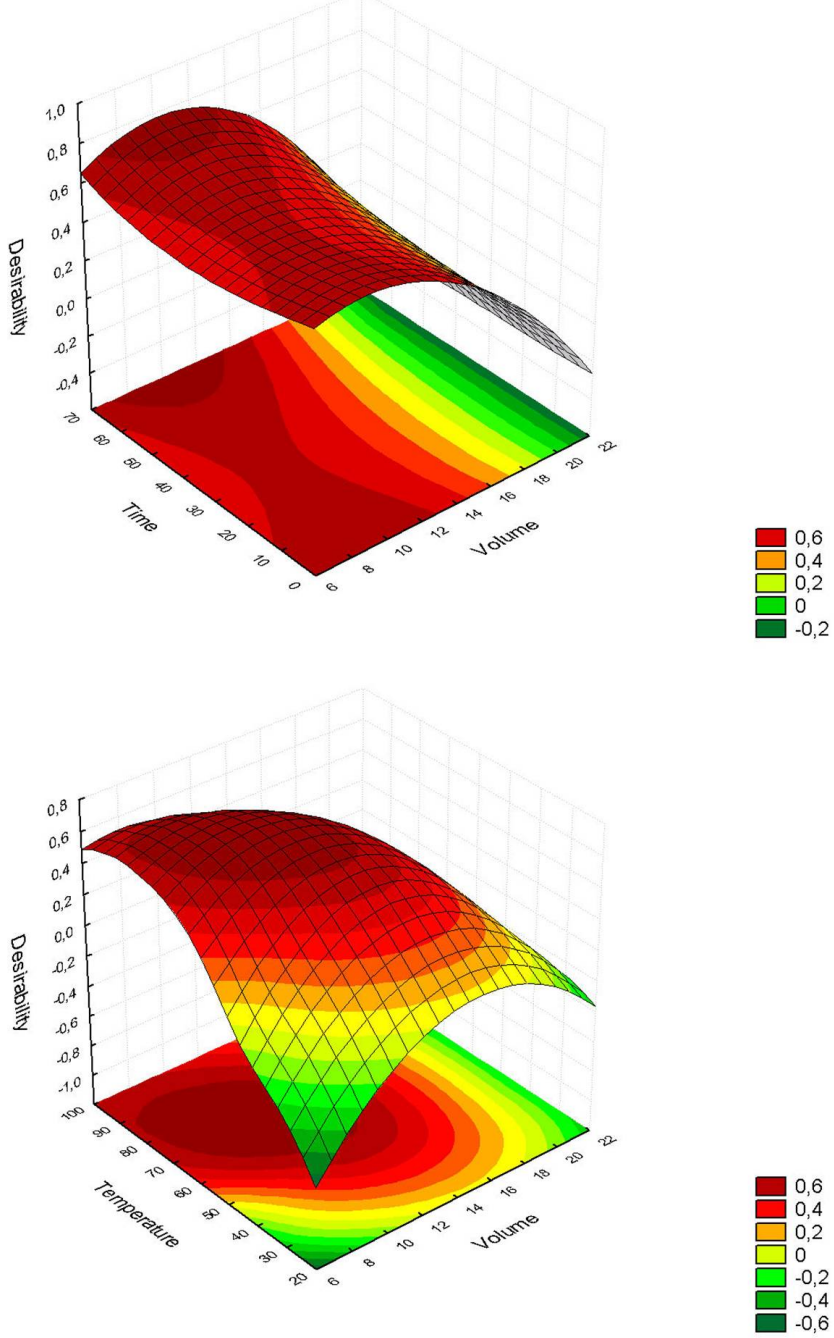


\subsection{Validação do método}

Os dados obtidos referentes ao LOD, LOQ, precisão intra e inter-dia estão demonstrados na Tabela 2.4.

Tabela 2.4: Dados da validação

\begin{tabular}{|c|c|c|c|c|c|c|c|}
\hline Fármacos & $\begin{array}{c}\text { Faixa } \\
\text { Linear } \\
\left(\mu \mathrm{g} \mathrm{L}^{-1}\right)\end{array}$ & $\begin{array}{c}\text { Dados da } \\
\text { regressão } \\
(\mathbf{b}, \mathbf{a}, \mathbf{r})\end{array}$ & $\begin{array}{c}\text { LOD } \\
\left(\mu \mathbf{g L}^{-1}\right)\end{array}$ & $\begin{array}{c}\mathbf{L O Q} \\
\left(\mu \mathbf{g L}^{-1}\right)\end{array}$ & Nível & $\begin{array}{c}\text { Precisão } \\
\text { intra-dia } \\
(\%)\end{array}$ & $\begin{array}{c}\text { Precisão } \\
\text { inter-dia } \\
(\%)\end{array}$ \\
\hline \multirow[t]{3}{*}{ IBU } & 0,5 a 10 & $7,1 \times 10^{-5}$ & 0,105 & 0,500 & baixo & 14 & 14 \\
\hline & & $6,6 \times 10^{-3}$ & & & médio & 4,3 & 4,3 \\
\hline & & 0,9932 & & & alto & 6,7 & 0,70 \\
\hline \multirow{3}{*}{ FEN } & 0,5 a 10 & $1,75 \times 10^{-4}$ & 0,154 & 0,500 & baixo & 1,4 & 1,4 \\
\hline & & $5,27 \times 10^{-2}$ & & & médio & 2,6 & 2,6 \\
\hline & & 0,9898 & & & alto & 3,1 & 4,0 \\
\hline \multirow[t]{3}{*}{ FLUR } & 0,5 a 10 & $1,03 \times 10^{-5}$ & 0,134 & 0,500 & baixo & 4,0 & 4,3 \\
\hline & & $1,34 \times 10^{-2}$ & & & médio & 6,7 & 6,7 \\
\hline & & 0,9834 & & & alto & 11 & 4,4 \\
\hline \multirow[t]{3}{*}{ NAP } & 0,5 a 10 & $1,17 \times 10^{-5}$ & 0,160 & 0,500 & baixo & 8,1 & 14 \\
\hline & & $5,22 \times 10^{-3}$ & & & médio & 4,4 & 4,4 \\
\hline & & 0,9928 & & & alto & 1,5 & 3,1 \\
\hline \multirow[t]{3}{*}{ KET } & 0,5 a 10 & $8,49 \times 10^{-6}$ & 0,157 & 0,500 & baixo & 14 & 14 \\
\hline & & $3,90 \times 10^{-3}$ & & & médio & 2,8 & 2,9 \\
\hline & & 0,9851 & & & alto & 11 & 11 \\
\hline \multirow[t]{3}{*}{ FLX } & 0,5 a 10 & $2,66 \times 10^{-4}$ & 0,163 & 0,500 & baixo & 2,7 & 2,70 \\
\hline & & $2,64 \times 10^{-1}$ & & & médio & 1,1 & 1,1 \\
\hline & & 0,9899 & & & alto & 2,2 & 2,2 \\
\hline \multirow[t]{3}{*}{ E1 } & 0,5 a 10 & $1,16 \times 10^{-4}$ & 0,160 & 0,500 & baixo & 15 & 15 \\
\hline & & $3,92 \times 10^{-2}$ & & & médio & 2,6 & 2,9 \\
\hline & & 0,9881 & & & alto & 8,5 & 8,5 \\
\hline \multirow{3}{*}{ E2 } & 0,5 a 10 & $8,04 \times 10^{-6}$ & 0,0952 & 0,500 & baixo & 9,3 & 9,3 \\
\hline & & $3,05 \times 10^{-3}$ & & & médio & 16 & 16 \\
\hline & & 0,9858 & & & alto & 5,6 & 5,6 \\
\hline \multirow[t]{3}{*}{ SIMV } & 0,5 a 10 & $5,70 \times 10^{-6}$ & 0,119 & 0,500 & baixo & 10 & 10 \\
\hline & & $1,43 \times 10^{-3}$ & & & médio & 7,5 & 13 \\
\hline & & 0,9973 & & & alto & 8,4 & 10 \\
\hline
\end{tabular}

$a=$ intercepto, $b=$ inclinação da reta e $r=$ coeficiente de correlação

baixo $=0,5 \mu \mathrm{g} \mathrm{L}-1$, médio $=3,0 \mu \mathrm{g} \mathrm{L}-1$ e alto $=10 \mu \mathrm{g} \mathrm{L}^{-1}$

A concentração de $0,5 \mu \mathrm{g} \mathrm{L}^{-1}$ foi o menor nível que permitiu observar claramente todos os íons monitorados, sendo estabelecido como LOQ para evitar o risco de falso positivo.

O método proposto apresentou LOQ e LOD menores que alguns métodos publicados recentemente $(38,66-69)$ e valores muito semelhantes ao método de Suchara et.al. (70). Apesar deste último trabalho ter sido feito em sistema de GC-MS com analisador tipo ion trap que apresenta melhor detectabilidade, por permitir acumular os íons e, dessa maneira, possuir melhor 
sensibilidade comparados com analisadores do tipo quadrupolo usado nesse estudo. Contudo, a derivatização não somente melhorou o perfil cromatográfico como também aumento a detectabilidade dos analitos em estudo. (71)

O método validado apresentou linearidade adequada ( $r>0,98)$, já que a ANOVA demonstrou falta de ajuste não-significativa para os modelos lineares obtidos. Além disso, a precisão intra e inter-dia foram inferiores a 16\%. A recuperação absoluta não foi estimada, uma vez que é necessário possuir os padrões dos analitos na forma derivatizada que não estão disponíveis comercialmente.

O efeito de matriz foi estimado ao se fazer curva de calibração em três diferentes matrizes (água de torneira, águas residuárias e esgoto industrial). Como esperado, a associação entre SPME e derivatização in situ sofreu efeito de matriz. A inclinação das curvas de calibração foram cerca de $30 \%$ de supressão para águas residuárias em relação água de torneira; e $1 \%$ com relação ao esgoto industrial. Esse fato está associado a presença de grande quantidade de matéria orgânica dissolvida e sólidos suspensos nessas amostras, como mostra a Figura 2.18.

Dessa forma, ao realizar SPME com a derivatização in situ, parte do agente derivatizante reagia com os componentes da matriz o que diminui a formação dos analitos derivatizados e, assim, o sinal de cada composto diminuiu em relação ao feito em água de torneira. Outra possibilidade a ser considerada, em amostras ricas em matéria orgânica é comum que os analitos de baixa polaridade tenham tendência a permanecer ligados a mesma. Dessa forma, os analitos ligados a matéria orgânica não serão extraídos diminuindo o seu sinal analítico. No entanto, o efeito de matriz foi contornado, ao realizar padronização por adição de padrão, juntamente com uso de padrão interno deuterado, possibilitando separar, quantificar e identificar fármacos presentes em amostras aquosas ambientais.

Figura 2.18: Filtro contendo partículas presentes na amostras (a) e frasco com amostra da entrada da ETE (b).

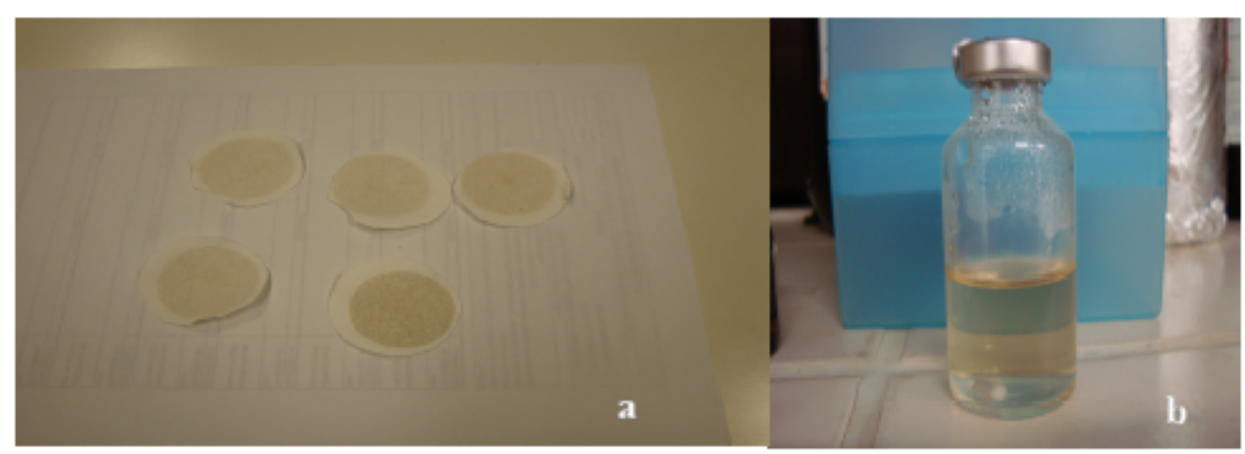




\subsection{Amostras ambientais}

O método foi aplicado em amostra de águas residuárias de entrada e saída de ETE do estado de São Paulo, esgoto industrial não-tratado, e amostras de água de rio que recebiam o esgoto industrial não-tratado (amostras coletadas antes e após o despejo do esgoto). As amostras foram analisadas no dia seguinte a coleta para evitar a proliferação de microorganismos, além da degradação dos possíveis fármacos presentes.

Para análise das amostras foram utilizadas fibras novas; cada fibra foi usada em apenas um tipo de amostra para evitar contaminação cruzada. As fibras duraram cerca de 20 a 25 injeções após esse uso, perderam sua eficiência na extração e apresentaram alterações macroscópicas na superfície polimérica indicando deterioração da mesma, conforme mostrado na Figura 2.19.

Nas amostras de esgoto industrial e de água de rio nenhum dos fármacos foram encontrados em nível superior ao LOQ. Apesar disso, na água residuária de entrada da ETE foram detectados IBU, FEN, FLUR, KET e FLX conforme mostra a Figura 2.20. Contudo, apenas KET estava presente em concentração acima do LOQ, cerca de $1050 \mathrm{ng} \mathrm{L}^{-1}$. Essa concentração está em concordância com estudos publicados previamente $(44,68,72,73)$, tendo uma variação de 300 a $1200 \mathrm{ng} \mathrm{L}^{-1}$ para o KET em amostra tratadas e não-tratadas de águas residuárias. O KET é um medicamento largamente utilizado como anti-inflamatório, antipirético e analgésico. São vendidos sem exigência de prescrição médica, sendo muito usado no tratamento da artrite reumatóide, com uma dose diária variando de 150 a $750 \mathrm{mg}$ por dia, o que pode explicar a presença desse fármaco na água residuária de entrada de ETE.

Figura 2.19: Foto da fibra de SPME com fase de PDMS/DVB nova (a) e após ter sido usado por 25 vezes em amostras ambientais (b).
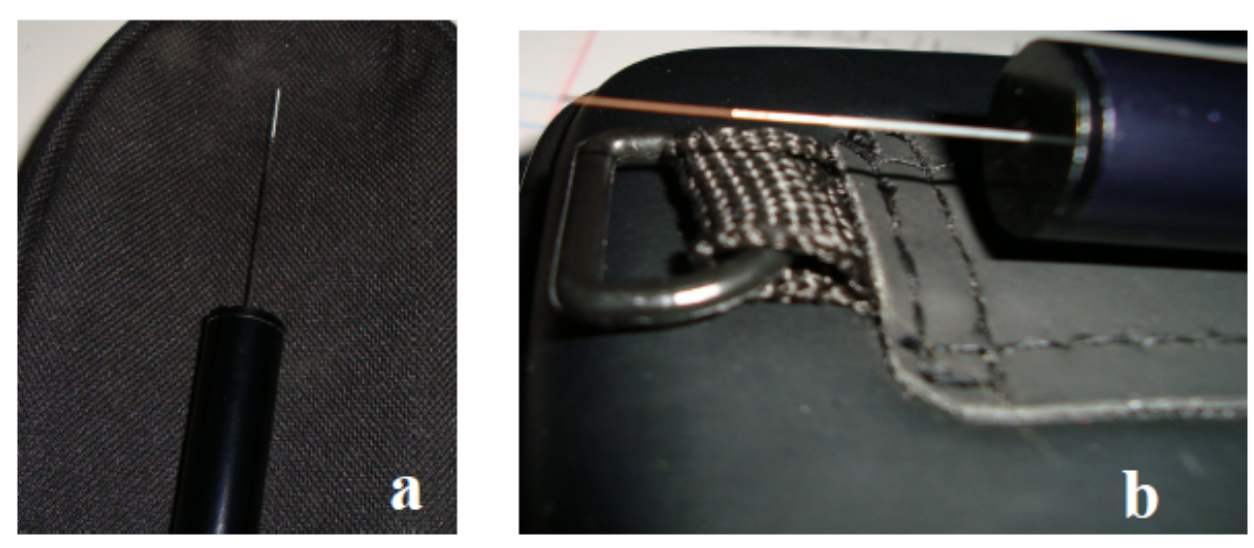
Figura 2.20: Cromatograma no modo SIM da entrada de ETE contendo IBU (1), FLUR (2), NAP (3), KET (4) e FLX (5), (1a) íon monitorado no modo SIM com relação massa/carga (m/z) 161 (IBU), e (4a) 209 (KET), respectivamente.
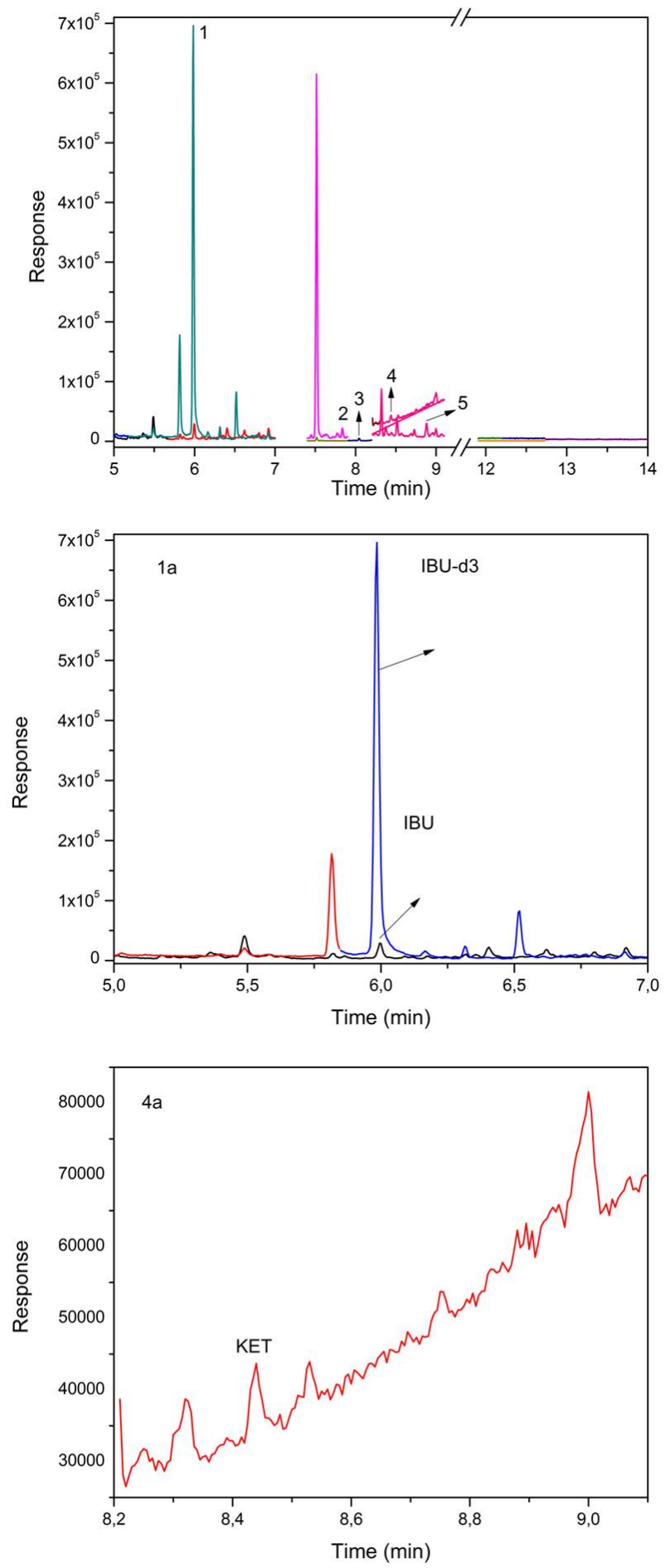


\subsection{Conclusões}

O método otimizado e validado permitiu a análise simultânea de nove fármacos emergentes de diferentes classes em matrizes aquosas. A SPME em conjunto com a derivatização in situ reduziu o número de etapas, gasto de reagente e tempo quando comparado com as reações de derivatização tradicionais.

Um número pequeno de experimento aliado com um uso racional de reagentes, e uma rápida otimização do método, foi conseguido ao aplicar o planejamento experimental.

O método apresentou linearidade, LOQ, precisão intra e inter-dia adequados, o que permitiu a aplicação em análise de águas residuárias, amostra de água de rio e esgoto industrial. Melhorias na detectabilidade poderiam ser feitas ao se utilizar sistemas mais modernos de MS, e/ou ao utilizar no preparo de amostra técnicas com maior capacidade extrativa, como a SBSE e outros. 


\section{CAPÍTULO 3}

\section{ANÁLISE DE RESÍDUOS DE FÁRMACOS EM ÁGUA DE RIO USANDO} MICROEXTRAÇÃO EM FASE SÓLIDA E
CROMATOGRAFIA BIDIMENSIONAL ABRANGENTE ACOPLADA À ESPECTROMETRIA DE MASSAS (SPME-GCXGC-TOF/MS)

\subsection{Introdução}

A presença de desreguladores endócrinos (EDC), como hormônios, em matrizes aquosas é preocupante em virtude da capacidade de causar distúrbios não somente em humanos como também na fauna e flora aquática. Efeitos como a feminilização de peixes já está documentada, mesmo que esses compostos estejam presentes em baixas concentrações. Além disso, em locais contaminados como na Baía de Newark, NJ, foi percebido uma alteração nos níveis da proteína vitelogenina (presente apenas em fêmeas dos peixes), o que causou distúrbios na reprodução desses animais. Esse fato é de extrema importância do ponto vista ecotoxicológico e também comercial. (74) Devido a esse e outros efeitos ainda desconhecidos é necessário monitorar a 
presença desses EDC.

Conforme demonstrado no Capítulo 2, métodos cromatográficos em conjunto com a espectrometria de massas (MS) são fundamentais para as etapas de monitoramento de micropoluentes no ambiente. Dentre essas técnicas, a cromatografia multidimensional tem destaque por utilizar duas ou mais colunas com fases diferentes, com a separação cromatográfica ocorrendo por mecanismos independentes, sendo esse processo de separação foi denominado de ortogonalidade. Essa técnica foi criada para sobrepor limitações da técnica com apenas uma coluna, chamada de primeira dimensão (1D) ou unidimensional. Em análise de amostra complexas a probabilidade de separação total dos analitos de interesse dos componentes da matriz pode variar 19 a $37 \%$ dependendo da matriz. $(75,76)$

As frações vindas da 1D podem ser totalmente introduzidas na segunda dimensão (2D), ou apenas parte dela. Quanto todos compostos da 1D são transferidos para a 2D, passa a ser denominada cromatografia multidimensional abrangente (multidimensional comprehensive chromatography representada pelo símbolo "X"). Do contrário, quando apenas pequenas frações da 1D é introduzida, chama-se de cromatografia multidimensional (símbolo "-"). Em ambos os modos podem ser feitas em fase líquida (LCxLC ou LC-LC) ou gasosa (GCxGC ou GC-GC).

Um sistema de GCxGC é apresenta a estrutura mostrada na Figura 3.1. Esse sistema apresenta como configuração convencional uma coluna na 1D não-polar com dimensões de 15 a 30 $\mathrm{m}$, e na 2D uma coluna polar ou de média polaridade, de dimensões curtas variando de 1,5 a 2 $\mathrm{m}$ de tamanho, muitas vezes com o diâmetro interno dessa coluna inferior ao da primeira. $\mathrm{Na}$ coluna de 1D normalmente os analitos são separados de acordo com sua polaridade, e na 2D serão separados de acordo com afinidade pela fase estacionária com interações tipo $\pi$ - $\pi$, efeitos estéricos e ligações de hidrogênio. (77) As colunas podem estar contidas no mesmo forno de aquecimento, ou serem colocadas em diferentes fornos a fim de garantir que a programação de temperatura precisa.

As colunas são ligadas por um pressfit, um tubo capilar de vidro contendo pequenas abas, que ao inserir o final da coluna $1 \mathrm{D}$ e o início da 2D, ficam seladas evitando vazamentos e perda dos analitos vindos da 1D. Em seguida, a coluna da 2D é inserida em um modulador. Esse dispostivo promove a amostragem dos analitos separados na $1 \mathrm{D}$ para a separação na 2D.

O modulador representado na Figura 3.1, é um modulador do tipo crigênico, apresenta 2 jatos de nitrogênio líquido e 2 jatos de nitrogênio. Então, é feito ciclo de congelamento e descongelamento para focalização e liberação da banda cromatográfica para separação na 2D. Esses ciclos fazem o fracionamento do banda cromatográfica, e mesmo havendo picos coeluídos, será possível com a seletividade da 2D, separar esses compostos. (77)

Em virtude da dimensão da segunda coluna ser inferior, em muitos casos, é utilizado coluna com diâmetro interno reduzido (inferior ao da 1D), a velocidade linear média é alta. Dessa 
maneira, os analitos são rapidamente separados, sendo necessário um sistema de aquisição de dados rápido e eficiente. Além disso, para corroborar com a necessidade de uma rápida aquisição dos dados, os picos cromatográficos são estreitos devido ao aprisionamento e focalização realizado no modulador.

Figura 3.1: Ilustração de um sistema de cromatografia gasosa multidimensional abrangente

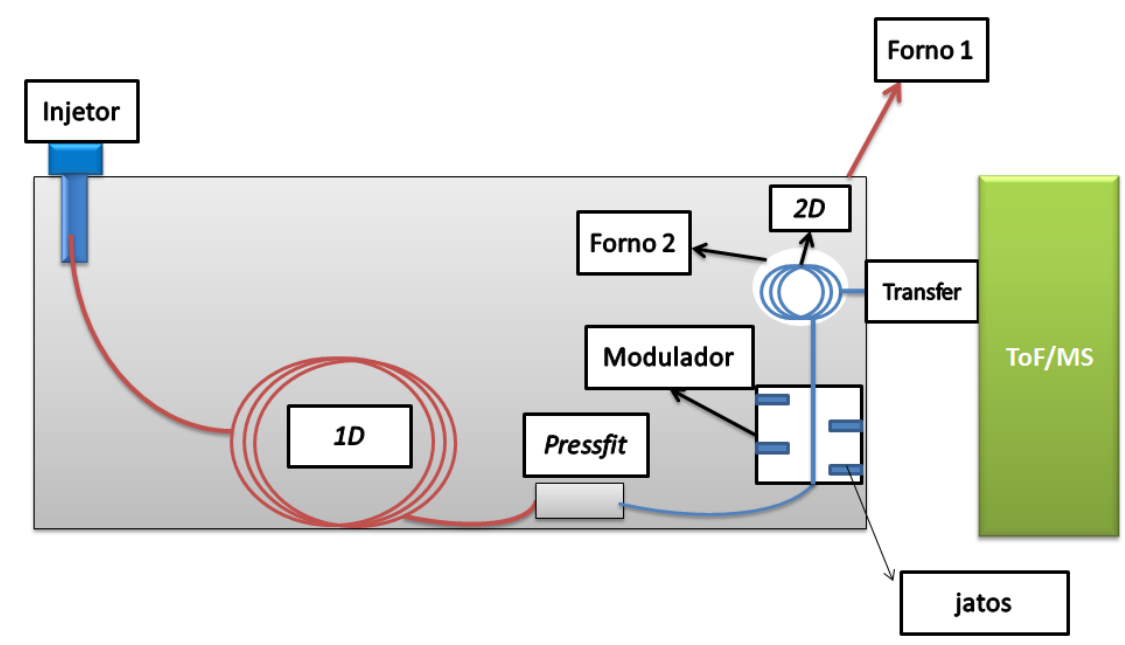

\section{Ortogonalidade e capacidade de pico}

Ortogonalidade refere-se ao uso de mecanismos de separação totalmente diferentes na primeira e na segunda coluna. Normalmente, o arranjo usual é coluna não-polar na $1 \mathrm{D}$ e na 2D uma coluna com pequenas dimensões polar. No entanto, pode ser utilizado uma coluna polar na $1 \mathrm{D}$ e coluna não-polar na 2D, dependente exclusivamente do tipo de analitos que serão analisados. $\mathrm{O}$ fato de se utilizar colunas com fases estacionárias diferentes não garante a ortogonalidade do sistema, o conjunto das colunas e a interação dos analitos nessas colunas irão gerar a ortogonalidade. (9) É necessário destacar que a coluna da 2D normalmente possui dimensões reduzidas para não aumentar excessivamente o tempo da análise, dessa forma, sua resolução e eficiência são sacrificados devido a um velocidade linear ser extremamente alta. Apesar disso, sua seletividade é mantida, o que permite separar melhor compostos vindos da 1D.

A Figura 3.2 mostra como a ortogonalidade do sistema afeta na capacidade de separar picos (peak capacity).

O conceito de capacidade de pico $\left(n_{z}\right.$ ou $\left.n_{y}\right)$, refere-se ao número máximo de compostos que um sistema cromatográfico consegue separar de uma mistura complexa. É natural ocorrer sobreposição de picos pela sua distribuição aleatória dentro sistema cromatográfico (overlapping), como visto na Figura 3.3.

No entanto, ao utilizar duas colunas com mecanismos distintos, teremos a capacidade de picos da $1 \mathrm{D}$ no eixo Z, dado $n_{z}$ e para $2 \mathrm{D}$ temos $n_{y}$, conforme Figura 3.2. Ao fazer $n_{z} \times n_{y}$, tendo 
Figura 3.2: Capacidade de pico em sistema ortogonal, retirado de (8).

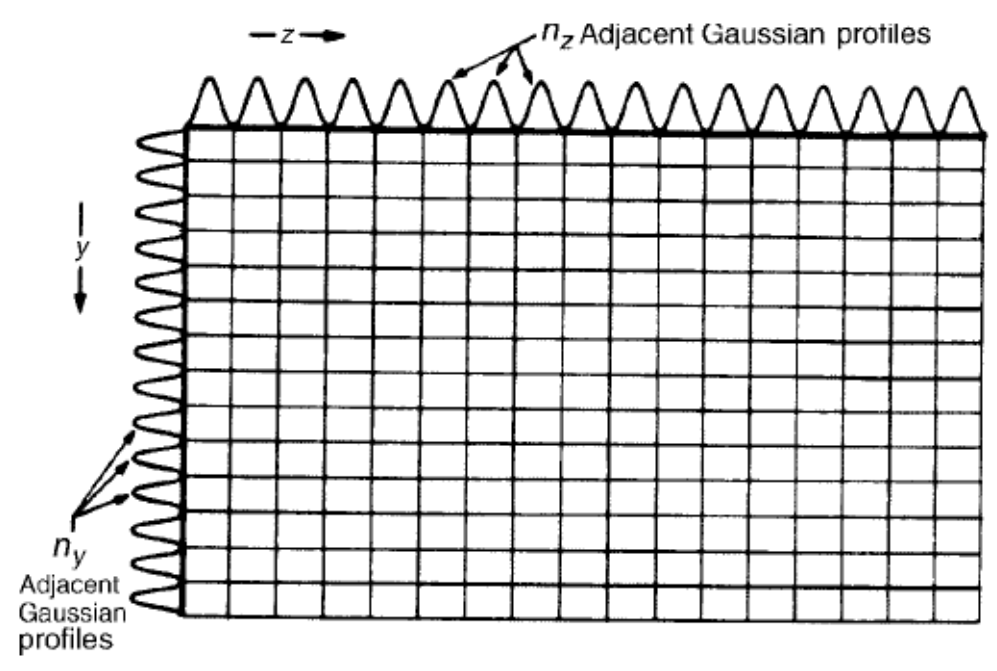

Figura 3.3: Sobreposição de pico em sistema 1D, retirado de (9).

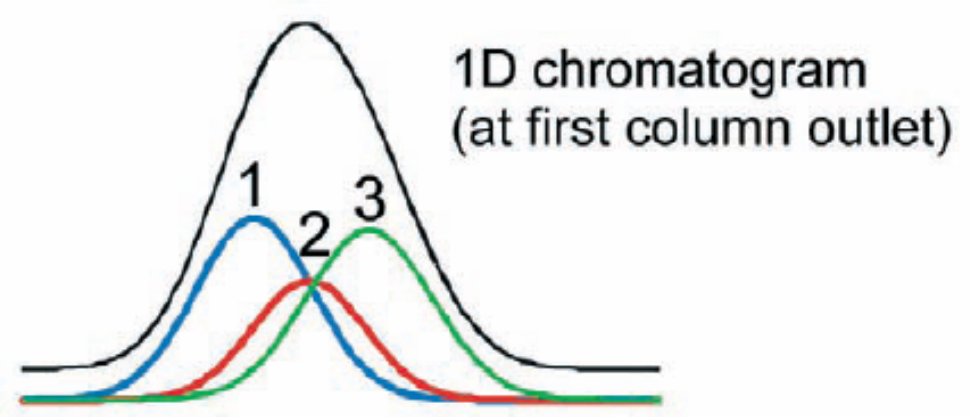

uma coluna na $1 \mathrm{D} n_{z}$ de 200 e na $2 \mathrm{D} n_{y}$ de 50 , valores facilmente atingidos por essas colunas utilizadas nesse sistema, teremos uma capacidade $10^{4}$. Para atingir essa mesma capacidade em sistema com apenas 1D, em uma coluna com fase de $0,25 \mu \mathrm{m}$, seria necessário uma coluna com $80 \mathrm{Km}$ de comprimento. (8) Atingindo essa capacidade de pico, em sistema 2D, é possível separar completamente 98 analitos de uma mistura contendo 100 compostos, ou por exemplo é possível separar 200 bifenilas policloradas de um total de 209 espécies existentes.

\section{Modulador}

A transferência dos analitos da 1D para 2D é essencial para manter a capacidade do sistema em separar o máximo de compostos presentes na mistura. Dessa forma, a utilização de moduladores é fundamental para servir de interface entre as colunas da 1D para 2D, sendo considerado o coração do sistema 2D. O modulador tem como função acumular as pequenas frações de analitos vindas da 1D, focalizar essas frações e enviá-las para a 2D em pulsos estreitos. Existem diferentes tipos de moduladores em GCxGC, os que utilizam apenas sistemas com válvulas e fluídos criogênicos. Os moduladores baseados em válvulas ainda estão sendo 
estudados, principalmente por tornar possível a miniaturização do sistema de GCxGC. (78) Os sistemas criogênicos são os mais utilizados tendo destaque para o longitudinalmente modulado (LMCS). (79) Esse sistema conta com 2 ou 4 jatos. No sistema de 4 jatos, 2 jatos são aquecidos e 2 jatos criogênicos. Primeiro os analitos vindos da 1D, são focalizados, após aquecidos, sofrendo mais uma nova focalização, e por último aquecidos e enviados para a segunda coluna. Esses 2 ciclos de aquecimento e criogenia são feitos para garantir o envio de uma banda estreita de analitos para a $2 \mathrm{D}$.

\section{Detectores}

Como a separação na coluna da 2D é extremamente rápida, os picos nessa coluna são muito estreitos, com largura de 100 a 600 ms. Pelo fato dos picos serem estreitos é necessário que o detector tenha um pequeno volume interno, uma rápida taxa de aumento do sinal e alta aquisição de dados para permitir a construção dos cromatogramas da 2D.

Detectores do tipo ionização de chama (FID) com volume interno praticamente nulo e taxas de aquisição de 50 a $200 \mathrm{~Hz}$ vem sendo utilizados. Além desse, o $\mu$-captura de elétrons $(\mu$ ECD) com volume interno de 30 a $150 \mu \mathrm{L}$ e aquisição de dados na frequência de $50 \mathrm{~Hz}$ também tem sido utilizado.

Desses detectores descritos acima, nenhum deles fornece a informação estrutural. Então o uso de detectores de massas (MS) é essencial. Dentre os detectores de MS, o analisador do tipo tempo de voo (ToF) permite aquisições rápidas da ordem 50 a 500 espectros de massas por segundo $(50$ a $500 \mathrm{~Hz}$ ). Além disso, devido a sua rapidez na aquisição dos espectros, permite a deconvulação dos picos cromatográficos. Esta ferramenta aliado com recursos de software é extremamente útil para fins de quantificação e identificação. Atualmente, analisadores tipo quadrupolo estão sendo melhorados e apresentando taxas de aquisição de $50 \mathrm{~Hz}$. (9)

Dessa maneira, unindo as vantagens de separação da GCxGC, juntamente com a capacidade de identificação, quantificação e detecção dos detectores de MS, em particular do analisador ToF. Esse estudo tem como objetivo a análise de treze fármacos (11 hormônios, 1 conservante e 1 estimulante) presentes em amostras aquosas, utilizando a análise GCxGC-ToF/MS. Os hormônios foram selecionados de acordo com o guia do EPA (80), o metilparabeno é um conservante presente em diversos produtos comésticos (81) e a cafeína é considerado um marcador antropogênico. (1)

A SPME foi usada na etapa de preparo de amostra, porém sem utilizar a derivatização nessa etapa. As variáveis da SPME foram otimizadas usando planejamento fatorial, de forma semelhante ao capítulo anterior. Um estudo preliminar usando um planejamento fracionário foi feito para estudar as principais variáveis do preparo de amostra, seguido da otimização usando a matriz de Doehlert. 


\subsection{Experimental}

\subsubsection{Reagentes}

Água ultrapura foi obtida no equipamento Milli Q Plus Ultra (Billerica, Estados Unidos), o fosfato de sódio dibásico foi adquirido da Merck (Darmstadt, Alemanha). O fosfato de potássio monobásico foi comprado da VWR (West Chester, Estados Unidos). Os padrões analíticos dos fármacos como estrona (E1), $\beta$-estradiol (E2), $17 \alpha$-etinilestradiol (EE), mestranol (MEE), metandrostanolona (MA), 4-androstenodiona (ADD), mesterolona (MST), metandriol (MTH), mestanolona (MSL), metilparabeno (MP), cafeína (CAF), Etiocolan-3 - $\alpha$-ol-17-ona (EC), 5 androsteno-4-ol-3 $\beta, 17 \beta$-diona-3-acetato (5-ADD) e testosterona deuterada (t-d3), usado como padrão interno (IS) por apresentar estrutura semelhante à maioria dos analitos, foram adquiridos da Sigma-Aldrich (St.Loius, Estados Unidos). As soluções estoque de $1000 \mathrm{mg} \mathrm{L}^{-1}$ foram preparadas em etanol (Pharmco-AAPER, Shelbyville, Estados Unidos) e mantidos em frascos âmbar a $-8{ }^{\circ} \mathrm{C}$. A solução do IS e intermediária dos fármacos foram preparadas na concentração de $50 \mathrm{mg} \mathrm{L}^{-1}$, sendo mantidas nas mesmas condições acima. As soluções intermediárias ou de uso eram utilizadas por 2 semanas, sendo feitas novamente após esse período de uso.

\subsubsection{Preparo de amostra}

Fibras de PDMS e PDMS/DVB foram adquiridas da Supelco (Bellefonte, Estados Unidos), sendo condicionadas conforme consta no manual do usuário. Todas as extrações foram feitas no modo direto, usando o amostrador automático MPS-2 Twister da Gerstel (Columbia, Estados Unidos). Primeiramente, foram pesados 4,3 g de cloreto de sódio, adicionando a frascos de headspace de $20 \mathrm{~mL}$, seguido da adição d $17 \mathrm{~mL}$ de amostra de água e $1 \mathrm{~mL}$ de tampão fosfato $0,5 \mathrm{~mol} \mathrm{~L}^{-1} \mathrm{com} \mathrm{pH}=8,0$. Então, a amostra de água é fortificada com a solução na concentração apropriada para a análise, e o IS foi adicionado na amostra na concentração de $30 \mu \mathrm{g} \mathrm{L}^{-1}$. Como etapa seguinte, o frasco foi pré-incubado durante 10 minutos, seguido de extração por 60 minutos. A dessorção foi feita no injetor do $\mathrm{GC}$ a $250{ }^{\circ} \mathrm{C}$, no modo splitless, com abertura da válvula de split após 3 minutos. A cada extração as fibras foram incubadas por 10 minutos no injetor do GC no modo split para evitar efeito de memória (carryover).

Amostras de rio $(n=4)$ foram coletadas na cidade de South Orange, NJ durante as duas últimas semanas de setembro de 2011. As amostras foram coletadas em frascos âmbar, filtradas em filtro de papel comum para retirada de macrocomponentes. Depois, foram transferidas para frascos âmbar, seladas e mantidas a $4{ }^{\circ} \mathrm{C}$ até sua análise. Esta foi realizada no dia seguinte a sua coleta. 


\subsubsection{Planejamento fatorial}

Os métodos foram avaliados estatisticamente usando o software Statistica 6.0 e 7.0. As variáveis da extração por SPME foram estudados usando ANOVA, sendo escolhidos os modelos que melhor se adequavam para análise.

Um planejamento fatorial fracionário $2^{4-1}$ avaliou a principais variáveis da extração por SPME (temperatura, tempo de extração, força iônica e pH), descrito na Tabela 3.1.

Tabela 3.1: Planejamento fatorial fracionário para avaliar as principais variáveis da extração por SPME.

\begin{tabular}{|c|c|c|c|c|}
\hline Experimentos & $\mathrm{pH}$ & Temperatura $\left({ }^{\circ} \mathrm{C}\right)$ & Tempo de extração (min) & Força iônica $(\mathrm{g})$ \\
\hline 1 & 8 & 40 & 60 & 0,9 \\
2 & 8 & 40 & 15 & 0,9 \\
3 & 3 & 40 & 60 & 5,4 \\
4 & 3 & 40 & 15 & 5,4 \\
5 & 8 & 80 & 60 & 5,4 \\
6 & 8 & 80 & 15 & 5,4 \\
7 & 3 & 80 & 60 & 0,9 \\
8 & 3 & 80 & 15 & 0,9 \\
9 & 6 & 60 & 37,5 & 3,15 \\
10 & 6 & 60 & 37,5 & 3,15 \\
11 & 6 & 60 & 37,5 & 3,15 \\
\hline
\end{tabular}

O tempo de extração e a força iônica demonstraram efeito significativo, sendo otimizada usando a matriz de Doehlert de acordo com a Tabela 3.2. O erro puro foi estimado pelo ponto central feito em triplicata em ambos os planejamentos.

Tabela 3.2: Matriz de Doehlert aplicado para otimizar a extração por SPME.

\begin{tabular}{|c|c|c|}
\hline Experimentos & Tempo de extração (min) & Força iônica (g) \\
\hline 1 & 37,3 & 2,8 \\
2 & 37,3 & 2,8 \\
3 & 37,3 & 2,8 \\
4 & 60 & 2,8 \\
5 & 45 & 5,0 \\
6 & 15 & 2,8 \\
7 & 25 & 0,6 \\
8 & 45 & 0,6 \\
9 & 25 & 5,0 \\
\hline
\end{tabular}




\subsubsection{Condições de análise}

\section{GCxGC-ToF/MS}

As análises foram feitas em um GCxGC-ToF/MS modelo Pegasus 4D da Leco (St. Joseph, Estados Unidos) equipado com um cromatógrafo a gás (GC) 6890 da Agilent (Wilmington, Estados Unidos). O processamento dos dados foi realizado no software ChromaToF. A coluna na primeira dimensão (1D) selecionada para análise foi uma RTX-5MS (Bellefonte, Estados Unidos) com dimensões de $15 \mathrm{~m} \mathrm{x} \mathrm{0,25} \mathrm{mm}$ x 0,25 $\mu \mathrm{m}$, tendo como segunda dimensão coluna RTX-200 com dimensões de 1,5 m x 0,25 mm x 0,25 $\mu \mathrm{m}$, usando hélio como gás de arraste. As análises foram feitas com fluxo constante de $1,0 \mathrm{~mL} \mathrm{~min}^{-1}$. A programação da temperatura na $1 \mathrm{D}$ iniciou com $40{ }^{\circ} \mathrm{C}$ permanecendo por 1 minuto, subindo com uma taxa de $20{ }^{\circ} \mathrm{C} \mathrm{min}-1$ até atingir $300^{\circ} \mathrm{C}$ (durante 5 minutos), tendo um tempo total de análise de 19 minutos. Para a segunda dimensão, iniciou a $45^{\circ} \mathrm{C}$ subindo até $305{ }^{\circ} \mathrm{C}$ na mesma taxa de aquecimento da $1 \mathrm{D}$. $\mathrm{O}$ modulador, a fonte de íons, o injetor e a linha de transferência do MS estavam aquecidos a 80, 230,250 e $260{ }^{\circ} \mathrm{C}$. O modulador iniciou com a temperatura de $80^{\circ} \mathrm{C}$, tendo como temperatura final $305^{\circ} \mathrm{C}$, tendo uma taxa de aquecimento de $20{ }^{\circ} \mathrm{C} \mathrm{min}-1$ a cada corrida. Os pulsos de jatos de $\mathrm{N}_{2}$ aquecido e criogênico tiveram períodos de 0,90 e 1,60 s, sendo o tempo de corrida na segunda dimensão de $5 \mathrm{~s}$, mesmo tempo de modulação. A faixa de varredura variou de 40 a 450 u, com uma taxa de Scan de 50 espectros por segundo, com voltagem do detector em $1,5 \mathrm{kV}$.

\section{GC-MS}

Análise de GC-MS foi feita em um GC 6890A acoplado com detector de massas 5973 da Agilent (Palo Alto, Estados Unidos) equipado com amostrador automático CTC CombiPal (Zwingen, Suiça) As análises foram feitas no modo pressão constante $(0,7 \mathrm{Kpsi}$ na cabeça da coluna), com fluxo inicial de $1,0 \mathrm{~mL} \mathrm{~min}^{-1}$. A coluna usada foi uma HP-5MS de $15 \mathrm{~m}$ x 0,25 mm x 0,25 $\mu \mathrm{m}$ (Wilmington, Estados Unidos), tendo como gás de arraste hélio. A programação de temperatura e as condições de injeção são as mesmas descritas para GCxGC-ToF/MS. A temperatura da linha de transferência e da fonte de íons de 305 e $250{ }^{\circ} \mathrm{C}$, demonstraram ser adequadas para a separação dos analitos. Análise foi feita no modo varredura (Scan) varrendo massas de 60 a 390 u, com velocidade de Scan de 4,27 Scan/s. Foi utilizado o modo íon selecionado (SIM), para avaliar a seletividade da separação.

\subsubsection{Validação do método}

O método foi validado baseado em guias de validação internacionalmente aceitos. $(52,54)$ A linearidade foi avaliada em cinco níveis de concentração ao fortificar água de torneira na concentração desejada, e extrair por SPME, sendo testado cada nível em triplicata. Os gráficos 
das curvas de calibração foram obtidos por calibração externa e padronização interna, ao fazer a razão da área do analito em relação a área do IS (testosterona-d3). A curva de calibração de cada analito foi avaliada usando ANOVA para avaliar a significância da falta de ajuste de cada analito, e assim assegurando que o modelo obtido apresentava linearidade adequada.

A precisão inter-dia foi avaliada somente no nível médio, enquanto que precisão intra-dia foi determinadas em três níveis de concentração (baixo, médio e alto).

O limite de detecção foi estimado segundo a fórmula:

$$
L O D=3,3 \frac{s}{S}
$$

Sendo $s$ é a resposta (desvio padrão) de uma amostra com relação sinal:ruído ( $\mathrm{S} / \mathrm{N})$ de 3 , e $S$ é a inclinação da curva de calibração. O limite de quantificação (LOQ) foi adotado como a menor concentração que permitisse quantificar com precisão, exatidão (RSD $\leq 20 \%$ ) e com relação $\mathrm{S} / \mathrm{N}$ de 10.

A recuperação foi avaliada comparando as extrações feitas em água de rio em relação aos mesmos níveis de concentração em água de torneira. A recuperação foi estimada pelos valores da área do pico do MP e CAF por serem os analitos com menor sinal analítico. As amostras de água de rio foram quantificadas usando o método de adição de padrão, para cada amostra coletada foi usada fibras novas para evitar contaminação cruzada.

\subsection{Resultados e Discussão}

As fibras de PDMS e de PDMS/DVB foram testadas, sendo PDMS adequada para extração da maioria dos compostos não-polares como os hormônios, porém não apresenta afinidade apropriada para extrair MP e CAF. A fibra de PDMS/DVB por ser uma fibra mista, contendo DVB que acrescenta à fibra a capacidade de extrair compostos polares, permitiu superar a dificuldade apresentada inicialmente. Dessa maneira, essa fibra foi selecionada para extração já que apresentou seletividade e compatibilidade química para extrair todos os analitos de interesse sem a necessidade de derivatização.

\subsubsection{Planejamento fatorial}

O planejamento fatorial foi aplicado em virtude da SPME possuir inúmeras variáveis que podem interagir entre elas e alterar o desempenho extração, consequentemente modificando a eficiência do método de análise. Primeiramente, um planejamento fatorial fracionário foi feito para avaliar as principais variáveis envolvidas na extração, verificando se essas variáveis são estatisticamente significativas. Após, um planejamento com matriz Doehlert foi aplicado para 
encontrar a melhor condição de extração.

\section{Planejamento fatorial fracionário}

A princípio, o planejamento fatorial fracionário foi composto por 11 experimentos $\left(2^{4-1}+\right.$ 3), sendo 8 experimentos feitos aleatoriamente e o ponto central em triplicata. As variáveis da SPME estão relacionadas com a dinâmica e cinética de extração, sendo o tempo de extração, o $\mathrm{pH}$, a temperatura e a força iônica. Como resposta foi considerada a área do pico e a relação S/N. O diagrama de Pareto do METH é representativo e mostra os efeitos obtidos para cada variável, o tempo de extração e a força iônica foram as únicas variáveis significativas, conforme pode ser visto na Figura 3.4.

É comum a extração por SPME ser afetada de forma significativa para a força iônica e o tempo de extração conforme foi observado por Suchara e colaboradores. (70) A força iônica foi avaliada pela adição de $\mathrm{NaCl}$ na relação de massa de sal por volume de 0 a $30 \%$. Esse parâmetro apresentou comportamento positivo, significando que o acréscimo de sal aumenta a quantidade de analito extraído. Esse fato é explicado pelo efeito salting out, água presente na solução solvata o $\mathrm{NaCl}$, deixando os analitos livres para interagir com a fibra de fase extratora da SPME. O tempo de extração está ligado a cinética da SPME, como a extração é regida por equilíbrio de partição, é necessário que a fibra esteja por um determinado tempo para alcançar esse equilíbrio. Esse efeito foi negativo, significando que o aumento do tempo de extração causa uma menor extração dos compostos, o que pode ser explicado pela difusão dos analitos, em um tempo superior ao necessário para se atingir o equilíbrio irá causar a dessorção dos analitos da fase extratora. Como esses foram os únicos fatores significativos, esses foram estudados em uma etapa seguinte para encontrar a melhor condição de extração por SPME usando a matriz de Doehlert.

Os outros fatores, $\mathrm{pH}$ e temperatura foram não-significativos, apesar de serem fatores extremamente importantes para a extração por SPME. O pH da solução influencia na condição do analito, se esse estará na forma ionizada ou não-ionizada, de acordo com o pKa de cada composto. A extração por SPME pode ser feita por absorção ou adsorção, para haver absorção é necessário os analitos estarem na sua forma não-ionizada, enquanto para a forma ionizada predomina a adsorção. Como o recobrimento de PDMS/DVB é misto, ambos os mecanismos podem ocorrer, por essa razão foi selecionado um $\mathrm{pH}$ que deixasse os analitos na forma nãoionizada. Dessa forma, o $\mathrm{pH}$ de 8 foi escolhido, já que todos os hormônios possuem pka > 10, CAF e MP de 10,4 e 8,50, respectivamente. Já a temperatura, apresenta um comportamento duplo (dual), o aumento da temperatura causa uma melhora na difusão dos analitos, por consequência um aumento na taxa de extração. Por outro lado, promove a diminuição do coeficiente de partição do analito para a fase extratora, diminuindo a eficiência da extração. $\mathrm{O}$ volume de amostra foi selecionada de acordo com a capacidade do frasco de amostragem, além 
Figura 3.4: Diagrama de Pareto do METH obtido do planejamento fatorial.

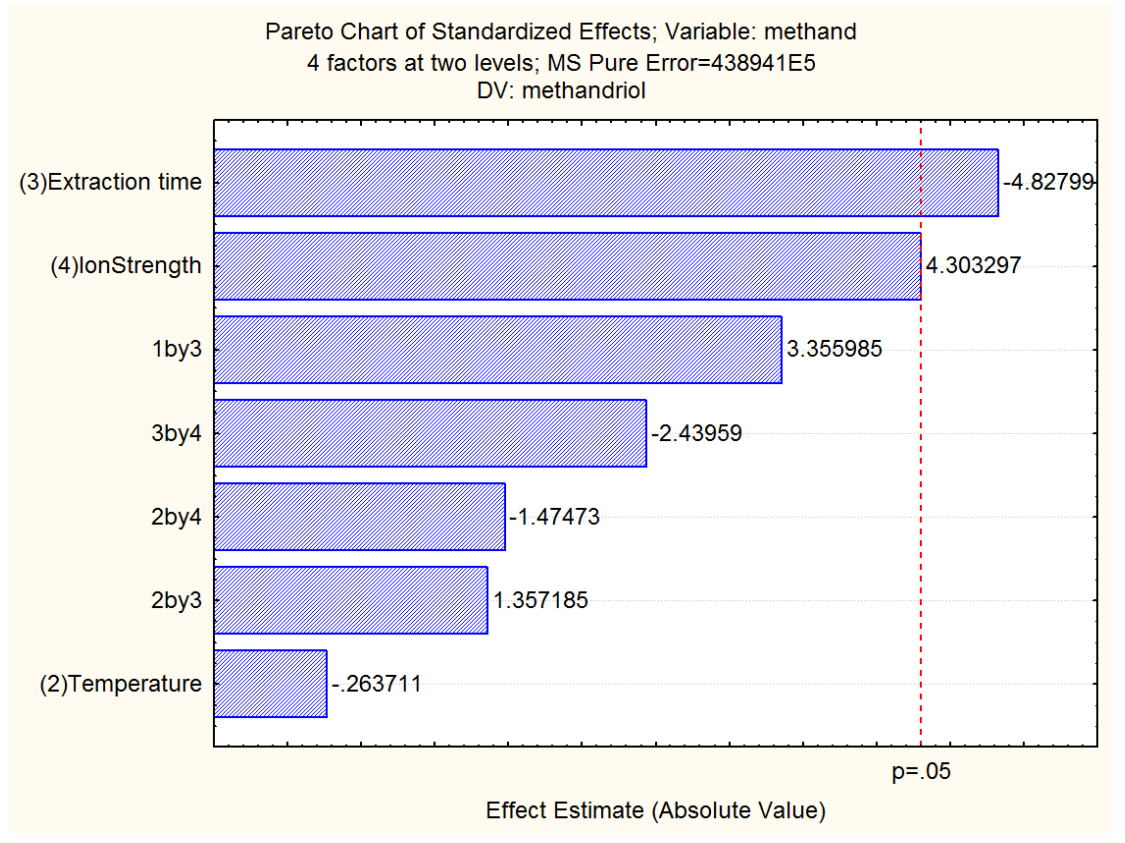

da capacidade do amostrador automático, sendo um volume de $17 \mathrm{~mL}$ utilizado para as análises.

Os valores do $\mathrm{pH}$ e da temperatura foram escolhidos a partir dos analitos que tiveram menor sinal analítico, na tentativa favorecer esses compostos e aumentar sua detectabilidade, sem comprometer a dos demais analitos. Para isso, o $\mathrm{pH}$ de 8,0 e a temperatura de $50{ }^{\circ} \mathrm{C}$ mostraram o melhor condição.

\section{Matriz de Doehlert}

A matriz de Doehlert foi usada na otimização da extração por SPME novamente em virtude do sucesso obtido no método do Capítulo 2, além de utilizar poucos experimentos distribuídos uniformimente, o que evita erros durante a avaliação da melhor condição do método. Um total de 10 experimentos foram feitos para a matriz de Doehlert, somando um total de 21 experimentos $(11+10$ do planejamento fatorial fracionário e matriz de Doehlert, respectivamente $)$ para se obter a condição ótima de extração.

A melhor condição obtida para o tempo de extração estava entre 60 a 70 minutos; já para a força iônica a adição de $\mathrm{NaCl}$ entre 4,3 a 5,2 g demonstraram ser o ponto ótimo, conforme pode ser visualizado na Figura 3.5. Essa figura é a superfície de resposta da CAF (representativa para os demais analitos) obtida tendo como resposta a relação S/N. Esse modelo apresentou uma correlação $\left(R^{2}=0,9934\right)$ superior ao mesmo obtido pela área do pico, porém em ambos a falta de ajuste foi não significativa. Então, como a aplicação do método envolve matriz complexa, o S/N é um parâmetro fundamental na otimização, foi escolhido o modelo obtido por $\mathrm{S} / \mathrm{N}$, caracterizado por um tempo de extração de 60 minutos e $4,3 \mathrm{~g}$ de sal. O tempo de 60 minutos 
Figura 3.5: Superfície de resposta da matriz de Doehlert obtida para a CAF.

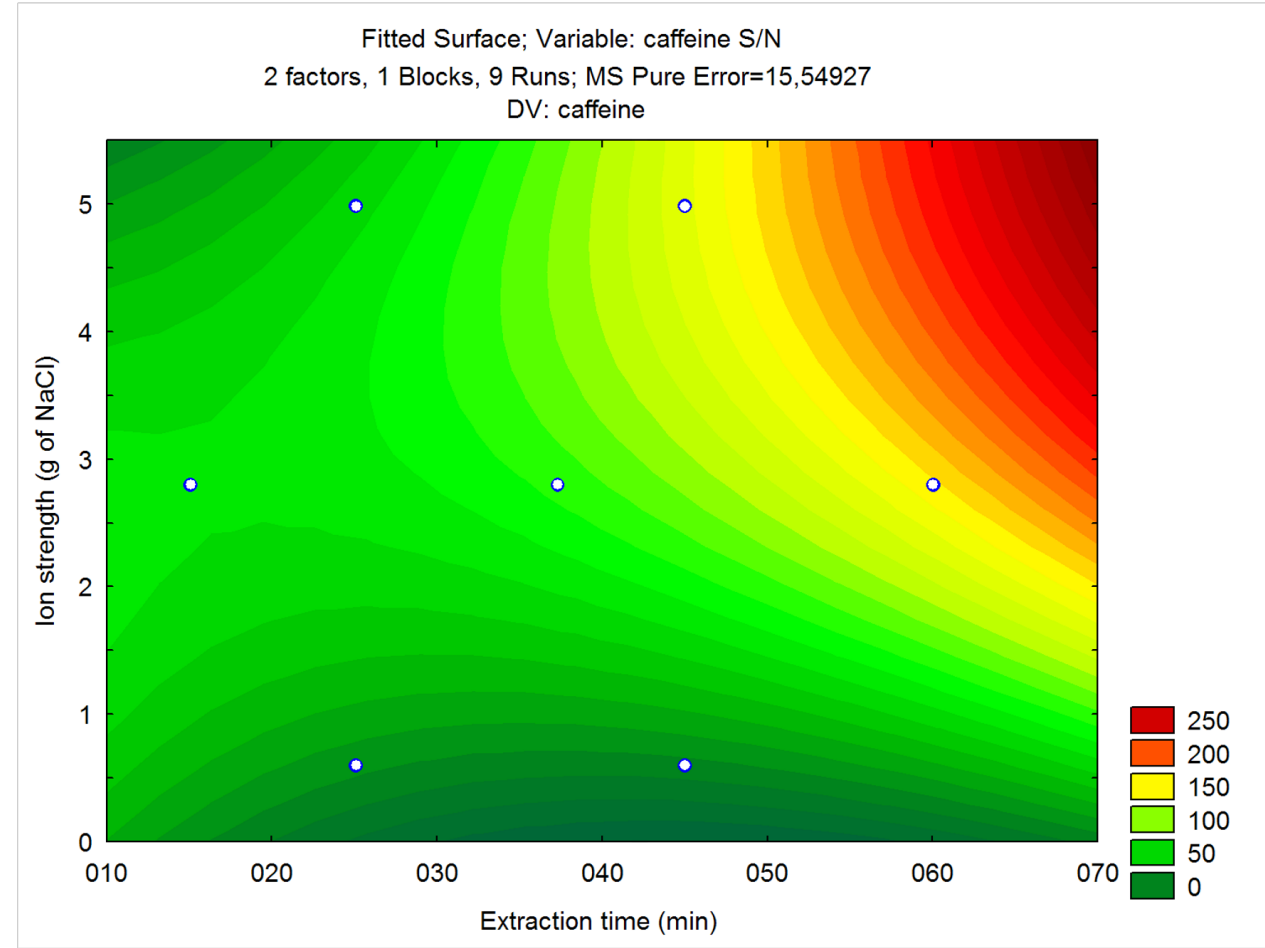

está dentro da região ótima, uma pequena perda foi observada em relação a 70 minutos de extração. O sal foi limitado a 4,3 g para evitar danos à superfície da fibra de SPME, é comum o sal acumular na agulha hipodérmica do dispositivo de SPME, causando danos irreversíveis. Mesmo reduzindo a quantidade de sal, após 10 injeções, a fibra de SPME e sua agulha foram limpa em uma solução de etanol e água (70:30) durante pelo menos 120 minutos.

\subsubsection{Análise por GC-MS}

A análise de fármacos por GC, em alguns casos requer derivatização, já que são compostos não-voláteis, muitas vezes termolábeis e podem degradar no injetor do cromatógrafo. (71) Além de evitar degradação no injetor, a derivatização auxilia em obter picos simétricos e estreitos, principalmente para os fármacos com grupos fenóis (hormônios e MP), aminas (CAF) e ácidos. Apesar dessas vantagens,durante a reação de derivatização pode ocorrer perdas, ou ainda formar inúmeros subprodutos prejudicando a análise. A Figura 3.6 apresenta um típico cromatograma no modo SIM de uma extração por SPME sem derivatização de água fortificada com os fármacos. Não houve degradação térmica de nenhum composto, os picos estão estreitos e com uma cauda residual.

O cromatograma apresentado demonstra a baixa seletividade usando um simples GC-MS, sete compostos co-eluíram em diferentes regiões do cromatograma, o que compromete a identificação e quantificação desses compostos ao utilizar esse sistema. A maioria dos compostos que 
Figura 3.6: Cromatograma no modo SIM da extração por SPME de água de torneira fortificada com $100 \mu \mathrm{g} \mathrm{L}^{-1}$ com 1 - MP, 2 - CAF, 3 - EC, 4 - MTH, 5 - MSL, 6 - MST + MEE + ADD, $7-\mathrm{E} 1+5-\mathrm{ADD}, 8-\mathrm{E} 2,9-\mathrm{EE}+\mathrm{MA}$.

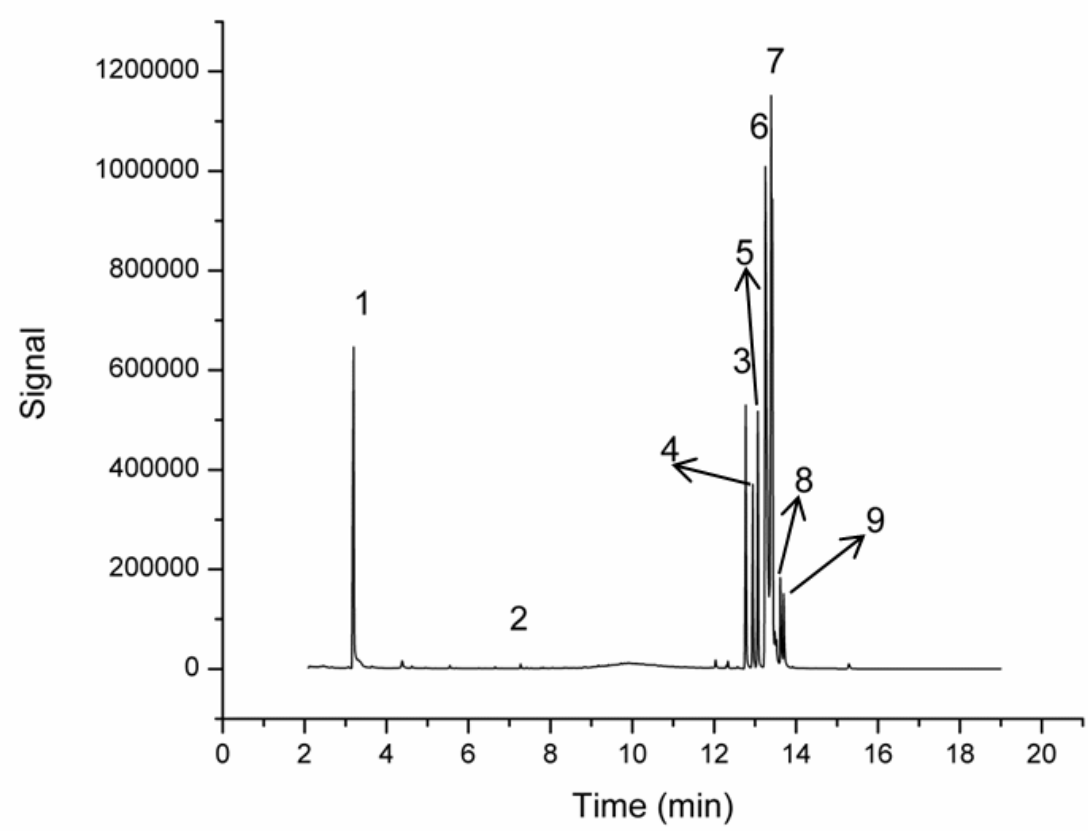

co-eluíram são classe dos hormônios, com alta similaridade estrutural sendo propício a ocorrer falso positivo em análise de amostras ambientais. Então, para análise simultânea desses analitos é necessário aumentar a seletividade para assim conseguir uma melhor separação cromatográfica. Uma alternativa é aplicar técnicas de separação com alta resolução, como cromatografia gasosa bidimensional abrangente ( $\mathrm{GCxGC}$ ) acoplada com espectrometria de massas por tempo de voo (ToF/MS).

\subsubsection{Análise por GCxGC-ToF/MS}

A configuração comumente usado em GCxGC foi utilizada, sendo uma coluna não-polar na primeira dimensão separando os analitos de acordo com pressão de vapor, e na segunda dimensão uma coluna polar que interage mais especificamente com os compostos de acordo com sua polaridade. A fase estacionária da primeira dimensão é a mesma testada para GC-MS descritas na subseção anterior. A coluna RTX-200 usada na segunda dimensão, é adequada para análise de fármacos, já tem sido aplicada com sucesso para esse tipo de análise. (82) Além disso, essa coluna suporta temperatura de $340{ }^{\circ} \mathrm{C}$, possui média polaridade em virtude da fase estacionária ser composta do polímero trifluoropropilmetilsiloxano que torna ainda mais adequado para análise de analitos com alta massa molecular e baixa volatilidade como os hormônios. 
A Figura 3.7 mostra diagrama de cores obtido para análise de fármacos usando a configuração descrita acima. A programação de temperatura em ambas colunas analíticas, aliado a seletividade da segunda dimensão permitiram uma completa separação dos analitos, sem coeluição na segunda dimensão. A temperatura inicial do modulador de $80{ }^{\circ} \mathrm{C}$ foi suficiente para evitar locais resfriados (cold spot) durante a modulação o que poderia gerar aparecimento de caudas cromatográfica. $\mathrm{O}$ tempo de modulação foi de $5 \mathrm{~s}$, suficiente para não se ter os picos dos compostos alvos fora do ciclo de modulação, conhecido como wrap-around, obtendo uma separação ortogonal com um total de corrida cromatográfica de 19 minutos. Além disso, os artefatos comuns nos sistema cromatográficos como ftalatos (dois picos de maior intensidade presente entre 10 a 13,3 min) e derivados do septo (região inferior do diagrama presente entre 13,3 a 16,7 min) são separados da região dos analitos aumentando a seletividade da análise quando comparada com análise convencionais, e ainda, melhora a relação sinal ruído, diminuindo a interferência desses artefatos na análise.

O analisador ToF é uma ferramenta poderosa e bem conhecida para identificação de compostos alvos e não-alvos, sendo necessário otimizar sua taxa de varredura Scan para obter picos estreitos e com reduzido ruído na linha de base. Isso é necessário para possibilitar uma reconstrução do cromatograma precisa, e dessa forma, uma exata quantificação. (9) A taxa de $50 \mathrm{~Hz}$ para a varredura foi suficiente para adquirir massas variando de 40 a 400 u, com baixo ruído na linha de base, o que permitiu desenvolver e validar o método para a etapa de quantificação.

Figura 3.7: Diagrama de cores obtido do SPME-GCxGC-ToF/MS aplicado na análise de fármacos em água de torneira, sendo: 1 - ADD, 2 - MA, 3 - T-d3, 4 - MSL, 5 - MST, 6 - E1, 7 E2, 8 - 5-ADD, 9 - EE, 10 - MEE, 11 - MTH, 12 - EC, 13 - CAF and 14 - MP.

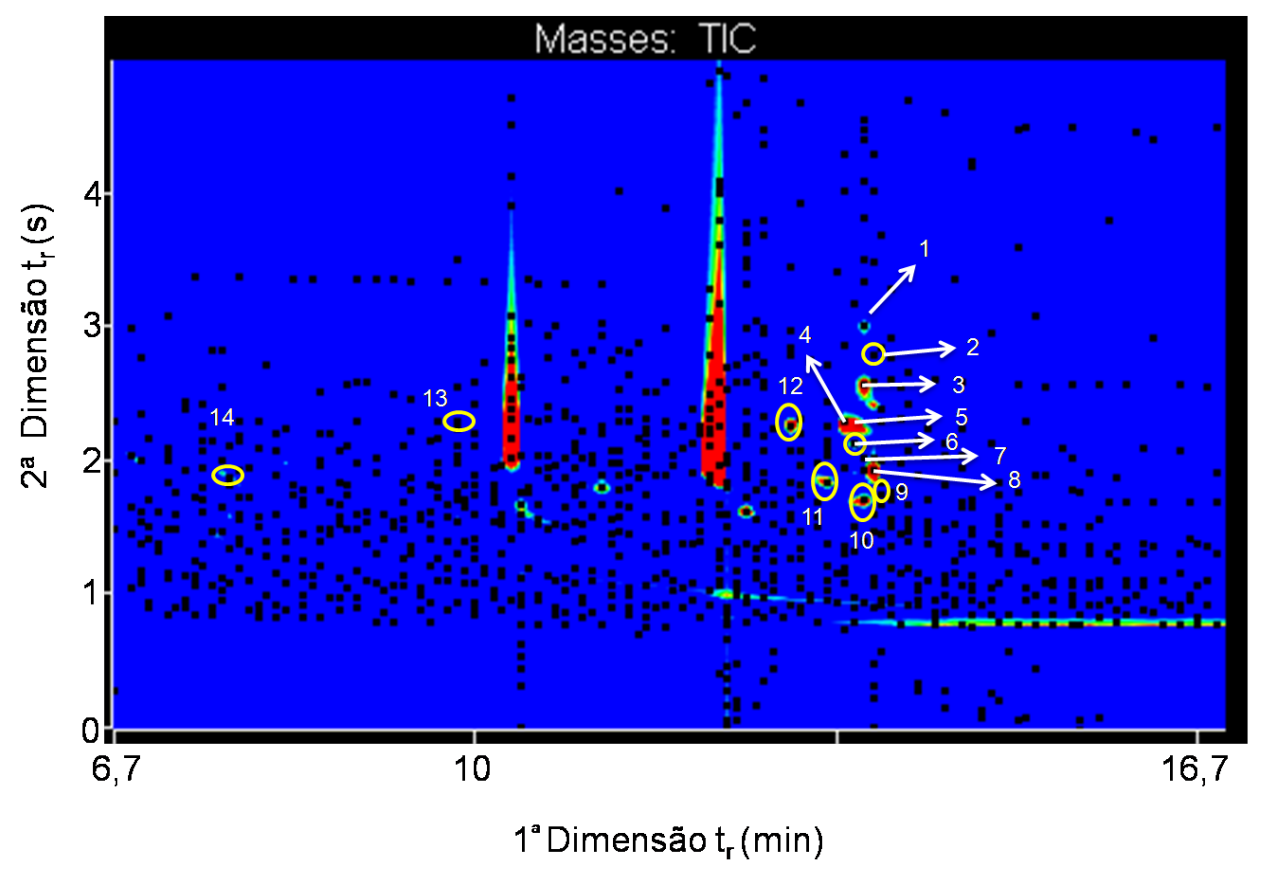




\subsection{Figuras de Mérito}

O estudo de linearidade foi realizado em água de torneira. Dois método de calibração, a princípio, foi usado calibração externa e depois padronização interna. Em ambas, atingiu-se $r^{2}$ maior do 0,98 , com falta de ajuste não-significativos. Contudo, foi adotado a padronização externa, já que sem o IS fica somente o resultado dos dados puros, considerando o ruído da matriz que, em amostras complexas como a ambiental, devem ser levados em conta para evitar problemas durante a análise.

Os dados obtidos da validação estão demonstrados na Tabela 3.3.

Tabela 3.3: Dados da validação obtidos para analise por SPME-GCxGC-ToF/MS.

\begin{tabular}{|c|c|c|c|c|c|c|c|}
\hline Fármacos & $\begin{array}{c}\text { Linearidade } \\
\left(\mu \mathbf{g ~ L}^{-1}\right)\end{array}$ & $\begin{array}{c}\text { Dados da } \\
\text { regressão } \\
\quad(\mathbf{a}, \mathbf{b}, \mathbf{r})\end{array}$ & $\begin{array}{c}\text { LOQ } \\
\left(\mu \mathbf{g ~ L}^{-1}\right)\end{array}$ & $\begin{array}{c}\text { LOD } \\
\left(\mu \mathbf{g ~ L}^{-1}\right)\end{array}$ & Nível & $\begin{array}{c}\text { Precisão } \\
\text { intra- } \\
\text { dia } \\
\text { (RSD \%) }\end{array}$ & $\begin{array}{c}\text { Precisão } \\
\text { inter- } \\
\text { dia } \\
\text { (RSD \%) }\end{array}$ \\
\hline \multirow[t]{3}{*}{ E1 } & $1,2-120$ & -676148 & 1,2 & 0,02 & Baixo & - & 11,5 \\
\hline & & 624351,5 & & & Médio & 13,7 & 10,9 \\
\hline & & 0,97 & & & Alto & - & 4,06 \\
\hline \multirow[t]{3}{*}{ E2 } & $2,1-50$ & -118214 & 2,1 & 1,34 & Baixo & - & 22,4 \\
\hline & & 61801,1 & & & Médio & n.e. & 7,40 \\
\hline & & 0,97 & & & Alto & - & 1,22 \\
\hline \multirow[t]{3}{*}{$\mathrm{EE}$} & $21-247$ & -186745 & 21 & 0.12 & Baixo & - & 3,89 \\
\hline & & 16938,5 & & & Médio & 10,9 & 12,9 \\
\hline & & 0,98 & & & Alto & - & 5,80 \\
\hline \multirow[t]{3}{*}{ MEE } & $0,62-15$ & $-42522,9$ & 0,62 & 0.008 & Baixo & - & 5,80 \\
\hline & & 99160,3 & & & Médio & 13,0 & 14,1 \\
\hline & & 0,98 & & & Alto & - & 9,34 \\
\hline \multirow[t]{3}{*}{ MTH } & $1,2-120$ & 39897,3 & 1,2 & 0,03 & Baixo & - & 8,22 \\
\hline & & 103088,2 & & & Médio & 1,05 & 2,21 \\
\hline & & 0,97 & & & Alto & - & 13,3 \\
\hline \multirow[t]{3}{*}{ MA } & $1,2-30$ & $-37230,6$ & 1,2 & 0,11 & Baixo & - & 13,4 \\
\hline & & 65081,9 & & & Médio & 12,9 & 9,44 \\
\hline & & 0,98 & & & Alto & - & 7,66 \\
\hline \multirow[t]{3}{*}{ ADD } & $2,1-50$ & $-4396,2$ & 2,1 & 0,28 & Baixo & - & 7,96 \\
\hline & & 55861,2 & & & Médio & n.e. & 1,49 \\
\hline & & 0,99 & & & Alto & - & 0,54 \\
\hline \multirow[t]{3}{*}{ MST } & $0,62-15$ & $-51451,5$ & 0,62 & 0.03 & Baixo & - & 15,3 \\
\hline & & 391943,6 & & & Médio & 17,0 & 5,84 \\
\hline & & 0,98 & & & Alto & - & 23,7 \\
\hline \multirow[t]{3}{*}{ MSL } & $0,62-15$ & -180581 & 0,62 & 0.05 & Baixo & - & 1,94 \\
\hline & & 512591,2 & & & Médio & 14 & 19,6 \\
\hline & & 0,99 & & & Alto & - & 9,83 \\
\hline MP & $59-600$ & -924627 & 59 & 3,77 & Baixo & - & 5,88 \\
\hline
\end{tabular}


Tabela 3.3: Dados da validacao obtidos para analise por SPME-GCxGC-ToF/MS. (cont.)

\begin{tabular}{|c|c|c|c|c|c|c|c|}
\hline Fármacos & $\begin{array}{c}\text { Linearidade } \\
\left(\mu \mathbf{g ~ L}^{-1}\right)\end{array}$ & $\begin{array}{c}\text { Dados da } \\
\text { regressão } \\
\text { (a,b,r) }\end{array}$ & $\begin{array}{c}\text { LOQ } \\
\left(\mu \mathbf{g ~ L}^{-1}\right)\end{array}$ & $\begin{array}{c}\text { LOD } \\
\left(\mu \mathbf{g} \mathbf{L}^{-1}\right)\end{array}$ & Nível & $\begin{array}{c}\text { Precisão } \\
\text { intra- } \\
\text { dia } \\
\text { (RSD \%) }\end{array}$ & $\begin{array}{c}\text { Precisão } \\
\text { inter- } \\
\text { dia } \\
\text { (RSD \%) }\end{array}$ \\
\hline & & 15860,1 & & & Médio & 14,6 & 4,77 \\
\hline & & 0,99 & & & Alto & - & 6,53 \\
\hline \multirow[t]{3}{*}{$\mathrm{CAF}$} & $100-1200$ & $-36920,8$ & 100 & 64,6 & Baixo & - & 14,4 \\
\hline & & 1832,1 & & & Médio & 6,68 & 0,55 \\
\hline & & 0,99 & & & Alto & - & 2,87 \\
\hline \multirow[t]{3}{*}{ EC } & $0,62-15$ & 43900,4 & 0,62 & 0.08 & Baixo & - & 1,08 \\
\hline & & 231105,4 & & & Médio & 15,3 & 10,6 \\
\hline & & 0,99 & & & Alto & - & 3,25 \\
\hline \multirow[t]{3}{*}{ 5-ADD } & $0,82-20$ & -159426 & 0,82 & 0.05 & Baixo & - & 1,58 \\
\hline & & 291512,9 & & & Médio & n.e. & 12,0 \\
\hline & & 0,98 & & & Alto & - & 7,44 \\
\hline
\end{tabular}

$a=$ intercepto, $b=$ inclinação da reta e $r=$ coeficiente de correlação

Nível baixo em $\mu \mathrm{g} \mathrm{L}^{-1}$ : MP 59; CAF 100; EE 20.6; E2, ADD 2.05; MA, E1, MTH 1.23; 5-ADD 0.82 ; MST, MSL, EC, MEE 0.61. Nível médio em $\mu \mathrm{g} \mathrm{L}^{-1}$ : MP 117; CAF 300; EE 61.8; E2, ADD 8.2; MA, E1, MTH, 3.7; 5-ADD 2.4 ; MST, MSL, EC, MEE 1.85. Nível alto em $\mu \mathrm{g}$ $\mathrm{L}^{-1}$ : MP 600; CAF 1200; EE 494; E2, ADD 50; MA, E1, MTH 30; 5-ADD 19.7; MST, MSL, EC, MEE 15.

- não avaliado, n.e. - não estudado.

Todos os resultados foram comparados com os requisitos feitos pelos guias da ANVISA (50), ICH (54) e FDA (52), apenas 2 compostos apresentaram resultados, em desacordo com as normas; o E2 apresentou um desvio padrão relativo (RSD\%) de $22 \%$ na concentração do LOQ, e a MST apresentou um RSD de $23 \%$ no nível mais alto da curva. Ambos podem ser explicados pela competição dos analitos a pela fase extratora da fibra que pode ser ainda mais ressaltado nos compostos que são extraídos predominantemente por adsorção, o que contribui para aumentar ainda mais a variação. Os demais compostos estão dentro da variação recomendada por esses guias.

O LOD variou de 0,008 a $64 \mu \mathrm{g} \mathrm{L}^{-1}$, inferior a outros métodos previamente publicados para esses compostos usando SPME-GC-MS $(83,84)$ e por LC com detecção ultravioleta (UV) e eletroquímica (ED). (85) O LOQ tiveram valores variado de 0,6 a $100 \mu \mathrm{g} \mathrm{L}^{-1}$. Esses valores foram muito similar ao observado em estudos anteriores realizados usando SPME-GCxGC-ToF/MS. (82) Matamoros e colaboradores (86) utilizaram GCxGC-ToF/MS para analisar contaminantes orgânicos em água de rio, mesmo usando preparo de amostra com alta capacidade de concentração como a extração em fase sólida (SPE), apresentou LOD e LOQ variando de 0,5 a 185 $\mu \mathrm{g} \mathrm{L}^{-1}$. Uma possível melhora na detectabilidade do método poderia ser alcançada ao utilizar métodos com maior capacidade de extração como extração em barras de sorção (SBSE). (87) 
Além disso, níveis menores poderiam ser atingidos se o software recebesse uma nova versão, pois a versão utilizada estava ultrapassada e apresentava problemas, como em concentrações baixas era possível visualizar o pico, porém não conseguia fazer a integração dos mesmos. Não havia no programa a possibilidade de integrar manualmente os picos, o que dificultava trabalhar em concentrações mais baixos, mesmo alterando todos os parâmetros de integração. Foi realizada uma pesquisa no manual do software que dizia a possibilidade de encontrar problemas na integração dos picos. Além disso, um contato com o fabricante do programa foi feito, as orientações dadas por eles solucionou o problema, no entanto, ao trabalhar em concentrações abaixo de $1,0 \mu \mathrm{g} \mathrm{L}^{-1}$ os picos eram perfeitamente visualizados, assim como o espectro, mas persistia esse problema. Esse fato restringiu em diminuir ainda mais os LOQ dos analitos presentes nesse método.

Amostras de rio foram coletadas na cidade de South Orange,NJ e foram analisados usando método de adição de padrão. Em nenhuma dessas amostras foi encontrada nenhum dos fármacos em análise. A recuperação foi estudada comparando as áreas do pico obtido em amostras de água de torneira contra amostra de água de rio fortificada na mesma concentração. Os valores de recuperação obtidos variaram de 73 a $115 \%$.

\subsection{Conclusão}

Cromatografia bidimensional abrangente apresenta seletividade suficiente que permitiu a completa separação dos analitos dos componentes da matriz sem co-eluição, sendo uma ferramenta fundamental na análise de fármacos no ambiente. Além disso, o analisador ToF/MS é essencial para identificação e quantificação de contaminantes emergentes devido sua capacidade de fazer rápidas varreduras das amostras analisadas permitindo extrair íons em estreitas janela de massas. Além disso, combinando GCxGC-ToF/MS com os algoritmos de deconvulação de picos presente no software em conjunto com pesquisa avançada nas bibliotecas fornece uma base confiável para análise de amostras complexas contendo analitos em nível de traço.

O método de extração otimizado permitiu analisar 13 fármacos, que incluem hormônios com estrutura similar em matrizes aquosas. O preparo de amostra usando a SPME possibilitou extração sem uso de solvente, com baixo consumo de amostra e reagentes, além de não ter sido necessário usar reação de derivatização. O planejamento experimental aplicado para SPME foi essencial para otimizar de forma racional, com reduzido número de experimentos e reagentes.

O método apresentou LOQ, linearidade, precisão intra-dia adequados, além de ser possível de aplicar em amostras ambientais reais, como amostras de água de rio. Melhorias na detectabilidade poderia ser feita caso fosse utilizado métodos de preparo de amostra com maior capacidade extrativa do que a SPME. 


\section{CAPíTULO 4}

\section{DESENVOLVIMENTO DE NOVOS} RECOBRIMENTOS POLIMÉRICOS PARA EXTRAÇÃO POR SORÇÃO EM BARRAS DE AGITAÇÃO (SBSE) E EXTRAÇÃO POR SORÇÃO NA PAREDE DO FRASCO

\subsection{Introdução}

A tendência da química analítica moderna é a miniaturização não somente dos instrumentos utilizados como também dos métodos de preparo de amostra. A redução do uso de solventes orgânicos, e a diminuição da quantidade de amostra utilizada nas análises são os grandes objetivos da diminuição de escala dos processos de extração.

São chamadas de técnicas de microextração aquelas cujo volume da fase extratora é inferior ao volume de amostra. Uma das técnicas mais difundidas e utilizadas nos últimos anos é a microextração em fase sólida (SPME) criada no ano de 1990. (42) O mecanismo de extração não é exaustivo, sendo regulado pelo equilíbrio de partição do analito presente na matriz para a fase polimérica extratora, apenas uma parte dos analitos presentes na matriz serão extraídos, de acordo com as suas características físico-químicas, como o coeficiente partição octanol-água $\left(K_{o / w}\right)$ e pKa. 
A SPME é uma técnica consolidada, com cerca de 22 anos desde seu primeiro relato, sendo utilizada em diversas áreas como farmacêutica, ambiental, fitoquímica, análise de alimentos, forense, e outras. A SPME possui diversos tipos de fases comercialmente disponíveis, cerca de 7 tipos de recobrimentos são encontrados, com custo mediano, podendo ser aplicada facilmente, tendo como principal sistema de análise a cromatografia gasosa (GC). A SPME apresenta variações como a SPME no tubo (in tube SPME), muito utilizada no acoplamento direto com sistema de cromatografia líquida (LC).

Após a SPME, surgiram diversos novos tipos de extração miniaturizada como a microextração em fase líquida (LPME), microextração em gota suspensa (SPDE), microextração em sorvente empacotado (MEPS), extração por sorção nas paredes do frasco (VWSE), extração por sorção em barras de agitação (SBSE), usando aspectos bem semelhantes aos da teoria de SPME.

A SBSE é uma técnica um pouco mais recente em relação à SPME, desenvolvida por Baltussen et. al. (3), no ano de 1999. Atualmente, já foi empregada em diversas áreas, assim como a SPME, no entanto ainda necessita ser aprimorada em alguns aspectos. São relatadas cerca de 468 métodos utilizando a SBSE na etapa de preparo de amostra, conforme mostra a Figura 4.1. Nessa figura apresenta uma progressão do número de publicações relatadas com a SBSE por ano até o mês de abril de 2012.

Figura 4.1: Número de publicações relacionados com a SBSE ao longo dos anos de 1999 a 2012, pesquisa retirada do Scopus, em busca avançada realizada no dia 17/04/2012 com a palavra SBSE estando presente no título, abstract, e keywords.

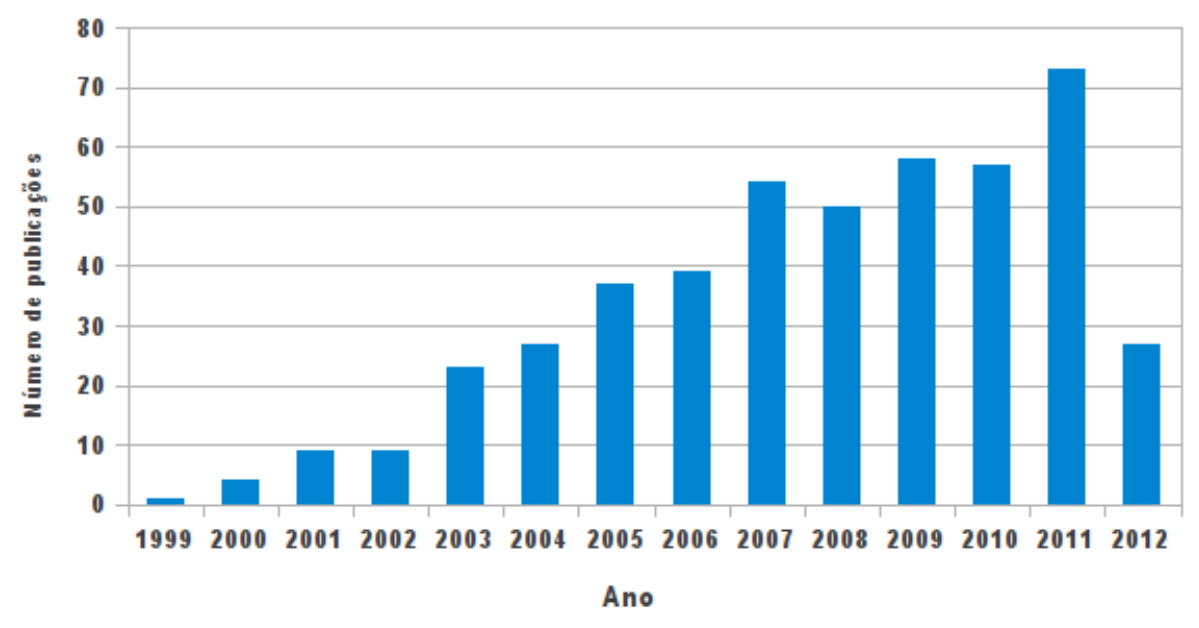

\subsubsection{SBSE}

A SBSE, por ser uma técnica mais recente, necessita ainda ser aperfeiçoada para aumentar a abrangência da sua aplicação. 
Dentre os aspectos que necessitam aperfeiçoamento, se encontra os recobrimentos poliméricos, já que apenas 2 fases poliméricas diferentes estão disponíveis comercialmente, com fases de polidimetilsiloxano (PDMS), e uma mistura de PDMS com etilenoglicol (PDMS-EG) desenvolvida recentemente. O PDMS é um polímero com uma rápida difusão, baixa sangria e alta estabilidade térmica, contudo, apresenta pouca afinidade para analitos polares, sendo uma limitação para aplicar a técnica em análise desses analitos em níveis de traço em matrizes complexas. $(88,89)$

Dessa forma, para superar essa limitação diversos mecanismos foram usados. Kawaguchi et. al. (90) utilizaram a SBSE no modo multi-shot com 5 barras de PDMS para extrair estrógenos em água de rio. $\mathrm{O}$ aumento do número de barras possibilitou uma maior concentração dos analitos, fornecendo limites de detecção de 0,2 a $1 \mathrm{pg} \mathrm{mL}^{-1}$ (ppt).

Outra forma de melhorar os resultados usando barras de PDMS foi a utilização de derivatização in situ, transformando os analitos polares em compostos de menor polaridade ao se transformar funções ácidas, aminas, fenóis e outros em estéres. $(91,92)$ Outra alternativa para diminuir ainda mais a polaridade das moléculas é uma dupla derivatização in situ sugerida por Kawaguchi e colaboradores. (93) A dupla derivatização retira o grupamento - $\mathrm{OH}$ das moléculas formando em éster etílico e um derivado silil, permitindo uma melhor extração usando a barra de PDMS, por deixar o analito não-polar.

Ainda buscando melhora na eficiência da extração de composto muito voláteis, uma nova interface de extração para SBSE foi desenvolvida. Essa interface resfriava seletivamente a barra de SBSE durante a extração por headspace, enquanto a amostra estava sendo aquecida. $\mathrm{O}$ aquecimento do vial de amostra em altas temperatura por prolongado tempo pode causar a perda dos analitos voláteis e semi-voláteis (semelhante a dessorção térmica dos analitos). Assim, ao resfriar a região em que a barra está presente, foi possível utilizar altas temperaturas por um tempo prolongado, sem ocorrer perdas dos analitos durante a extração. (94)

O maior problema na SBSE está justamente na parte de dessorção térmica e injeção. Contrariando a simplicidade da SPME, a SBSE necessita de um dispositivo especial para realizar a dessorção térmica. Por possuir um volume polimérico maior, a dessorção térmica (TD) é um processo lento, sendo necessário aprisionar os analitos antes de ser feita a injeção na coluna cromatográfica. Para isso, a empresa que detém a patente da SBSE fez um dispositivo que acopla apenas a um tipo de sistema de GC, o que inviabiliza o uso da dessorção térmica. Como saída para esse problema foi feita a dessorção em solvente, seguida de sua injeção no GC ou até mesmo no sistema de LC. Porém, a dessorção em líquido (LD) não apresenta a mesma eficiência da TD, sendo recomendado o uso de sistemas de injeção de grande volume em GC para atingir níveis muito baixos de detecção. $(95,96)$

Além de novas interfaces, diversas alternativas foram buscadas para melhorar a técnica e aumentar sua aplicação em análises de rotina. Para isso, é necessário desenvolver novos 
tipos de recobrimento polimérico para expandir a capacidade de extrair uma maior variedade de compostos químicos. Bicchi et al. (88) foi um dos pioneiros ao desenvolver uma barra de SBSE contendo PDMS e carvão ativo nas extremidades para aprimorar a análise de compostos voláteis, para analisar voláteis presentes no café e na sálvia.

Outro fator que deve ser levado em consideração é o custo para adquirir as barras de SBSE comerciais, que ainda está elevado, inviabilizando a difusão da técnica. O que torna uma alternativa interessante o uso das barras de SBSE confeccionadas em laboratório, denominadas labmade. Já foram publicados cerca de 41 estudos propondo novas fases poliméricas para a SBSE com diferentes aplicações, estão descritos na Tabela 4.1.

Tabela 4.1: Revisão das inovações para técnica de SBSE.

\begin{tabular}{|c|c|c|}
\hline Autor & Ano & Inovação \\
\hline Liu et. .al. (97) & 2004 & Preparo de barras de SBSE por sol-gel \\
\hline Bicchi et. .al. (88) & 2005 & $\begin{array}{c}\text { Barras de SBSE mistas } \\
\text { com carvão nas extremidades }\end{array}$ \\
\hline Lambert et. .al. (98) & 2005 & $\begin{array}{c}\text { Barra de SBSE com fase } \\
\text { contendo material de acesso restrito (RAM) }\end{array}$ \\
\hline Zhu et. .al. (99) & 2006 & $\begin{array}{l}\text { Barra de SBSE com fase de polímero } \\
\text { molecularmente impresso (MIP) para } \\
\quad \text { extração de organofosforado }\end{array}$ \\
\hline Hu et. .al. (100) & 2007 & $\begin{array}{c}\text { Fase de PDMS } / \beta \text {-ciclodextrina } \\
\text { para SBSE obtida por processo sol-gel }\end{array}$ \\
\hline Neng et. .al. (101) & 2007 & $\begin{array}{c}\text { Desenvolvimento, otimização } \\
\text { e aplicação da fase de poliuretana }\end{array}$ \\
\hline Huang et. .al. (102) & 2007 & $\begin{array}{l}\text { Fase monolítica obtida da copolimerização } \\
\text { de octil metacrilato com etileno dimetacrilato }\end{array}$ \\
\hline Yu e Hu (103) & 2007 & $\begin{array}{c}\text { Fase de polidimetilsiloxano } \\
\text { - } \beta \text {-ciclodextrina } \\
\text { (PDMS- } \beta \text {-CD) }\end{array}$ \\
\hline Bicchi et. .al. (89) & 2007 & $\begin{array}{l}\text { Teste com materiais adsorventes como tenax } \\
\text {, carbopack contendo } 5 \% \text { carbowax } \\
\text { e } \beta \text {-ciclodextrina }\end{array}$ \\
\hline Portugal et. .al. (104) & 2008 & Fase de poliuretana para SBSE \\
\hline Ji et .al. (105) & 2008 & $\begin{array}{l}\text { Preparo de fase derivadas de } \\
\text { silicones para SBSE } \\
\text { preparadas por processo sol-gel }\end{array}$ \\
\hline Silva et. .al. (106) & 2008 & $\begin{array}{l}\text { Comparação do desempenho da fase de poliuretana } \\
\text { com a de PDMS na análise de compostos ácidos }\end{array}$ \\
\hline
\end{tabular}


Tabela 4.1: Revisão da inovações para técnica de SBSE. (cont.)

\begin{tabular}{|c|c|c|}
\hline Autor & Ano & Inovação \\
\hline Grossi et. .al. (107) & 2008 & Novo sistema para extração headspace-SBSE \\
\hline Zhu e Zhu (108) & 2008 & Fase para SBSE derivada de MIP do nylon-6 \\
\hline Huang et. .al. (109) & 2008 & $\begin{array}{c}\text { SBSE de material monolítico com fase } \\
\text { poly(vinylpyridine-ethylene dimethacrylate) }\end{array}$ \\
\hline Huang et. .al. (110) & 2008 & $\begin{array}{c}\text { SBSE de material monolítico com fase } \\
\text { poly(methacrylic acid stearyl ester-ethylene dimethacrylate) }\end{array}$ \\
\hline Guan et. .al. (111) & 2008 & $\begin{array}{c}\text { Fase de poly(phthalazine ether sulfone ketone) } \\
\text { para análise de organoclorados }\end{array}$ \\
\hline Huang et. al. (112) & 2009 & $\begin{array}{l}\text { Fase monolítica para SBSE para extração } \\
\text { de metais pesados e compostos orgânicos }\end{array}$ \\
\hline Huang et. .al. (113) & 2009 & $\begin{array}{l}\text { Fase monolítica para SBSE para extração } \\
\text { de sulfonamidas em leite }\end{array}$ \\
\hline Huang et. .al. (114) & 2009 & $\begin{array}{l}\text { SBSE de material monolítico com fase } \\
\text { poly(vinylimidazole-divinylbenzene) }\end{array}$ \\
\hline Huang et. .al. (115) & 2009 & $\begin{array}{l}\text { SBSE de material monolítico com fase } \\
\text { poly(vinylpyrrolididone-divinylbenzene) }\end{array}$ \\
\hline Melo et. .al. (116) & 2009 & Fase mista de PDMS/pirrol para SBSE \\
\hline Yu e Hu (117) & 2009 & $\begin{array}{c}\text { Fase de PDMS/poli(vinialcool) } \\
\text { para extração de organofosforados em mel }\end{array}$ \\
\hline Yu et. .al. (118) & 2009 & Preparo de fase PDMS-CD-divinilbenzeno \\
\hline Talebpour et. .al. (119) & 2010 & $\begin{array}{c}\text { Fase de methyl methacrylate-ethyleneglycol } \\
\text {-dimethacrylate-acrylic acid } \\
\text { PMA-EG para SBSE }\end{array}$ \\
\hline Hu et. .al. (120) & 2010 & $\begin{array}{l}\text { Fase de SBSE feita pela técnica } \\
\text { de MIP para análise de triazinas }\end{array}$ \\
\hline Huang et. .al. (121) & 2010 & $\begin{array}{l}\text { Fase de troca aniônica para SBSE } \\
\text { derivada de material monolítico }\end{array}$ \\
\hline Huang et. .al. (122) & 2010 & $\begin{array}{l}\text { SBSE com fase mista derivada de material monolítico } \\
\text { para análise quinolonas em água }\end{array}$ \\
\hline Portugal et. .al. (123) & 2010 & $\begin{array}{l}\text { Potencial da fase de poliuretana na análise } \\
\text { de metabólitos triazínicos em água }\end{array}$ \\
\hline Carson et. .al. (124) & 2010 & $\begin{array}{l}\text { Uso da barra de SBSE para local de oviposição } \\
\text { do mosquito Culex quinquefasciatus }\end{array}$ \\
\hline $\mathrm{Xu}$ et. .al. (125) & 2010 & $\begin{array}{l}\text { SBSE com fase derivada de MIP de } \beta \text {-agonista } \\
\text { para análise em amostras complexas }\end{array}$ \\
\hline
\end{tabular}


Tabela 4.1: Revisão da inovações para técnica de SBSE. (cont.)

\begin{tabular}{ccc}
\hline Autor & Ano & Inovação \\
\hline Yang et. .al. $(126)$ & 2010 & $\begin{array}{c}\text { SBSE com fase derivada de MIP } \\
\text { do herbicida nicosulfuron }\end{array}$ \\
\hline Huang et. .al. $(127)$ & 2011 & $\begin{array}{c}\text { Barra de SBSE com fase monolítica de } \\
\text { poly(vinylphthalimide-co-N,N'-methylenebisacrylamide) }\end{array}$ \\
\hline Wan Ibrahim et. .al. & 2011 & $\begin{array}{c}\text { Preparo de uma nova fase por sol-gel } \\
\text { PDMS-tetraetoxisilona }\end{array}$ \\
\hline Barletta et. .al. $(128)$ & 2011 & $\begin{array}{c}\text { Desenvolvimento de nova fase de SBSE mista de } \\
\text { PDMS/carvão ativo (PDMS/ACB) }\end{array}$ \\
\hline Sequeiros et. .al. (129) & 2011 & Análise de testosterona e metenolona em urina \\
\hline Talebpour et. .al. (130) & 2012 & $\begin{array}{c}\text { Barra de SBSE com fase de PDMS e PMA-EG } \\
\text { combinados com líquidos iônicos } \\
\text { na etapa de dessorção líquido }\end{array}$ \\
\hline Bratkowska et. .al. (132) & 2012 & Fase de pirrol eletropolimerizada para SBSE \\
\hline
\end{tabular}

\subsubsection{Extração por sorção na parede do frasco}

A extração na parede do frasco foi desenvolvida recentemente por Kawaguchi e seus colaboradores (4) para análise de progesterona em soro humano. Esse dispositivo utilizou o PDMS como fase polimérica, e mostrou ser promissor por apresentar um maior volume polimérico e superfície de contato quando comparado com a SBSE.

Em vista da expansão e da necessidade de desenvolvimento nessa área de polímeros direcionados para extração, aliado a experiência do laboratório de Cromatografia da Instituto de Química de São Carlos (Croma-IQSC) na confecção de dispositivos poliméricos, parte do projeto foi dedicado a esse tema, desenvolvendo novos dispositivos para confecção de barras de SBSE, além de novas fases poliméricas para SBSE e VWSE.

Nesse capítulo será apresentado os dados obtidos para SBSE e VWSE, desde a confecção das fases até a extração. As barras de SBSE foram aplicadas na extração de variados analitos em água e urina, enquanto a VWSE foi testada exclusivamente na extração de fármacos em água. 


\subsection{Experimental - SBSE}

\subsubsection{Reagentes}

Os polímeros OV-17-vinil, OV-17 e OV-17-OH (Ohio Valley, Estados Unidos), RTX-17 e RTX (cedidos pela Restek, Estados Unidos), agente de entrecruzamento azo-tert-butano e o polipirrol (Sigma-Aldrich, Alemanha) foram adquiridos durante o projeto. Água ultra pura fornecida pelo Elga Ultra OS (High Wyncombe, Inglaterra). Piridina e ácido clorídrico foram adquiridos da Merck (Darmstadt, Alemanha), hidróxido de sódio, carbonato de sódio, fenol, 4-cloro-3-metilfenol e carvão ativo da Synth (Diadema, Brasil), hidrogeno carbonato de sódio adquirido da J.T. Baker (Phillipsbourg, EUA), metanol e etanol vindo da Tedia (Fairfield, EUA). Os padrões analíticos de ibuprofeno, fenoprofeno, flurbiprofeno, naproxeno, cetoprofeno, fluoxetina, estrona, divinilbenzendo (DVB), 2,2-Azobis(2-metilpropionitrila) (AIBN) foram adquiridos da Sigma (Steinheim, Alemanha). O 17- $\beta$ estradiol foi comprado da Alfa Aesar (Karlsruhe, Alemanha) e a simvastatina fornecido pela Krebs (Andrha Pradesh, Índia). O cloroformato de etila (ECF), agente derivatizante utilizado, foi fornecido pela Aldrich (Steinheim, Alemanha). Monômero de PDMS e seu iniciador, PDMS Sylgard adquiridos da Dow Corning (Midland, EUA).

Os padrões de fármacos e compostos fenólicos foram preparados em etanol na concentração de $1000 \mathrm{mg} \mathrm{L}^{-1}$, sendo estocados em frascos âmbar a - $4{ }^{\circ} \mathrm{C}$, descartadas após 1 mês de uso.

As barras magnéticas usadas eram fios ortodônticos de aço inox. O molde para confecção das barras de SBSE utilizado era de teflon, como mostrado na Figura 4.2. A confecção das barras seguiu a metodologia desenvolvida por Nogueira (133) desenvolvida em nosso laboratório.

Para a síntese de barras de PDMS, adiciona-se em um frasco limpo de vidro o monômero de PDMS, em seguida, o seu catalisador na proporção 10:1 (monômero:catalisador). Essa solução é misturada por cerca de 5 minutos para ficar bem homogênea, logo após é colocada sob pressão reduzida para eliminar as bolhas formadas por volta de 60 minutos. Para sintetizar outras fases, o procedimento é semelhante, o PDMS foi usado como suporte para os demais monômeros, polímeros, e agentes adsorventes. Esses são componentes adicionados em um proporção em porcentagem de massa do PDMS, por exemplo, uma barra 5\% de carvão ativo (ACB) possui $5 \%$ de carvão ativo e $95 \%$ de PDMS.

Após essa etapa, a mistura polimérica é retirada do vácuo sendo colocada no molde contendo uma barra magnética. Esse molde vai para um forno aquecido a uma temperatura de 60 ${ }^{o} \mathrm{C}$ permanecendo por 60 minutos. Então, após essa etapa, o molde é colocado em um banho de gelo para resfriar o molde, promovendo uma contração do mesmo, o que facilita sua abertura. Ao abrir, a barra é retirada cuidadosamente para evitar danos na sua superfície. Em seguida, a barra é condicionada em uma rampa de temperatura começando $60^{\circ} \mathrm{C}$ por 30 minutos, após 
Figura 4.2: Primeiro molde usado para confecção das barras de SBSE.

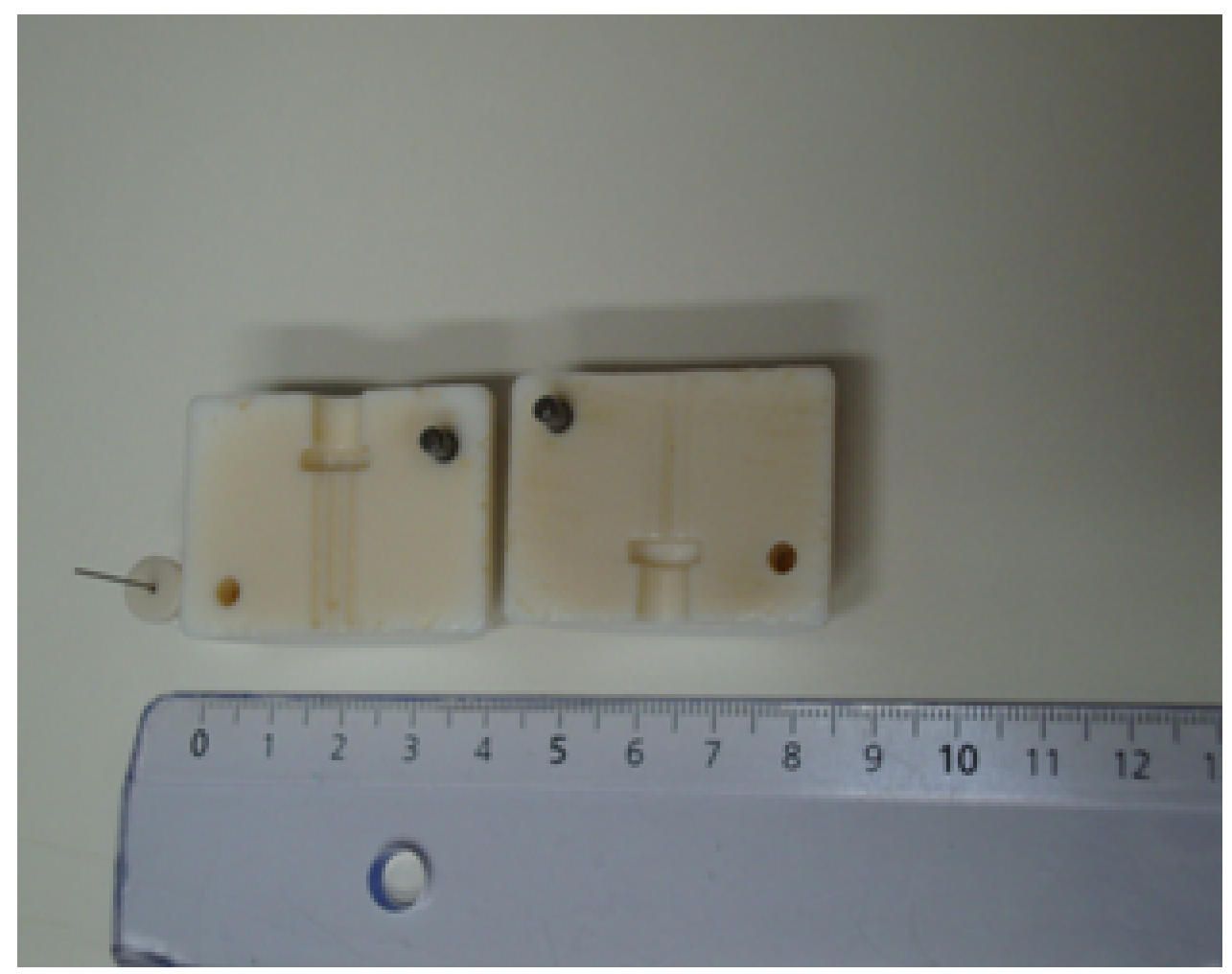

sobe $30{ }^{\circ} \mathrm{C} \min ^{-1}$ entre 180 a $220{ }^{\circ} \mathrm{C}$ (dependendo do polímero formado) mantendo por 120 minutos. Para barras homogêneas essa seria a última etapa, já para barras mistas é necessário entrecruzar o polímero formado para obter uma rede polimérica homogênea. Esse entrecruzamento é feito usando $1 \mu \mathrm{L}$ de azo-tert-butano a temperatura de 120 a $180{ }^{\circ} \mathrm{C}$ por 1 hora, limitado pelo tipo de polímero usado. Esse procedimento é repetido por 3 vezes e a barra está disponível para uso.

\subsubsection{Extração de fármacos em água - testes preliminares}

A extração foi realizada em $10 \mathrm{~mL}$ de água, $1 \mathrm{~mL}$ de tampão para acertar o $\mathrm{pH}$ de acordo com o pka dos analitos para estarem na sua forma não-ionizada. A solução foi fortificada com $1 \mathrm{mg} \mathrm{L}{ }^{-1}$ dos fármacos de cada grupo, sendo testados quinolonas, sulfas, hormônios, antiinflamatórios esteroidais e não-esteroidais. As barras foram deixadas em agitação a $600 \mathrm{rpm}$ por cerca de 90 minutos na solução, em seguida os analitos foram dessorvidos em $1 \mathrm{~mL}$ de metanol:tolueno (8:2) a $40{ }^{\circ} \mathrm{C}$ por 20 minutos em banho ultrassônico. Por último, a solução é evaporada em nitrogênio $\left(\mathrm{N}_{2}\right)$ em um banho de água a $40^{\circ} \mathrm{C}$, em seguida a solução é adicionado $100 \mu \mathrm{L}$ de metanol para suspender novamente a solução, sendo injetada no GC-MS. Também foram testadas reações de derivatização in situ utilizando anidrido acético e cloroformato de etila $(\mathrm{ECF})$.

O GC-MS utilizado era um Shimadzu QP5000, aquisição no modo Scan, injeção de $1 \mu \mathrm{L}$ 
no modo splitless, injetor a $250{ }^{\circ} \mathrm{C}$, forno com uma programação de temperatura de $80{ }^{\circ} \mathrm{C}$ por 2 minutos, aquecendo $30^{\circ} \mathrm{C} \mathrm{min}{ }^{-1}$ até alcançar $280{ }^{\circ} \mathrm{C}$ mantendo por 52 minutos, tendo uma corrida de 60 minutos. A interface está aquecida a $300{ }^{\circ} \mathrm{C}$, o solvent delay foi de 5 minutos, o fluxo inicial de gás de arraste (He) de $2 \mathrm{~mL} \mathrm{~min}^{-1}$, operando no modo pressão constante. A coluna usada foi uma RTX-5MS nas dimensões de $30 \mathrm{~m}$ x 0,25 mm x 0,25 m), da Restek.

\subsubsection{Novo molde projetado}

Um novo molde foi projetado para aprimorar a confecção das barras. Esse foi um estudo conjunto realizado com o Grupo de Polímeros Prof. Bernhard Gross do Instituto de Física de São Carlos (IFSC) sob orientação do Prof. Dr. Oswaldo Novais Júnior, da funcionária Débora Terezia e a Msc. Juliana Yamashita Barletta. (134)

Com esse novo molde foram feitas cerca de 10 barras diferentes. Estas foram testadas também testadas na análise de fármacos de acordo com o seguinte procedimento: primeiro adiciona $10 \mathrm{~mL}$ de água deionizada em frascos de headspace de $20 \mathrm{~mL}$, em seguida $1 \mathrm{~mL}$ de tampão carbonato $0,5 \mathrm{~mol} \mathrm{~L}^{-1} \mathrm{pH}=10$, fortifica a solução com os padrões de fármaco de acordo com a concentração desejada. Adiciona $0,3 \mathrm{~mL}$ de uma mistura etanol:piridina (et:pyr 3:2), acrescenta $0,16 \mathrm{~mL}$ de cloroformato de etila e por último adiciona a barra de SBSE, selando o frasco com septo de PTFE. A extração foi feita durante 60 minutos a $80{ }^{\circ} \mathrm{C}$, em seguida a barra era limpa com um jato de água deionizada e seca com papel. A barra é colocada em um vial contendo insert preenchido com $0,1 \mathrm{~mL}$ de metanol, e a dessorção é feita em ultrassom durante 20 minutos a $60^{\circ} \mathrm{C}$. Apenas $1 \mu \mathrm{L}$ foi injetado no GC-MS.

As análises foram realizadas em um GC-MS QP 5000 da Shimadzu (Kyoto, Japão). O gás de arraste usado foi o hélio, com pureza 99,9999\% (Linde, Brasil). As condições cromatográficas foram: forno iniciava a $80{ }^{\circ} \mathrm{C}$ ( $2 \mathrm{~min}$ ) subindo até $280^{\circ} \mathrm{C}$ com uma taxa de aquecimento de $30{ }^{\circ} \mathrm{C} \mathrm{min}^{-1}$ permanecendo nessa temperatura por 5 minutos, tendo a corrida cromatográfica 14,7 minutos. O injetor e a interface do MS estavam aquecidos a $250{ }^{\circ} \mathrm{C}$ e $300{ }^{\circ} \mathrm{C}$, respectivamente. A injeção de $1 \mu \mathrm{L}$ no modo splitless, mantendo sua válvula fechada por 3 minutos. $\mathrm{O}$ impacto de elétrons foi o modo de ionização escolhido, com energia de $70 \mathrm{eV}$. A coluna usada na separação dos fármacos foi a RTX-5MS (15 m x 0,25 mm x 0,25 $\mu \mathrm{m})$, com pressão constante aplicada na cabeça da coluna de 2,2 Kpa.

\subsubsection{Análise de fenol usando barra de SBSE labmade}

Das barras confeccionadas no novo molde, uma foi selecionada para análise de fenol em urina, mais especificamente, a barra de 5\% ACB. Foram utilizados $10 \mathrm{~mL}$ de urina, adicionando $1 \mathrm{~mL}$ de tampão carbonato $0,5 \mathrm{~mol} \mathrm{~L}^{-1} \mathrm{pH}=9 ; 0,3 \mathrm{~mL}$ de et:pyr na proporção $3: 2$, e por último, 
foram adicionados $0,16 \mathrm{~mL}$ de ECF, agente derivatizante. Amostra foi submetida à agitação magnética a $400 \mathrm{rpm}$ durante 60 minutos. Em seguida, a barra era limpa com água destilada, e seca em papel. A dessorção dos analitos deve ser realizada em banho ultrassônico a $60{ }^{\circ} \mathrm{C}$ durante 20 minutos, usando $0,2 \mathrm{~mL}$ de acetato de etila.

A separação cromatográfica foi feita no GC-MS usando a mesma coluna da seção anterior. A seguinte programação de temperatura foi usada: inicialmente $80{ }^{\circ} \mathrm{C}$ por 2 minutos, subindo $10{ }^{\circ} \mathrm{C} \mathrm{min}-1$ até atingir $110{ }^{\circ} \mathrm{C}$ e em seguida aquecimento até atingir $260{ }^{\circ} \mathrm{C}$, mantendo nessa temperatura por 3 minutos. A pressão inicial na coluna estava a 2,8 Kpa, a injeção foi feita no modo splitless, com split permanecendo fechado por 3 minutos e o injetor estava aquecido a $250{ }^{\circ} \mathrm{C}$. A interface e a fonte de íons estavam aquecidos a $280{ }^{\circ} \mathrm{C}$. O tempo do solvente foi de 4 minutos, após esse tempo o filamento do GC era ligado, sendo feitas monitoramentos no modo Scan (varredura) e SIM, para verificar a formação dos analitos derivatizados, e quantificar a presença do fenol.

\subsection{Preparo dos dispositivos de extração na parede do frasco (VWSE)}

Os frascos foram limpos usando água e acetona. Em seguida, a ativação dos grupos silanóis foi feita utilizando $1 \mathrm{~mol} \mathrm{~L}^{-1}$ de $\mathrm{NaOH}$, em seguida é adicionado $\mathrm{HCl} 0,1 \mathrm{~mol} \mathrm{~L}^{-1}$ deixando por 180 minutos cada solução. Por último o excesso desses reagentes são retirados usando água deionizada.

A fase mista de ACB 18 e $23 \%$ foram preparadas de acordo com o procedimento abaixo: O monômero de PDMS e seu iniciador são misturados na proporção de 10:1, o carvão ativado é adicionado na percentagem de massa 18 e $23 \% \mathrm{~m} / \mathrm{m}$. A mistura é homogenizada, colocada a pressão reduzida por 10 minutos. Cerca de $400 \mu \mathrm{L}$ dessa mistura é acrescentada no frasco. Este é colocado no forno a $60^{\circ} \mathrm{C}$ e mantido nessa temperatura por 60 minutos. Após esse período, o frasco é condicionado com a seguinte programação de temperatura: $60^{\circ} \mathrm{C}$ subindo $10{ }^{\circ} \mathrm{C} \mathrm{min}-1$ até $120{ }^{\circ} \mathrm{C}$ mantendo por 120 minutos.

A síntese da fase PDMS/DVB foi baseada nos trabalhos prévios de Yu et.al. (118) e Bratkoswska et.al. (135). Para a fase de PDMS/DVB primeiramente foi pesado o monômero de PDMS e seu iniciador. Em seguida foi adicionado DVB e o AIBN de acordo com a Tabela 4.2. Após essa etapa, a solução foi homogenizada, e colocada a pressão reduzida durante 10 minutos para eliminar bolhas presentes na mistura. Em seguida, uma alíquota de $400 \mu \mathrm{L}$ foi transferida para o frasco previamente tratado, adicionando nitrogênio gasoso. Por último o frasco era colocado em forno que aquecia de $30{ }^{\circ} \mathrm{C}$ até $70{ }^{\circ} \mathrm{C}$ em uma taxa de $0,5^{\circ} \mathrm{C} \mathrm{min}-1$, permanecendo por 24 horas. Em seguida, vem o condicionamento feito nas mesmas condições dos frascos 
Tabela 4.2: Confecção das fases poliméricas de PDMS/DVB.

\begin{tabular}{|c|c|c|c|c|c|}
\hline $\begin{array}{c}\text { Fase } \\
\text { (\% mistura) } \\
\text { (PDMS:DVB) }\end{array}$ & $\begin{array}{c}\text { Massa } \\
\text { de } \\
\text { PDMS } \\
(\mathrm{mg})\end{array}$ & $\begin{array}{c}\text { Iniciador } \\
\text { do } \\
\text { PDMS - } \\
10 \% \mathrm{~m} / \mathrm{m} \text { de } \\
\text { PDMS } \\
\text { (mg) }\end{array}$ & $\begin{array}{c}\text { Massa } \\
\text { de } \\
\text { DVB } \\
(\mathrm{mg})\end{array}$ & $\begin{array}{c}\text { Massa } \\
\text { de } \\
\text { AIBN - } \\
0,3 \% \mathrm{~m} / \mathrm{m} \text { de } \\
\text { DVB } \\
(\mathrm{mg})\end{array}$ & $\begin{array}{c}\text { Massa } \\
\text { total } \\
\text { de } \\
\text { monômeros } \\
\text { (mg) }\end{array}$ \\
\hline $70: 30$ & 560 & 56 & 240 & 0,72 & 800 \\
\hline $85: 15$ & 340 & 34 & 60 & 0,18 & 400 \\
\hline $90: 10$ & 360 & 36 & 40 & 0,12 & 400 \\
\hline $95: 5$ & 380 & 28 & 20 & 0,06 & 400 \\
\hline
\end{tabular}

de ACB. Terminada essa etapa, o entrecruzamento foi executado acrescentando alíquotas de $5 \mu \mathrm{L}$ de AZB e aquecendo o frasco até $90{ }^{\circ} \mathrm{C}$, permanecendo por 60 minutos. Esse procedimento foi repetido 3 vezes, e um novo condicionamento descrito acima é feito ao final da etapa entrecruzamento.

Em ambos os processos descritos acima, os polímeros foram depositados somente no fundo do frasco.

\section{Preparo de VWSE com polímeros em volta da parede do frasco}

De maneira semelhante ao anterior, os frascos foram pré-tratados antes da polimerização. Tratados com $\mathrm{NaOH} 0,5 \mathrm{~mol} \mathrm{~L}^{-1}$ por 30 minutos, água ultrapura e com $\mathrm{HCl} 0,1 \mathrm{~mol} \mathrm{~L}^{-1}$ por 60 minutos. Primeiramente, foram desenvolvidas fases que continham somente PDMS e catalisador na proporção de 10:1 (m/m), respectivamente. Em seguida, foram preparadas misturas homogêneas de PDMS, e de 5, 10, 15 ou $20 \%$ de carvão ativado. Os frascos foram preenchidos com as fases, e um sistema à pressão reduzida foi montado para eliminar as bolhas que surgiram devido ao processo de homogeneização.

Com a finalidade de aumentar a superfície de contato entre a fase extratora e a amostra, fez-se a polimerização em toda a parede do frasco com auxílio de uma parafusadeira e uma fonte externa de aquecimento. Para esses frascos, a polimerização ocorreu com auxílio de temperatura aproximadamente de $75^{\circ} \mathrm{C}$, com os frascos rotacionando horizontalmente por 15 minutos quando a fase continha $5 \%$ de carvão ativado, e de 20 a 30 minutos quando a fase era constituída de 10, 15 ou $20 \%$ de carvão ativado. Esse estudo, foi desenvolvido em conjunto com a aluna de iniciação científica Camila Centurion Silva, aplicando esses frascos na análise de fármacos em água. 


\subsubsection{Procedimento de extração para VWSE}

\section{Teste dos protótipos}

Para os protótipos a extração seguiu os seguintes passos: Agua deionizada, 4,5 mL, são adicionados no frasco. Em seguida, é adicionado $1 \mathrm{~mL}$ de tampão carbonato $\mathrm{pH}=10$ 0,5 mol $\mathrm{L}^{-1}$, após fortifica com os fármacos na concentração desejada, acrescenta $0,21 \mathrm{~mL}$ de et:pyr e $65 \mu \mathrm{L}$ de ECF. O frasco é fechado com sua tampa contendo septo de PTFE, a extração feita em ultrassom por 60 minutos a $35^{\circ} \mathrm{C}$. A dessorção foi feita usando $0,2 \mathrm{~mL}$ de metanol em ultrassom durante 20 minutos.

\section{Teste dos novos VWSE}

Já para os frascos reformulados e com polímeros na parede interna e no fundo, o preparo das amostras apresentaram basicamente quatro etapas.

- Condicionamento e limpeza dos frascos: Os fracos com as fases poliméricas foram condicionados com 1,0 mL de metanol por 10 minutos, e em seguida, lavados com 1,0 mL de água por mais 10 minutos.

- Extração da amostra: Progesterona: $0,5 \mathrm{~mL}$ de água foram fortificados com solução padrão de progesterona e agitado em vórtex por 30 minutos. Cafeína: $0,5 \mathrm{~mL}$ de água foram fortificados com solução padrão de cafeína. Adicionaram-se $0,5 \mathrm{~mL}$ de solução tampão carbonato $0,5 \mathrm{~mol} \mathrm{~L}^{-1} \mathrm{pH}=9,55$.

- Limpeza: Os fracos foram lavados com 1,0 mL de água por 3 vezes.

- Dessorção: $50 \mu \mathrm{L}$ de metanol foram adicionados aos frascos, e estes foram agitados em vórtex por 10 minutos.

As análises dos eluatos da extração foram realizadas em um GC-MS QP 5000 da Shimadzu (Kyoto, Japão). O gás de arraste usado foi o hélio, com pureza 99,9999\% (Linde, Barueri). As condições cromatográficas foram: forno iniciava a $80{ }^{\circ} \mathrm{C}(2 \mathrm{~min})$ subindo até $280{ }^{\circ} \mathrm{C}$ com uma taxa de aquecimento de $30{ }^{\circ} \mathrm{C} \min ^{-1}$ permanecendo nessa temperatura por 5 minutos, tendo a corrida cromatográfica 14,7 minutos. O injetor e a interface do MS estavam aquecidos a $250{ }^{\circ} \mathrm{C}$ e $300{ }^{\circ} \mathrm{C}$, respectivamente. A injeção de $1 \mu \mathrm{L}$ no modo splitless, mantendo sua válvula fechada por 3 minutos. O impacto de elétrons foi o modo de ionização escolhido, com energia de $70 \mathrm{eV}$. A coluna usada na separação dos fármacos foi a RTX-5MS (15 m x 0,25 mm x 0,25 $\mu \mathrm{m}$ ), com pressão constante aplicada na cabeça da coluna de 2,2 Kpa 


\subsection{Resultados e Discussão}

\subsubsection{Moldes e novos recobrimentos poliméricos desenvolvidos}

Após várias etapas de síntese foi possível sintetizar cerca de 6 barras, contendo as fases de PDMS, fases mista tendo PDMS como suporte de OV-17, OV-17-vinil, OV-17-OH, polipirrol e carvão ativo. Todas as fases foram testadas na extração dos fármacos, como descrito anteriormente. As barras tiveram afinidade apenas pelos hormônios e 2 anti-inflamatórios (ibuprofeno e flurbiprofeno); para os demais fármacos, mesmo realizando reações de derivatização, as barras não demonstraram afinidade pelos analitos. Esse fato pode ser explicado pela polaridade dos analitos. Analitos com Log P menor que 2, tem baixa eficiência na extração por SBSE. Aliado a esse fato, e com grande chance de ser o principal motivo, as barras preparadas no molde apresentavam volume por volta de 22 a $35 \mu \mathrm{L}$, enquanto as barras comerciais possuem um volume de 55 a $219 \mu \mathrm{L}$. Esse fato explicaria a perda de eficiência na extração usando as barras de SBSE sintetizadas no laboratório, conforme mostra a Figura 4.3.

Além do fato do pequeno volume de fase polimérica descrito anteriormente, pelas fotos apresentadas é perceptível falhas na superfície da barra contribuindo para a baixa eficiência na extração. Essas falhas foram causadas no momento de abrir o molde, apesar de ser de teflon, ao ocorrer polimerização parte do polímero se adere a superfície do teflon. Além disso, o teflon ao ser exposto diversas vezes a temperatura variando de 60 a $90{ }^{\circ} \mathrm{C}$ começou a apresentar danos na sua superfície (o teflon amarelou), perdendo suas propriedades anti-adesivas. Com o uso intenso para síntese das barras, ao se tentar fazer as barras não ocorria se quer a polimerização. Grande parte da mistura polimérica vazava do molde devido à presença de ranhuras no molde causadas pelo desgaste do mesmo. Além disso, o teflon é bom isolante térmico fazendo com que o aquecimento fornecido pelo forno não atingisse com a mesma intensidade na parte interna do molde, fator também crucial para as reações de polimerização principalmente dos derivados do silicone, conforme mostrado na Figura 4.4

Figura 4.3: Barras de SBSE (a) 5\% carvão ativo, (b) $10 \%$ polipirrol, (c) 50\% OV-17, (d) $50 \%$ OV-17-OH, (e) 5\% OV-17-vinil e (f) 100\% PDMS.

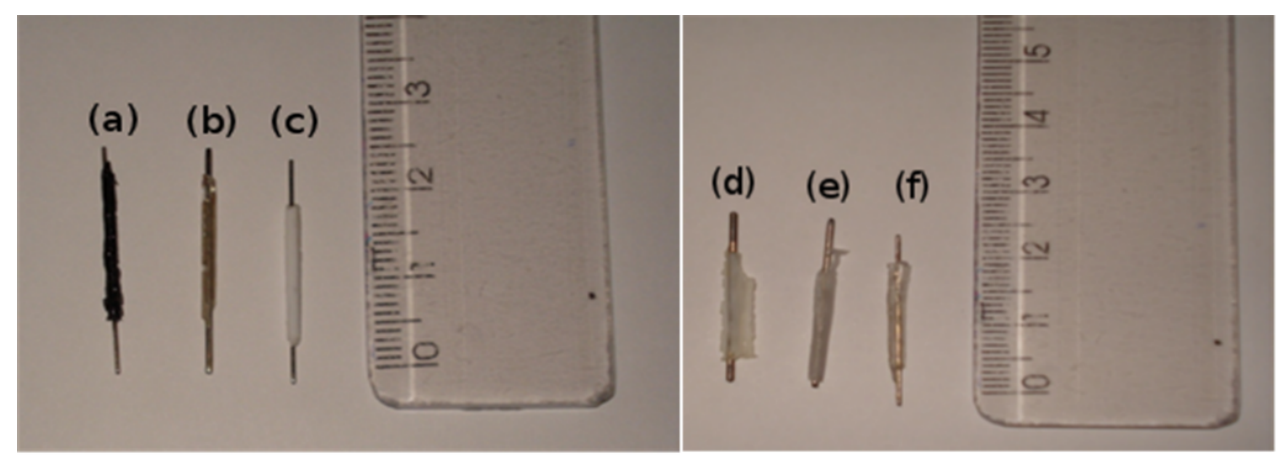

Com todos esse problemas foi necessário aprimorar a confecção das barras.O primeiro me- 
Figura 4.4: Molde de teflon apresentando amarelamento.

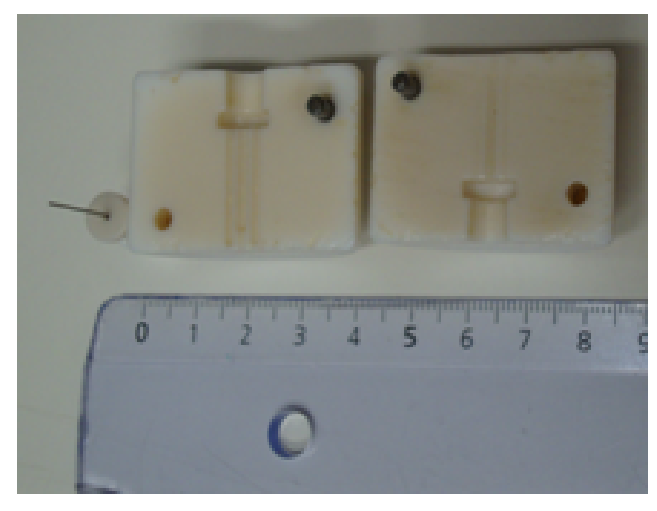

lhoramento feito no molde foi um corte no molde antigo, adaptando duas partes metálicas para poder aquecer a região que fica em contato com o magneto. Mas na prática esse molde não foi funcional, e está mostrado na Figura 4.5.

Então, uma nova alternativa foi testada. Um novo molde foi projetado possuindo apenas a base de teflon, com um pequeno furo central para fixar o magneto, e uma abertura maior na superfície do teflon para se encaixar o capilar de vidro, um bom condutor térmico, conforme foto ilustrativa na Figura 4.6.

Figura 4.5: Molde de teflon com base de aço inox para melhorar o aquecimento na região em contato com o magneto.

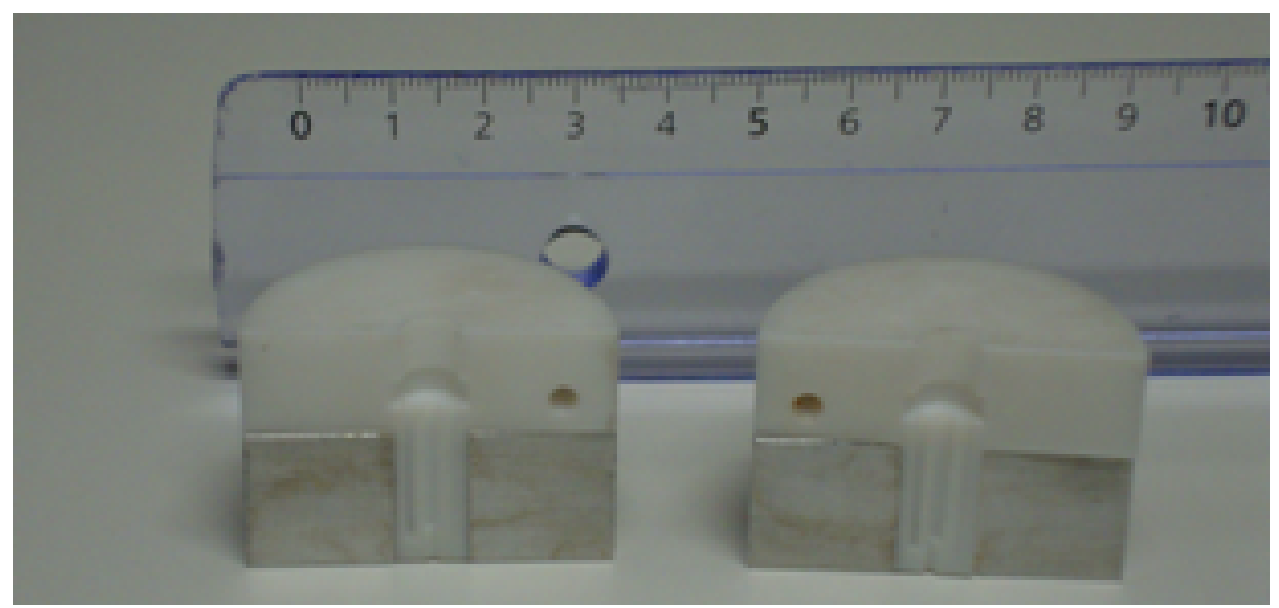


Figura 4.6: Novo molde projetado em um trabalho conjunto entre os grupos de pesquisa Croma e de Polímeros do IFSC.

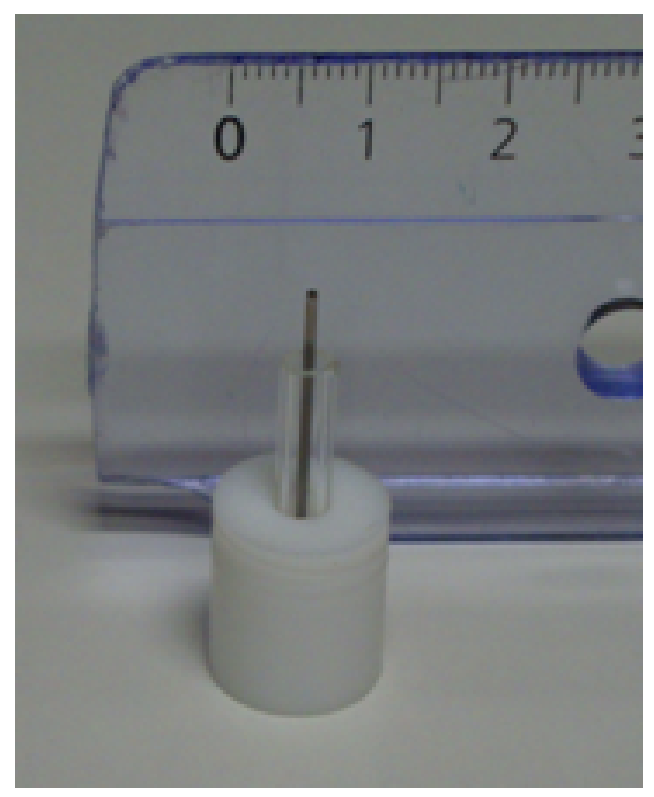

O processo de preparo do polímero continuou sendo o mesmo, porém é possível adicionar cerca de $200 \mu \mathrm{L}$ de fase polimérica nesse molde. Após o molde ser aquecido em forno, por um tempo inferior ao método anterior, cerca de 25 minutos, já é possível observar toda a polimerização da barra de PDMS. O molde é resfriado até atingir a temperatura ambiente, retira-se o conjunto magneto e o capilar de vidro a sua volta. O capilar é quebrado e a barra está pronta, tendo cuidado apenas no momento da quebra para evitar que estilhaços de vidro penetrem no polímero . Esse novo molde permitiu obter barras sem falhas na sua superfície e com volume polimérico superior ao anterior, cerca de $92 \mu \mathrm{L}$ de fase polimérica foi obtida. (128) A Figura 4.7 ressalta o aumento de volume polimérico conseguido com o novo molde, comparando uma barra de PDMS feita no molde novo contra uma barra de PDMS feita no molde antigo.

Com esse novo molde foi possível sintetizar por volta de 10 diferentes tipos de fases poliméricas para SBSE, como mostrado na Figura 4.8.

Essas fases foram testadas na análise de fármacos em água e fenol em urina, conforme será descrito.

Um terceiro molde (ver Figura 4.9) foi desenvolvido para sintetizar os polímeros em um magneto envolto em um capilar de vidro. Esse capilar de vidro permite o uso das barras em sistemas de dessorção térmica sem que haja comprometimento da fase polimérica ou mesmo dos analitos, já que, o aquecimento aliado ao contato com o aço inox do magneto causa reações de degradação do polímero ou até mesmo do analito. Esse molde não chegou a ser muito utilizado nesse projeto, nas próximas etapas será mais estudado. 
Figura 4.7: Fotografia apresentando a barra de PDMS feita no novo molde, enquanto na parte da direita mostra a mesma barra de PDMS obtida usando o molde antigo.

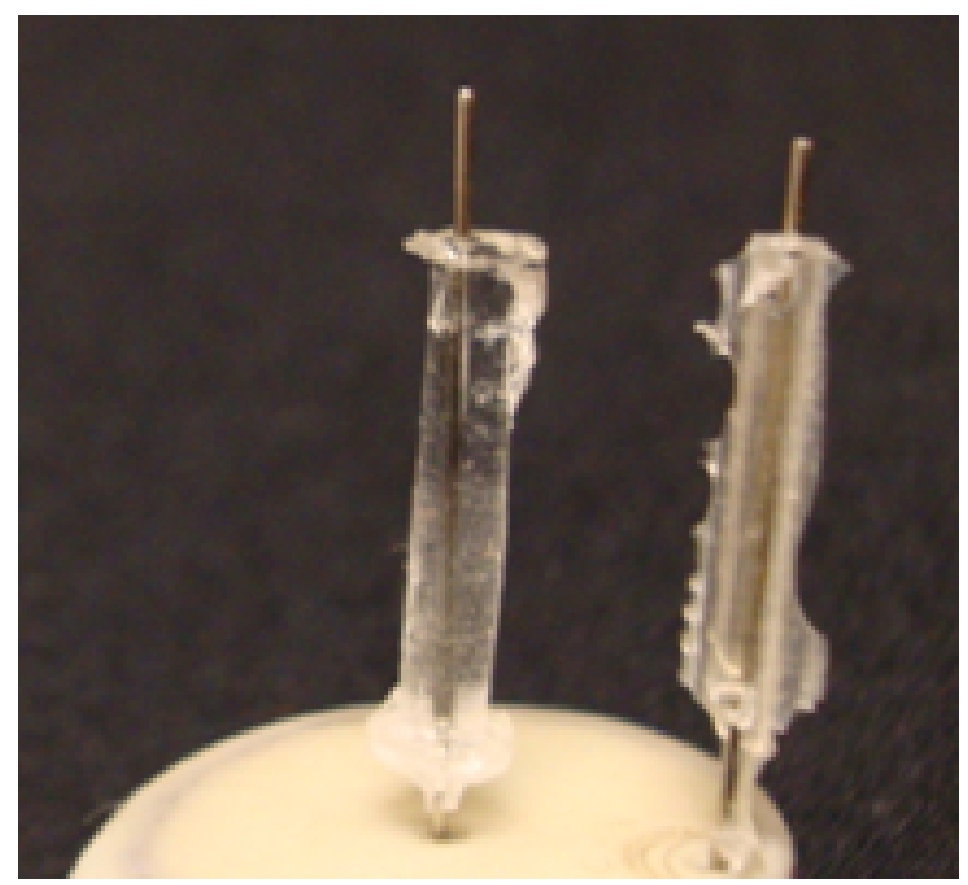

\subsubsection{Aplicação das barras de SBSE na análise de fármacos}

As novas fases de SBSE foram testadas usando o método otimizado para SPME na determinação de fármacos em água usando conjuntamente a derivatização in situ. (136) Das dez novas fases, sete foram testadas e comparadas com a fase comercial disponível de PDMS. A fase de PDMS/DVB ficou muito quebradiça, não sendo aplicado nesse estudo. Das barras derivadas de carvão ativo foram estudados apenas 3 tipos.

Na Figura 4.10 pode ser percebido uma grande diversidade de capacidade extrativa entre as barras. Cada barra tem uma resposta analítica de acordo com o tipo ou grupo de fármacos,

Figura 4.8: Barras de SBSE com novos revestimentos poliméricos: (a) PDMS/DVB, (b) PDMS $100 \%$, (c) OV-17 vinil 30\%, (d) OV-17 vinil 25\%, (e) carvão ativo 4\%- ACB, (f) ACB 5\%, (g) ACB 9\%, (h) ACB 13\%, (i) ACB 18\% e (j) polipirrol $20 \%$.

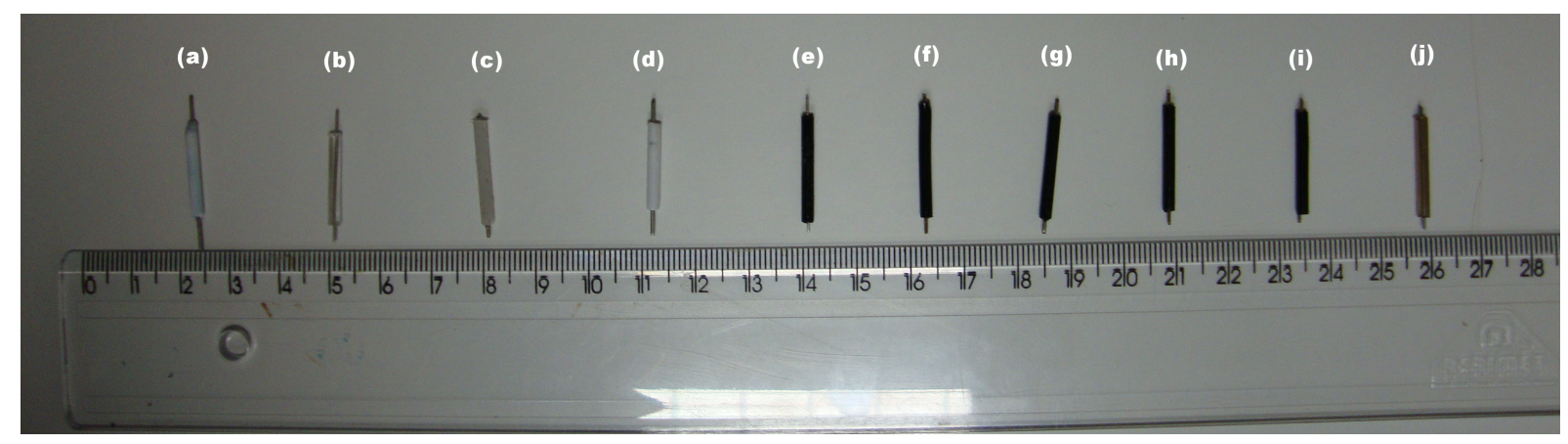


Figura 4.9: (a) Molde novo contendo magneto envolvido em vidro silanizado. (b) Barra de PDMS com magneto envolto por um capilar de vidro sintetizada no molde novo.
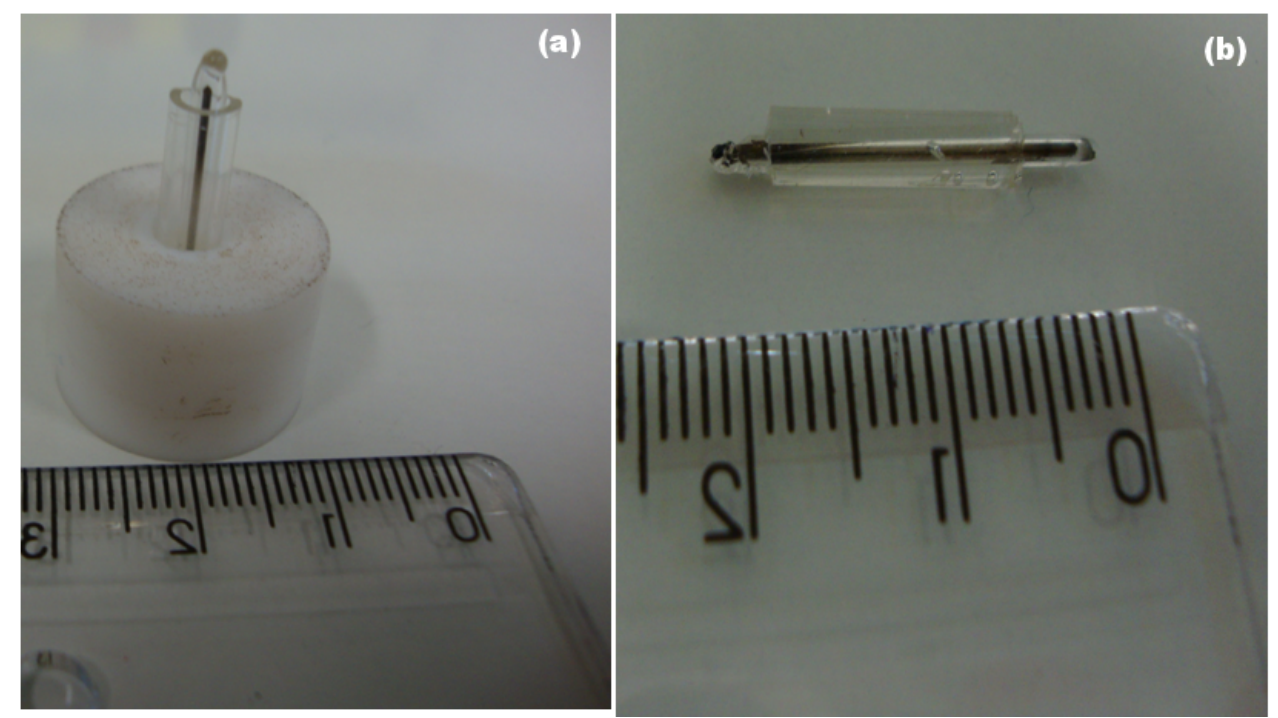

esse comportamento está relacionado com o mecanismo de extração e afinidade dos fármacos pela fase extratora. Normalmente, a extração ocorre por absorção, quando o analito penetra na fase extratora. Outro mecanismo de extração é a adsorção, a fase polimérica possui pequenos espaços na superfície da fase, e os analitos penetram nesse espaço de acordo com o tamanho da molécula. Ou ambos os mecanismos podem acontecer dependendo do tipo fase polimérica, por exemplo uma fase mista.

As barras que demonstraram uma boa capacidade extrativa para os fármacos foram: fase polimérica mista de ACB 18\%, OV-17-vinil 30\% e a barra homogênea de PDMS labmade. Essas barras apresentaram um melhor desempenho comparado ao da barra disponível comercialmente.

A barra de ACB 18\% já havia sido testada anteriormente para os praguicidas em canade-açúcar e apresentou um excelente resultado. (128) Sua eficiência de extração é dada pela possibilidade dos analitos serem extraídos por absorção e adsorção, o que amplia seu potencial extrativo.

A barra de OV-17-vinil, possui uma fase semelhante a utilizada em colunas de GC, contendo grupos metilsiloxanos e fenil com radical vinil terminal na proporção de 1:1. Esses grupos fornecem uma característica diferenciada tendo maior afinidade por compostos polares contendo dupla ligação e anéis aromáticos. Nessa fase há interações hidrofóbicas com a cadeia carbonílica do metilsiloxano, e interações $\pi-\pi$ interagindo com compostos orgânicos contendo dupla ligação e anéis aromáticos.

Já a barra de PDMS, terá maior afinidade por compostos não-polares, sendo observado um bom desempenho, principalmente na extração da fluoxetina e estrona, que para os demais seu 
Figura 4.10: Comparação entre novas fases extratoras.

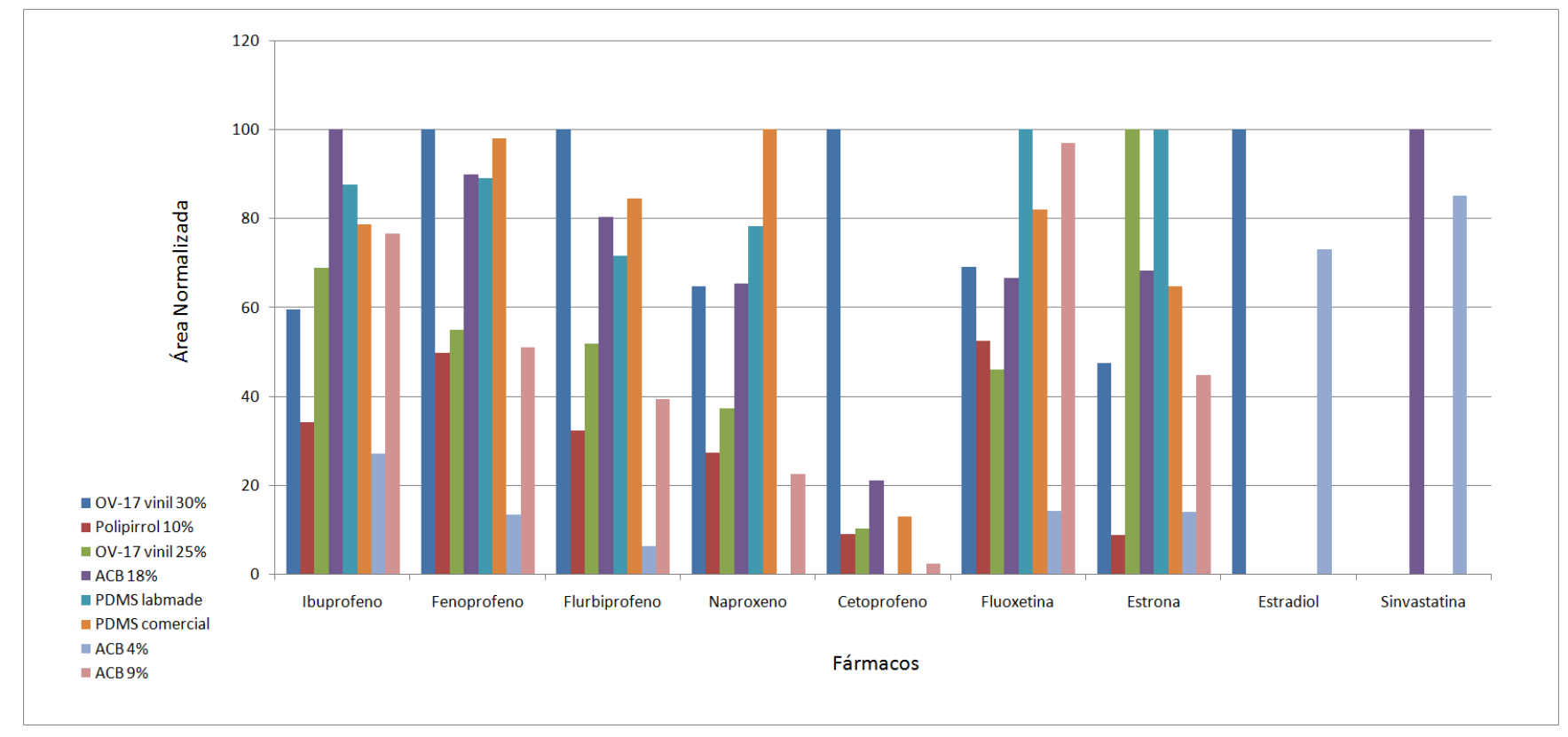

desempenho não foi tão elevado. Essa variação ocorre pela competição que os analitos podem sofrer para interagir com os novos recobrimentos poliméricos, o que pode prejudicar a extração desses analitos e favorecer a extração de outros presentes na mesma matriz, dependendo do tipo de fase extratora escolhida. Uma alternativa interessante para solucionar esse problema seria o modo multi-shot, um tipo de barra seria usado para extrair um determinado grupo, enquanto outra ou outras para os demais grupos de fármacos, não extráidos com a mesma eficiência da primeira barra. Esse modo aumenta a seletividade do método, e possivelmente, a detectabilidade do método, conforme destacado por Kawaguchi et.al. (90).

A Figura 4.11 mostra o cromatograma no modo SIM de todas as 3 novas fases citadas acima, e sua comparação com a barra comercial. Com base no cromatograma, todos os picos estão separados entre si, é perceptível uma assimetria com a presença de caudas que estão sendo causadas pelo desgaste da coluna.

Ao se comparar as extrações com os novos polímeros com a SPME usando a dessorção térmica (TD), era esperada, um maior valor da área dos picos para SPME, já que a TD é mais efetiva na dessorção dos analitos em relação à dessorção líquida (LD) empregada nas extrações por SBSE. A Figura 4.12, mostra que a extração por SBSE com LD corresponde de 1 a $46 \%$ em relação a mesma extração feita por SPME-TD.

$\mathrm{Na}$ dessorção, nos primeiros estudos usando as barras labmade, foi utilizado somente ultrassom, e como solvente de dessorção uma mistura de metanol e tolueno na proporção 8:2. Contudo, com essa combinação picos dos silanóis vindos do PDMS da fase polimérica apareciam durante toda a corrida cromatográfica, já que o tolueno possui afinidade pelo PDMS, sendo 
capaz de solubilizá-lo mesmo usando baixas quantidades. Assim, para evitar artefatos na coluna do GC, e possivelmente, os mesmos artefatos na fonte de íons provocariam a necessidade de limpeza da fonte antes do prazo necessário, outros solventes foram testados. Os solventes que apresentaram melhores resultados foram o metanol e o acetato de etila. No caso da análise de fármacos, a dessorção em solvente o metanol foi escolhido, por não ter afinidade pela fase polimérica, além de apresentar uma boa solubilidade para os fármacos estudados. Com uso de ultrassom e temperatura de $60{ }^{\circ} \mathrm{C}$ foi possível melhorar a dessorção dos analitos, sem observar degradação dos compostos durante os 20 minutos deixados no ultrassom a $60{ }^{\circ} \mathrm{C}$.

Figura 4.11: Cromatograma no modo SIM para as barras com fase de ACB 18\%, OV-17-vinil $30 \%$, PDMS labmade e PDMS comercial, extração feita na concentração $0,5 \mathrm{mg} \mathrm{L}^{-1}$. 1 ibuprofeno, 2 - fenoprofeno, 3 - flurbiprofeno , 4 - naproxeno, 5 - fluoxetina, 6 - cetoprofeno, 7 - estrona, 8 - estradiol e 9 simvastatina.
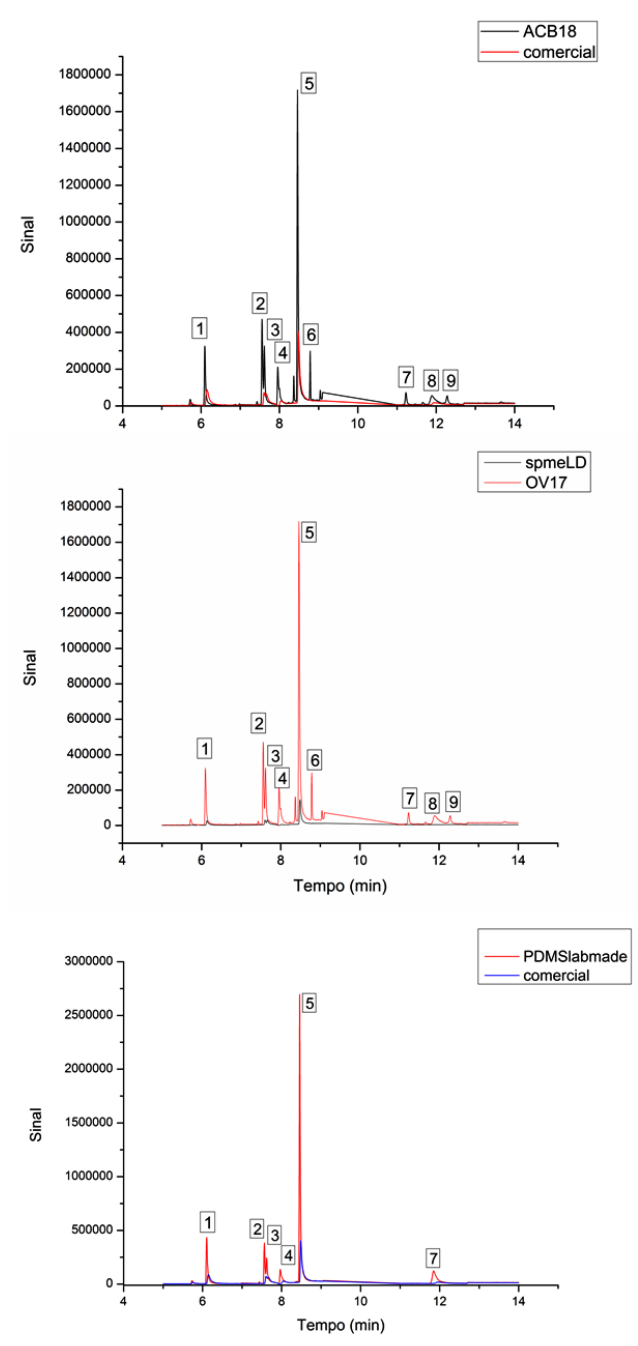
Figura 4.12: Comparação SBSE versus SPME.

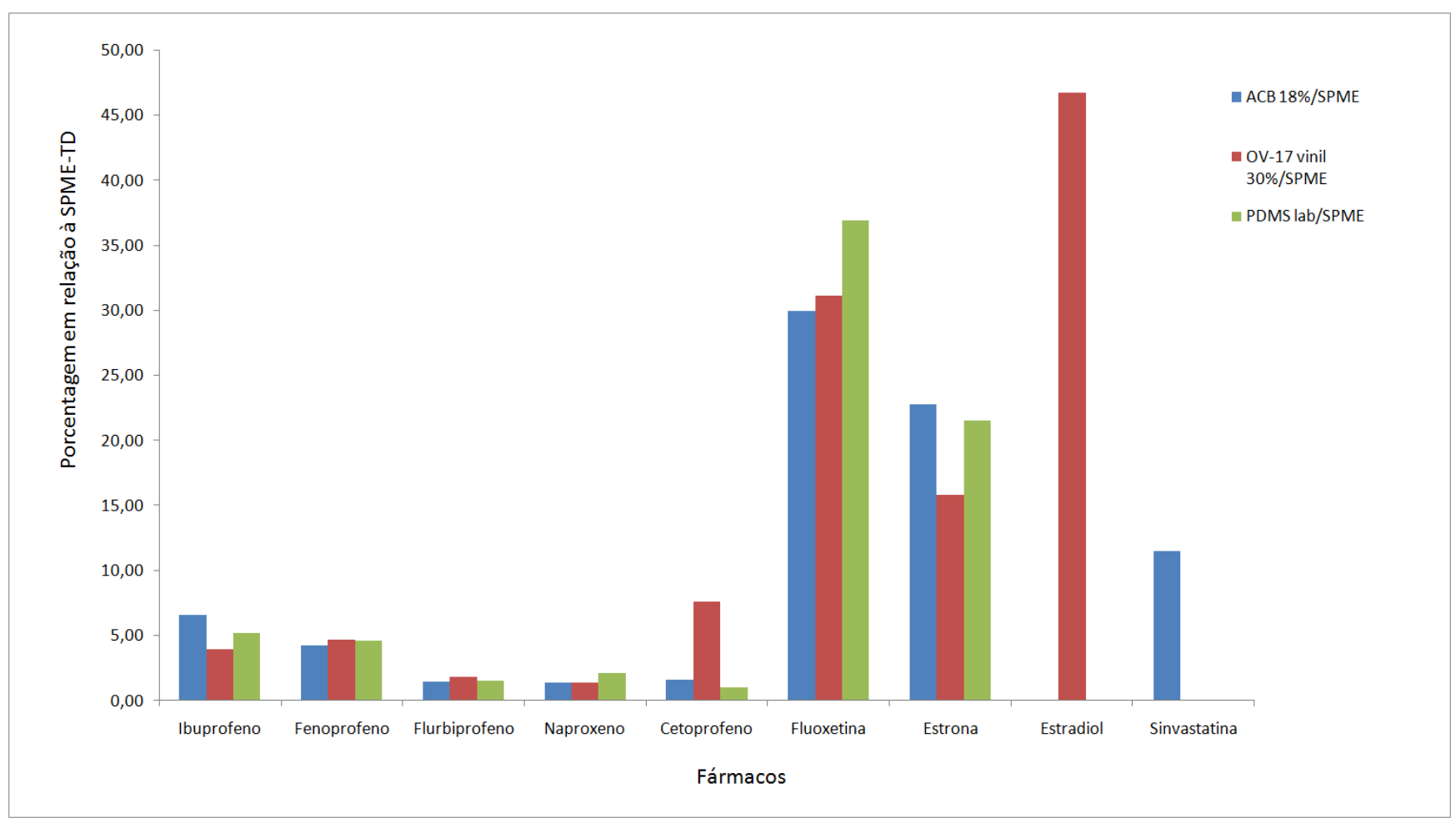

Para comparar de forma mais semelhante, foi feita a dessorção líquida para SPME. A SBSE possui uma maior capacidade extrativa já que possui um maior volume de fase polimérica capaz de absorver e/ou adsorver mais analitos. O cromatograma da Figura 4.13, mostra como SPME/LD tem seu sinal analítico inferior ao obtido pela SBSE. Apenas é necessário ressaltar que foi utilizada uma fase comercial de PDMS/DVB para a extração por SPME, já que não há fases cormeciais semelhantes a das barras de SBSE, e ainda, a fase de PDMS/DVB foi que mostrou melhor seletividade para extrair todos os fármacos.

Outro fator observado refere-se a agitação magnética, muitas das barras labmade não apresentaram uma boa agitação, em virtude do magneto feito para sua confecção ser muito leve. Como a reação de derivatização in situ gerava $\mathrm{CO}_{2}$ algumas barras saiam do fundo do frascos de amostra indo para superfície, sendo necessário usar um magneto extra para retornar a barra para o fundo do frasco. Como a agitação exerce papel fundamental na cinética da extração é necessário alterar as barras feitas usando um magneto mais denso do que utilizado previamente. No entanto, apesar dessa deficiência, as barras mostraram resultados superiores a barra comercial, e ainda, com resultado superior ao SPME com dessorção líquida. 
Figura 4.13: Cromatograma no modo SIM comparando extração por SBSE usando barra de OV-17-vinil 30\% e SPME (fase PDMS/DVB), ambos com dessorção em solvente. Extração feita na concentração de $0,5 \mathrm{mg} \mathrm{L}^{-1}$.

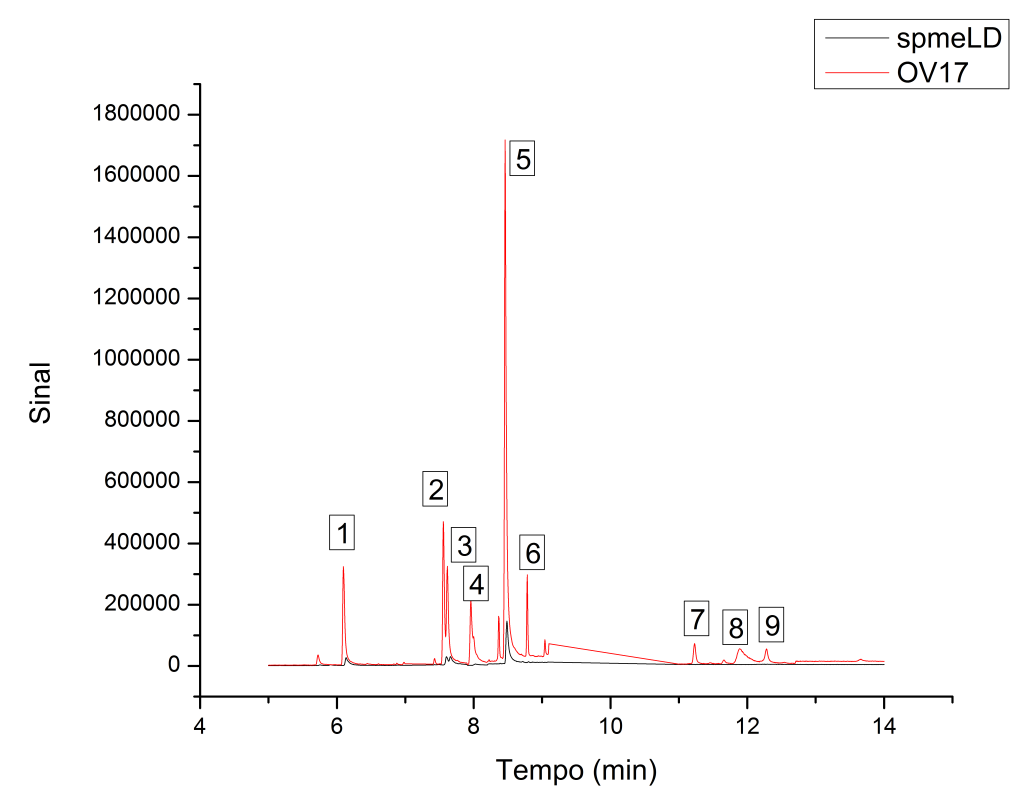

\subsubsection{Aplicação da SBSE na análise de fenol em urina}

Um método para análise de fenol em urina foi desenvolvido usando a barra de ACB 5\%, tendo usado o 4-cloro-3-metilfenol como padrão interno (IS). Durante o desenvolvimento, a otimização feita foi univariada, considerando o tempo de extração e pH. O pH de 9 foi escolhido, já que o pka = 10 do fenol, e de 9,6 do IS, para manter as espécies na forma não-ionizada.

O tempo de extração de 60 minutos foi o suficiente para alcançar o equilíbrio. Não foi utilizado adição de sal ou solvente, já que durante os testes não apresentaram melhora na extração. A temperatura de $25^{\circ} \mathrm{C}$ apresentou melhor resposta para extração do fenol e seu IS. Então, as condições otimizadas de extração obtidas foram 60 minutos de extração a $25^{\circ} \mathrm{C}$. Contudo, foi necessário realizar uma derivatização nesses composto para evitar caudas e picos assimétricos. A reação de derivatização escolhida foi a in situ, por ser possível realizar a derivatização em conjunto com a extração. Além disso, o novo recobrimento polimérico desenvolvido foi testado em condições de derivatização, o que permitiu avaliar a possibilidade de ocorrer alterações ou danos no recobrimento polimérico após o processo de preparo de amostra. Na Figura 4.14 mostra o cromatograma obtido para o fenol e IS, apresentando simetria adequada. 
Figura 4.15: Mecanismo da reação da derivatização in situ para os compostos fenólicos.
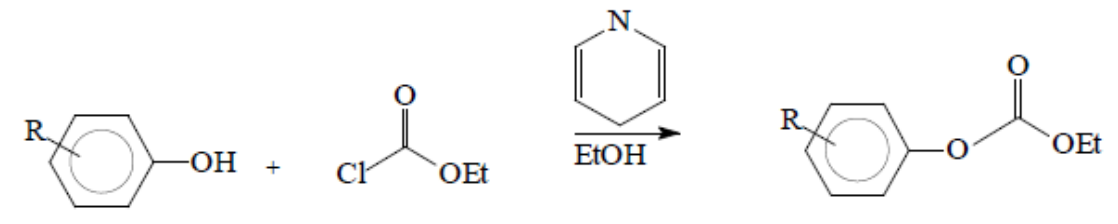

Figura 4.14: Cromatograma do íon total (TIC) da extração de fenol em urina por SBSE usando barra ACB 5\%. Extração feita na concentração de $10 \mathrm{mg} \mathrm{L}^{-1}$.

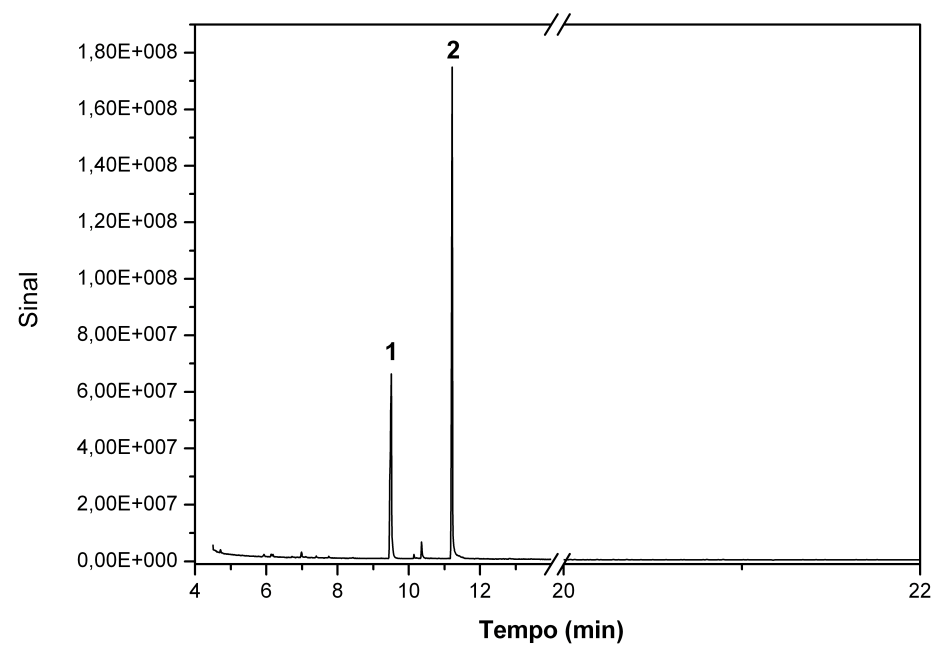

A reação escolhida é a mesma apresentada no Capítulo 2 dessa tese, o hidrogênio dos compostos fenólicos são deslocados pela piridina. A carga negativa no oxigênio permitiu atacar o carbono do agente derivatizante (ECF), formando um carbonato, conforme pode ser visto nas Figuras 4.15. Esse carbonato é caracterizado pelo íons moleculares com 73 u a mais do que o composto original na sua forma não-derivatizada, conforme pode ser visto nas Figuras 4.16 e 4.17 .

Após a otimização da extração, o método foi validado em urina por adição de padrão, tendo como faixa linear variando de $100 \mathrm{a} 1000 \mu \mathrm{g} \mathrm{L}^{-1}$. Como resposta analítica foi adotado a área relativa obtida pela razão da área do fenol dividida pela área do IS. O método validado apresentou homocedasticidade, com falta de ajuste não-significativa no intervalo de confiança de 1\%, após ter sido feito estudo pela análise de variância (ANOVA) dos dados da validação. Além disso, apresentou precisão intra-dia inferiores a $15 \%$ nas amostras analisadas em triplicata, conforme é mostrado na Tabela 4.3. 
Figura 4.16: Espectro de massas obtido para o fenol após ser derivatizado.

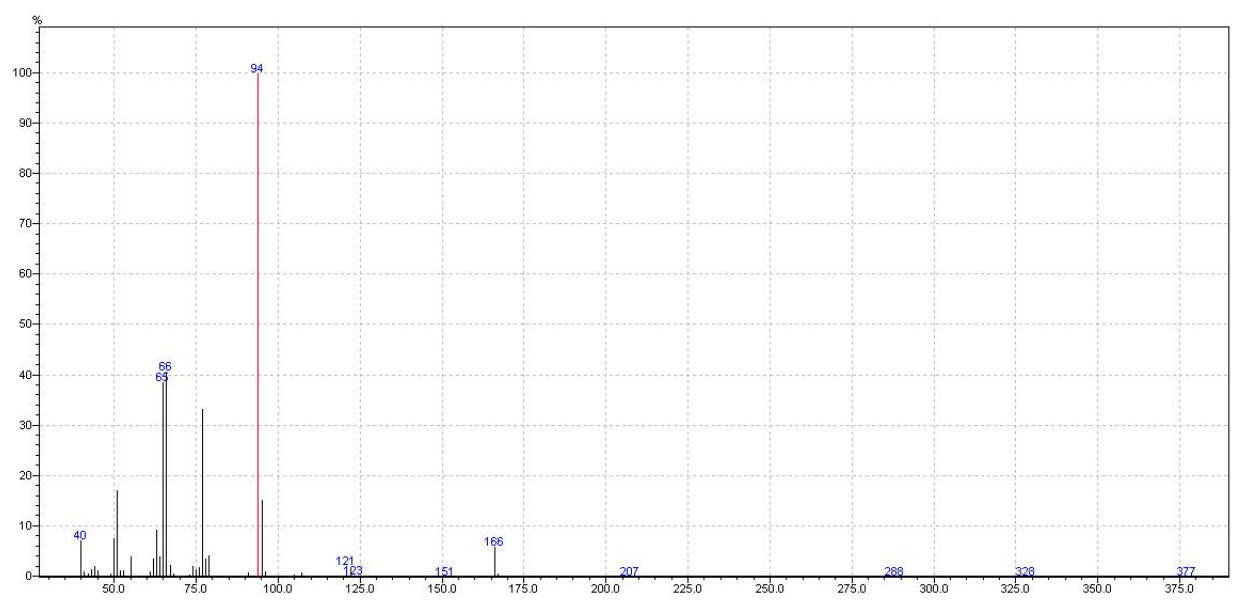

Figura 4.17: Espectro de massas obtido para o 4-cloro-3-metilfenol após ser derivatizado.

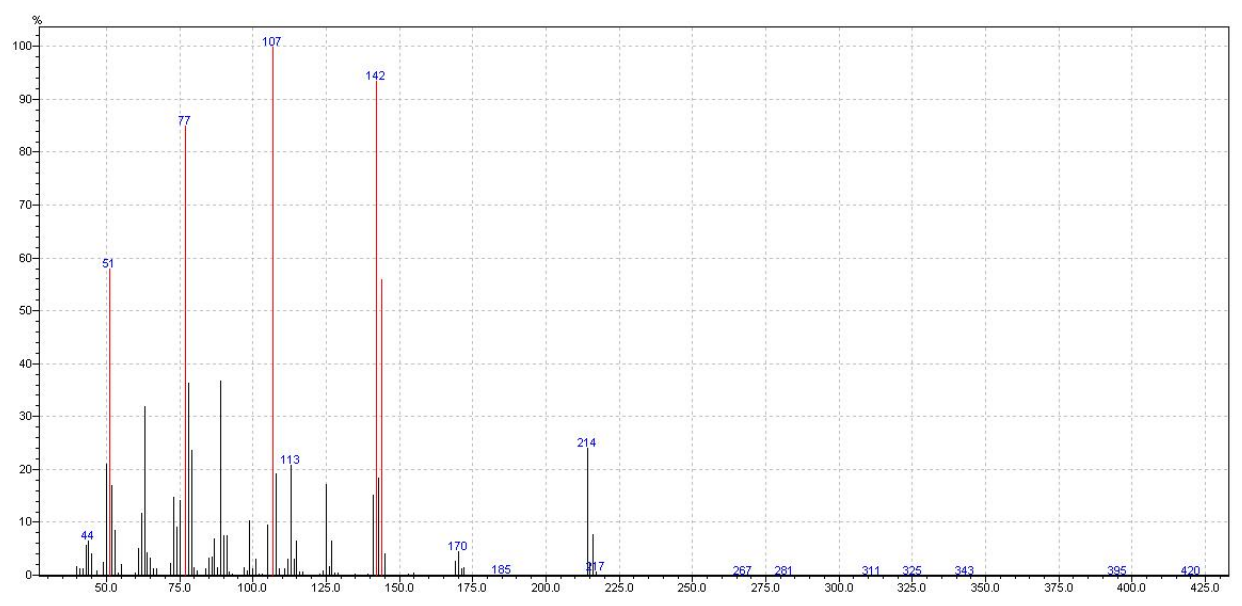

Tabela 4.3: Dados da validação da análise de fenol em urina usando a SBSE.

\begin{tabular}{ccc}
\hline Concentração $\left(\mu \mathrm{g} \mathrm{L}^{-1}\right)$ & Precisão $(\mathrm{RSD} \%)$ & Equação da reta \\
\hline 100 & 4,6 & $Y=0,0016-0,0435$ \\
200 & 7,1 & \\
300 & 4,6 & $r^{2}=0,994$ \\
500 & 7,6 & \\
1000 & 15 & \\
\hline
\end{tabular}


A calibração por adição de padrão é destinada para matrizes complexas, como os fluídos biológicos. Para descobrir a concentração presente na amostra original é necessário fazer uma extrapolação da reta até que ela toque no eixo $\mathrm{x}$, o que fornecerá uma resposta $\mathrm{y}=\mathrm{o}$. Assim, basta dividir o intercepto da curva pela inclinação da reta também da curva de calibração, para obter o valor presente na amostra. Esse procedimento deve ser feito para cada amostra que analisada por adição de padrão, seguindo esse tipo de calibração. Usando os dados obtidos, obtém-se $27 \mu \mathrm{g} \mathrm{L}^{-1}$ de fenol em urina, sendo necessário fazer uma correção pela quantidade de creatinina excretada pelo indivíduo, já que a condição renal pode alterar completamente os resultados. Nesse estudo, não foi feito a dosagem de creatinina, já que o intuito desse estudo era avaliar a versatilidade e a aplicação da barra de ACB 5\%. Esta barra demonstrou sucesso na análise fenol em urina, uma amostra complexa, e mesmo usando derivatização in situ, não apresentou nenhum tipo dano ou perda de capacidade extrativa mesmo após o método ter sido otimizado e validado, por volta de 50 análises.

\subsubsection{Aplicação dos VWSE}

Para os testes com VWSE foram confeccionados 7 frascos contendo diferentes tipos de recobrimentos, o primeiro grupo corresponde a fase mista de PDMS/DVB em diferentes proporções, sendo o PDMS fase suporte, sintetizadas conforme a Tabela 4.2. Da mesma maneira foi feita com relação a mistura PDMS e ACB em proporções de $18 \%$ e $23 \%$, além de uma fase homogênea com 100\% PDMS. Na Figura 4.18 são apresentados os primeiros protótipos feitos em laboratório. Os frascos contendo fase de ACB foram feitos novamente para evitar um volume excessivo de fase, como observado na foto referente ao ACB 23\%, e também evitar que tenha resquícios de fase na parede do vial, tendo apenas fase no fundo do frasco.

Os VWSE têm como vantagem um maior volume de fase polimérica, além de ser muito simples a síntese. Tendo como vantagem sobre a SBSE não necessitar de quebrar capilar ao final da etapa de síntese. Apesar de aumentar a capacidade de extração, como a técnica baseia nos mesmos princípios da SPME e SBSE, para atingir o equilíbrio em um maior volume de fase extratora necessita de um tempo superior ao observado para SPME e/ou SBSE.

Figura 4.18: Fases confeccionadas para os protótipos de VWSE, sendo 70:30, 85:15, 90:10, 95:5\% para PDMS/DVB, 100\% PDMS e ACB 18 e 23\%.

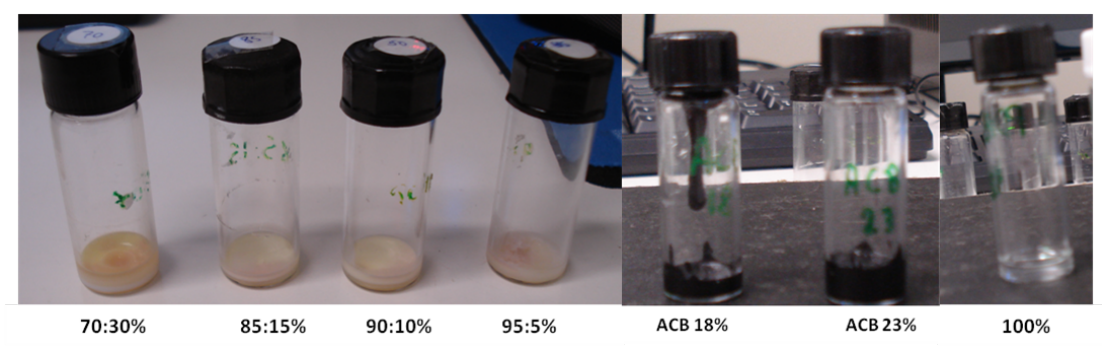


Inicialmente, a extração usando VWSE foram feitas em ultrassom aquecido a $35^{\circ} \mathrm{C}$ durante 60 minutos. Após foi feita dessorção em solvente, $0,2 \mathrm{~mL}$ de metanol em ultrassom por 20 minutos. Os fármacos analisados foram os mesmo utilizados no Capítulo 2. E ainda a extração foi feita utilizando derivatização in situ e análise por GC-MS segundo Lima Gomes e colaboradores. (136) Contudo, a única fase que apresentou sucesso foi a fase de 95:5\% PDMS/DVB, conforme o cromatograma da Figura 4.19. Foi possível extrair ibuprofeno, flurbiprofeno, fenoprofeno, naproxeno e fluoxetina. No entanto, os esteróides e a simvastatina não foram extraídas. As demais fases de PDMS/DVB apresentaram problemas como separação das fases poliméricas, mudança na coloração do polímero e desprendimento da fase do fundo do frasco. Aliado a esse fato é possível perceber nos cromatogramas um excessivo ruído e instabilidade na linha de base, sendo necessário ainda aprimorar a síntese do frasco contendo PDMS/DVB como fase extratora, apesar de ser promissor o seu uso.

A separação das fases indica que os polímeros não formaram um rede homogênea, apesar de se utilizar um agente de intercruzamento (azo-tert-butano), cuja finalidade é justamente promover o ligações em PDMS e DVB ocorram não somente na superfície do polímero como também no seu interior. Contudo, foi observado separação de fase nos frascos de VWSE contendo PDMS/DVB nas proporções 70:30, 85:15 e 90:10 em virtude da baixa ligação dos grupamentos DVB com PDMS. Em menores proporções de DVB, ocorre a formação de polímeros homogêneos.

Figura 4.19: Cromatograma no modo SIM usando VWSE de 95:5 PDMS/DVB na concentração de $0,5 \mathrm{mg} \mathrm{L}^{-1}$. 1 - ibuprofeno, 2 - fenoprofeno, 3 - flurbiprofeno, 4 - naproxeno, 5 fluoxetina.

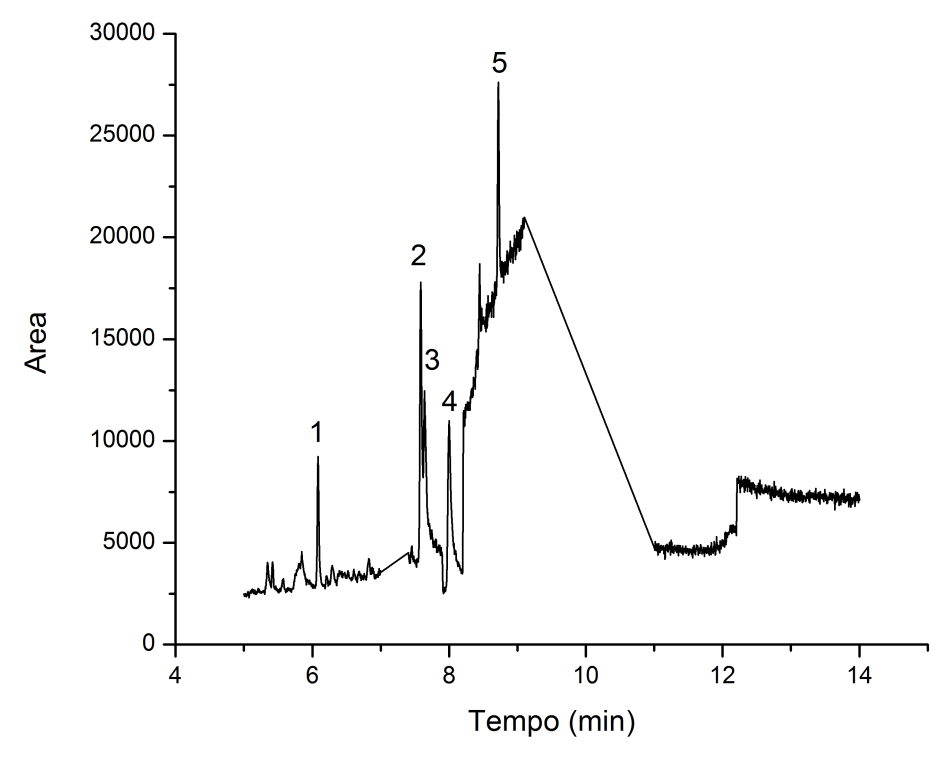

A mudança na coloração do polímero deve ser causado pelo uso de agente derivatizante 
estar reagindo com a fase e causando danos a superfície do polímero. Outro fato, grupos radicalares do catalisador AIBN utilizado para catalisar a formação do DVB a partir do seu monômero, podem estar em excesso. Consequentemente ao colocar em aquecimento, em ultrassom e com outro agente reativo, causaria as reações observadas na superfície dos polímeros.

O desprendimento da fase pode ser associada aos demais acontecimentos acima e ainda estar relacionado ao uso do ultrassom por um longo período, tanto na extração como na dessorção. Não era esperada esse acontecimento, pois antes de adicionar os monômeros no frasco, foi realizado a ativação dos grupos silanóis do vidro ativados seguindo Hu et.al. (100). Dessa maneira os grupos silanóis terminais se ligam aos grupamentos do PDMS impedindo que o recobrimento saia do fundo do frasco.

Como o polímero de PDMS/DVB precisa de melhorias na sua síntese, esse será mais estudado em processos futuros. Novos testes serão realizados na ausência de derivatizante para ver sua interferência na fase polimérica, uma vez que em fibras de SPME com fase PDMS/DVB é notável o escurecimento dessas fases após seu uso na extração de fármacos com derivatização in situ, sendo necessário descartar as fibras após 25 extrações. As extrações serão testadas em vórtex e comparados com ultrassom, com relação ao acontecimento do desprendimento da fase polimérica do fundo do frasco.

As fases mistas de ACB nas mesmas condições testadas apenas extraiu somente o ibuprofeno, conforme demonstra a Figura 4.20.

Figura 4.20: Cromatograma no modo SIM usando VWSE de ACB 18\% na concentração de $0,5 \mathrm{mg} L^{-1} .1$ - ibuprofeno.

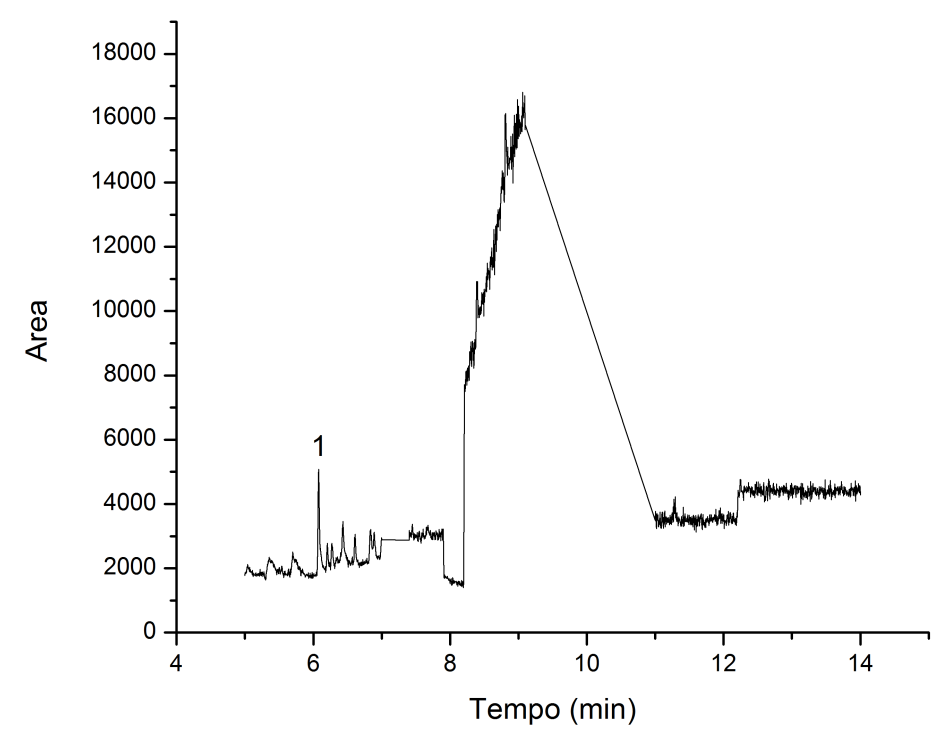

Devido o sucesso parcial dos protótipos, foram feitos novamente os VWSE tendo basica- 
mente a fase de PDMS e ACB de 20, 10 e 5\%, já que o acima de 20\% de carvão deixa o polímero muito viscoso, sendo difícil o depósito no fundo do frasco. Esses dispositivos foram aplicados na extração de progesterona, já que essa foi a proposta de Kawaguchi e colaboradores (4), para verificar e localizar possíveis erros na confecção dos protótipos. Porém, com os novos frascos foi possível extrair a progesterona tanto no recobrimento contendo PDMS como no ACB. No entanto, devido a progesterona ser não-polar $(\log \mathrm{P}=3,9)$ teve uma afinidade maior pela fase de PDMS, conforme mostra na Figura 4.21.

Já no estudo da progesterona, um nova alternativa para aumentar ainda mais a área superficial foi testado. O depósito de polímero no fundo e nas parede internas do frasco foi usado, e seu efeito avaliado. Para a progesterona, mesmo com ACB nas paredes internas e no fundo do frasco, o PDMS mostrou afinidade superior, independente da condição da extração, como pode ser visualizado na Figura 4.21. Apesar disso, mostra ser uma alternativa interessante, principalmente em análises de compostos mais polares.

A confecção desses frascos com polímeros nas paredes internas só foi possível com o uso de uma parafusadeira e uma fonte de temperatura, conforme mostra a Figura 4.22. Esse trabalho contou com a colaboração da aluna iniciação científica Camila Centurion Silva.

Figura 4.21: Comparações das áreas obtidas nas extrações de progesterona: (a) Extração realizada com $\mathrm{V}=0,5 \mathrm{~mL}$ e tempo de extração de 30 minutos.

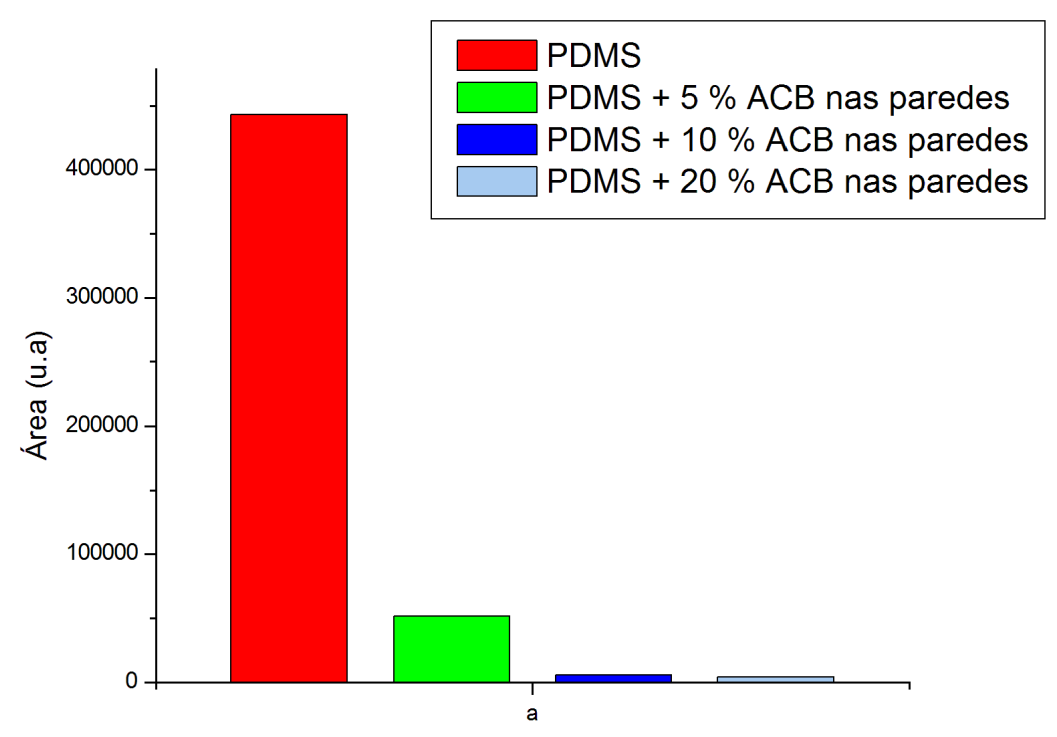


Figura 4.22: Configuração para síntese de polímeros depositados no fundo e nas paredes internas do frasco.

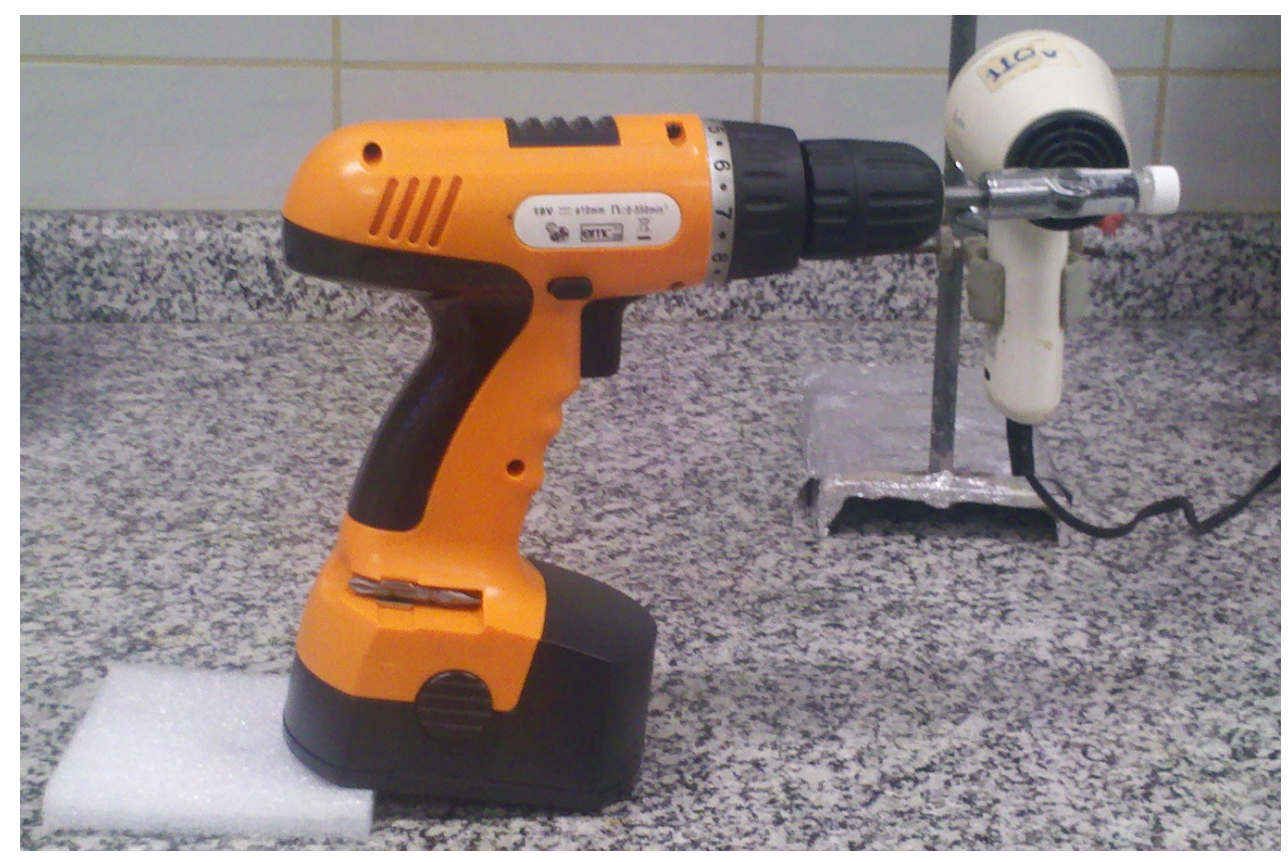

A Figura 4.23 mostra os novos dispositivos de VWSE feitos, tendo como destaque o VWSE com fase depositado nas paredes internas e no fundo do frasco.

Para verificar a aplicabilidade em compostos mais polares, a cafeína foi escolhida por possuir um Log $\mathrm{P}$ de - 0,07. A Figura 4.24 mostra que à medida que a porcentagem de ACB adicionado ao PDMS é aumentada, há uma melhora na extração da cafeína. Além disso, fica comprovada a deficiência da fase de PDMS para extração de compostos com a mesma polaridade da cafeína, sendo necessário o uso de novos polímeros para aumentar a abrangência da VWSE

Figura 4.23: Fases de ACB na parede de frasco (a), ACB (b) e PDMS (c) no fundo do frasco.

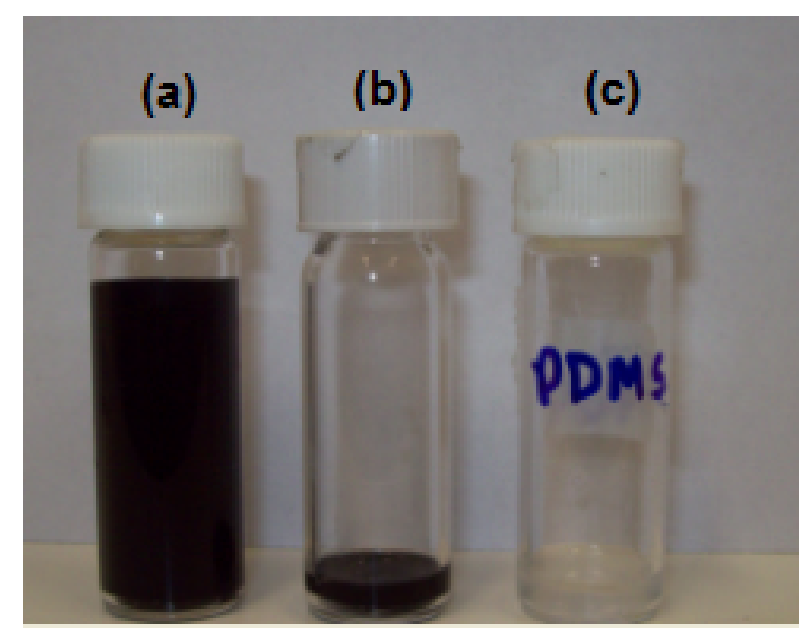


Figura 4.24: Gráfico da comparação das áreas obtidas da análise de cafeína utilizando frascos com diferentes porcentagens de carvão ativado.

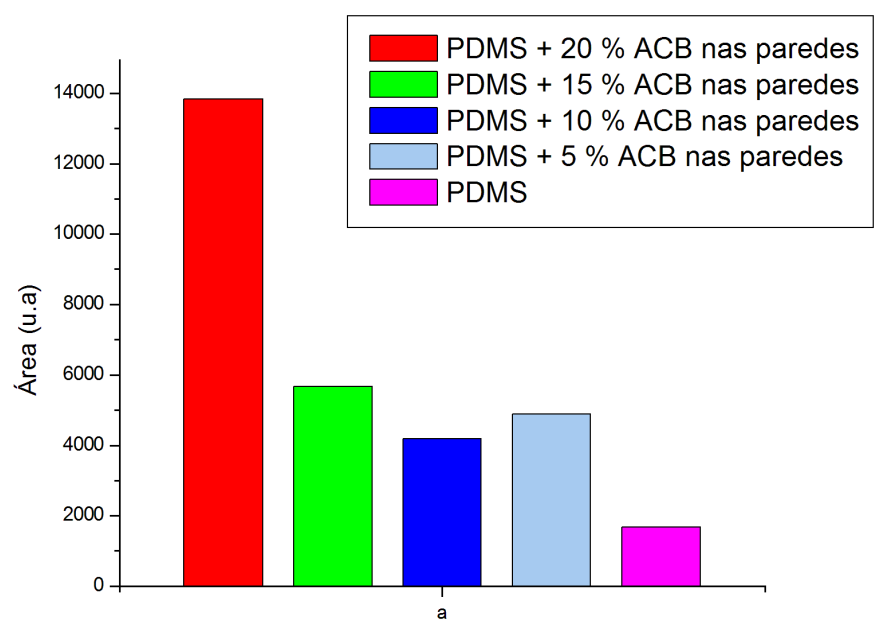

\subsection{Conclusões}

As várias etapas no processo de síntese das barras foram essenciais para melhorar o procedimento até alcançar o novo molde. O desenvolvimento do novo molde foi essencial para facilitar a síntese de novas barras de SBSE, tendo novos recobrimentos poliméricos. Esses novos recobrimentos apresentaram aplicabilidade adequada para diversos analitos em diferentes matrizes, e mesmo usando reações de derivatização, as barras permaneceram estáveis.

Uma nova fase polimérica foi desenvolvida para a VWSE, e ainda uma nova configuração da VWSE foi usada com filme polimérico presente nas paredes internas e no fundo do frasco. A VWSE demonstra capacidade de extrair compostos polares e não-polares em amostras de água, tendo um potencial que necessita ainda ser melhor avaliado.

\subsection{Perspectivas futuras}

Aplicar as novas barras de SBSE e os dispositivos de VWSE, já que não houve tempo hábil para finalizar um estudo completo utilizando as novas fases. Além disso, refazer as barras usando o magneto mais denso, e utilizar molde apropriado para confecção das barras com esse magneto denso envolvido por vidro. 


\section{REFERÊNCIAS BIBLIOGRÁFICAS}

1 FATTA-KASSINOS, D.; MERIC, S.; NIKOLAOU, A. Pharmaceutical residues in environmental waters and wastewater: current state of knowledge and future research. Analytical and Bioanalytical Chemistry, v. 399, n. 1, p. 251-275, 2011.

2 PARREIRA, F. V.; CARDEAL, Z. L. Amostragem de compostos organicos voláteis no ar utilizando a técnica de microextração em fase sólida. Quimica Nova, v. 28, p. 646-654, 2005.

3 BALTUSSEN, E.; SANDRA, P.; DAVID, F.; CRAMERS, C. Stir bar sorptive extraction (SBSE), a novel extraction technique for aqueous samples: Theory and principles. Journal of Microcolumn Separations, v. 11, n. 10, p. 737-747, 1999.

4 KAWAGUCHI, M.; FUJII, S.; ITOH, N.; ITO, R.; NAKAZAWA, H.; TAKATSU, A. Development of vial wall sorptive extraction and its application to determination of progesterone in human serum. Journal of Chromatography A, v. 1216, n. 44, p. 7553-7557, 2009.

5 GOUPY, J.; CREIGTHTON, L. Introduction to design of experiments. 3th. ed. Cary: SAS Institute, 2007. $473 \mathrm{p}$.

6 COMMITTEE, A. M.; HOWARTH, R.; MILLER, J. N.; NEWMAN, E. J. Is my calibration linear? Analytical Methods Committee, v. 119, p. 2363-2366, 1994.

7 PIMENTEL, M. F.; BARROS NETO, B. Calibração: uma revisão para químicos analíticos. Química Nova, v. 19 , n. 3, p. 268-277, 1996.

8 MONDELLO, L.; LEWIS, A. C.; BARTLE, K. D. Multidimensional chromatography. New York, NY: John Wiley, 2002. 448 p.

9 DALlUGE, J.; BEENS, J.; BRINKMAN, U. A. T. Comprehensive two-dimensional gas chromatography: a powerful and versatile analytical tool. Journal of Chromatography A, v. 1000, n. 1-2, p. 69-108, 2003.

10 YING, G.-G.; KOOKANA, R. S.; RU, Y.-J. Occurrence and fate of hormone steroids in the environment. Environment International, v. 28, n. 6, p. 545-551, 2002.

11 SUPELCO. SPME fiber coating. 2011. Disponível em: < http://www.sigmaaldrich.com/analyticalchromatography/sample-preparation/spme/selecting-spme-fiber.html>. Acesso em: 30 abr. 2012.

12 TEOFILO, R. F.; FERREIRA, M. M. C. Quimiometria II: planilhas eletrônicas para calculos de planejamentos experimentais, um tutorial. Quimica Nova, v. 29, p. 338-350, 2006.

13 MOE, C. L.; RHEINGANS, R. D. Global challenges in water, sanitation and health. Journal of Water and Heath, v. 4, n. 1, p. 41-57, 2006.

14 GOODMAN, L. S.; GILMAN, A. G. As bases farmacológicas da terapêutica. 10th. ed. Rio de Janeiro: The McGraw-Hill, 2005. 1825 p.

15 SILVA, P. Farmacologia. Rio de Janeiro: Guanabara Koogan, 2002. 1398 p. 
16 OGA, S.; CAMARGO, M. A.; BATISTUZZO, J. A. O. Fundamentos de toxicologia. São Paulo: Atheneu, 2008. $677 \mathrm{p}$.

17 WERNER, K. Pharmacogenetics and personalised medicine. Fundamental \& Clinical Pharmacology, v. 16, n. 5, p. 337-342, 2002.

18 U. S. FOOD AND DRUG ADMINISTRATION (FDA). Environmental Assessment of Human Drug and Biologics Applications. Rockville, 1998. v. 1, 42 p. (CMC 6 Revison).

19 JJEMBA, P. K. Excretion and ecotoxicity of pharmaceutical and personal care products in the environment. Ecotoxicology and Environmental Safety, v. 63, n. 1, p. 113-30, 2006.

20 DIAZ-CRUZ, M. S.; ALDA, M. J.; BARCELO, D. Environmental behavior and analysis of veterinary and human drugs in soils, sediments and sludge. Trends in Analytical Chemistry, v. 22, n. 6, p. 340-351, 2003.

21 SUKUL, P.; LAMSHöFT, M.; ZÜHLKE, S.; SPITELLER, M. Sorption and desorption of sulfadiazine in soil and soil-manure systems. Chemosphere, v. 73, n. 8, p. 1344-1350, 2008.

22 RADJENOVIC, J.; PETROVIC, M.; BARCELÓ, D. Analysis of pharmaceuticals in wastewater and removal using a membrane bioreactor. Analytical and Bioanalytical Chemistry, v. 387, n. 4, p. 1365-1377, 2007.

23 JONES-LEPP, T.; STEVENS, R. Pharmaceuticals and personal care products in biosolids/sewage sludge: the interface between analytical chemistry and regulation. Analytical and Bioanalytical Chemistry, v. 387, n. 4, p. 1173-1183, 2007.

24 VAJDA, A. M.; BARBER, L. B.; GRAY, J. L.; LOPEZ, E. M.; BOLDEN, A. M.; SCHOENFUSS, H. L.; NORRIS, D. O. Demasculinization of male fish by wastewater treatment plant effluent. Aquatic Toxicology, v. 103, n. 3-4, p. 213-21, 2011.

25 PASCOE, D.; KARNTANUT, W.; MÜLLER, C. T. Do pharmaceuticals affect freshwater invertebrates? a study with the cnidarian Hydra vulgaris. Chemosphere, v. 51, n. 6, p. 521 - 528, 2003.

26 WATTS, M. M.; PASCOE, D.; CARROLL, K. Population responses of the freshwater amphipod Gammarus pulex (L.) to an environmental estrogen, 17 $\alpha$-ethinylestradiol. Environmental Toxicology and Chemistry, v. 21, n. 2, p. 445-450, 2002.

27 ENVIRONMENTAL PROTECTION AGENCY (EPA). Removal of endocrine disruptor chemicals using drinking water treatment processes. Cincinatti, 2001. 27 p. EPA/625/R-00/015.

28 HARVEY, P. W.; EVERETT, D. J. Regulation of endocrine-disrupting chemicals: Critical overview and deficiencies in toxicology and risk assessment for human health. Best Practice \& Research Clinical Endocrinology \& Metabolism, v. 20, n. 1, p. 145 - 165, 2006.

29 DIAZ-CRUZ, M. S.; BARCELO, D. LC-MS ${ }^{2}$ trace analysis of antimicrobials in water, sediment and soil. Trends in Analytical Chemistry, v. 24, n. 7, p. 645-657, 2005.

30 DIAZ-CRUZ, M.; BARCELO, D. Determination of antimicrobial residues and metabolites in the aquatic environment by liquid chromatography tandem mass spectrometry. Analytical and Bioanalytical Chemistry, v. 386 , n. 4 , p. $973-985,2006$.

31 GOMEZ, M. J.; PETROVIC, M.; FERNANDEZ-ALBA, A. R.; BARCELO, D. Determination of pharmaceuticals of various therapeutic classes by solid-phase extraction and liquid chromatography-tandem mass spectrometry analysis in hospital effluent wastewaters. Journal of Chromatography A, v. 1114, n. 2, p. 224-233, 2006.

32 RODRIGUEZ-MOZAZ, S.; ALDA, M. J. L.; BARCELO, D. Advantages and limitations of on-line solid phase extraction coupled to liquid chromatography-mass spectrometry technologies versus biosensors for monitoring of emerging contaminants in water. Journal of Chromatography A, v. 1152, n. 1-2, p. 97-115, 2007.

33 DIAZ-CRUZ, S. M.; LLORCA, M.; BARCELO, D. Organic UV filters and their photodegradates, metabolites and disinfection by-products in the aquatic environment. Trends in Analytical Chemistry, v. 27, n. 10, p. 873-887, 2008.

34 ANTONIC, J.; HEATH, E. Determination of NSAIDs in river sediment samples. Analytical and Bioanalytical Chemistry, v. 387, n. 4, p. 1337-1342, 2007. 
35 ARAUJO, L.; WILD, J.; VILlA, N.; CAMARGO, N.; CUBILlAN, D.; PRIETO, A. Determination of anti-inflammatory drugs in water samples, by in situ derivatization, solid phase microextraction and gas chromatography-mass spectrometry. Talanta, v. 75, n. 1, p. 111-115, 2008.

36 CANOSA, P.; RODRIGUEZ, I.; RUBIO, E.; BOLLAIN, M. H.; CELA, R. Optimisation of a solid-phase microextraction method for the determination of parabens in water samples at the low ng per litre level. Journal of Chromatography A, v. 1124, n. 1-2, p. 3-10, 2006.

37 GOMEZ, M. J.; AGUERA, A.; MEZCUA, M.; HURTADO, J.; MOCHOLA, F.; FERNANDEZ-ALBA, A. R. Simultaneous analysis of neutral and acidic pharmaceuticals as well as related compounds by gas chromatography-tandem mass spectrometry in wastewater. Talanta, v. 73, n. 2, p. 314-320, 2007.

38 QUINTANA, J. B.; RODIL, R.; MUNIATEGUI-LORENZO, S.; LOPEZ-MAHIA, P.; PRADARODRIGUEZ, D. Multiresidue analysis of acidic and polar organic contaminants in water samples by stir-bar sorptive extraction-liquid desorption-gas chromatography-mass spectrometry. Journal of Chromatography A, v. 1174, n. 1-2, p. 27-39, 2007.

39 GOMEZ, M. J.; HERRERA, S.; SOLE, D.; GARCIA-CALVO, E.; FERNANDEZ-ALBA, A. R. Automatic searching and evaluation of priority and emerging contaminants in wastewater and river water by stir bar sorptive extraction followed by comprehensive two-dimensional gas chromatography-time-of-flight mass spectrometry. Analytical Chemistry, v. 83, n. 7, p. 2638-2647, 2011.

40 PAVLOVIC, D. M.; BABIC, S.; HORVAT, A. J. M.; KASTELAN-MACAN, M. Sample preparation in analysis of pharmaceuticals. Trends in Analytical Chemistry, v. 26, n. 11, p. 1062-1075, 2007.

41 ZORITA, S.; LARSSON, L.; MATHIASSON, L. Comparison of solid-phase sorbents for the determination of fluoroquinolone antibiotics in wastewater. Journal of Separation Science, v. 31, n. 16-17, p. 3117-3121, 2008.

42 ARTHUR, C. L.; PAWLISZYN, J. Solid phase microextraction with thermal desorption using fused silica optical fibers. Analytical Chemistry, v. 62, n. 19, p. 2145-2148, 1990.

43 PAWLISZYN, J. Solid phase microextraction:: theory and practice. Richmond: Ontario, 1997. 264 p.

44 STALIKAS, C.; FIAMEGOS, Y.; SAKKAS, V.; ALBANIS, T. Developments on chemometric approaches to optimize and evaluate microextraction. Journal of Chromatography A, v. 1216, n. 2, p. 175-189, 2009.

45 BARROS NETO, B.; SCARMINIO, I. S.; BRUNS, R. E. 25 anos de quimiometria no Brasil. Quimica Nova, v. 29, p. 1401-1406, 2006.

46 FERREIRA, S. L. C.; BRUNS, R. E.; FERREIRA, H. S.; MATOS, G. D.; DAVID, J. M.; BRANDAO, G. C.; SILVA, E. G. P.; PORTUGAL, L. A.; REIS, P. S.; SOUZA, A. S.; SANTOS, W. N. L. Box-Behnken design: An alternative for the optimization of analytical methods. Analytica Chimica Acta, v. 597, n. 2, p. 179-186, 2007.

47 BEZERRA, M. d. A. Aplicação de matriz de Doehlert na otimização de um sistema de pré-concentração em linha para deteminação de cobre usando Espectrometria de absorção atômica com chama. 2003. Dissertação (Mestrado) — Instituto de Química, Universidade Federal da Bahia, 2003.

48 NECHAR, M.; MOLINA, M. F. M.; RODRIGUEZ, L. C.; SENDRA, J. M. B. The application of Doehlert designs in the optimization of experimental variables in solid phase spectrophotometry. Analytica Chimica Acta, v. 316, n. 2, p. 185-193, 1995.

49 RIBANI, M.; BOTTOLI, C. B. G.; COLLINS, C. H.; JARDIM, I. C. S. F.; MELO, L. F. C. Validação em métodos cromatográficos e eletroforéticos. Quimica Nova, v. 27, n. 5, p. 771-780, 2004.

50 AGENCIA NACIONAL DE VIGILANCIA SANITARIA (ANVISA). Guia para métodos analíticos e bioanalíticos, Resolução RE n⿳0 899 ANVISA, de 29 de maio de 2003. Brasília. Série 1.

51 INSTITUTO NACIONAL DE METROLOGIA (INMETRO). Orientações sobre validação de métodos de ensaios químicos DOQ-CGCRE-008. Rio de Janeiro, 2003. 35 p.

52 U.S. FOOD AND DRUG ADMINISTRATION. Bioanalytical Method Validation. Rockville, 2001. 25 p.

53 THOMPSON, M.; ELISSON, S. L. R.; WOOD, R. Harmonized guidelines for single-laboratory validation of methods of analysis. Durham, 2002. v. 74, n. 5, 855 p.

54 INTERNATIONAL CONFERENCE ON HARMONISATION (ICH). Validation of analytical procedutes: Methodology. Geneva, 1996. Q2(R1), 1-13 p. 
55 CASSIANO, N. M.; BARREIRO, J. C.; MARTINS, L. R. R.; OLIVEIRA, R. V.; CASS, Q. B. Validação em métodos cromatográficos para análises de pequenas moléculas em matrizes biológicas. Química Nova, v. 32, p. 1021 - 1030, 002009.

56 DEJAEGHER, B.; HEYDEN, Y. V. Ruggedness and robustness testing. Journal of Chromatography A, v. 1158 , n. $1-2$, p. $138-157,2007$.

57 MANSILHA, C.; MELO, A.; REBELO, H.; FERREIRA, I. M. P. L. V. O.; PINHO, O.; DOMINGUES, V.; PINHO, C.; GAMEIRO, P. Quantification of endocrine disruptors and pesticides in water by gas chromatography-tandem mass spectrometry. Method validation using weighted linear regression schemes. Journal of Chromatography A, v. 1217, n. 43, p. 6681-91, 2010.

58 MILLER, J. N.; MILLER, J. C. Statistics and chemometrics for analytical chemistry. Harlow: Pearson, 2005. $285 \mathrm{p}$.

59 RICHARDSON, S. D. Environmental mass spectrometry: Emerging contaminants and current issues. Analytical Chemistry, v. 82, n. 12, p. 4742-4774, 2010.

60 OAKS, J. L.; GILBERT, M.; VIRANI, M. Z.; WATSON, R. T.; METEYER, C. U.; RIDEOUT, B. A.; SHIVAPRASAD, H. L.; AHMED, S.; IQbal CHAUDHRY, M. J.; ARSHAD, M.; MAHMOOD, S.; ALI, A.; AHMED KHAN, A. Diclofenac residues as the cause of vulture population decline in pakistan. Nature, v. 427, n. 6975, p. 630-633, 2004.

61 RODRIGUEZ-MOZAZ, S.; ALDA, M. J. L. d.; BARCELO, D. Picogram per liter level determination of estrogens in natural waters and waterworks by a fully automated on-line solid-phase extraction-liquid chromatography-electrospray tandem mass spectrometry method. Analytical Chemistry, v. 76, n. 23, p. 6998-7006, 2004.

62 HOECK, E. V.; CANALE, F.; CORDERO, C.; COMPERNOLLE, S.; BICCHI, C.; SANDRA, P. Multiresidue screening of endocrine-disrupting chemicals and pharmaceuticals in aqueous samples by multi-stir bar sorptive extraction-single desorption-capillary gas chromatography/mass spectrometry. Analytical and Bioanalytical Chemistry, v. 393, n. 3, p. 907-919, 2009.

63 FERNANDES, C.; HOECK, E. V.; SANDRA, P.; LANCAS, F. M. Determination of fluoxetine in plasma by gas chromatography-mass spectrometry using stir bar sorptive extraction. Analytica Chimica Acta, v. 614, n. 2, p. 201-207, 2008.

64 STOPFORTH, A.; BURGER, B. V.; CROUCH, A. M.; SANDRA, P. The analysis of estrone and 17 $\beta$ estradiol by stir bar sorptive extraction-thermal desorption-gas chromatography/mass spectrometry: Application to urine samples after oral administration of conjugated equine estrogens. Journal of Chromatography B, v. 856, n. 1-2, p. 156-164, 2007.

65 ZHOU, Y.; JIANG, Q.; PENG, Q.; XUAN, D.; QU, W. Development of a solid phase microextraction-gas chromatography-mass spectrometry method for the determination of pentachlorophenol in human plasma using experimental design. Chemosphere, v. 70, n. 2, p. 256-262, 2007.

66 SODRE, F.; LOCATELLI, M.; JARDIM, W. Occurrence of emerging contaminants in brazilian drinking waters: A sewage-to-tap issue. Water Air and Soil Pollution, v. 206, n. 1, p. 57-67, 2009.

67 VERA-CANDIOTI, L.; GARCIA, M. D. G.; GALERA, M. M.; GOICOECHEA, H. C. Chemometric assisted solid-phase microextraction for the determination of anti-inflammatory and antiepileptic drugs in river water by liquid chromatography-diode array detection. Journal of Chromatography A, v. 1211, n. 1-2, p. 22-32, 2008.

68 PAVON, J. L. P.; MARIA, C. F. A.; LAESPADA, M. E. F.; CORDERO, B. M. In situ derivatization reaction and determination of ibuprofen in water samples using headspace generation-programmed temperature vaporization-gas chromatography-mass spectrometry. Journal of Chromatography A, v. 1216, n. 39, p. 6728-6734, 2009.

69 RODRIGUEZ, I.; QUINTANA, J. B.; CARPINTEIRO, J.; CARRO, A. M.; LORENZO, R. A.; CELA, R. Determination of acidic drugs in sewage water by gas chromatography-mass spectrometry as tert.-butyldimethylsilyl derivatives. Journal of Chromatography A, v. 985, n. 1-2, p. 265-274, 2003.

70 SUCHARA, E. A.; BUDZIAK, D.; MARTENDAL, E.; COSTA, L. L. F.; CARASEK, E. A combination of statistical and analytical evaluation methods as a new optimization strategy for the quantification of pharmaceutical residues in sewage effluent. Analytica Chimica Acta, v. 613, n. 2, p. 169-176, 2008. 
71 KAWAGUCHI, M.; INOUE, K.; YOSHIMURA, M.; ITO, R.; SAKUI, N.; OKANOUCHI, N.; NAKAZAWA, $\mathrm{H}$. Determination of bisphenol A in river water and body fluid samples by stir bar sorptive extraction with in situ derivatization and thermal desorption-gas chromatography-mass spectrometry. Journal of Chromatography B, v. 805, n. 1, p. 41-48, 2004.

72 STASHENKO, E. E.; MARTÍNEZ, J. R. Derivatization and solid-phase microextraction. Trends in Analytical Chemistry, v. 23, n. 8, p. 553-561, 2004.

73 RISTICEVIC, S.; NIRI, V.; VUCKOVIC, D.; PAWLISZYN, J. Recent developments in solid-phase microextraction. Analytical and Bioanalytical Chemistry, v. 393, n. 3, p. 781-795, 2009.

74 BUGEL, S. M.; WHITE, L. A.; COOPER, K. R. Decreased vitellogenin inducibility and $17 \beta$-estradiol levels correlated with reduced egg production in killifish (Fundulus heteroclitus) from Newark Bay, NJ. Aquatic Toxicology, v. 105, n. 1-2, p. 1-12, 2011.

75 DAVIS, J. M.; GIDDINGS, J. C. Statistical method for estimation of number of components from single complex chromatograms: theory, computer-based testing, and analysis of errors. Analytical Chemistry, v. 57, n. 12 , p. $2168-2177,1985$.

76 CORTES, H. J.; WINNIFORD, B.; LUONG, J.; PURSCH, M. Comprehensive two dimensional gas chromatography review. Journal of Separation Science, v. 32, n. 5-6, p. 883-904, 2009.

77 ZINI, C. A. Cromatografia gasosa bidimensional. Scientia Chromatographica, v. 1, n. 1, p. 31-49, 2009.

78 SIEGLER, W. C.; FITZ, B. D.; HOGGARD, J. C.; SYNOVEC, R. E. Experimental study of the quantitative precision for valve-based comprehensive two-dimensional gas chromatography. Analytical Chemistry, v. 83, n. 13, p. 5190-5196, 2011.

79 MARRIOTT, P. J.; KINGHORN, R. M. Longitudinally modulated cryogenic system. a generally applicable approach to solute trapping and mobilization in gas chromatography. Analytical Chemistry, v. 69, n. 13, p. 2582-2588, 1997.

80 ENVIRONMENTAL PROTECTION AGENCY (EPA). Method 1694:: Pharmaceuticals and personal care products in water, soil, sediment, and biosolids by hplc/ ms/ ms. Cincinatti, 2007. 1-77 p.

81 POCURULL, E.; PEDROUZO, M.; BORRULL, F.; MARCE, R. M. Analytical methods for personal-care products in environmental waters. Trends in Analytical Chemistry, v. 30, n. 5, p. 749-760, 2011.

82 BARNES, B. B.; SNOW, N. H. Analysis of salvinorin a in plants, water, and urine using solid-phase microextraction-comprehensive two-dimensional gas chromatography-time of flight mass spectrometry (spme-gcxgc-tofms). Journal of Chromatography A, v. 1226, p. 110-115, 2012.

83 ANIZAN, S.; BICHON, E.; MONTEAU, F.; CESBRON, N.; ANTIGNAC, J.-P.; BIZEC, B. L. A new reliable sample preparation for high throughput focused steroid profiling by gas chromatography-mass spectrometry.

Journal of Chromatography A, v. 1217, n. 43, p. 6652-6660, 2010.

84 YANG, L.; LUAN, T.; LAN, C. Solid-phase microextraction with on-fiber silylation for simultaneous determinations of endocrine disrupting chemicals and steroid hormones by gas chromatography-mass spectrometry. Journal of Chromatography A, v. 1104, n. 1-2, p. 23-32, 2006.

85 PENALVER, A.; POCURULl, E.; BORRULL, F.; MARCE, R. M. Method based on solid-phase microextraction-high-performance liquid chromatography with UV and electrochemical detection to determine estrogenic compounds in water samples. Journal of Chromatography A, v. 964, n. 1-2, p. 153-160, 2002.

86 MATAMOROS, V.; JOVER, E.; BAYONA, J. M. Part-per-trillion determination of pharmaceuticals, pesticides, and related organic contaminants in river water by solid-phase extraction followed by comprehensive two-dimensional gas chromatography time-of-flight mass spectrometry. Analytical Chemistry, v. 82, n. 2, p. 699-706, 2010.

87 OCHIAI, N.; IEDA, T.; SASAMOTO, K.; TAKAZAWA, Y.; HASHIMOTO, S.; FUSHIMI, A.; TANABE, K. Stir bar sorptive extraction and comprehensive two-dimensional gas chromatography coupled to high-resolution time-of-flight mass spectrometry for ultra-trace analysis of organochlorine pesticides in river water. Journal of Chromatography A, v. 1218, n. 39, p. 6851-6860, 2011.

88 BICCHI, C.; CORDERO, C.; LIBERTO, E.; RUBIOLO, P.; SGORBINI, B.; DAVID, F.; SANDRA, P. Dual-phase twisters: A new approach to headspace sorptive extraction and stir bar sorptive extraction. Journal of Chromatography A, v. 1094, n. 1-2, p. 9-16, 2005. 
89 BICCHI, C.; CORDERO, C.; LIBERTO, E.; SGORBINI, B.; DAVID, F.; SANDRA, P.; RUBIOLO, $\mathrm{P}$. Influence of polydimethylsiloxane outer coating and packing material on analyte recovery in dual-phase headspace sorptive extraction. Journal of Chromatography A, v. 1164, n. 1-2, p. 33-39, 2007.

90 KAWAGUCHI, M.; ISHII, Y.; SAKUI, N.; OKANOUCHI, N.; ITO, R.; INOUE, K.; SAITO, K.; NAKAZAWA, H. Stir bar sorptive extraction with in situ derivatization and thermal desorption-gas chromatography-mass spectrometry in the multi-shot mode for determination of estrogens in river water samples. Journal of Chromatography A, v. 1049, n. 1-2, p. 1-8, 2004.

91 KAWAGUCHI, M.; ISHII, Y.; SAKUI, N.; OKANOUCHI, N.; ITO, R.; SAITO, K.; NAKAZAWA, H. Stir bar sorptive extraction with in situ derivatization and thermal desorption-gas chromatography-mass spectrometry for determination of chlorophenols in water and body fluid samples. Analytica Chimica Acta, v. 533, n. 1, p. $57-65,2005$.

92 KAWAGUCHI, M.; SAKUI, N.; OKANOUCHI, N.; ITO, R.; SAITO, K.; IZUMI, S.; MAKINO, T.; NAKAZAWA, H. Stir bar sorptive extraction with in situ derivatization and thermal desorption-gas chromatography-mass spectrometry for measurement of phenolic xenoestrogens in human urine samples. Journal of Chromatography B, v. 820, n. 1, p. 49-57, 2005.

93 KAWAGUCHI, M.; ITO, R.; SAKUI, N.; OKANOUCHI, N.; SAITO, K.; NAKAZAWA, H. Dual derivatization-stir bar sorptive extraction-thermal desorption-gas chromatography-mass spectrometry for determination of $17 \beta$-estradiol in water sample. Journal of Chromatography A, v. 1105, n. 1-2, p. 140-147, 2006.

94 CARMI, J. D.; OLIVARES, I.; GROSSI, P.; LANCAS, F. M. Refrigerated sorptive extraction: Determination of btex in water samples. Journal of Chromatographic Science, v. 47, p. 812-816, 2009.

95 HU, R.; ZHANG, L.; YANG, Z. Picogram determination of estrogens in water using large volume injection gas chromatography-mass spectrometry. Analytical and Bioanalytical chemistry, v. 390, n. 1, p. 349-59, 2008.

96 BARRIADA-PEREIRA, M.; SERODIO, P.; GONZALEZ-CASTRO, M. J.; NOGUEIRA, J. M. F.

Determination of organochlorine pesticides in vegetable matrices by stir bar sorptive extraction with liquid desorption and large volume injection-gas chromatography-mass spectrometry towards compliance with European Union directives. Journal of Chromatography A, v. 1217, n. 1, p. 119-126.

97 LIU, W.; WANG, H.; GUAN, Y. Preparation of stir bars for sorptive extraction using sol-gel technology. Journal of Chromatography A, v. 1045, n. 1-2, p. 15-22, 2004.

98 LAMBERT, J.-P.; MULLETT, W. M.; KWONG, E.; LUBDA, D. Stir bar sorptive extraction based on restricted access material for the direct extraction of caffeine and metabolites in biological fluids. Journal of Chromatography A, v. 1075, n. 1-2, p. 43-49, 2005.

99 ZHU, X.; CAI, J.; YANG, J.; SU, Q.; GAO, Y. Films coated with molecular imprinted polymers for the selective stir bar sorption extraction of monocrotophos. Journal of Chromatography A, v. 1131, n. 1-2, p. $37-44,2006$.

100 HU, Y.; ZHENG, Y.; ZHU, F.; LI, G. Sol-gel coated polydimethylsiloxane/ $\beta$-cyclodextrin as novel stationary phase for stir bar sorptive extraction and its application to analysis of estrogens and bisphenol a. Journal of Chromatography A, v. 1148, n. 1, p. 16-22, 2007.

101 NENG, N. R.; PINTO, M. L.; PIRES, J.; MARCOS, P. M.; NOGUEIRA, J. M. F. Development, optimisation and application of polyurethane foams as new polymeric phases for stir bar sorptive extraction. Journal of Chromatography A, v. 1171, n. 1-2, p. 8-14, 2007.

102 HUANG, X.; YUAN, D. Preparation of stir bars for sorptive extraction based on monolithic material. Journal of Chromatography. A, v. 1154, n. 1-2, p. 152-7, 2007.

103 YU, C.; HU, B. Novel combined stir bar sorptive extraction coupled with ultrasonic assisted extraction for the determination of brominated flame retardants in environmental samples using high performance liquid chromatography. Journal of chromatography. A, v. 1160, n. 1-2, p. 71-80, 2007.

104 PORTUGAL, F. C. M.; PINTO, M. L.; NOGUEIRA, J. M. F. Optimization of polyurethane foams for enhanced stir bar sorptive extraction of triazinic herbicides in water matrices. Talanta, v. 77, n. 2, p. 765-773, 2008. 
105 JI, X.; YANG, C.; LAN, X. Preparation of silicone rubbers coating on stir bar by sol-gel- sulfurization method for sorptive extraction. Fenxi Huaxue/ Chinese Journal of Analytical Chemistry, v. 36, n. 12, p. $1641-1645,2008$.

106 SILVA, A.; PORTUGAL, F.; NOGUEIRA, J. Advances in stir bar sorptive extraction for the determination of acidic pharmaceuticals in environmental water matrices. comparison between polyurethane and polydimethylsiloxane polymeric phases. Journal of Chromatography A, v. 1209, n. 1-2, p. 10-16, 2008.

107 GROSSI, P.; OLIVARES, I. R. B.; FREITAS, D. R.; LANCAS, F. M. L. A novel hs-sbse system coupled with gas chromatography and mass spectrometry for the analysis of organochlorine pesticides in water samples. Journal of Separation Science, v. 31, n. 20, p. 3630-3637, 2008.

108 ZHU, X.; ZHU, Q. Molecular imprinted nylon-6 stir bar as a novel extraction technique for enantioseparation of amino acids. Journal of Applied Polymer Science, v. 109, n. 4, p. 2665-2670, 2008.

109 HUANG, X.; QIU, N.; YUAN, D. Direct enrichment of phenols in lake and sea water by stir bar sorptive extraction based on poly (vinylpyridine-ethylene dimethacrylate) monolithic material and liquid chromatographic analysis. Journal of Chromatography A, v. 1194, n. 1, p. 134-138, 2008.

110 HUANG, X.; YUAN, D.; HUANG, B. Determination of steroid sex hormones in urine matrix by stir bar sorptive extraction based on monolithic material and liquid chromatography with diode array detection. Talanta, v. 75, n. 1, p. 172-7, 2008.

111 GUAN, W.; WANG, Y.; XU, F.; GUAN, Y. Poly(phthalazine ether sulfone ketone) as novel stationary phase for stir bar sorptive extraction of organochlorine compounds and organophosphorus pesticides. Journal of Chromatography A, v. 1177, n. 1, p. 28-35, 2008.

112 HUANG, X.; QIU, N.; YUAN, D.; HUANG, B. A novel stir bar sorptive extraction coating based on monolithic material for apolar, polar organic compounds and heavy metal ions. Talanta, v. 78, n. 1, p. 101-106, 2009.

113 HUANG, X.; QIU, N.; YUAN, D. Simple and sensitive monitoring of sulfonamide veterinary residues in milk by stir bar sorptive extraction based on monolithic material and high performance liquid chromatography analysis. Journal of Chromatography A, v. 1216, n. 46, p. 8240-8245, 2009.

114 HUANG, X.; QIU, N.; YUAN, D.; LIN, Q. Sensitive determination of strongly polar aromatic amines in water samples by stir bar sorptive extraction based on poly(vinylimidazole-divinylbenzene) monolithic material and liquid chromatographic analysis. Journal of Chromatography A, v. 1216, n. 20, p. 4354-4360, 2009.

115 HUANG, X.; QIU, N.; YUAN, D. Development and validation of stir bar sorptive extraction of polar phenols in water followed by HPLC separation in poly(vinylpyrrolididone-divinylbenzene) monolith. Journal of Separation Science, v. 32, n. 9, p. 1407-14, 2009.

116 MELO, L. P.; NOGUEIRA, A. M.; LANCAS, F. M.; QUEIROZ, M. E. C. Polydimethylsiloxane/polypyrrole stir bar sorptive extraction and liquid chromatography (SBSE/LC-UV) analysis of antidepressants in plasma samples. Analytica Chimica Acta, v. 633, n. 1, p. 57-64, 2009.

117 YU, C.; HU, B. Sol-gel polydimethylsiloxane/poly(vinylalcohol)-coated stir bar sorptive extraction of organophosphorus pesticides in honey and their determination by large volume injection gc. Journal of Separation Science, v. 32, n. 1, p. 147-153, 2009.

118 YU, C.; YAO, Z.; HU, B. Preparation of polydimethylsiloxane/ $\beta$-cyclodextrin/divinylbenzene coated "dumbbell-shaped" stir bar and its application to the analysis of polycyclic aromatic hydrocarbons and polycyclic aromatic sulfur heterocycles compounds in lake water and soil b. Analytica Chimica Acta, v. 641, n. 1-2, p. 75-82, 2009.

119 TALEBPOUR, Z.; SAFARI, M.; MOLAABACI, F.; ALIZADEH, A.; ABOUL-ENEIN, H. Methyl methacrylate-ethyleneglycol dimethacrylate-acrylic acid surface as stationary phase for stir bar sorptive extraction. Chromatographia, v. 72, n. 7-8, p. 707-712, 2010.

120 HU, Y.; LI, J.; HU Y.AND LI, G. Development of selective and chemically stable coating for stir bar sorptive extraction by molecularly imprinted technique. Talanta, v. 82, n. 2, p. 464-470, 2010.

121 HUANG, X.; LIN, J.; YUAN, D. A new anionic exchange stir bar sorptive extraction coating based on monolithic material for the extraction of inorganic anion. Journal of Chromatography A, v. 1217, n. 30, p. 4898-4903, 2010. 
122 HUANG, X.; QIU, N.; YUAN, D.; LIN, Q. Preparation of a mixed stir bar for sorptive extraction based on monolithic material for the extraction of quinolones from wastewater. Journal of Chromatography A, v. 1217, n. 16, p. 2667-2673, 2010.

123 PORTUGAL, F.; PINTO, M.; PIRES, J.; NOGUEIRA, J. Potentialities of polyurethane foams for trace level analysis of triazinic metabolites in water matrices by stir bar sorptive extraction. Journal of Chromatography A, v. 1217 , n. 23 , p. $3707-3710,2010$.

124 CARSON, C.; BIRKETT, M.; LOGAN, J.; MAWA, K.; PATES, H.; PICKETT, J.; RWEGOSHORA, R.; TUNGU, P.; CAMERON, M. Novel use of stir bar sorptive extraction as a tool for isolation of oviposition site attractants for gravid culex quinquefasciatus. Bulletin of Entomological Research, v. 100, n. 1, p. 1-7, 2010.

125 XU, Z.; HU, Y.; HU, Y.; LI, G. Investigation of ractopamine molecularly imprinted stir bar sorptive extraction and its application for trace analysis of $\beta_{2}$-agonists in complex samples. Journal of Chromatography A, v. 1217, n. 22, p. 3612-8, 2010.

126 YANG, L.; ZHAO, X.; ZHOU, J. Selective enrichment and determination of nicosulfuron in water and soil by a stir bar based on molecularly imprinted polymer coatings. Analytica Chimica Acta, v. 670, n. 1-2, p. 72-7, 2010.

127 HUANG, X.; CHEN, L.; YUAN, D.; LUO, X. Preparation, characterization and application of a new stir bar sorptive extraction based on poly(vinylphthalimide-co-n,n'-methylenebisacrylamide) monolith. Journal of Separation Science, v. 34, n. 23, p. 3418-3425, 2011.

128 BARLETTA, J. Y.; GOMES, P. C. F. L.; SANTOS-NETO, A. J.; LANCAS, F. M. Development of a new stir bar sorptive extraction coating and its application for the determination of six pesticides in sugarcane juice. Journal of Separation Science, v. 34, n. 11, p. 1317-1325, 2011.

129 SEQUEIROS, R.; NENG, N.; PORTUGAL, F.; PINTO, M.; PIRES, J.; NOGUEIRA, J. Development and application of stir bar sorptive extraction with polyurethane foams for the determination of testosterone and methenolone in urine matrices. Journal of Chromatographic Science, v. 49, n. 4, p. 297-302, 2011.

130 TALEBPOUR, Z.; TARAJI, M.; ADIB, N. Stir bar sorptive extraction and high performance liquid chromatographic determination of carvedilol in human serum using two different polymeric phases and an ionic liquid as desorption solvent. Journal of Chromatography A, v. 1236, p. 1-6, 2012.

131 ESMAEIL, B.; MIRABI, A.; GHODRATI, R. An electropolymerized pyrrole-based coating for stir bar sorptive extraction of btex from water followed by gas chromatography-mass spectrometry. Chinese Journal of Chemistry, v. 30, n. 3, p. 557-562, 2012.

132 BRATKOWSKA, D.; FONTANALS, N.; CORMACK, P.; BORRULL, F.; MARCé, R. Preparation of a polar monolithic stir bar based on methacrylic acid and divinylbenzene for the sorptive extraction of polar pharmaceuticals from complex water samples. Journal of Chromatography A, v. 1225, p. 1-7, 2012.

133 NOGUEIRA, A. M. Desenvolvimento, avaliação e aplicações de novas fases para extração por sorção em barras de agitação (SBSE). 2007. 118 p. Dissertação (Mestrado) — Instituto de Química de São Carlos, Universidade de São Paulo, 2007.

134 BARLETTA, J. Y. Desenvolvimento e Aplicação de uma Nova Fase para Extração por Sorção em Barra de Agitação(SBSE). 2010. 102 p. Dissertação (Mestrado) — Instituto de Química de São Carlos, Universidade de São Paulo, 2010.

135 BRATKOWSKA, D.; MARCE, R. M.; CORMACK, P. A. G.; SHERRINGTON, D. C.; BORRULL, F.; FONTANALS, N. Synthesis and application of hypercrosslinked polymers with weak cation-exchange character for the selective extraction of basic pharmaceuticals from complex environmental water samples. Journal of Chromatography A, v. 1217, n. 10, p. 1575-1582, 2010.

136 GOMES, P. C. F. L.; BARLETTA, J. Y.; NAZARIO, C. E. D.; SANTOS-NETO, A. J.; WOLFF, M. A. V.; CONEGLIAN, C. M. R.; UMBUZEIRO, G. A.; LANCAS, F. M. Optimization of in situ derivatization spme by experimental design for gc-ms multi-residue analysis of pharmaceutical drugs in wastewater. Journal of Separation Science, v. 34, n. 4, p. 436-445, 2011. 